\title{
Results of LWR
}

NUREG/CR-5870 PNL-8051

\section{Snubber Aging Research}

Prepared by

D. P. Brown/LEC

E. V. Werry, D. E. Blahnik/PNL

Lake Engineering Company

Pacific Northwest Laboratory

Prepared for

U.S. Nuclear Regulatory Commission 


\section{AVAILABILITY NOTICE}

Availability of Reference Materials Cited in NRC Publications

Most documents cited in NAC publications will be avallable from one of the following sources:

1. The NRC Public Document Room, $2120 \mathrm{~L}$ Street, NW., Lower Level, Washington, DC 20555

2. The Superintendent of Documents, U.S. Government Printing Office, P.O. Box 37082, Washington. DC 20013-7082

3. The National Technical Information Service, Springfield, VA 22161

Although the listing that follows represents the majority of documents cited in NRC publications, it is not intended to be exhaustive.

Referenced docurnents available for inspection and copying for a fee from the NRC Public Document Room include NRC correspondence and internal NRC memoranda: NRC bulletins, circulars, information notices, Inspection and investigation notices; licensee event reports: vendor reports and correspondence; Commission papers; and applicant and licensee documents and correspondence.

The following documents in the NUREG series are available for purchase from the GPO Sales Program: formal NRC staff and contractor reports, NRC-sponsored conference proceedings, international agreement reports, grant publications, and NRC booklets and brochures. Also available are regulatory guides, NRC regulations in the Code of Federal Regulations, and Nuclear Regulatory Commission Issuances.

Documents available from the National Technical Information Service include NUREG-series reports and technical reports prepared by other Federal agencies and reports prepared by the Atomic Energy Commission, forerunner agency to the Nuclear Regulatory Commission.

Documents avallable from public and special technical libraries include all open literature items, such as books, journal articles, and transactlons. Federal Register notices, Federal and State legislation, and congressional reports can usually be obtained from these libraries.

Documents such as theses, dissertations, foreign reports and translations, and non-NRC conference proceedings are available for purchase from the organization sponsoring the publication cited.

Single copies of NRC draft reports are available free, to the extent of supply, upon written request to the Office of Administration, Distribution and Mail Services Section, U.S. Nuclear Regulatory Commission. Washington, DC 20555.

Copies of Industry codes and standards used in a substantive manner in the NRC regulatory process are maintained at the NRC Library, 7920 Norfolk Avenue. Bethesda, Maryland, for use by the public. Codes and standards are usually nopyrighted and may be purchased from the originating organization or, if they are American National Standurds, from the American National Standards Institute, 1430 Broadway, New York. NY 10018.

\section{DISCLAIMER NOTICE}

This report was prepared as an account of work sponsored by an agency of the United States Government. Neither the United States Government nor any agency thereof, or any of their employees, makes any warranty. expressed or implied, or assumes any legal liability of responsibility for any third party's use, or the results of such use, of any information, apparatus, product or process disclosed in this repon, or represents that its use by such third party would not infringe privately owned rights. 
NUREG/CR-5870

PNL-8051

RV, R9

\section{Results of LWR Snubber Aging Research}

Manuscript Completed: March 1992

Date Published: May 1992

Prepared by

D. P. Brown, Lake Engineering Company

E. V. Werry, D. E. Blahnik, Pacific Northwest Laboratory

Lake Engineering Company

P.O. Box 296

10 Austin Avenue

Greenville, RI 02828

Under Contract to:

Pacific Northwest Laboratory

Richland, WA 99352

\section{Prepared for}

Division of Engineering

Office of Nuclear Regulatory Research

U.S. Nuclear Regulatory Commission

Washington, DC 20555

NRC FIN B2911 


\section{$0582-7010$ ) \\ $12018-17 / 9$ \\ QPI 19.}

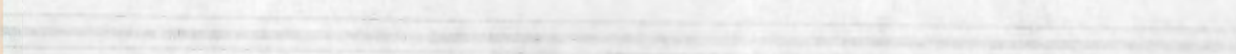

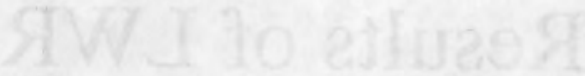

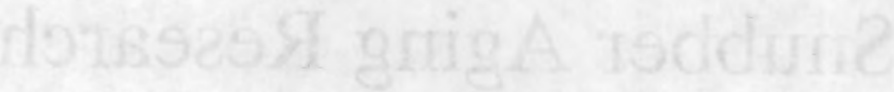

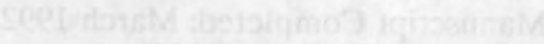

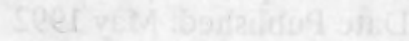

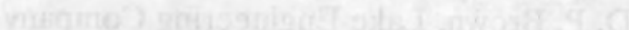

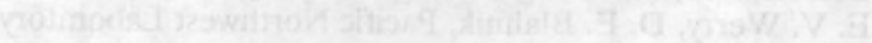

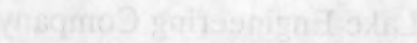

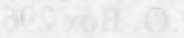

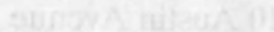

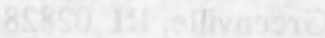

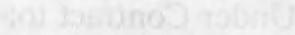

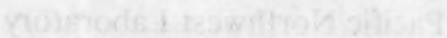

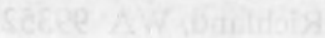

Tuin beveco 9

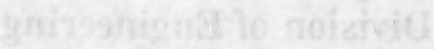

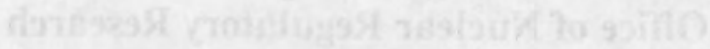

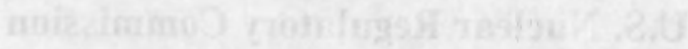

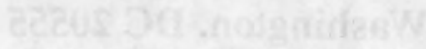

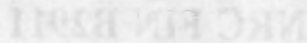




\begin{tabular}{|c|c|}
\hline $\begin{array}{l}\text { his report describes the aging research results and } \\
\text { ecommendations for snubbers used in commercial } \\
\text { uclear power plants. Snubbers are safety-related } \\
\text { evices used to restrain undesirable dynamic loads at } \\
\text { arious piping and equipment locations in nuclear } \\
\text { ower plants (NPPs). Each snubber must accommodate } \\
\text { plant's normal thermal movements and must be cap- } \\
\text { ble of restraining the maximum off-normal dynamic } \\
\text { ads, such as a seismic event or a transient, postulated } \\
\text { rr its specific location. The effects of snubber aging } \\
\text { nd the factors that contribute to the degradation of } \\
\text { eir safety performance need to be better understood. }\end{array}$ & $\begin{array}{l}\text { Thus, Phase II of Nuclear Plant Aging Research was } \\
\text { conducted to enhance the understanding of snubber } \\
\text { aging and its consequences. Pacific Northwest Labora- } \\
\text { tory staff and their subcontractors, Lake Engineering } \\
\text { and Wyle Laboratories, visited eight sites (encom- } \\
\text { passing thirteen plants) to conduct interviews with NPP } \\
\text { staff and to collect data on snubber aging, testing, and } \\
\text { maintenance. The Phase II research methodology, eval- } \\
\text { uation, results, conclusions, and recommendations are } \\
\text { described in the report. Effective methods for service- } \\
\text { life monitoring of snubbers are included in the } \\
\text { recommendations. }\end{array}$ \\
\hline
\end{tabular}




\section{jownedR}

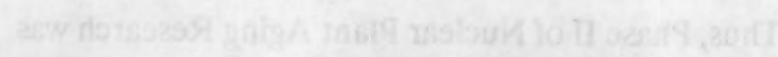

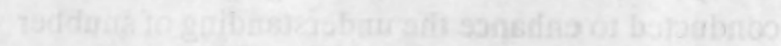

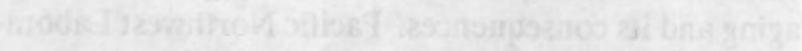

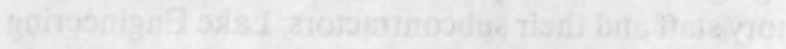

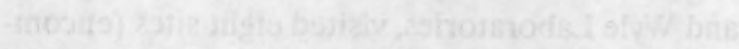

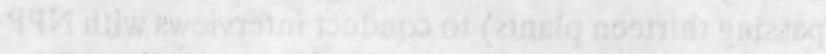

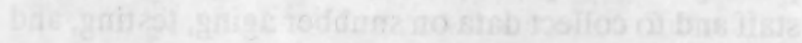

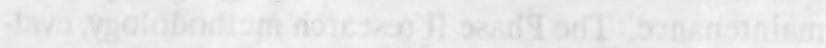

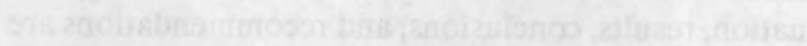

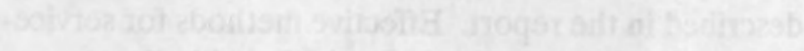

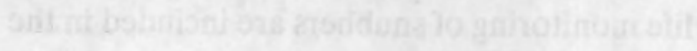

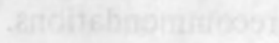

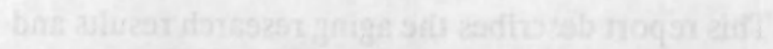

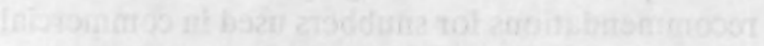

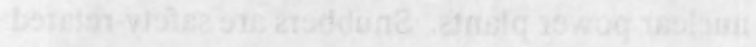

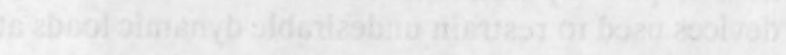
7040

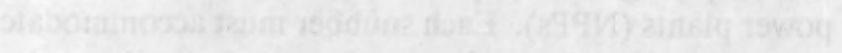

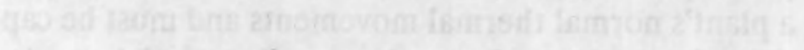

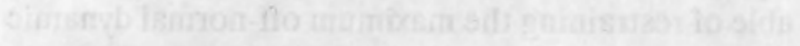

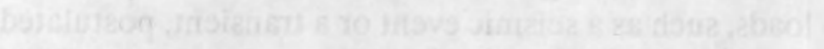

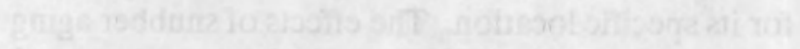

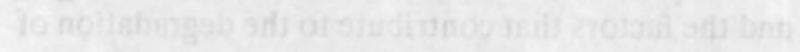

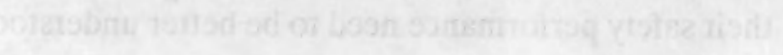




\section{Contents}

Page

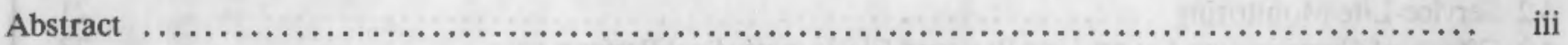

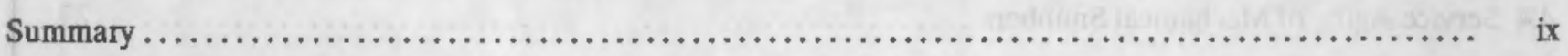

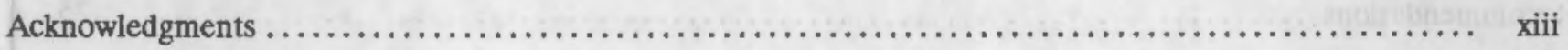

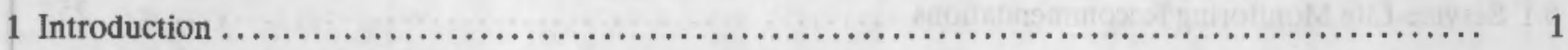

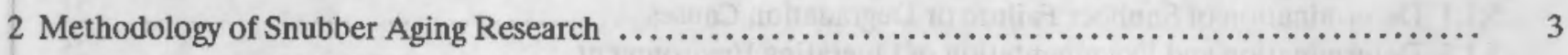

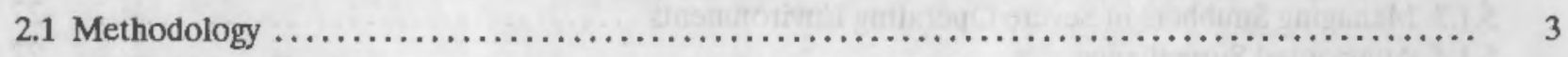

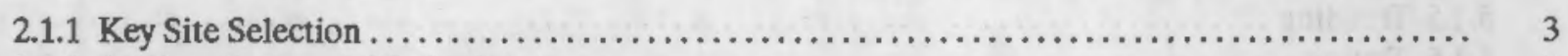

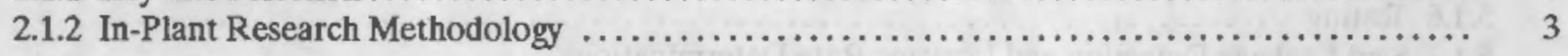

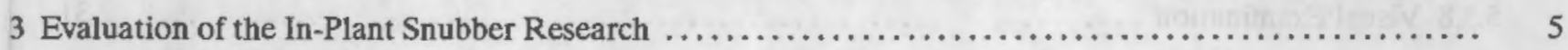

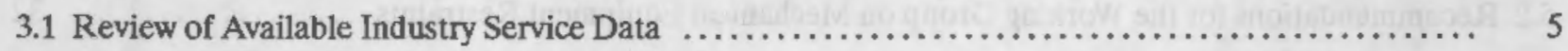

3.1.1 Snubber Performance Versus Failure Mechanisms

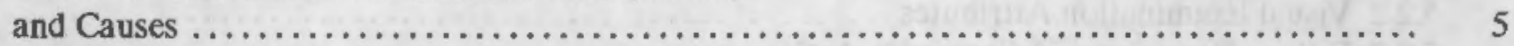

3.1.2 Aging-Related Versus Nonaging-Related Failures $\ldots \ldots \ldots \ldots \ldots \ldots \ldots \ldots \ldots \ldots \ldots \ldots, 6$

3.1.3 Environmental Effects on Elastomeric Seal Degradation Rate $\ldots \ldots \ldots \ldots \ldots \ldots \ldots \ldots \ldots \ldots .7$

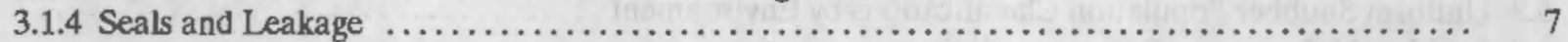

3.1.5 Evaluation of Plant Service-Life Monitoring Methods $\ldots \ldots \ldots \ldots \ldots \ldots \ldots \ldots \ldots \ldots \ldots \ldots \ldots$

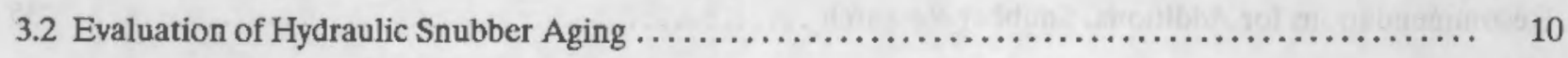

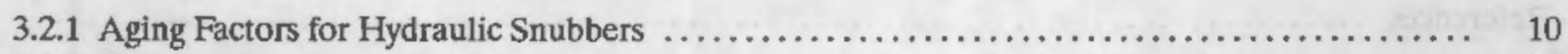

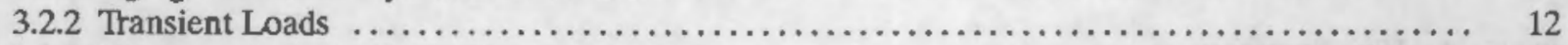

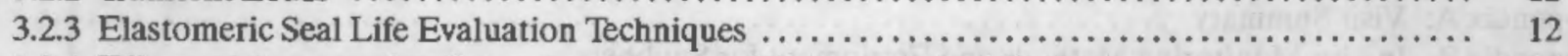

3.2.4 Effects of Compression Set on Low-Pressure Elastomeric Seal Performance .............. 14

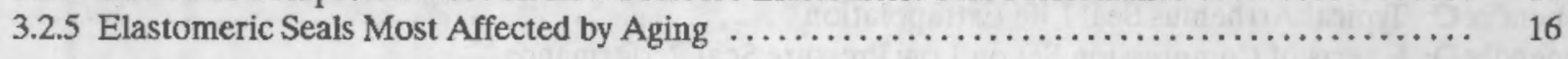

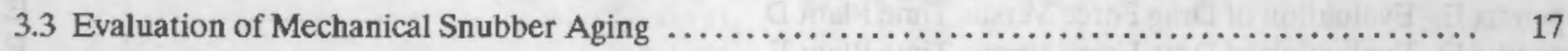

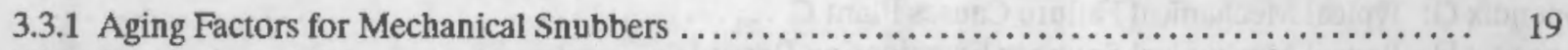

3.3.2 Evaluation of Changes in Drag Loads Versus Service Time $\ldots \ldots \ldots \ldots \ldots \ldots \ldots \ldots \ldots \ldots \ldots$

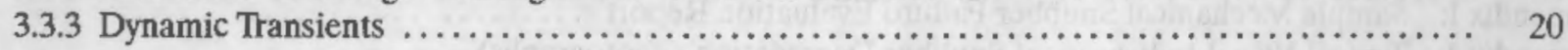

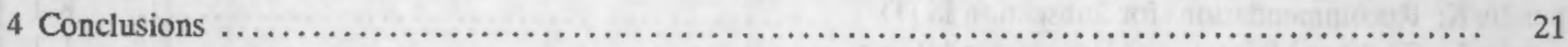

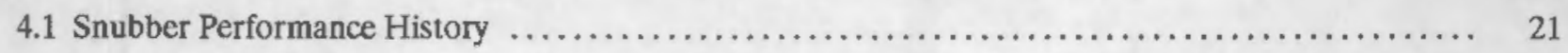


Contents

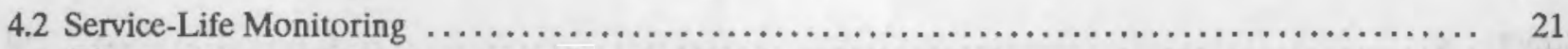

4.3 Effects of Compression Set on Low Pressure Elastomeric Seal Performance . . . . . . . . . . . . . 23

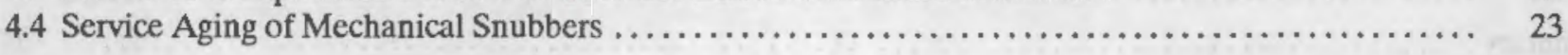

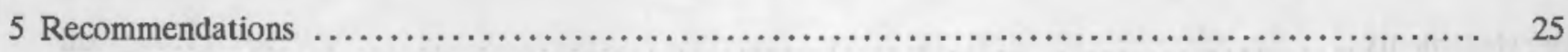

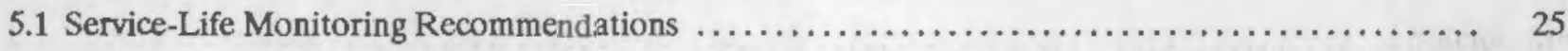

5.1.1 Determination of Snubber Failure or Degradation Causes ...................... 25

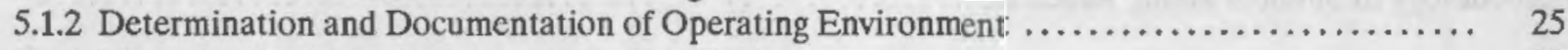

5.1.3 Managing Snubbers in Severe Operating Environments $\ldots \ldots \ldots \ldots \ldots \ldots \ldots \ldots \ldots \ldots \ldots \ldots \ldots \ldots \ldots \ldots$

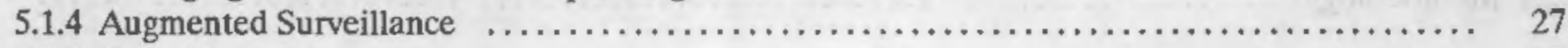

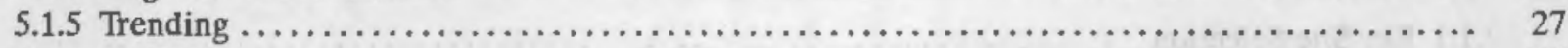

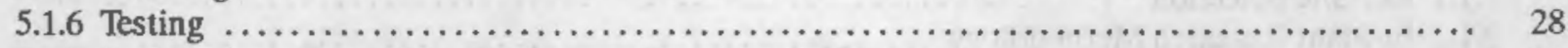

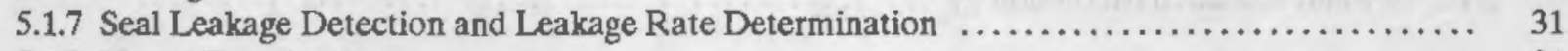

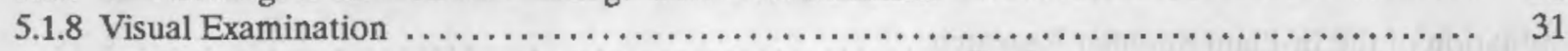

5.2 Recommendations for the Working Group on Mechanical Equipment Restraints $\ldots \ldots \ldots \ldots \ldots \ldots \quad 32$

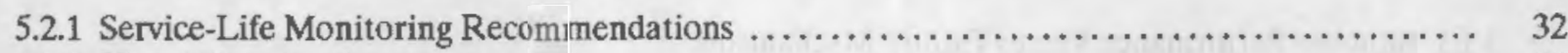

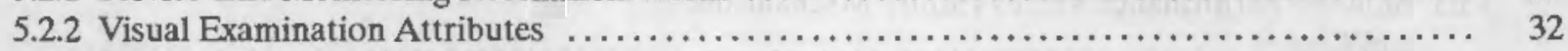

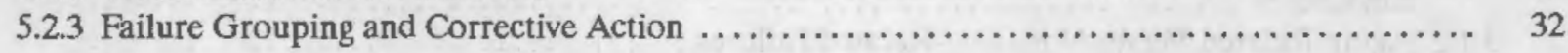

5.3 Uniform Snubber Population Classifications by Environment $\ldots \ldots \ldots \ldots \ldots \ldots \ldots \ldots \ldots \ldots \ldots \ldots \ldots \ldots \ldots$

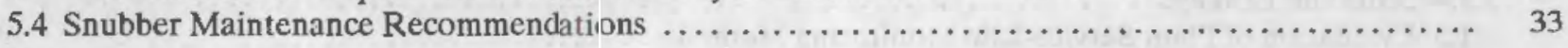

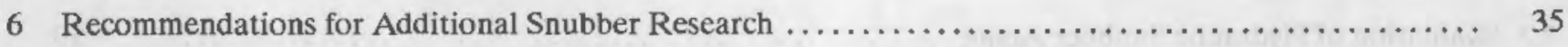

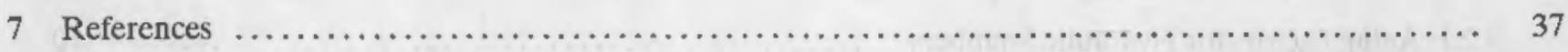

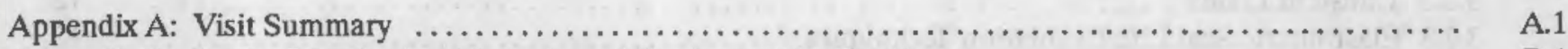

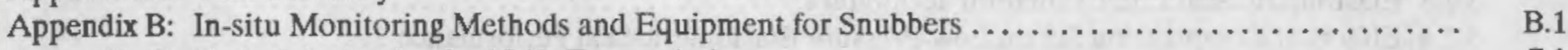

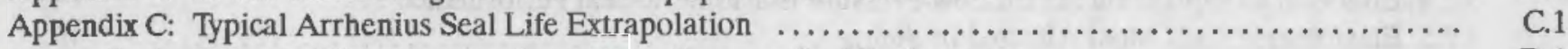

Appendix D: Effects of Compression Set on Low Pressure Seal Performance . . . . . . . . . . . . . . .

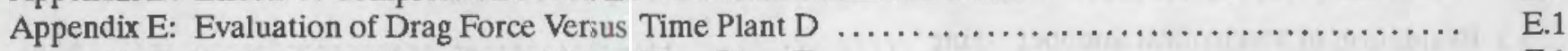

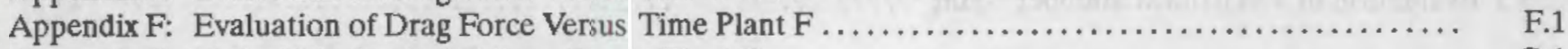

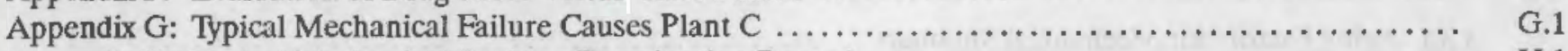

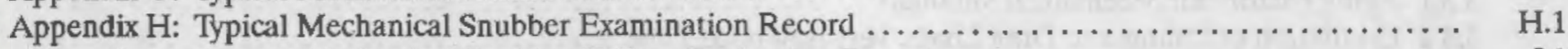

Appendix I: Sample Mechanical Snubber Failure Evaluation Report $\ldots \ldots \ldots \ldots \ldots \ldots \ldots \ldots \ldots \ldots \ldots \ldots \ldots \ldots \ldots \ldots \ldots$

Appendix J: Typical Visual Indicators of Snubber Degradation (Photographs) $\ldots \ldots \ldots \ldots \ldots \ldots \ldots \ldots \ldots$ J.1

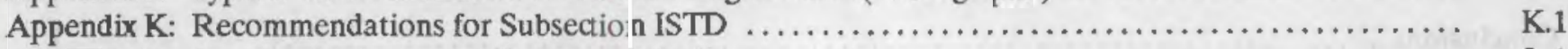

Appendix L: Snubber Maintenance Recommendations . . . . . . . . . 
Contents

\section{Figures}

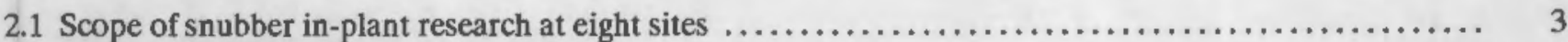

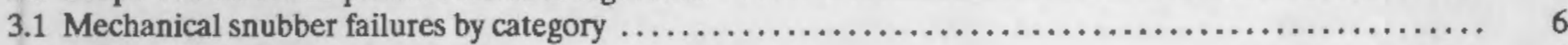

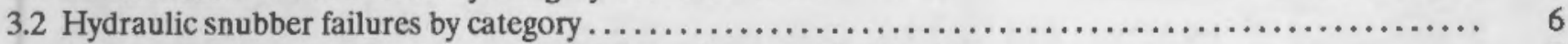

3.3 Aging-related versus nonaging-related failures in mechanical snubbers $\ldots \ldots \ldots \ldots \ldots \ldots \ldots \ldots \ldots \ldots, 7$

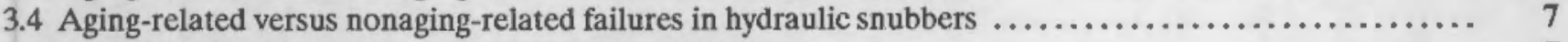

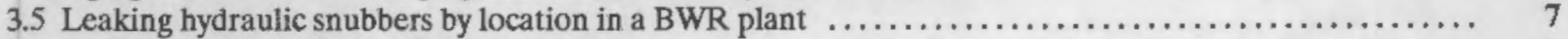

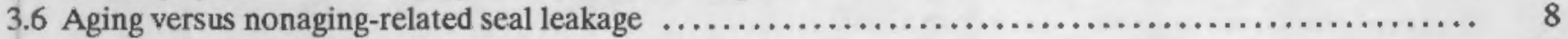

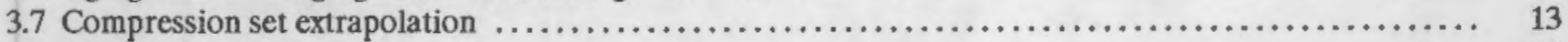

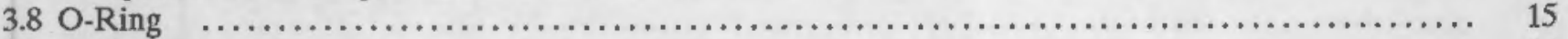

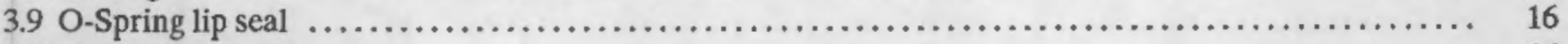

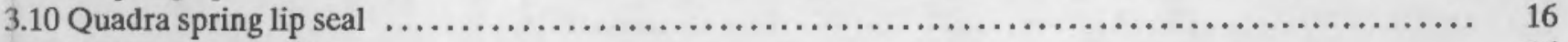

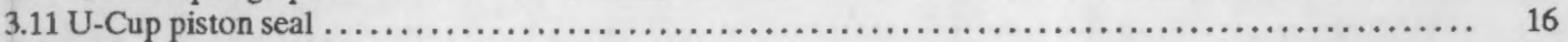

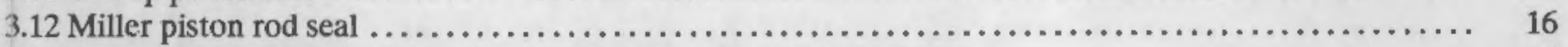

3.13 Average drag force versus service time for 47 mechanical snubbers $\ldots \ldots \ldots \ldots \ldots \ldots \ldots \ldots \ldots \ldots \ldots .20$

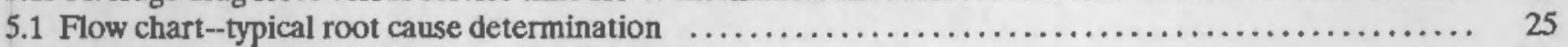

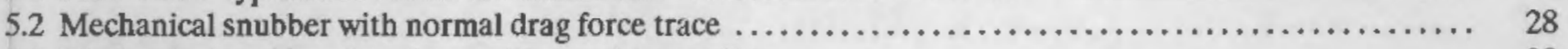

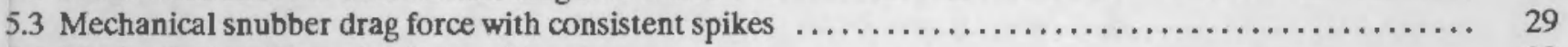

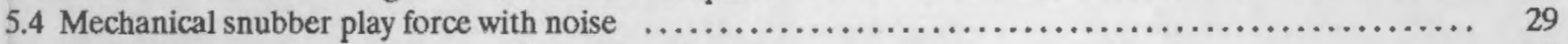

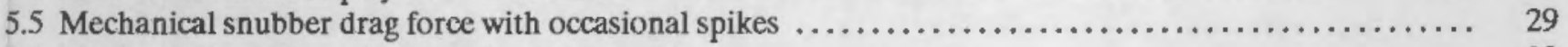

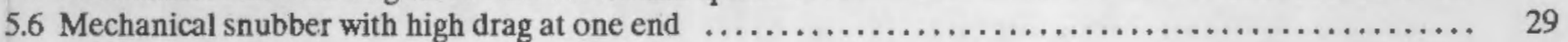

Tables

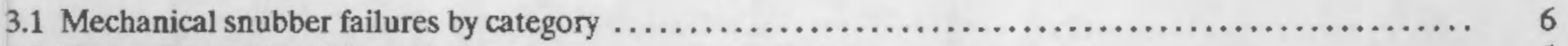

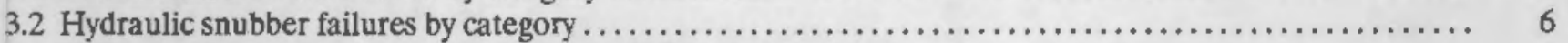

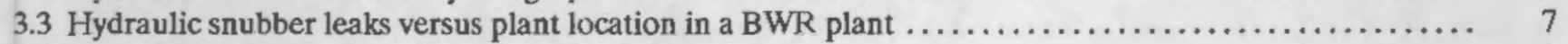

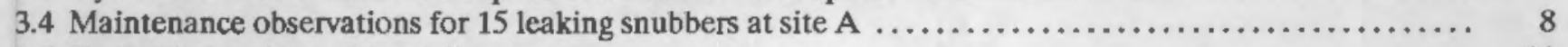

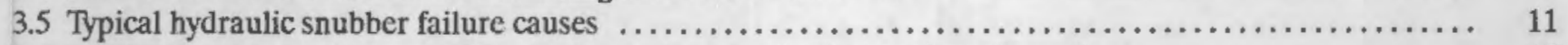

3.6 Maximum measured compression set for various nonleaking seal configurations $\ldots \ldots \ldots \ldots \ldots \ldots \ldots .15$

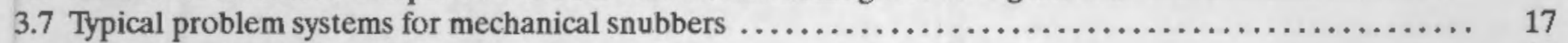

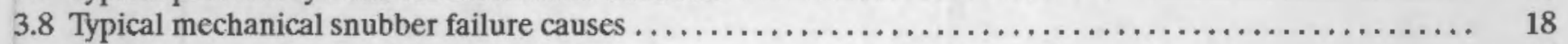

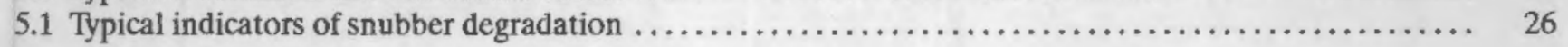




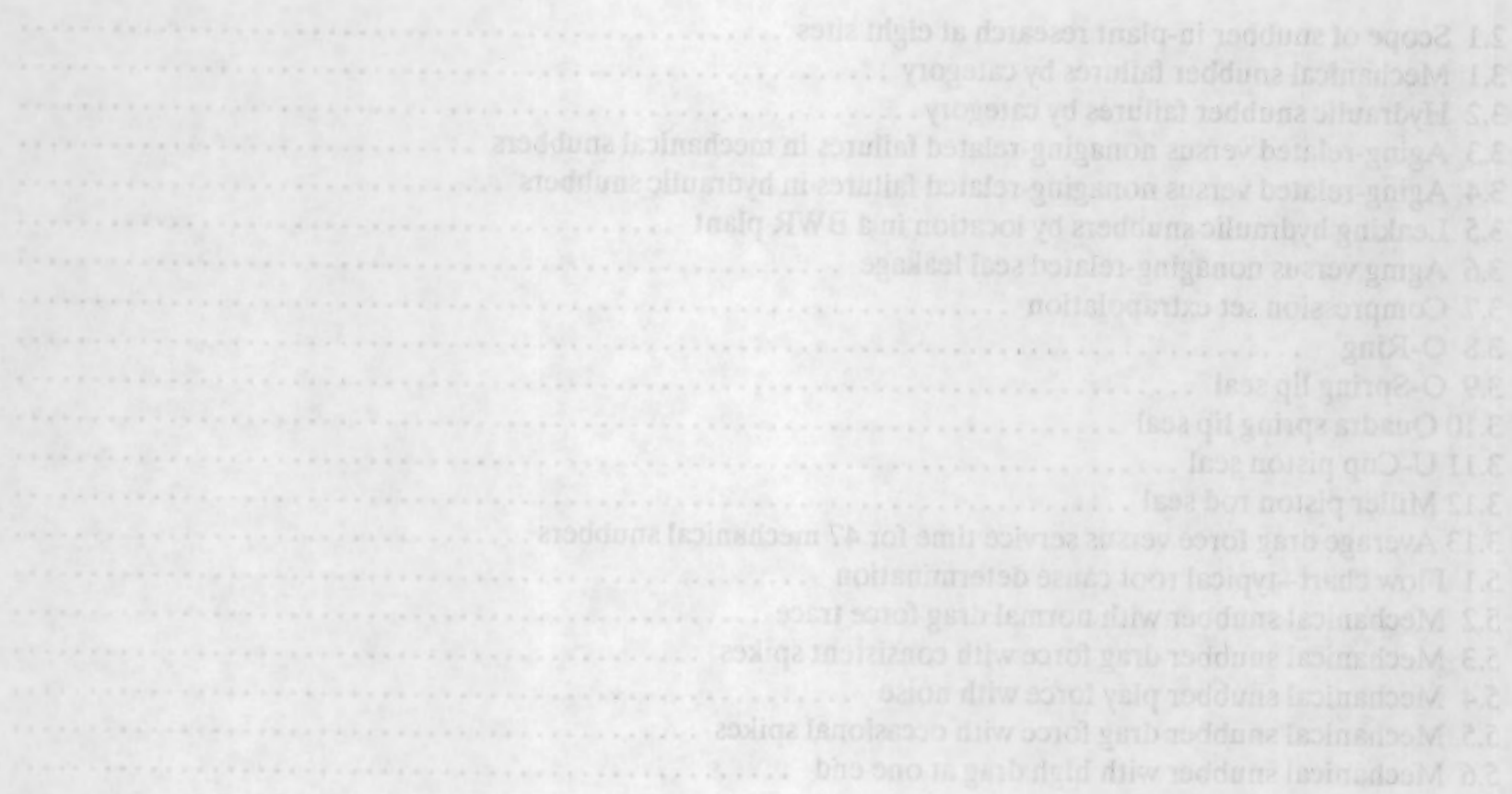




\section{Summary}

Snubbers are safety-related devices used to restrain undesirable dynamic loads at various piping and equipment locations in nuclear power plants (NPPs). Snubber operability is mandated by the Code of Federal Regulations (CFRs). The CFRs stipulate that systems, structures, and components (SSCs), e.g., snubbers, shall be designed to withstand the effects of normal and offnormal dynamic phenomena. ${ }^{1}$ In the mid 1980 s, the U.S. Nuclear Regulatory Commission (NRC) recognized the need to enhance snubber performance through aging studies and improved service-life monitoring techniques. The NRC's Nuclear Plant Aging Research (NPAR) Program Plan provided the vehicle and the logical sponsorship to undertake preliminary investigations into snubber performance and aging. Pacific Northwest Laboratory (PNL) and its subcontractors, Lake Engineering (Greenville, Rhode Island) and Wyle Laboratories (Huntsville, Alabama), performed the snubber research.

This report describes the Phase II NPAR in-plant aging research conducted to enhance the understanding of snubber aging and its consequences. The in-plant aging research was based on a research plan by Brown et al. ${ }^{2}$, which clarified the relationship between snubber aging and snubber degradation and identified additional information on aging hydraulic and mechanical snubbers that requires further investigation and analysis.

This report presents snubber aging research, testing and failure data, and service-life monitoring recommendations that distinguish between aging- and nonagingrelated snubber failures. The graphics, tables, and supporting text illustrate this distinction. The report supports the perspective that snubber failures are closely related to age-related degradation caused by

\footnotetext{
${ }^{1}$ Normal dynamic reactions are those associated with thermal expansion and contraction of plant systems during normal startups or shutdowns. Off- normal dynamic reactions involve loads not associated with normal operations such as postulated seismic events. ${ }^{2}$ Brown, D. P., G. R. Palmer, E. V. Werry, and D. E. Blahnik. 1990. Basis for Snubber Aging Research: Nuclear Plant Aging Research Program. NUREG/CR-5386 (PNL-6911), prepared for the U.S. Nuclear Regulatory Commission by Pacific Northwest Laboratory, Richland, Washington.
}

inservice operational environmental influences, e.g., vibration and elevated temperature. Due to the lack of service-related information pertaining to mechanical snubbers, special emphasis was placed on gathering such information for these devices.

The following objectives were developed for the aging investigation of mechanical and hydraulic snubbers:

- enhance the understanding of how snubbers degrade due to aging

- enhance the understanding of snubber failure characteristics

- determine the technical information needed to improve the level of snubber performance.

To meet these objectives, in-plant research was undertaken with cooperating nuclear utilities. Two information-gathering methods were used during the research. The first method included interviews with plant maintenance and engineering staff. The second involved analysis of plant operating data, including maintenance records and inservice testing and examination records. Plant selection was based on several factors, including availability of staff, plant procedures, snubber types and length of service, and plant types (BWR and PWR). It should be noted that the in-plant research was conducted on generic types of snubbers, i.e. acceleration-limiting mechanicals and lockup/bleed hydraulics. These generic types constitute a majority of snubbers installed in U.S. NPPs.

Thirteen plants at eight different sites were visited during a three-month interval. Snubbers used at five of the sites were primarily mechanical; snubbers at the remaining three sites were primarily hydraulic. In addition to the site visits, over 70 telephone interviews were conducted with knowledgeable staff at NPPs throughout the U.S. Snubber "hands-on" research was also conducted at Lake Engineering's facilities; this work involved the disassembly, examination, and measurement of mating parts associated with hydraulic snubber seals. 
Summary

A primary goal of the site visits was to gather information that would fulfill the objectives. The first two objectives were met through an assessment and evaluation of recent snubber performance history at the sites visited. By distinguishing between snubber failures related to service (aging) and failures related to nonservice (nonaging) causes, it was concluded that approximatcly half of all snubber failures may be attributed to service-related influences. Service-related failures are defined as those due to environmental influences, transients, and vibration; nonservice-related failures are defined as those due to other influences such as installation damage, maintenance deficiencies, manufacturing defects, not related to service time.

All of the environmental influences, including elevated temperature, vibration, and moisture, can degrade the performance of mechanical snubbers by increasing drag and breakaway forces and by changing the activation acceleration thresholds. Data in one plant indicated an increasing trend in mechanical snubber drag force with service time. For hydraulic snubbers, high temperatures in isolated operating areas can rapidly degrade seal performance. Radiation probably contributes less significantly to aging than was originally hypothesized. The research indicates that fluid leakage in hydraulic snubbers is commonly associated with leaking hydraulic fittings; however, it was not determined precisely what percentage of the fitting leakage is caused by this service environment. Furthermore, the research indicates that a significant number of seal leaks are attributed to short-term degradation in high temperature applications. At one BWR plant, the incidence of seal leakage was higher at elevated temperatures in the drywell than in other areas of the plant. This finding supports the premise that seal degradation can be accelerated by exposure to higher temperatures.

The following recommendations for service-life monitoring guidelines were developed as a result of the inplant research:

- It is important to distinguish between servicerelated and nonservice-related failures. For this reason, the root cause of snubber failure or degradation should be determined. Diagnostic testing is useful for this purpose as well as visual evaluation, particularly during snubber disassembly. Personnel training in these activities is also recommended.

- Because plant operating environments may differ from design specifications, general area and environmental conditions should be monitored. Depending on the range of environmental stressors in the plant, it may be practical to establish more than one service-life population.

- Snubber applications (locations) involving specific severe environmental influences (e.g., high temperatures, high amplitude vibration) should be isolated and assessed on a case-by-case basis. Such applications may require in situ monitoring, frequent surveillance, maintenance or snubber replacement.

- Service life for the general snubber population (i.e., snubbers in a moderate environment that are not subject to short-term degradation) should be established by trending relevant degradation parameters. Because the primary failure mechanism of concern for seals is low pressure leakage, snubber seal life should be primarily based on predicted low pressure seal performance. Baseline data is essential for trending.

- "Hands-on" evaluation methods, such as hand stroking, are useful in identifying potential snubber degradation, particularly degradation caused by dynamic load transients.

- Evaluation of test parameter time traces obtained during routine functional tests is useful in identifying performance anomalies that may be indicators of snubber degradation.

- Test machines used for trending and for diagnostic tests should be capable of providing a time trace of load and velocity. Important criteria for test 
machines used for trending are accuracy and repeatability. Another important feature, especially for diagnostic testing, is the ability of a test machine to vary the magnitude of test parameters such as velocity and load.

Service-life projections based on data from snubbers exposed to the actual plant operating environment are generally preferable to analytical service-life projections.
Overall, the nuclear industry is making progress in snubber inspection, testing, maintenance, and reduction programs. These activities provide a basis for an improved understanding of snubber performance. Plant staff have identified severe environments and have modified the environment or replaced snubbers with more durable models. Additionally, more effective and realistic functional test acceptance limits have been developed to significantly reduce failure rates. Although many plants routinely evaluate snubbers for failure causes, the research, indicates that many plants have yet to implement formal service-life monitoring programs. 
wathing

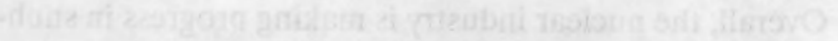

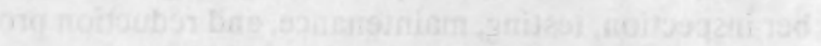

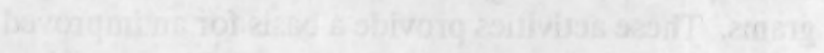

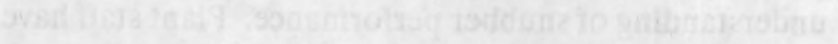

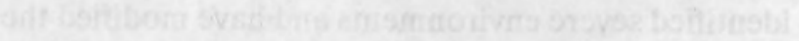

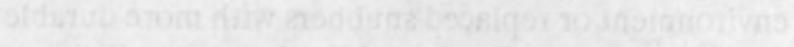

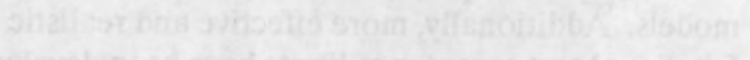

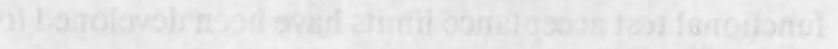

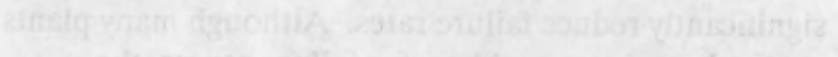

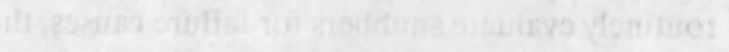

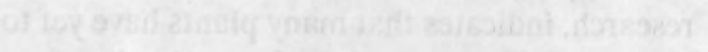

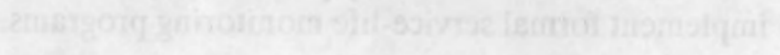

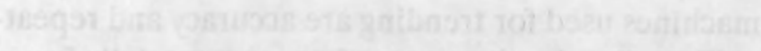

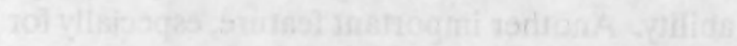

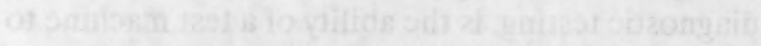

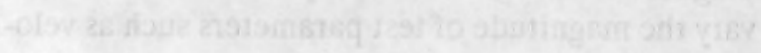

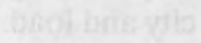

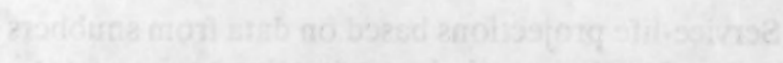

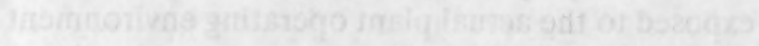

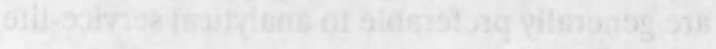
afitivgsion 


\section{Acknowledgments}

The authors of this report acknowledge the support and technical guidance of J. P. Vora and J. J. Burns, Jr., of the Nuclear Regulatory Commission during the course of this research under the Nuclear Plant Aging Research (NPAR) Program. We extend our appreciation the Snubber Utility Group (SNUG) and the ASME Operation and Maintenance (ISTD) Working Group on Mechanical Equipment Restraints for their cooperation and support throughout the work and for their technical comments on the research results. We also wish to thank the nuclear power plant industry, especially those utilities that provided information and/or participated in the in-plant research visitations. A special thanks goes to Glen Palmer, Siemens Nuclear Power Service, Inc., for his technical comments and input to this work and his long-term contributions to snubber research through his Phase II research efforts and association with the ASME ISTD Working Group. We also thank M. H. Kimel, of Wyle Laboratories, who provided strong program management support for the in-plant research and Mr. John Mucci, of Wyle Laboratories, for his productive site interviews and data collection efforts. We are grateful for the contributions from the following staff members of Pacific Northwest Laboratory: A. B. Johnson, Jr., for Project Management support and technical guidance; $\mathrm{S}$. H. Bush, for his timely peer review and assistance throughout the research effort; and R. C. Pedersen for his propitious technical editing of the report. 



\section{Definitions}

Activation:

Aging:

Aging management:

Aging mechanism:

As-found testing:

Bleed rate:

Breakaway force:

Compression set:

Degradation:

Degradation cause:

Degradation mechanism:

Degradation mode:

Diagnostic testing:

Drag force:

Dynamic seal:

Examination:

External seal:
The change of conditions from passive to active, in which the snubber resists the rapid displacement of the attached pipe or component.

Showing the effects of time or use in the physical characteristics of a snubber.

Engineering, operations, and maintenance activities to control aging degradation and failures due to aging of snubbers to within acceptable limits.

Process that gradually changes the physical characteristics of a snubber with time or use.

Testing before conducting any activity that could affect test results (usually applies to snubber testing after removal of a snubber from service, but before any maintenance activities are conducted).

(See "Release rate.")

The minimum applied force required to initiate extension or retraction of the snubber.

The amount of permanent deformation of a seal expressed as a percentage of the initial seal deflection.

Immediate or gradual deterioration in the physical characteristics of a snubber, which could impair performance of any of its design functions.

The circumstances during design, manufacture, or use that have led to degradation.

Physical process that results in degradation.

The manner or state in which a snubber degrades.

Testing to determine the cause or mechanism associated with degradation or failure.

The force required to maintain snubber movement at a low velocity before activation.

A seal used where there is relative motion between the seal and its mating surface.

Visual observation for detecting of improper installation and impaired functional ability caused by physical damage, leakage, corrosion, or degradation from environmental or operating conditions.

A seal used to isolate the hydraulic system from the surrounding environment. 
Definitions

Failure:

Failure analysis:

Failure mechanism:

Failure mode:

Failure mode group (FMG):

High-amplitude vibration:

High-pressure seal:

Hydraulic snubber:

Inspection:

Internal seal:

Locking velocity:

Low-amplitude vibration:

Low-pressure leakage:

Low-pressure seal:

Mechanical snubber:

Normal operating conditions:
Inability or interruption of ability of a snubber to perform its design function within acceptance criteria.

Systematic process of determining and documenting the mode, mechanism, causes, and root cause of the failure of a snubber.

Physical process that results in a failure.

The manner or state in which a snubber fails.

A group of snubbers that have failed and those other snubbers that have potential for similar failure.

Vibration having an amplitude greater than the mechanical clearances in the snubber's end attachments.

A seal that provides a sealing function under high-pressure conditions (i.e., greater than $100 \mathrm{psi}$ ).

A restraining device in which load is transmitted through a hydraulic fluid.

Observation or measurement to verify that the physical characteristics of a snubber conform to acceptance criteria.

A seal used to isolate high-pressure and low-pressure chambers in the snubber.

The extension or retraction velocity of the snubber piston rod at which the control valve locks, no longer allowing free motion.

Vibration having an amplitude less than the mechanical clearances in the snubber's end attachments.

Seal leakage when the snubber is not activated (i.e., when the snubber is unlocked and not pressurized).

A seal that functions under low-pressure conditions (i.e., less than $100 \mathrm{psi}$ ).

A mechanical device designed to restrain piping or equipment during abnormal accelerations and to allow free thermal movement under normal operating conditions.

Operating conditions during reactor startup, operating at power, hot standby, reactor cooldown, and cold shutdown. 
Definitions

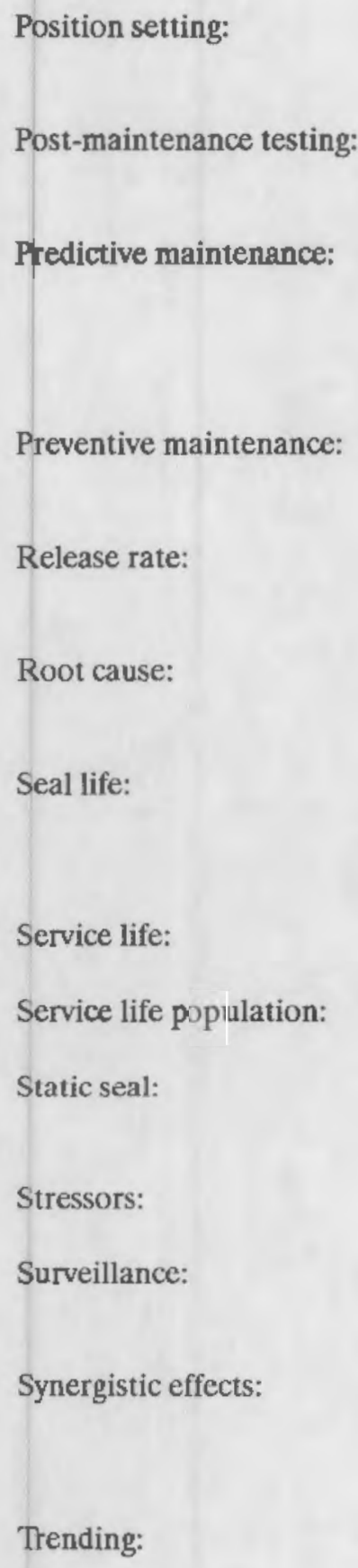

Measurement that indicates stroke location as measured from the snubber's fully retracted position.

Testing after maintenance for component functionality and for verifying correct maintenance.

A form of preventive maintenance performed periodically or continuously to monitor, inspect, test, diagnose, or trend a snubber's performance or condition indicators; results indicate or forecast functional ability or the nature and schedule of planned maintenance prior to failure.

Periodic, predictive, or planned maintenance performed before failure of a snubber in order to extend its service life.

The rate of the axial snubber movement under a specified load after the snubber is activated.

The fundamental reason(s) for an observed condition, which when corrected prevents its recurrence.

The amount of time that a seal is allowed to remain in service without replacement. Seal life begins at the time that the seal is installed and continues for a pre-established period based upon expected performance.

Period from initial operation of a snubber to retirement or overhaul.

A population of snubbers having the same service life.

A seal application where there is no relative motion between the seal and its mating surface.

Factors that promote degradation.

Observation or measurement of the performance or physical characteristics of a snubber to verify that it conforms to acceptance criteria.

Changes in the physical properties of a snubber or a subcomponent caused by two or more stressors interacting so that the total change is different from the changes caused by each stressor acting independently.

Recording and analyzing in service data with respect to some independent parameter (usually time or cycles). 


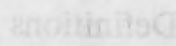

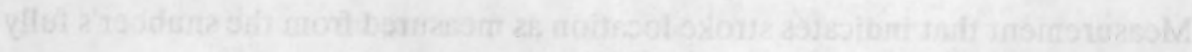

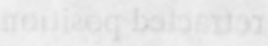

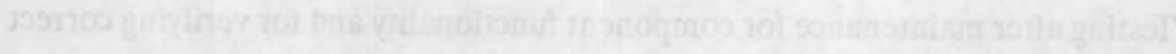

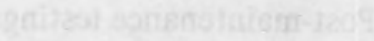

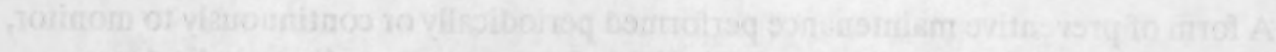

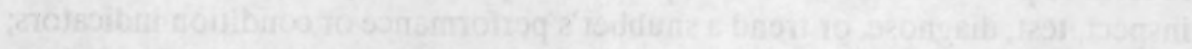

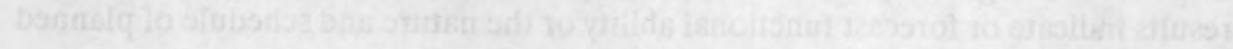

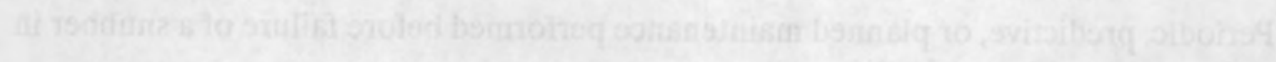

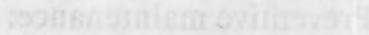

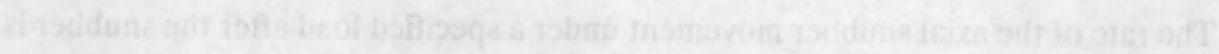

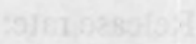

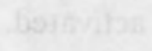

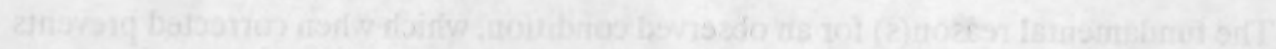

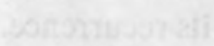

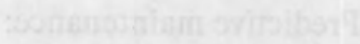

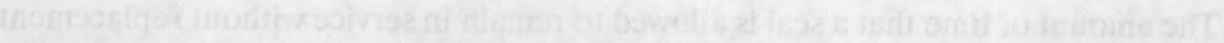

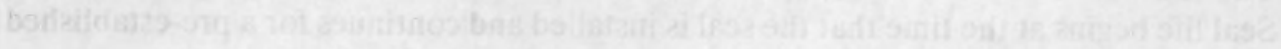

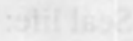

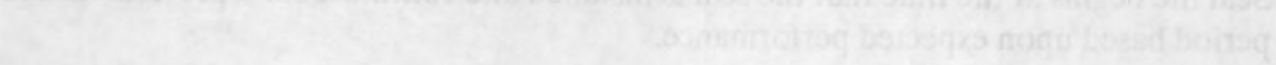

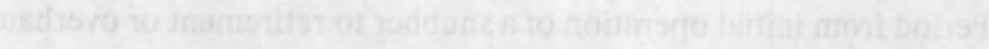

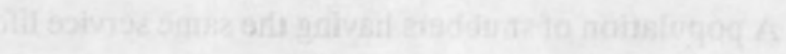

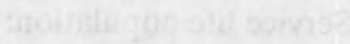

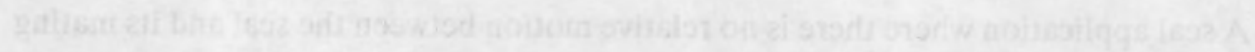

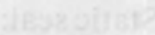
29.9.

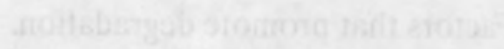

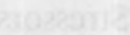

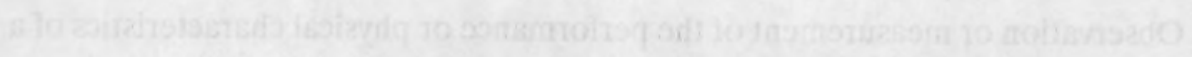

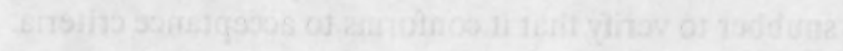

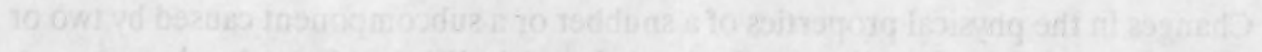

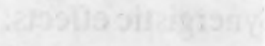

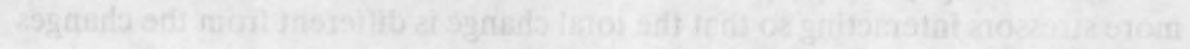

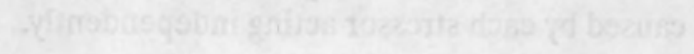

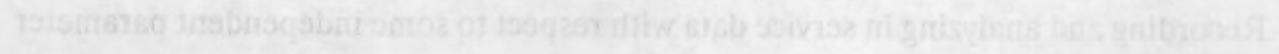

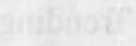




\section{Introduction}

Mechanical and hydraulic snubbers are safety-related devices designed to restrain undesirable dynamic loads at various piping and equipment locations in nuclear power plants (NPPs). Snubber operability in Nuclear Power Plants (NPPs) is mandated by Title 10, Part 50 of the Code of Federal Regulations (CFRs), Appendix A and Appendix B. These regulations stipulate that systems, structures, and components (SSCs), which includes snubbers, shall be designed to withstand the effects of normal and off-normal dynamic phenomena. ${ }^{1}$ Each snubber must accommodate normal thermal movements of plant piping or equipment and be capable of restraining the maximum off-normal dynamic loads postulated for its specific location. However, snubbers are subject to the effects of aging, and the factors that degrade their safety performance need to be better understood. This report describes the Phase II NPAR in-plant aging research conducted to enhance the understanding of snubber aging and to mitigate aging effects.

In the mid 1980s, the U.S. Nuclear Regulatory Commission (NRC) recognized the need to enhance snubber performance through aging studies and improved service-life monitoring techniques. The NRC's Nuclear Plant Aging Research (NPAR) Program Plan, Rev. 1, (USNRC 1987) $^{2}$ provided the vehicle and the logical sponsorship to undertake preliminary investigations into snubber performance and aging.

The NPAR Program Strategy has traditionally specified a two-phase approach. Phase I of the NPAR snubber research was undertaken by the Pacific Northwest Laboratory ${ }^{3}$ in 1985 and resulted in an initial aging assessment of snubbers and a snubber reduction evaluation study by Bush et al. (1986). The Phase II snubber research was conducted by PNL with support from Lake Engineering (Greenville, Rhode Island) and Wyle

\footnotetext{
${ }^{1}$ Normal dynamic reactions are those associated with thermal expansion and contraction of plant systems during normal startups or shutdowns. Off nomal dynamic reactions involve loads not associated with normal operations such as postulated seismic events.

${ }^{2}$ The NRC's initial version of the NPAR program plan was issued in July of 1985 .

${ }^{3}$ Pacific Northwest I aboratory is operated by Batielle Memorial Institute for the U.S. Department of Energy under Contract DE-AC06-76RLO 1830.
}

Laboratories (Huntsville, Alabama). The interim Phase II study by Brown et al. (1990) resulted in preliminary investigations that further clarified the aging questions and identified additional information on aging that should be assembled and analyzed for both hydraulic and mechanical snubbers. Twenty-four nuclear power utilities were also surveyed for information on snubber operating experiences.

The preliminary Phase II investigations defined the snubber in-plant research scope and determined that a special research emphasis should be placed on mechanical snubbers. The following objectives provide the scope of the Phase II research described in this report:

- determine how snubbers age and degrade

- define snubber failure characteristics

- determine the technical information needed to improve snubber service-life performance.

To meet these objectives the in-plant research involved:

- reviewing existing service data

- evaluating the effects of compression set of hydraulic snubber scals

- developing service-life monitoring guidelines

- improving the understanding of aging in mechanical snubbers.

The research staff planned and conducted in-plant research that involved selecting the sites for research, visiting the sites, and gathering and analyzing data on snubber performance.

The methodology of the snubber in-plant research is described in Section 2.0. Sections 3.0,4.0, and 5.0 discuss the results, conclusions, and recommendations from the in-plant research, respectively. Section 6.0 includes recommendations for additional snubber research. In addition to supplementing investigations by 
Introduction

Brown et al. (1990), the research findings presented in this report support key elements of the NPAR program strategy, including dissemination of technical information, recommendations to improve applicable codes and standards, guidelines for service-life predictions, and liaison with industry and NRC staff. Additionally, the report supports the assumption that snubber failures are closely related to aging degradation caused by operational environmental influences, e.g., vibration and elevated temperature. 


\section{Methodology of Snubber Aging Research}

This section describes the site selection process and the in-plant research methodology used to determine the effects of aging on snubber performance.

\subsection{Methodology}

Plant selection and the method of on-site visits are discussed in the following sections.

\subsubsection{Key Site Selection}

Selecting the cooperative key sites was an important preliminary step of the in-plant research. Key sites are defined as those plants that participated directly in the research by providing their facilities and making available appropriate engineering and maintenance staff for on-site interviews by NPAR staff and subcontractors. Plants with effective inspection and testing programs and staff with experience in root cause analysis were primary candidates.

The following criteria were applied in the site selection process:

- willingness to participate

- snubber type, i.e., mechanical or hydraulic

- plant type, i.e., BWR or PWR

- snubber service time

- knowledge and/or available information in the following areas:

- failure evaluation

- root cause evaluation

- identification of operating environment and measurement of the level of environmental stressors

- effects of environments on snubber performance
- testing

- snubber tracking

- snubber trending

- experience in utilizing in situ environmental monitoring instrumentation.

\subsubsection{In-Plant Research Methodology}

After the key sites were selected, site visits were planned and scheduled. Technical staff at each plant devoted two to three days to assist in gathering relevant information during the site visits, and extensive snubber documentation was made available for review by the in-plant investigators. A total of thirteen plants at eight sites (A through $G$ ) were visited during a three-month interval (see Figure 2.1). Five sites were designated as key sites in evaluating mechanical snubbers. Of these, three (six plants) are of PWR design and two (four plants) are of BWR design. Two sites were designated as key sites in evaluating hydraulic snubber aging. Both of these sites (4 plants) are BWR design. One site was visited for information pertaining to in situ monitoring of environmental stressors; the plant is a BWR design.
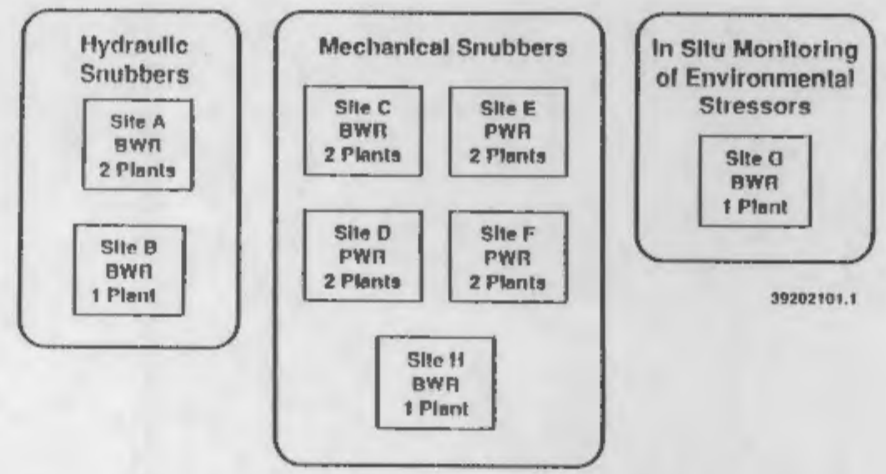

Figure 2.1 Scope of Snubber In-plant Research at Eight Sites (A through G) 
Methodology

The research methodology used during the site visits consisted principally of the following:

- on-site interviews with knowledgeable plant personnel

- review of plant operating history

- snubber tracking databases

- failure evaluation reports

- functional test data

- maintenance practices.

Other methods used during the in-plant research consisted of the following:
- approximately 70 telephone contacts made with various operating plant personnel

- specific research involving snubber disassembly, examination, and measurement of parts. The activity occurred both on-site and off-site. (This activity was conducted at Lake Engineering Company's, Rhode Island, facility for the evaluation of compression set of hydraulic snubber seals. This work is discussed further in Section 3.2.3 of this report.)

- use of "in-house" information available to Wyle Laboratories, Lake Engineering Company and PNL. (Personnel from Wyle Laboratories and Lake Engineering Company have many years of experience working with NPP snubbers and supporting equipment.) 


\section{Evaluation of the In-Plant Snubber Research}

In this section, the research data on snubber performance and failure causes and mechanisms is evaluated.

\subsection{Review of Available Industry Service Data}

A key goal of the plant visits was to evaluate the recent performance history for both mechanical and hydraulic snubbers in NPP service. Data on the number of recorded failures and data on the types of failures and degradation was also reviewed. An important distinction was made between data on aging-related and nonaging-related failures; this is addressed in Section 3.1.2. Summary reports for all site visits are included in Appendix A.

During the site visits, information was obtained from plant operating records. The Snubber Utility Group (SNUG) database ${ }^{1}$ and "in-house" databases were also reviewed. It should be noted that the majority of failures for both mechanical and hydraulic snubbers have been identified by functional testing. The number of failures found by visual examination, on the other hand, has been minimal.

From the number of failures evaluated during the site visits, some correlations can be made between failure mechanisms and failure causes under comparable service conditions. However, significant differences in plant design, the lack of precise time-based environmental data and the effects of more than one environmental stressor often prevent the use of snubber aging data on a generic basis. This supports the need for some degree of plant-specific service-life monitoring.

It should be noted here that approximately $95 \%$ of all mechanical snubbers in NPP service are the acceleration limiting type; most of the remaining $5 \%$ incorporate a

${ }^{1}$ The first compilation of data on snubber inspections and tests covering the period 1976 to 1988 , issued by SNUG, was made available by the Nuclear Management and Resources Council (NUMARC) to the NRC and PNL in January 1989. An internal, unpublished, review of the data was provided by PNL staff in September of 1989. velocity limiting feature. Approximately $99 \%$ of all hydraulic snubbers in NPP service utilize a dual mode, lock-up/bleed type control valve; the remaining 1\% utilize a single mode, velocity limiting design. The aging research primarily focused on the aging characteristics of acceleration limiting mechanical snubbers and lockup/bleed type hydraulic snubbers. Much of the information, however, obtained in the research would also be expected to be characteristic of the remaining snubber types due to similarities of design features, e.g., ball nut and screw for mechanicals, seals for hydraulics, and common environmental stressors.

\subsubsection{Snubber Performance Versus Failure Mechanisms and Causes}

Snubber failure causes may be generally categorized into five groups:

- Deficiencies in installation, handling, and maintenance

- Environmental influences (e.g., elevated temperature, moisture, etc.)

- Transients (overloading)

- Vibration

- Design or manufacturing deficiencies.

\subsubsection{Mechanical Snuhbers}

Table 3.1 lists by category the number and causes of 357 mechanical snubber failures reported by Sites C, D, E and $\mathrm{F}$. Data supporting these failure causes were obtained during plant site visits. Table 3.1 is graphically illustrated in Figure 3.1. A more detailed discussion of the effects of aging on mechanical snubbers is provided in Section 3.3.

\subsubsection{Hydraulic Snubbers}

Of a total of 86 reported hydraulic snubber failures from plant Sites A and B, the number of failures is listed by 
Evaluation

Table 3.1 Mechanical snubber failures by category

\begin{tabular}{lc}
\hline \multicolumn{1}{c}{ Category } & $\begin{array}{c}\text { Number } \\
\text { of } \\
\text { Failures }\end{array}$ \\
\hline Installation/mishandling/maintenance & 143 \\
Environment & 59 \\
Transients and vibration & 94 \\
Manufacturing Defects & 52 \\
Unknown & $\underline{9}$ \\
Total Number of Failures & $\mathbf{3 5 7}$ \\
\hline
\end{tabular}

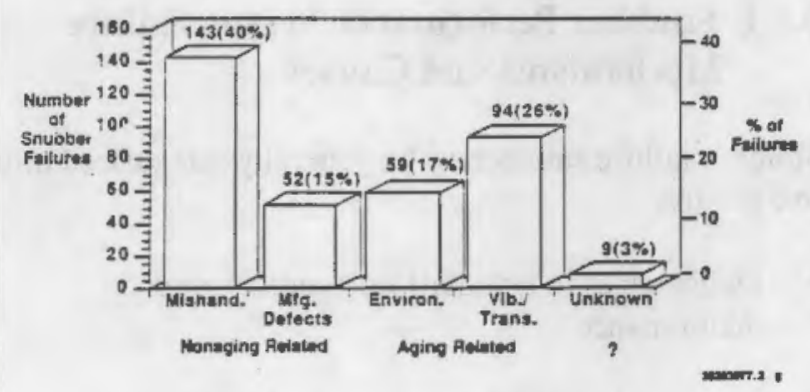

Figure 3.1 Mechanical snubber failures by category

failure cause category in Table 3.2. This is graphically illustrated in Figure 3.2.

\subsubsection{Aging-Related Versus Nonaging-Related Failures}

As shown in Figure 3.1, for mechanical snubbers, 59 failures were attributed to the environment category and 94 were attributed to the transients and vibration category. Thus, approximately $43 \%$ ( 153 out of 357 ) of the failures were associated with actual plant service and are classified as aging-related failures (see Figure 3.3).
Table 3.2 Hydraulic snubber failures by category

\begin{tabular}{lc}
\hline \multicolumn{1}{c}{ Category } & $\begin{array}{c}\text { Number } \\
\text { of } \\
\text { Failures }\end{array}$ \\
\hline Installation/mishandling/maintenance & 16 \\
Environment & 26 \\
Transients and vibration & 18 \\
Manufacturing Defects & 4 \\
Unknown & $\underline{22}$ \\
Total Number of Failures & $\mathbf{8 6}$ \\
\hline
\end{tabular}

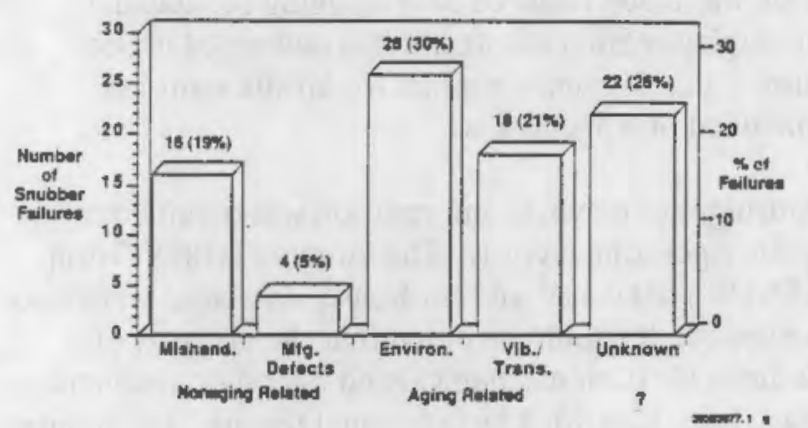

Figure 3.2 Hydraulic snubber failures by category

As sbown in Figure 3.2, for hydraulic snubbers, 26 failures were attributed to the environment category and 18 were attributed to the transients and vibration category. Plant service influences, therefore, accounted for approximately $51 \%$ of the total number of aging-related failures (see Figure 3.4).

Note: Data for both hydraulic and mechanical snubbers reflects failures identified between 1984 and 1990. The majority of mechanical snubber data reflect failures identified during the first three or four refueling outages. The hydraulic snubber data reflect failures identified between the tenth and fifteenth years of plant operation. 
Evaluation

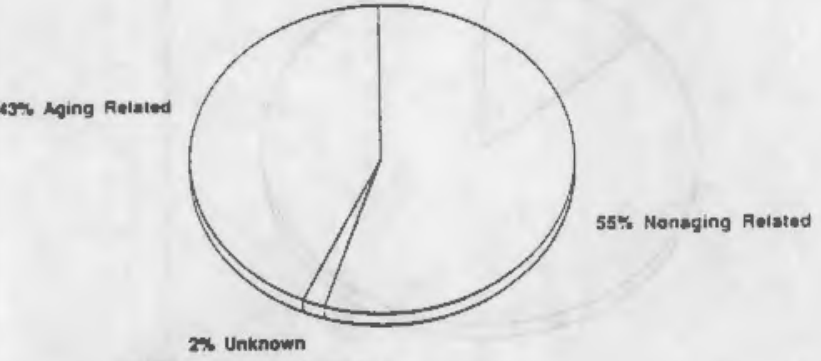

Figure 3.3 Aging-related versus nonaging-related failures in mechanical snubbers

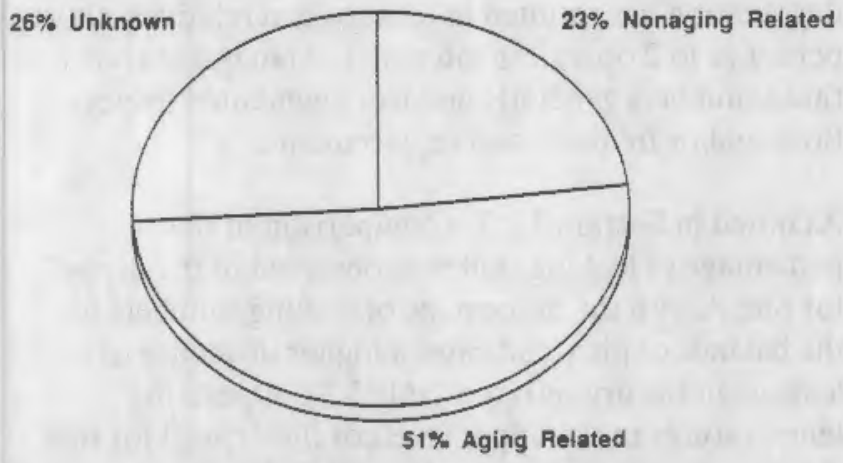

Figure 3.4 Aging-related versus nonaging-related failures in hydraulic snubbers

\subsubsection{Environmental Effects on Elastomeric Seal Degradation Rate}

The number of leaking snubbers noted in the drywell during a recent visual examination for one plant at Site A was compared with those found in the remainder of the plant. The results are tabulated in Table 3.3. As indicated in the data, the incidence of leakage was significantly greater for those snubbers installed in the drywell (see Figure 3.5 ). This indicates that, at least for this plant, monitoring a separate population (by plant area) for purposes of establishing seal life may be practical.

\subsubsection{Seals and Leakage}

The following subsections discuss maintenance practices and aging phenomena that are associated with hydraulic fluid leakage.
Table 3.3 Hydraulic snubber leaks versus plant location in a BWR plant

\begin{tabular}{lccc}
\hline \multicolumn{1}{c}{ Area } & $\begin{array}{c}\text { Total } \\
\text { Snubbers } \\
\text { Inspected }\end{array}$ & $\begin{array}{c}\text { No. of } \\
\text { Indicated } \\
\text { Leaks }\end{array}$ & $\begin{array}{c}\text { \% of } \\
\text { Indicated } \\
\text { Leaks }\end{array}$ \\
\hline Drywell & 263 & 39 & 14.8 \\
$\begin{array}{l}\text { Remainder of } \\
\text { the Plant }\end{array}$ & 287 & 27 & 9.4 \\
\hline
\end{tabular}

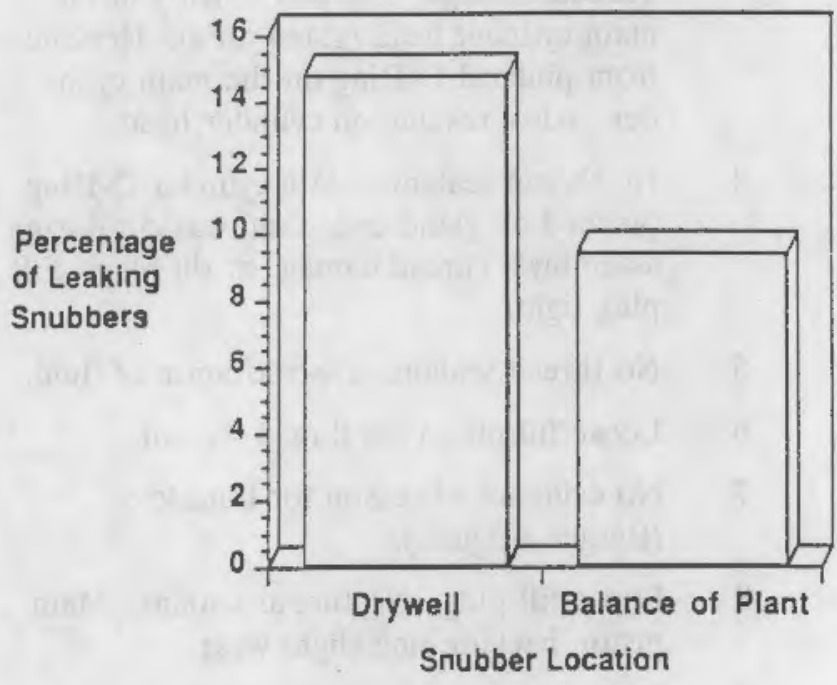

Figure 3.5 Leaking bydraulic snubbers by location in a BWR plant

\subsubsection{Aging Versus Non-Aging Related Seal Degradation}

Most cases of hydraulic snubber seal leakage are not directly attributable to long-term environmental effects. This conclusion is based, in part, upon data collected in the research as well as discussions with plant personnel and the field experience of the authors. This is illustrated by the maintenance observation data presented in Table 3.4. Table 3.4 indicates that from a total of 15 hydraulic snubbers at Site A removed from service because of significant leakage, there was very little evidence of seal degradation due to aging (see Figure 3.6). However, most operating plants have identified a limited number of snubbers in isolated areas (generally involving high temperature) where seal 
Table 3.4 Maintenance observations for 15 leaking snubbers at Site $\mathbf{A}$

\begin{tabular}{|c|c|}
\hline Snubber & Observations \\
\hline 1 & Finger-tight fill plug. No thread sealant. \\
\hline 2 & $\begin{array}{l}\text { Elevated temperature affected paint. No } \\
\text { thread sealant. } 1 / 2 \text {-diameter tear in the } \\
\text { accumulator piston seal. Particles in the } \\
\text { fluid. }\end{array}$ \\
\hline 3 & $\begin{array}{l}\text { No thread sealant. Loose fill plug. } \\
\text { Thread damage. Pinched O-Ring in the } \\
\text { main cylinder head (gland area). Residue } \\
\text { from pinched O-Ring on the main cylin- } \\
\text { der. Also, residue on cylinder head. }\end{array}$ \\
\hline 4 & $\begin{array}{l}\text { No thread sealant. Main cylinder O-Ring } \\
\text { pinched on gland end. Seal was cut during } \\
\text { assembly. Thread damage at fill plug. Fill } \\
\text { plug tight. }\end{array}$ \\
\hline 5 & No thread sealant. Discoloration of fluid. \\
\hline 6 & Loose fill plug. No thread sealant. \\
\hline 7 & $\begin{array}{l}\text { No evidence of reason for fluid loss. } \\
\text { (Bergen original). }\end{array}$ \\
\hline 8 & $\begin{array}{l}\text { Loose fill plug. No thread sealant. Main } \\
\text { piston backing ring slight wear. }\end{array}$ \\
\hline 9 & $\begin{array}{l}\text { No thread sealant. Loose fill plug. } \\
\text { Thread damage accumulator head. } \\
\text { Pinched main cylinder seal. }\end{array}$ \\
\hline 10 & Loose fill plug. \\
\hline 11 & $\begin{array}{l}\text { Poor O-Ring installation in accumulator } \\
\text { cap/aceumulator cylinder. Loose fill plug. }\end{array}$ \\
\hline 12 & Loose fill plug. Damaged fill plug threads. \\
\hline 13 & Torn accumulator piston seal. \\
\hline 14 & $\begin{array}{l}\text { Loose fill plug. Wear on fill plug hold } \\
\text { threads. }\end{array}$ \\
\hline 15 & No thread sealant. Fill plug tight. \\
\hline
\end{tabular}

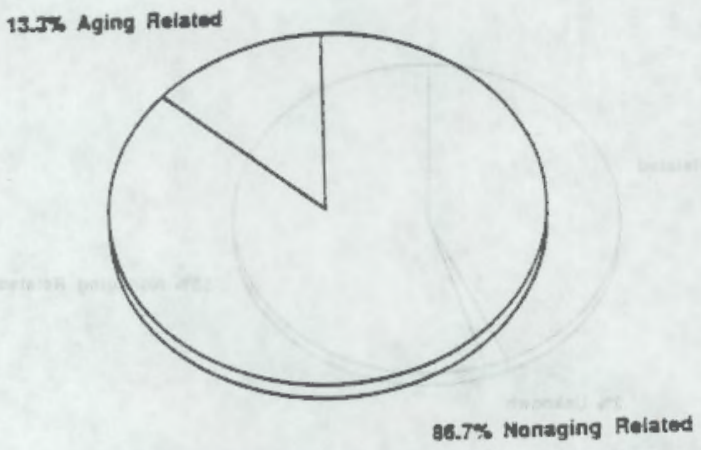

Figure 3.6 Aging versus nonaging-related seal leakage

degradation has resulted in leakage in a relatively short period ( 1 to 2 operating intervals). Management of these snubbers generally involves augmented inspections and/or frequent seal replacements.

As noted in Section 3.1.3, a comparison of the percentage of leaking snubbers observed in the drywell for Site A with the percentage of leaking snubbers for the balance of plant indicates a higher incidence of leakage in the drywell (see Table 3.3). Operating temperatures in the upper levels of the drywell for this plant are known to have exceeded $220^{\circ} \mathrm{F}$; short-term degradation of ethylene propylene (less than two years) can be expected under such conditions. Operating temperatures for most plants, on the other hand, are significantly less than this, i.e., $150^{\circ} \mathrm{F}$ or less. The higher incidence of leakage for the Site A drywell snubbers is probably the result of a combination of seal degradation and a lower fluid viscosity at elevated temperatures.

A number of plants have implemented programs for monitoring elastomeric seal degradation in the general snubber population. Such programs can extend or reduce seal life based on operating experience. They are described in more detail in Section 3.2.3 of this report.

\subsubsection{Thread Seals}

Thread seals used with the control valve screws for some hydraulic snubbers have commonly exhibited low-level fluid leakage that is generally not sufficient to render the snubber inoperable between refueling outages. 
It should be noted, however, that, despite the susceptibility of these seals to aging degradation, thread seal leakage is often the result of seal damage due to improper installation of the seals or other nonservicerelated degradation. For example, installing snubbers without using washers between the seal and lock nut invariably results in damage to the seal.

\subsubsection{Hydraulic Fitting Leakage}

A significant portion of the total number of hydraulic snubber leakage problems, for the nuclear industry in general, has been associated with leaking hydraulic fittings. These fittings are used to connect the control valve to the hydraulic cylinder and to connect the reservoir to the control valve.

It is not possible to determine precisely what percentage of the leaking fittings is directly the result of the service environment. However, it should be noted that such fittings are highly susceptible to leakage due to misalignment, damage, and abuse. The SNUG database ${ }^{1}$ indicates that from a total of 247 hydraulic snubbers that were found to be leaking due to either seal or fitting leakage, 157 of these $(64 \%)$ were the result of fitting leakage.

\subsubsection{Evaluation of Plant Service-Life Monitoring Methods}

The NRC Standard Technical Specifications (STS) (USNRC 1984) require that plants maintain a servicelife monitoring program. The Working Group on Mechanical Equipment Restraints is developing servicelife monitoring requirements that will likely be included in Subsection ISTD of the Operations and Maintenance (OM) Code. A non-mandatory appendix that will provide some guide lines for service-life monitoring is also being developed by the Working Group.

Formal service-life monitoring programs have not been established at all NPPs. For some plants, service-life

\footnotetext{
${ }^{1}$ The first compilation of data, covering the period 1976 to 1988 , on snubber inspections and tests issued by SNUG, was made available by the Nuclear Management and Resources Council (NUMARC) to the NRC and PNL in January 1989. An internal, unpublished, review of the data was provided by PNL staff in September 1989.
}

monitoring involves ensuring that only seals and fluid are replaced in hydraulic snubbers at prescribed intervals. However, it should be noted that most plants have implemented maintenance practices that have helped to identify practical methods for a service-life monitoring program.

\subsubsection{Realistic Determination of Snubber Failure or Degradation Causes}

In many cases, determining the cause of snubber failure has been a relatively simple task. In other cases, it has been impossible to determine the actual cause of failure or degradation. From interviews with plant personnel and review of failure evaluation data, it is apparent that the experience and judgement of personnel involved in failure evaluations have been critical in identifying realistic failure causes. In some cases, inspectors have erroneously identified the failure cause as a result of either the lack of an in-depth evaluation or inadequate training.

\subsubsection{Determination and Documentation of Snubber Operating Environment}

Plants have used a variety of methods to determine the operating environment. For some plants the defined snubber operating environment is based on the maximum value of various environmental parameters described in the plant design specification. However, the research has determined that, in isolated applications, environmental parameter values can exceed specified design levels. Such applications are generally plant specific and are often identified by monitoring snubber degradation.

In many cases, severe operating environments that were previously unidentified were brought to light by characteristics noted during visual examination, snubber overhaul, or during failure evaluation. Examples of such characteristics and the environments to which they relate are discussed in Table 5.1 .

In some cases, various types of measuring instruments (see Appendix B) have been used to define the environment precisely. However, such equipment is generally limited to applications where moderate to severe 
environments are anticipated or where the equipment is used as a diagnostic aid to identify the cause of service degradation.

Some plants have obtained localized area temperature data, for example, at various levels in the drywell, using portable temperature monitoring devices. In cases of rapid snubber degradation resulting from high temperatures, precise temperature information has been limited. In general, more precise information is needed in this regard to establish practical temperature-time limits.

Area radiation information is typically available from a plant's radiation protection department. Since there is little documented evidence of degradation due to radiation (see Section 3.2.1.1), radiation monitoring of specific snubber locations is not common.

Most plants have identified the existence of high amplitude vibration (see Appendix B) from information obtained during visual examination, testing, or failure evaluation. Metal filings, darkened hydraulic fluid, deformed connecting pins, elongated attachment holes, and fretting of mating parts are all signs of vibration effects. Some plants have instrumented snubbers in order to obtain more specific information in this regard (see Appendix B). In addition to loosening of threaded fasteners, significant wear of connecting pins and attachment hardware can result from low amplitude vibration in combination with snubber weight forces. A photo of a worn clevis pin damaged from low amplitude vibration is illustrated in Appendix J, Figure J-9.

\subsubsection{Transients}

As with vibration, transients, such as those caused by water or steam hammer, turbine trip, etc., can induce loads that are beyond the snubber's design capacity, often rendering the snubber immediately inoperable. Some snubbers are exposed to periodic load transients that are within the rated capacity of the snubber; however, if such transients are not mitigated, snubbers might undergo progressive degradation that can also result in failure.

\subsubsection{Management of Snubbers Subject to Rapid Degradation}

Many plants have augmented inspection procedures for evaluating snubbers that are susceptible to rapid degradation due to a severe operating environment or dynamic transients. For example, freedom of movement for snubbers suspected of having experienced a dynamic transient is often verified by hand stroking or rotation of the snubber about its spherical end bearings.

\subsubsection{Other Useful Monitoring Considerations}

A number of additional considerations and maintenance practices identified in the plant research are discussed in Section 5.4. These are used to form a basis for the service-life monitoring recommendations in Section 5.1.

\subsection{Evaluation of Hydraulic Snubber Aging}

The following subsections discuss the primary aging factors associated with degradation in hydraulic snubber performance, such as, elevated temperature, vibration and moisture. Typical failure modes for the majority of hydraulic snubbers, and associated failure mechanisms and causes, are shown in Table 3.5. Separate subsections are also included pertaining to the effects of load transients, service-life evaluation techniques, and the effects of compression set on low pressure seal performance. Elastomeric seals most affected by aging are also discused in a separate subsection.

\subsubsection{Aging Factors for Hydraulic Snubbers}

\subsubsection{Radiation}

During the course of the snubber aging research, no cases of snubber degradation were identified that were specifically attributed to radiation. However, this may be partially due to the lack of in-depth failure analysis data. Although the effects of radiation on snubber degradation are probably less than was originally anticipated, radiation cannot be totally dismissed as a contributor to seal and fluid degradation. 
Evaluation

Tahle 3.5 Typical hydraulic snubber failure causes

\begin{tabular}{|c|c|c|}
\hline $\begin{array}{l}\text { Failure } \\
\text { Mode }\end{array}$ & $\begin{array}{c}\text { Failure } \\
\text { Mechanism }\end{array}$ & Failure Cause \\
\hline \multirow{4}{*}{$\begin{array}{l}\text { Low- } \\
\text { Locking } \\
\text { Velocity }\end{array}$} & $\begin{array}{l}\text { High fluid } \\
\text { viscosity }\end{array}$ & $\begin{array}{l}\text { Inadequate material control; } \\
\text { low test temperature }\end{array}$ \\
\hline & Gelated fluid & Component vibration \\
\hline & $\begin{array}{l}\text { Incorrect } \\
\text { valve parts }\end{array}$ & $\begin{array}{l}\text { Inadequate material control; } \\
\text { improper assembly }\end{array}$ \\
\hline & $\begin{array}{l}\text { Incorrect } \\
\text { setting }\end{array}$ & $\begin{array}{l}\text { Field tampering; inadequate } \\
\text { calibration }\end{array}$ \\
\hline \multirow{4}{*}{$\begin{array}{l}\text { Low } \\
\text { Bleed } \\
\text { Rate }\end{array}$} & $\begin{array}{l}\text { High fluid } \\
\text { viscosity }\end{array}$ & $\begin{array}{l}\text { Inadequate material control; } \\
\text { low test temperature }\end{array}$ \\
\hline & Gelated fluid & Component vibration \\
\hline & $\begin{array}{l}\text { Incorrect } \\
\text { setting }\end{array}$ & $\begin{array}{l}\text { Field tampering; inadequate } \\
\text { calibration }\end{array}$ \\
\hline & $\begin{array}{l}\text { Particulate } \\
\text { contamination }\end{array}$ & Inadequate parts cleaning \\
\hline \multirow{5}{*}{$\begin{array}{l}\text { High- } \\
\text { Locking } \\
\text { Velocity }\end{array}$} & $\begin{array}{l}\text { Low fluid } \\
\text { viscosity }\end{array}$ & $\begin{array}{l}\text { Inadequate material control; } \\
\text { high test temperature }\end{array}$ \\
\hline & Air in fluid & $\begin{array}{l}\text { Inadequate purge; seal } \\
\text { degradation resulting in loss } \\
\text { of fluid }\end{array}$ \\
\hline & Incorrect setting & $\begin{array}{l}\text { Inadequate calibration } \\
\text { procedure }\end{array}$ \\
\hline & $\begin{array}{l}\text { Incorrect valve } \\
\text { par }\end{array}$ & Improper assembly \\
\hline & $\begin{array}{l}\text { Piston seal } \\
\text { by-pass }\end{array}$ & Seal degradation \\
\hline \multirow{5}{*}{$\begin{array}{l}\text { High } \\
\text { Bleed } \\
\text { Rate }\end{array}$} & Air in fluid & Inadequate purge; seal \\
\hline & & degradation resulting in lass \\
\hline & & of fluid \\
\hline & $\begin{array}{l}\text { Low lluid } \\
\text { viscosity }\end{array}$ & $\begin{array}{l}\text { Inadequate material control; } \\
\text { high test temperatere }\end{array}$ \\
\hline & Water in Iluid & High humidity environment \\
\hline
\end{tabular}

Laboratory evaluations pertaining to the effects of gamma radiation on elastomeric seals have been conducted (Barbarin 1977 and Mosca 1977). However, the results of such evaluations are difficult to apply in service because of the absence of precise radiation level information for each snubber location, variations in seal materials and compounds, and shielding provided by the snubbers' metallic components. The potentially synergistic effects of radiation in combination with other environmental stressors have also not been fully substantiated.

\subsubsection{Elevated Temperature}

Elevated temperature is generally considered to be the most prevalent degradation stressor for hydraulic snubbers. This is based on the relatively high incidence of degradation or failure in high temperature applications. In applications where hydraulic snubbers are subjected to abnormally high temperatures (above $250^{\circ} \mathrm{F}$ ) significant degradation may result in a relatively short period, e.g., within one or two operating intervals. In applications involving low temperatures, (less than $120^{\circ} \mathrm{F}$ ) degradation may progress gradually over a period of ten or more years.

Specifically, the effects of elevated temperature include

- acceleration of compression set inducement in elastomeric seals

- accelerated oxidation effects on elastomeric seals, i.e., cross-linking, resulting in embrittlement and/or surface fissures.

- deformation of plastic hydraulic reservoirs

- adhesion of dynamic seals to mating surfaces

\subsubsection{Moisture}

Hydraulic snubber degradation due to moisture is generally in the form of corrosion. In some cases, severe corrosion has resulted in structural failure of springs used in pressurized reservoirs; however, this problem was limited to a specific snubber design in a particularly humid environment and has since been corrected. Some snubbers have experienced pitting of piston rod plating in a very humid environment, e.g., in coastal areas.

Regarding hydraulic snubbers subjected to moisture, internal corrosion resulting in the generation of corrosion products can cause a malfunction of the snubber control valve. Such degradation has been documented for a limited number of hydraulic snubbers in high humidity environments, with reservoirs that are vented to the atmosphere. 


\subsubsection{Vibration}

High-amplitude vibration, i.e., vibration with an amplitude greater than the clearances in the end attachments, can result in wear and localized overheating of mating parts. Such wear can result in particle generation, potentially effecting control valve performance. The incidence of seal wear due to vibration is surprisingly low. Applications involving continuous high- or lowamplitude vibration can result in loosening of threaded fasteners and/or wear or deformation of clevis pins and attachment holes (see Appendix J, Figure J.9).

High amplitude vibration has also resulted in deformation of poppets and poppet seats in hydraulic snubber control valves. However, the incidence of such degradation has been mitigated by the incorporation of improved materials.

In many cases, extreme high-amplitude vibration can result in gelation of the hydraulic fluid (see Appendix J, Figure J.2). The exact cause of this gelation is not known; however, it is speculated that the gelation is caused by localized mechanical working of the hydraulic fluid due to continuous motion of the piston, resulting in changes in the fluid's physical properties.

\subsubsection{Transient Loads}

Snubbers are subject to transient dynamic loads due to abnormal operating conditions such as water hammer, turbine trip, etc. Such transients occasionally exceed the rated load capacity of the snubber, in which case significant damage can result, rendering the snubber immediately inoperable. Such damage is typically in the form of a bent piston rod for compressive loads and sheared piston/piston rod threads for tensile loads.

Hydraulic snubbers are also subject to transient dynamic loads that are less than the design capacity of the snubber. Such transients can cause excessive wear of mating parts, fatigue of structural members, and gelation of hydraulic fluid.

\subsubsection{Elastomeric Seal Life Evaluation Techniques}

Seal replacement intervals recommended by snubber manufacturers have generally been conservative due to the lack of service data at the time of the recommendations. Recent experience with seals manufactured from environmentally suitable elastomers such as ethylene propylene and fluorocarbon rubber (Viton) ${ }^{1}$ has indicated minimal degradation.

Methods used to predict seal life fundamentally involve either accelerated aging studies or actual inservice data, these are discussed below.

\subsubsection{Accelerated-Aging Studies}

Seal life for some plants is based on a mathematical model (Arrhenius) (Gillen 1980) that correlates a given degradation parameter, e.g., stress relaxation, with a given environmental stressor, e.g., temperature and time. Seal life is then monitored based on recorded time at various operating temperatures. An example of this approach, used at Site A, is included in Appendix C.

The accelerated-aging model and associated analytical seal life projections are useful design tools for selecting optimum materials and designs. However, to predict seal life from this approach alone--without substantiation by service data--is impractical because of the number of variables involved. Such variables include:

- seal material or compound

- seal configuration, e.g., O-ring, lip seal, tee seal, boss seal, thread seal, and spring-energized seal

- seal thickness

- fluid medium

${ }^{1}$ Viton is a registered tradename of duPont Company. 
- mating surface finish

- initial squeeze.

Furthermore, the accelerated-aging model becomes overly complicated and unreliable when more than one environmental stressor is involved, e.g.,

- temperature

- radiation

- moisture

- air exposure

- fluid effects.

\subsubsection{Evaluation of Seals Removed from Service}

Many plants monitor seal life based on data from seals removed from actual service in the plant. With this approach, a practical seal life may be projected and periodically updated for the general snubber population. Snubbers needing more frequent attention in particularly severe environments may also be identified and managed on a case-by-case basis.

The most commonly used seal life projection method is extrapolation of compression set (which is directly related to seal relaxation). The basis for this approach is illustrated in Figure 3.7.

For example, for a static seal that had been in service for seven years with a measured compression set of $50 \%$, using a compression set limit of $90 \%$, seal life, $\mathrm{t}_{2}$, may be calculated using the following equation:

$$
t_{2}=t_{1} \times \frac{C_{L}}{C_{\max }}=\frac{(7)(90)}{50}=12.6 \text { years }
$$

where $t_{2}=$ seal life (in years)

$\mathbf{t}_{1}=$ accumulated service time ( 7 years)

$\mathrm{C}_{\mathrm{L}}=$ compression set limit $(90 \%)$

$\mathrm{C}_{\max }=$ measured compression set value $(50 \%)$.

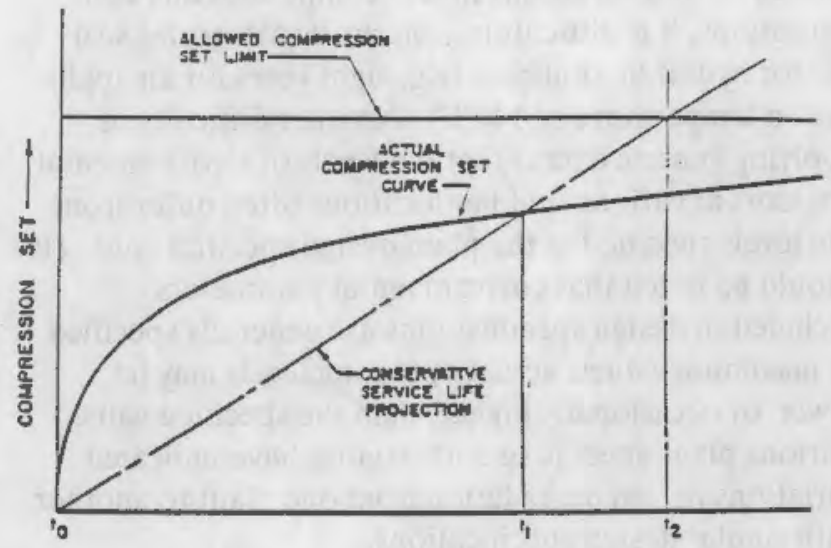

Figure 3.7 Compression set extrapolation

\subsubsection{Other Elastomeric Seal Life Evaluation Methods}

A number of other approaches have been used to substantiate seal life for snubbers. These include seal life projections based upon available laboratory data and evaluation of trends in snubber functional test data.

Accurate determination of seal life based on laboratory test data is difficult. Conclusive laboratory data supporting the long-term effects of temperature aging on seals is limited. This is primarily due to the difficulties encountered in simulating the effects of time. Although some information is available pertaining to the effects of radiation on elastomeric sealing materials, it is extremely difficult to apply this information to establish a practical seal life for snubbers in service (see Section 3.2.1.1).

Since the incorporation of environmentally suitable elastomers, there has been little evidence of seal failure when a snubber is activated, i.e., pressurized. Moreover, the primary aging concern is gradual relaxation of sealing force when the snubber is not activated. Therefore, a substantiation of seal life based solely on functional test results is not appropriate.

\subsubsection{Plant-Specific Seal Life Considerations}

Seal life evaluations, for the most part, have been plantor site-specific. Due to the lack of precise environmental data, the potential for combined environmental 
Evaluation

influences and variations in seal compounds and configurations, it is difficult to generically categorize seal life for hydraulic snubbers (e.g, eight years for an application temperature of $140^{\circ} \mathrm{F}$ ). Another difficulty in applying generic data is that the levels of environmental stressors at various snubber locations often differ from the levels specified in the plant design specifications. (It should be noted that environmental parameters included in design specifications are generally specified as maximum values; actual operating levels may be lower, or occasionally higher, than the specified value.) Various plant-specific seal life studies have indicated variations in seal degradation from one plant to another with similar design specifications.

Plant-specific seal life evaluations are appropriate for most hydraulic snubbers. However, it may be generally stated that seals manufactured from most ethylene propylene compounds, in mild operating environments (low temperature, low humidity, low radiation level) will likely exhibit little or no degradation over extended periods of time. More precise plant data is needed, however, in order to quantify seal life in this regard.

Ultimately, seal life should be based on successful of operating experience in the actual plant environment. Seal life extension evaluations should be considered as interim site-specific methods for progressively extending seal life from current conservative limits.

\subsubsection{Effects of Compression Set on Low- Pressure Elastomeric Seal Performance}

The purpose of this portion of the in-plant research was to verify practical compression set limits for the various seal configurations that are commonly used in hydraulic snubbers.

The chief concern regarding aging of hydraulic snubber seals is relaxation of sealing force under low-pressure conditions. Compression set is most often used as a direct indicator of the level of seal relaxation. Seal life projections are often based on comparison of a predicted compression set level with an established compression set limit.
Compression set, $\mathrm{C}$, may be defined by the following equation:

$$
\mathrm{C}=\frac{\mathrm{w}_{\mathrm{o}}-\mathrm{w}_{1}}{\mathrm{w}_{\mathrm{o}}-\mathrm{w}_{\mathrm{s}}}
$$

where $\mathrm{W}_{\mathrm{o}}=$ original seal thickness

$\mathrm{W}_{\mathrm{s}}=$ compressed seal thickness as it is installed in the seal gland

$\mathrm{w}_{1}=$ recovered seal thickness after the seal is removed from the gland.

Most static seals (seals where there is no relative motion between mating parts) will still perform adequately under low pressure conditions at $100 \%$ compression set. For a degree of conservatism, a compression set limit of $90 \%$ is typically used for projecting seal life in static seals used in hydraulic snubbers. For an additional degree of conservatism, a compression set limit of $80 \%$ is typically used for dynamic seals, i.e., seals where there is relative motion between mating parts.

Note: As a design tool, when selecting an optimum seal material based on laboratory-aging simulation, more conservative limits may be specified, due to the absence of actual service data.

\subsubsection{Methodology to Collect Compression Set Data}

The basic approach was to obtain nonleaking snubbers with seals that are expected to have a high level of compression set. Snubbers with extended service in a high-temperature environment were priority candidates. It was anticipated that such snubber samples could be found in either nonsafety-related applications in nuclear plants or in fossil fuel plants. Although snubbers in high-temperature environments were sought for their higher propensity for compression set, correlating operating temperatures with compression set is not a part of this study.

The selected snubbers were then subjected to a preliminary evaluation. The purpose of the preliminary evaluation was to determine, by measuring compression 
Evaluation

set in one or two representative seals, whether or not the remaining seais could be expected to have a high level of compression set.

Snubbers meeting the criteria established in the preliminary evaluation were then subjected to a secondary evaluation in which compression set was measured for all seals expected to have high levels of compression set.

A total of 24 NPP personnel were contacted either for candidate snubbers that might be available from the plant or for the names of fossil fuel plant contacts in the same utility. Eight major utilities with fossil fuel plants were also contacted. In addition, two hydraulic snubber vendors were contacted for snubber candidates available from their services groups.

\subsubsection{Results of the Compression Set Examinations}

A total of only six snubber samples were made available. Two major factors that limited the availability of snubber samples were 1) the limited amount of lead time allowed to obtain the required snubber samples in NPPs (snubber availability generally coincides with scheduled overhauls), and 2) the lack of replacement snubbers in fossil fuel plants.

Of the six available samples only two snubbers showed sufficient seal degradation in the preliminary evaluation to warrant a secondary evaluation. A summary of the preliminary and secondary evaluations is included in Appendix D.

\subsubsection{Additional Data Evaluation}

In order to augment the limited amount of data obtained in the evaluations described above, additional in-house data were reviewed for maximum recorded compression set levels for various nonleaking seal configurations.

\subsubsection{Summary of Compression Set Evaluation}

Table 3.6 lists maximum measured values for compression set for various nonleaking seal configurations. These configurations are illustrated in Figures 3.8 through 3.12. It should be noted that tabulated compression set values by no means reflect a limit for
Table 3.6 Maximum measured compression set for various nonleaking seal configurations

\begin{tabular}{|c|c|c|c|}
\hline Seal Configuration & Seal Type & $\begin{array}{c}\text { Maximum } \\
\text { Measured } \\
\text { Nominal (3) } \\
\text { Compression } \\
\text { Set }\end{array}$ & $\begin{array}{c}\text { Source } \\
\text { of } \\
\text { Data (S) }\end{array}$ \\
\hline O-Ring & Static & $57 \%$ & (2) \\
\hline O-Spring Lip Seal & Dynamic & $69 \%$ & (1) \\
\hline Quadra Spring Lip Seal & Dynamic & $69 \%$ & (2) \\
\hline U-Cup Piston Seal(4) & Dynamic & $100 \%$ & (2) \\
\hline $\begin{array}{l}\text { Miller Piston Rod Seal } \\
\text { (Static Portion) }\end{array}$ & Static & $93 \%$ & (1) \\
\hline
\end{tabular}

Note: (1) NPAR study.

(2) In-house data.

(3) Nominal compression set is calculated using nominal cross-section dimensions for original seal thickness.

(4) Internal seal integrity verified by functional testing.

(5) These data were obtained from 5 different snubbers.
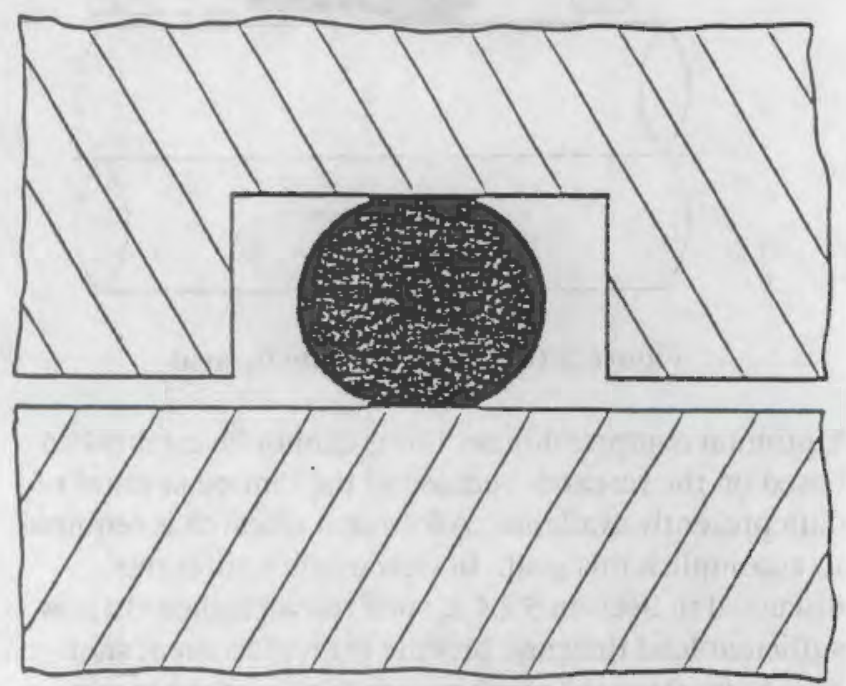

Figure 3.8 0-Ring

compression set for the respective seal configurations. They reflect only the maximum compression set value recorded, providing some degree of support for the typical compression set limits discussed in this section. 


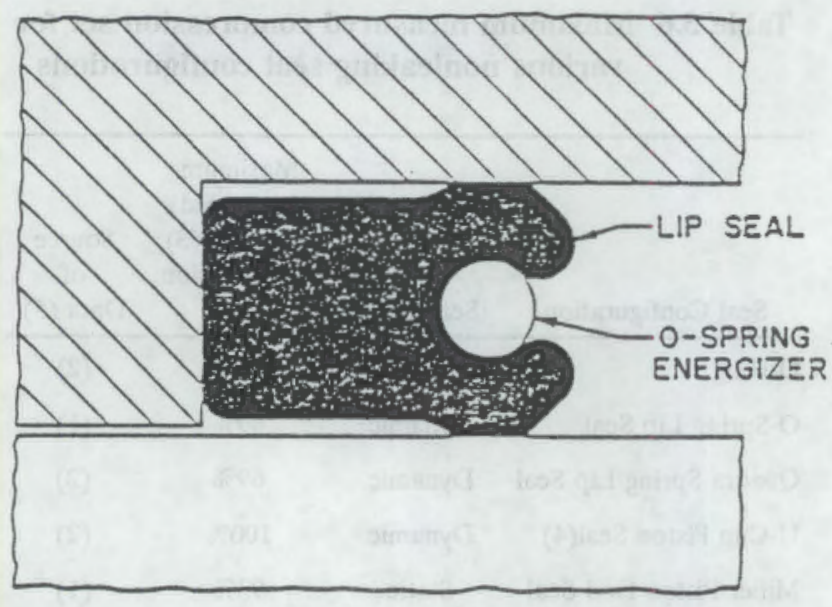

Figure 3.9 O-Spring lip seal

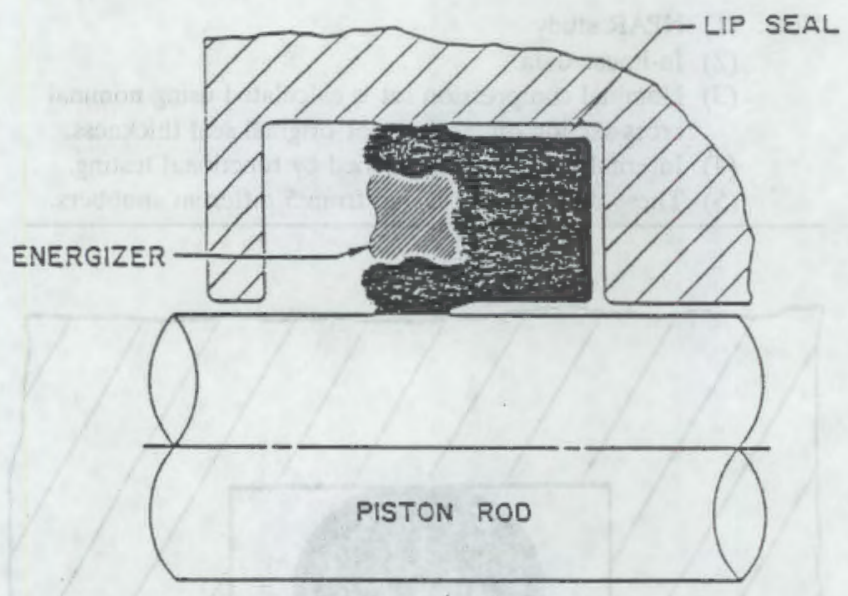

Figure 3.10 Quadra spring lip seal

Optimum compression set limits cannot be established based on the research because of the limited amount of data presently available. Additional research is required to accomplish this goal. In view of the limitations discussed in Section 3.2.4.2, such research should allow sufficient lead time and provide for replacement snubbers to increase the number of available snubber samples. Future seal data from plants with extended service will also be useful in further substantiating compression set limits.

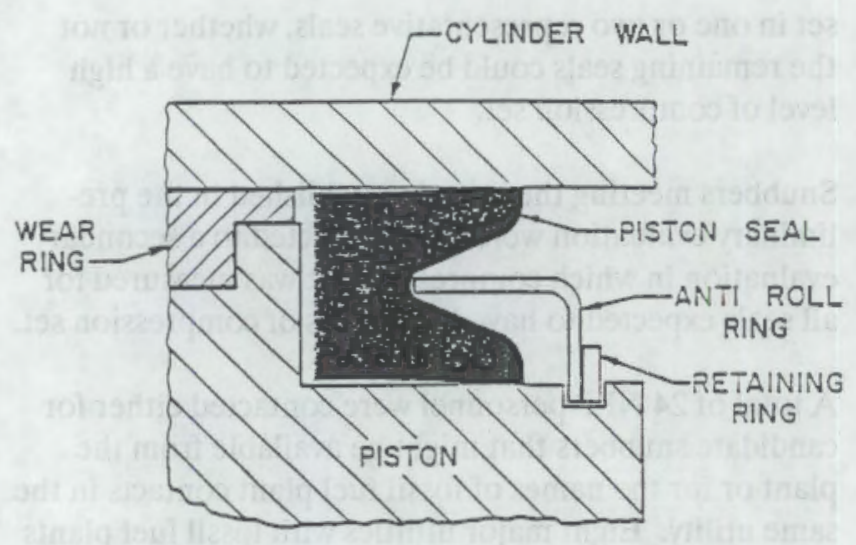

Figure 3.11 U-Cup piston seal

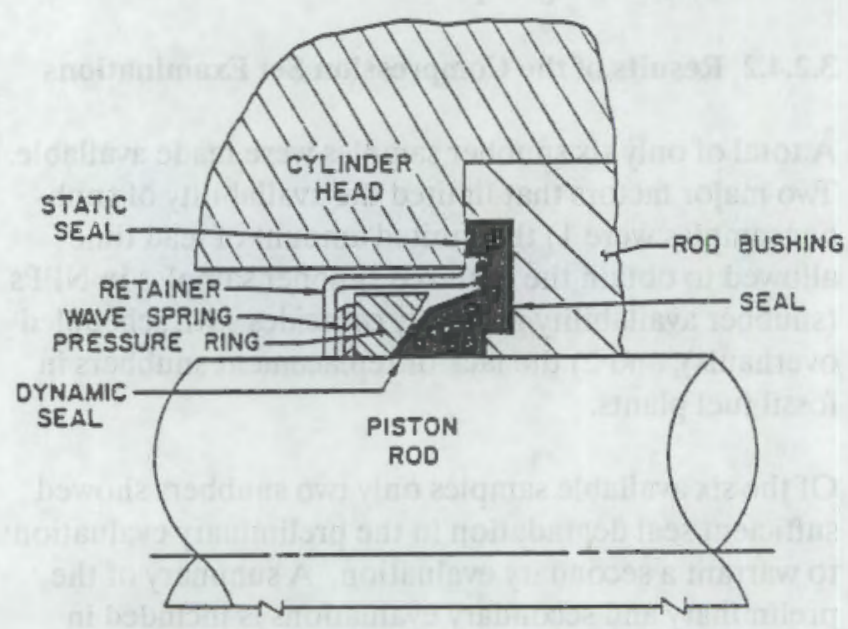

Figure 3.12 Miller piston rod seal

\subsubsection{Internal Seals}

The primary consideration regarding degradation of internal seals, e.g., piston seals, is progressive relaxation of sealing force such that locking velocity or bleed rate might be affected. However, snubbers with U-Cup piston seals with a measured compression set of $100 \%$ have been tested with no observed effect on these parameters.

\subsubsection{Elastomeric Seals Most Affected by Aging}

As discussed in Section 3.2.4, low pressure sealing capability is of primary concern for the effects of aging on hydraulic snubber seals. External seals, i.e., seals that, if 
Evaluation

leaking, would result in loss of fluid from the snubber, are considered to be the most critical in this regard.

The propensity of seals to age-related degradation may be characterized as follows:

- In general, the higher the surface area to volume ratio, the greater the propensity for a seal to take a set. Seals with a small cross-section thickness, therefore, are more susceptible to compression set inducement.

- Seals installed near or on the snubber surface appear to be more affected by the service environment (in terms of embrittlement and high compression set) than seals that are installed deeper within the snubber.

- Seals that are exposed to air are prone to degradation due to oxidation, particularly at elevated temperatures. Although seals also degrade due to radiation, signigicant effects in this regard have not been substantiated by the service data.

- Dynamic seals are generally more susceptible to leakage due to the relatively low initial squeeze that is characteristic of such seals, continuous changes in the seal-gland interface, and the potential for wear.

- Thread seals used to seal straight threads on some snubber models are particularly prone to service degradation, generally in the form of increased hardness and high set. It should be noted that thread seals are installed at the surface of the snubber and are exposed to air.

\subsection{Evaluation of Mechanical Snubber Aging}

The purpose of this evaluation is to develop an improved understanding of aging of mechanical snubbers based on recent operating experience.

Systems typically identified as problem safety-related systems for mechanical snubbers are listed in Table 3.7. Snubbers used on non-safety-related systems are also subject to degradation. However, plant data in this regard are not as comprehensive.
Table 3.7 Typical problem systems for mechanical snubbers

\begin{tabular}{ll}
\hline \multicolumn{1}{c}{ PWR Plant } & \multicolumn{1}{c}{ BWR Plant } \\
\hline - Component Cooling & - High-Pressure Core Spray \\
- Reactor Coolant & - Low-Pressure Core Spray \\
- Safety Injection & - Residual Heat Removal \\
- Steam Generator Blow & - Main Steam (particularly \\
Down & $\begin{array}{l}\text { between isolation valves and stop } \\
\text { valves) }\end{array}$ \\
\hline
\end{tabular}

Snubbers on small piping branching from relatively large piping (e.g., drain lines and instrumentation lines) are particularly susceptible to overloading caused by dynamic transients. Snubbers installed at pipe locations near connections to rotating equipment are susceptible to degradation due to vibration.

Until recently, service data on mechanical snubbers was limited because mechanical snubbers were not used on a large scale in nuclear plants until the late 1970s. A significant portion of the data that have been available pertained to some of the earlier problems encountered during pre-operational tests and initial ISI. Many of the reported failures were associated with construction damage, manufacturing defects, and isolated severe environments that have since been corrected.

Failure modes of mechanical snubbers may be grouped in three basic categories:

- high-drag or high-breakaway force (this includes frozen snubbers)

- high-acceleration threshold

- low-acceleration threshold. ${ }^{1}$

Table 3.8 represents a consolidation of typical mechanical snubber failure causes associated with the three failure modes described above. A more detailed classification of failure causes, as determined by failure analysis for Site C, is included in Appendix G.

\footnotetext{
${ }_{1}^{1}$ Some plants have a lower limit for acceleration. Although a low acceleration by itself is not a major concern, it may indicate a problem within the snubber that could lead to inoperability.
} 


\section{Evaluation}

Table 3.8 Typical mechanical snubber failure causes

\begin{tabular}{|c|c|c|}
\hline Failure Mode & Failure Mechanism & Failure Cause \\
\hline \multirow{6}{*}{ High Drag Force } & Bent screw shaft & Overload \\
\hline & Inertia mass rubbing against dust cover & Overload \\
\hline & Foreign materials on screw shaft & Dusty Envir. \\
\hline & Foreign materials on indicator tube & Dusty Envir. \\
\hline & Cracked thrust bearing & Overload \\
\hline & Dry lubricant & Elev. Temp. \\
\hline \multirow{11}{*}{ 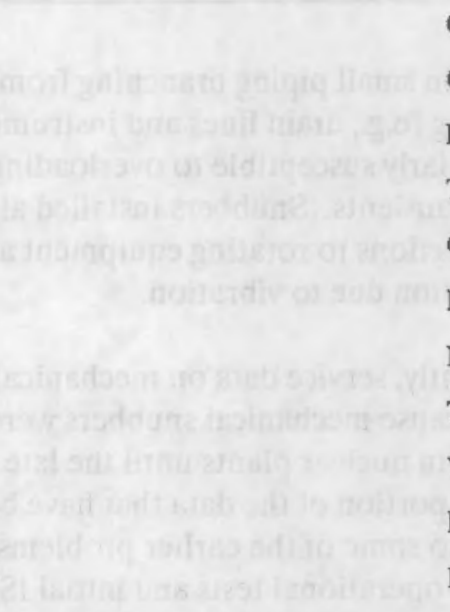 } & Corrosion of torque drum & Moisture \\
\hline & Corrosion of capstan spring & Moisture \\
\hline & Rough spots on planetary gears & Handling Damage \\
\hline & Thrust bearing fretting & Vibration \\
\hline & Capstan spring wound too tight & Mfg. Def. \\
\hline & Binding of telescoping members & High Side Load \\
\hline & Loose bearing retainer nut & Mfg./Hand. Def. \\
\hline & Telescoping members not concentric & Mfg. Def. \\
\hline & Weld spatter on indicator tube & Const. Damage \\
\hline & Bent guide rods & Overload \\
\hline & Flaked plating on ball screw & Mfg. Def. \\
\hline \multirow{9}{*}{$\begin{array}{l}\text { Exceeded Maximum } \\
\text { Acceleration Limit }\end{array}$} & Capstan spring not wound tight enough & Mfg. Def. \\
\hline & Capstan spring not installed correctly & Mfg. Def. \\
\hline & Worn capstan spring & Vibration \\
\hline & Keeper ring not installed correctly & Mfg. Def. \\
\hline & Excessive lubricant on torque drum & Mfg. Def. \\
\hline & Lubricant on inertia mass & Mfg. Def. \\
\hline & Bent clutch tang & Mfg. Def. \\
\hline & Fractured ball screw shaft & Overload \\
\hline & Capstan spring wear & Vibration \\
\hline \multirow{5}{*}{$\begin{array}{l}\text { Below Minimum } \\
\text { Acceleration Limit }\end{array}$} & Corrosion of capstan spring & Moisture \\
\hline & Corrosion of clutch spring & Moisture \\
\hline & Damaged capstan spring & Mfg. Def./Vibr. \\
\hline & Darnaged thrust bearing & Overload/Vibr. \\
\hline & Torque drum retainer bent & Overload \\
\hline
\end{tabular}


Evaluation

Failure causes listed in Table 3.8 may be grouped into three basic categories:

- service-related, single occurrence

- service-related, progressive degradation

- nonservice-related.

\subsubsection{Aging Factors for Mechanical Snubbers}

The primary influences associated with progressive degradation in mechanical snubber performance are vibration, moderate load transients, ${ }^{1}$ elevated temperature, and moisture.

\subsubsection{Effects of Vibration on Mechanical Snubbers}

Mechanical snubbers, particularly the smaller sizes, are subject to degradation from high- and low-amplitude vibration. High-amplitude vibration is vibration having an amplitude that exceeds the mechanical clearances in the snubber's end attachments. This type of vibration can result in localized fretting and wear of mating parts, such as the lead screw, thrust bearing, capstan spring, pins, and attachment lugs. It can also result in an increase in drag force, an incrcase in mechanical clearances, jamming, and/or an increase in the acceleration threshold.

Low-amplitude vibration is defined as vibration with an amplitude less than the mechanical clearances in the snubber. This type of vibration can lead to loosening of fasteners and, in combination with the weight of the snubber, can cause wear of clevis pins and attachments, resulting in elongated attachment holes. Continuous high-frequency, low-amplitude vibration can cause internal wear, which may increase drag force.

\subsubsection{Elevated Temperature}

Elevated temperature has often caused solidification of lubricants used in mechanical snubbers. This effect increases friction and results in an increase in drag force.

${ }^{1}$ Moderate load transients are defined as frequently occurring load transients that are less than the rated capacity of the snubber, such as those occurring during pump start-up.

\subsubsection{Moisture}

Moisture can cause internal corrosion that in turn can lead to increasing drag force, jamming, and/or a decrease in the snubber's acceleration threshold as a result of a build up of rust between the capstan and capstan spring. Moisture-related corrosion has been a concern for snubbers installed in a vertical orientation, whereby water may be trapped in the snubber.

Degradation due to moisture can occur over an extended period. Degradation can also occur in a relatively short time due to a one-time exposure to large amounts of moisture, e.g., steam leak. Identification of the specific cause requires a comprehensive root cause evaluation.

\subsubsection{Evaluation of Changes in Drag Loads Versus Service Time}

As was discussed in Section 3.3.1.1, progressively increasing drag force is another consideration. There is some justification for periodic drag force testing of representative snubber samples from the general snubber population. An evaluation of the effects of service time on mechanical snubber drag force is discussed in the following subsections.

\subsubsection{Average Drag Force Versus Time - Different Snubber Samples}

For Site D (two plants), data were available for snubbers of the same size that were tested on the same test machine. Unfortunately, no snubber had been tested more than once to date (i.e., there were no repeat tests for any one snubber). However, it was anticipated that, if service time significantly affects drag force, then an average of the measured drag force values for the same size snubber for successive refueling outages might indicate such a trend.

Data from both units for five successive refueling outages were reviewed for two sizes of mechanical snubbers. The data were evaluated for both peak and avcrage drag 
force in tension and compression. The number of samples for each size at each Reactor Fuel Outage (RFO) ranged from 4 to 26 .

Associated data and plots of drag force versus time are included in Appendix E. As may be observed in the time plots, the results of the evaluation are inconclusive.

\subsubsection{Average Drag Force Versus Time - Same Snubber Samples}

For Site F, data were available for a total of 47 mechanical snubbers of the same size that had been tested on at least two and sometimes three occasions using the same test machine. Peak and average drag force values for each RFO were plotted versus time (see Figure 3.13). Associated data and trending plots for individual snubbers are included in Appendix F. As with Plant D, both average drag force and peak drag force for both the tension and compression directions were evaluated. It should be noted that all snubbers had been in service for approximately five years before the initial test data point was obtained.

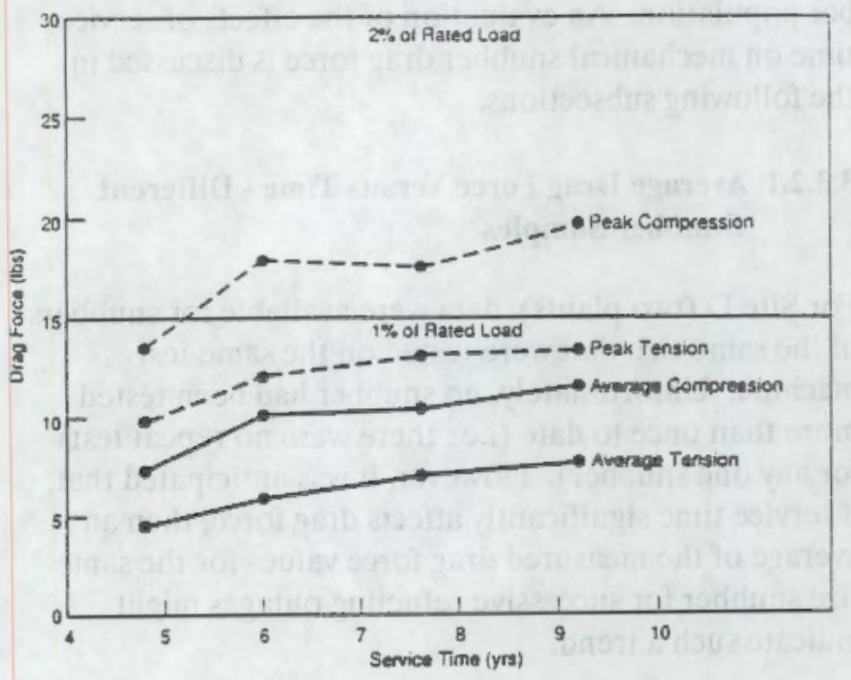

Figure 3.13 Average drag force versus service time for 47 mechanical snubbers
As can be observed from Figure 3.13, there appears to be a slight trend toward increasing drag force with service time, at least for one mechanical snubber model and size at this particular plant. The data support the need to monitor snubbers in moderate environments, possibly using a selected number of representative snubbers. However, the magnitude of the drag force value is generally small, i.e., less than $2 \%$ of rated load for all but four snubber samples, and less than $3 \%$ of rated load for all but one snubber sample.

\subsubsection{Dynamic Transients}

A significant number of cases of documented degradation or failures in mechanical snubbers have been associated with dynamic transients. Some transients, such as those caused by water or steam hammer, can significantly overload a snubber and result in instantaneous failure. Other, lower load transients such as those due to sudden valve opening may result in progressive degradation depending on the number of load cycles.

Typical failure mechanisms associated with overload involve fracture of the thrust bearing and/or buckling of the ball screw or slender attachment hardware. Inability of the snubber to provide free motion in the passive mode is often the result of such damage (i.e., jamming or high drag).

Failure mechanisms associated with lower load transients generally involve wear or local fretting similar to that resulting from high-amplitude vibration. Such degradation can result in an increase in snubber drag force. Many plants have implemented procedures whereby snubbers that are potentially subject to transients are identified and evaluated using augmented inspection methods (Section 3.1.5.4). 


\section{Conclusions}

\subsection{Snubber Performance History}

For most plants, the greatest number of snubber failures has been associated with nonservice-related influences, such as mishandling damage and manufacturing defects that were detected during initial plant operation. After identifying isolated severe environments during initial plant operation, plant personnel have modified the snubbers' environment, replaced snubbers with more durable models, or eliminated the snubbers as part of a snubber reduction program. Snubber functional test acceptance limits have also been generally broadened. ${ }^{1}$ These methods of snubber management have significantly reduced snubber failure rates.

Aging management for snubbers involves 1) identifying snubbers susceptible to rapid degradation and minimizing their potential for failure by conducting augmented inspections or by requiring frequent maintenance or replacement, and 2) monitoring for progressive degradation in the remaining plant snubbers and scheduling preventive maintenance accordingly. Many plants have implemented elastomeric seal life monitoring programs for hydraulic snubbers. Beyond seal life studies, however, most plants have yet to implement a formal service-life monitoring program for snubbers.

In general, approximately one-half of all recent snubber failures for the key plants evaluated have been caused by aging-related service influences. By contrast, review of failure evaluation data for one plant indicated that only $25 \%$ of the evaluated seal failures were aging related.

The most significant influences resulting in snubber degradation are elevated temperature, vibration, dynamic transients, and moisture. The effects of radiation, on the other hand, appear to be significantly less than originally anticipated. This is probably because of the relatively low actual radiation levels, the shielding effects provided by the snubber body, and the frequency of seal replacements.

'Some plants initially applied manu[acturer's production acceptance limits, which are generally much more narrow than limits required for snubber operability.

\subsection{Service-Life Monitoring}

The following conclusions are drawn from the in-plant snubber research and provide the basis for service-life monitoring guidelines:

- Many plants utilize an automated database that simplifies tracking and retrieval of pertinent information that may be used for monitoring snubber service life. An example of a snubber data sheet associated with such a system is included in Appendix $\mathrm{H}$.

- Plant data indicate that a significantly large portion of the total number of snubber failures have resulted from nonservice-related influences. This supports the need to distinguish between servicerelated and nonservice-related degradation or failures to ensure that nonservice-related failures are excluded from the database that is used to monitor snubber service life.

- Variations in snubber degradation rate due to significant variations in environment from one area in the plant to another may warrant establishing separate service-life categories for different snubber populations.

- The primary degradation influences for both hydraulic and mechanical snubbers are elevated temperature, vibration, and load transients.

- Moisture can cause corrosion of both internal and external snubber parts. Such degradation is more prevalent for mechanical snubbers. External corrosion is easily detected during visual examination and may be an indicator of internal corrosion. Methods used to identify internal corrosion include boroscopic examination, hydraulic fluid analysis, and snubber disassembly.

- Snubbers are particularly susceptible to service degradation when installed 
- on small piping branching from large piping

- near high temperature components

- in congested areas with significant personnel traffic

- near connections to rotating equipment.

- Plant-specific seal life evaluation studies have been conducted at several plants. Some plants are trending drag force data in a selected number of mechanical snubbers. Realistic service-life projections have involved the use of trendable degradation parameters that relate to the anticipated degradation mechanisms.

- Plant systems for which snubber degradation appears to be prevalent include

- component cooling

- reactor coolant

- safety injection

- steam generator blowdown

- high-pressure core spray

- low-pressure core spray

- residual heat removal

- main steam.

- Typical failure mechanisms and causes are listed in Tables 3.3 and 3.7.

- Mechanisms and root causes for failure and dcgradation should be determined (where practical). This requires experienced personnel.

- Plant operating environments may differ from the original design specification. General area operating parameters, therefore, should be measured over time and documented.
- Plants should make a concerted effort to identify applications involving severe operating environments. Snubber failures in such applications may be mitigated by augmented surveillance, frequent maintenance or replacement, retrofit with more durable snubbers, or by eliminating the snubber in an approved design review.

- Augmented surveillance may be appropriate for snubbers in severe operating environments and may involve attributes that are not normally included during inservice inspection (ISI) visual examination.

- "Hands-on" surveillance methods may be used in addition to visual inspections. Such methods can be used to detect vibration and elevated temperature and to identify frozen snubbers. They can also be used to identify anomalies that may indicate the need for preventive maintenance.

- Evaluation of functional test traces is very useful in identifying the cause of snubber failure, or in identifying anomalies indicative of impending snubber failure.

- Diagnostic tests may be used to augment inservice test data in identifying the cause of snubber failure or degradation. Snubber test equipment that provides a time trace of test parameters is useful for evaluating snubber degradation or failure. Variation of test parameters is often necessary for diagnostic testing. Test machine accuracy and repeatability is required for trending.

- Elastomeric seal life evaluations include analytical methods, e.g. Arrhenius projections, and methods based on service data. Any seal life evaluation method for snubbers should be based primarily on predicting low-pressure seal performance and should be updated based on service data.

- Monitoring of snubber reservoir fluid level is the most practical method for verifying fluid leakage.

- Snubber damage due to mishandling or personnel traffic may be minimized by inspection of such snubbers just before start-up following an outage. 
Conclusions

- One plant has reported that acceleration thresholds have decreased for some mechanical snubbers as a result of internal corrosion that effectively decreases the clearance between the capstan spring and the braking surface (See Appendix A). As a result, this plant has established minimum and maximum acceptance limits for acceleration threshold. In the absence of baseline data, however, it is difficult to determine whether or not the acceleration threshold has actually decreased or whether it was low to begin with. In areas where baseline data are available, acceleration threshold may be an effective parameter for identifying such degradation.

- Critical snubber parts should be identified and may vary depending on the environmental stressor involved. Snubber service life should be based on the part anticipated to have the shortest life for the primary environmental stressor.

- Snubber test parameters generally include activation level, release rate, and breakaway or drag force. These parameters are useful for both ISI and for service-life monitoring. A clear definition of any parameter should be established by each plant. This definition should be consistently applied thereafter. Parameter definitions for ISI purposes may differ from the corresponding definitions used for service-life monitoring.

\subsection{Effects of Compression Set on Low-Pressure Elastomeric Seal Performance}

Static seals in hydraulic snubbers can seal adequately, even at a compression set of $100 \%$. However, general limits used for most seal life evaluations are $90 \%$ for static seals and $80 \%$ for dynamic seals. These limits were substantiated to some degree using compression set data obtained in this study. However, further research involving more substantial data is needed in this area.

\subsection{Service Aging of Mechanical Snubbers}

Mechanical snubber performance can be progressively affected by aging, particularly when snubbers are exposed to one or more environmental stressors. Performance is related to drag force, breakaway force, and acceleration threshold. Primary influences affecting degradation are elevated temperature, vibration, moisture, and dynamic transients.

Snubbers subject to severe environments should be identified and managed with appropriate preventive maintenance. Long-term service in moderate operating environments may also affect snubber performance. Mechanical snubbers in moderate operating environments should be monitored by testing representative samples; baseline data are extremely important in this regard. 



\section{Recommendations}

\subsection{Service-Life Monitoring Recommendations}

The following recommendations for service-life monitoring are based on the results and conclusions of the inplant research activities.

\subsubsection{Determination of Snubber Failure or Degradation Causes}

A principal goal of a service-life monitoring program should be to develop means for separating servicerelated and nonservice-related failures. It is important that the root cause of snubber failure or degradation (e.g., snubber overload due to dynamic transient, highamplitude vibration beyond the design capacity of the snubber, and application temperature exceeding that specified for continuous use) be identified along with the failure mode (e.g., high drag force or low activation) and the failure mechanism (e.g., deformation of the ball screw shaft or solidification of grease).

Failure evaluation data sheets should include key categories such as failure mode, failure mechanism, failure cause, environment, service time, abnormal conditions, visual observations, test data, and test observations. It is important that personnel involved in failure evaluation be adequately trained in correctly tracing a failure to its cause. Failure evaluation data sheets should be designed and formatted in a manner that encourages systematic and thorough analysis.

Figure 5.1 illustrates a systematic analysis approach to root cause failure identification. Table 5.1 lists typical irregularities that may be observed during visual examination or during snubber disassembly. The table characterizes features of snubber degradation and may be useful in pinpointing the potential cause.

\subsubsection{Determination and Documentation of Operating Environment}

Service-life monitoring takes into consideration the capability of the various snubber models to endure the

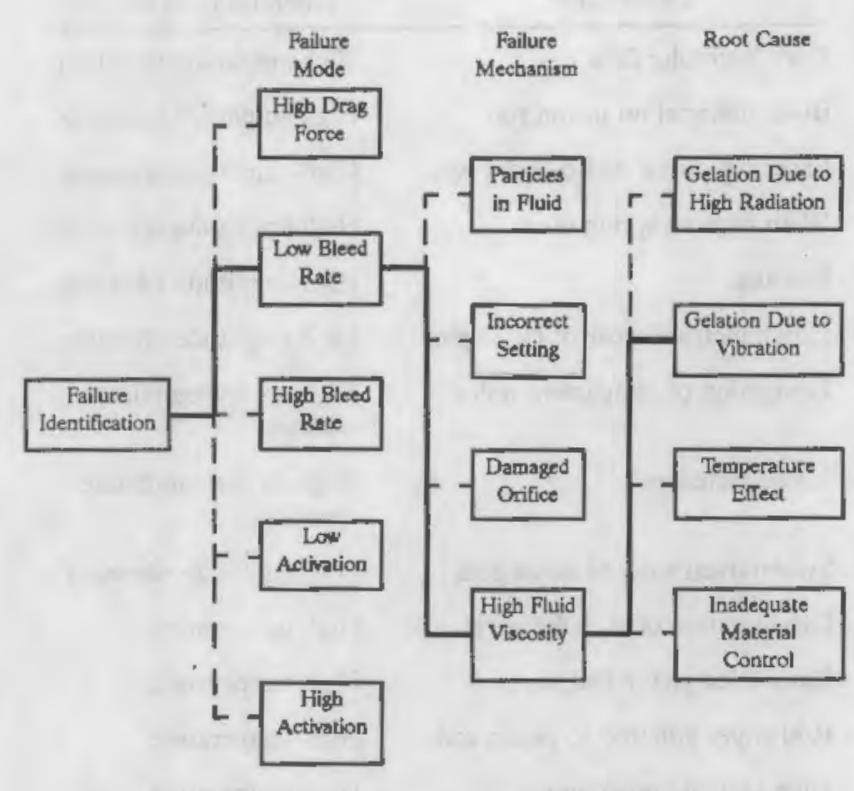

Figure 5.1 Flow chart - typical root cause determination

full range of plant environments (benign to severe). Indicators of severe operating conditions can often be identified during snubber overhauls and other maintenance-related activities.

Determining specific environmental information often involves specialized instrumentation and equipment that would be impractical for use at every snubber location. Such equipment, therefore, should be used in applications where moderate to severe environments are anticipated or as a diagnostic aid in determining the cause of snubber degradation or failure. Various methods and equipment used to identify or measure specific environmental parameters are described in Sections 5.1.2.1 through 5.1.2.4. Additional information in this regard is included in Appendix B.

\subsubsection{Temperature}

Continuous temperature recording devices are available to indicate the general area temperatures within the plant (which often vary by elevation) or to measure local snubber or component temperatures. Temperaturesensitive tape may be placed directly on the snubber to 
Table 5.1 Typical indicators of snubber degradation

\begin{tabular}{|c|c|}
\hline Observation & Potential Indicator of: \\
\hline Dark hydraulic fluid & High-amplitude vibration \\
\hline Black material on piston rod & High-amplitude vibration \\
\hline Excessive piston and cylinder wear & High-amplitude vibration \\
\hline Worn capstan spring tangs & High-amplitude vibration \\
\hline Fretting & High-amplitude vibration \\
\hline Unsymmetrical wear of clevis pins & High-amplitude vibration \\
\hline Elongation of attachment holes & $\begin{array}{l}\text { High-or low-amplitude } \\
\text { vibration }\end{array}$ \\
\hline Loose fasteners & $\begin{array}{l}\text { High- or low-amplitude } \\
\text { vibration }\end{array}$ \\
\hline Symmetrical wear of clevis pins & Low-amplitude vibration \\
\hline Discoloration of metallic parts & High temperature \\
\hline Embrittled piston rod wiper & High temperature \\
\hline Rod wiper adhered to piston rod & High temperature \\
\hline High seal compression set & High temperature \\
\hline Seal surface cracks & High temperature in air \\
\hline Lack of fluid pigmentation & High-radiation level \\
\hline Corrosion of metallic parts & $\begin{array}{l}\text { High-humidity/leaking } \\
\text { components }\end{array}$ \\
\hline Bent piston rod or attachments & Overloading \\
\hline $\begin{array}{l}\text { Changes in cold/hot position } \\
\text { setting }\end{array}$ & $\begin{array}{l}\text { Increased drag or } \\
\text { jamming }\end{array}$ \\
\hline
\end{tabular}

determine maximum temperature. One shortcoming of this approach, however, is that a time/temperature profile is not provided. Contact and noncontact temperature measuring devices (e.g., infrared type) are also available.

\subsubsection{Radiation}

Normal radiation levels of an operating plant do not usually contribute significantly to snubber degradation. This is probably due to the following considerations:

- actual in-plant radiation levels are, in most cases, less than was originally anticipated

- the snubber body provides a significant amount of shielding
- originally anticipated radiation effects were based upon a 40-year dose; in actuality, snubber parts that are sensitive to radiation degradation are replaced at intervals that are significantly less than 40 years.

Data pertaining to plant radiation levels can generally be obtained from health physics area surveys. Measurement of radiation levels specifically for service-life monitoring is not recommended except in evaluating the cause of snubber degradation in cases where other causes have been ruled out.

\subsubsection{Vibration}

Vibration may be continuous, in which case snubbers may degrade in as little time as one operating interval. Vibration may also be intermittent (e.g., during pump startup), in which case it may be undetected for long periods and result in long-term degradation of the snubber.

The available methods for detecting and measuring vibration vary from simple visual observation, detection by feel, portable vibration measuring instrumentation, and remote vibration measuring equipment. Examples of some alternatives to detect vibration, along with actual inservice applications, are described in Appen$\operatorname{dix} \mathbf{A}$ (Site G) and Appendix B.

Snubbers subject to vibration can often be detected by visual examination. Metal filings, darkened hydraulic fluid, deformed connecting pins, elongated attachment holes, and fretting of mating parts are all signs of vibration effects.

\subsubsection{Transients}

As with vibration, the existence of dynamic load transients may often be identified during routine snubber inspections, augmented inspections, and failure evaluation. Deformed structural members, jammed snubbers, and deformed internal parts are all potential indicators of dynamic overloading. In situ devices such as loadmeasuring clevis pins are available for monitoring snubber loads in applications where such transients are suspected (Appendix B). 


\subsubsection{Managing Snubbers in Severe Operating Environments}

Significant environmental stressors that can affect snubber performance include overloading, vibration, elevated temperature, moistnre, chemicals, and radiation. Despite the best design and post-startup inspections, isolated cases of snubbers operating in severe environments may be identified as plant operation continues. Unfortunately, such applications are often not identified until the snubbers are functionally tested. This supports the need for some random functional testing; however, the extent of functional testing currently required by technical specifications may not be necessary as plants gain empirical knowledge pertaining to the plant operating environments and the associated snubber capabilities.

Snubber failures in applications involving severe operating environments may be mitigated by conducting augmented inspections, periodic maintenance, periodic replacement with like kind, retrofitting with snubbers more suitable for the environment, or eliminating the snubber by approved engineering analysis methods.

\subsubsection{Augmented Surveillance}

A number of practices may be used for evaluating snubbers for degradation and for identifying operating environments. Since evaluation methods often do not employ quantifiable parameters, judgment is required on the part of the inspector. Experience of inspection personnel is therefore important.

\subsubsection{Hand-Stroking}

Probably the most common "hands-on" evaluation method is hand-stroking of mechanical snubbers. This method is often used to identify snubbers that are damaged or jammed due to transients. In this method, the inspector removes the connecting pin at one end of the snubber and slowly strokes the snubber while feeling and listening for abnormalities such as intermittent or continuous excess noise or resistance.

Using this method, an experienced inspector can often identify impending failure. For example, when a mechanical snubber is hand-stroked, periodic resistance, accompanied by a chaffing sound for each revolution of the inertia mass, indicates binding caused by lack of concentricity of rotating parts. Irregular, intermittent noise and resistance, on the other hand, indicate surface discontinuities on the lead screw.

\subsubsection{Rotation of Snubbers in Place}

Jammed snubbers (i.e., snubbers unable to allow free thermal motion) may often be identified by attempting to rotate the snubber about its spherical end attachment bearings. If the snubber is not free to rotate, it is possible that axial loading exists that is the result of jamming or premature lockup. It should be noted, however, that this method is most effective for snubbers with a load capacity of $3,000 \mathrm{lb}$, or less. Normal friction in the bearings often prevents rotation of larger sizes.

\subsubsection{Hand Detection of Vibration}

Detection of vibration by placing a hand on the snubber during operation is a useful technique for evaluating accessible snubbers.

\subsubsection{End of Outage Inspection}

Just before startup, reinspection of snubbers that are susceptible to damage due to outage-related activities will reduce the probability of plant operation with inoperable snubbers. Future verification that consequent failures were not the result of service-related influences would otherwise be more difficult.

\subsubsection{Trending}

Note: Trending of test data is discussed further in Section 5.1.6.4.

Progressive degradation in the general snubber population (i.e., those snubbers not subject to rapid degradation) should be monitored by trending applicable degradation parameters for a selected number of snubbers that are representative of the plant operating environment. Such degradation parameters might include compression set for elastomeric seals (Section 3.2.2) or drag force for mechanical snubbers (Section 3.3.2). Some important considerations in this regard are listed below: 
Recommendations

- The establishment of baseline data is essential for identifying trends. Data to be used for identifying trends should be sufficiently accurate to demonstrate trends.

- Trending parameters that relate directly to the anticipated aging failure mode should be used. Such parameters might include drag force for mechanical snubbers or elastomeric seal compression set for hydraulic snubbers.

Note: An important example of inappropriate monitoring parameters is the use of functional test data, i.e., locking velocity and release rate for monitoring or trending seal degradation. Although functional test results can be affected to some extent by seal degradation, the primary aging failure mode for snubber seals (i.e., loss of low-pressure seal integrity) would not be reflected in functional test data.

- Acceleration threshold (activation level) in acceleration-limiting mechanical snubbers is a potentially trendable parameter that may indicate internal snubber degradation. A decreasing acceleration threshold may indicate internal corrosion (Section 4.2) or increased friction between the inertia mass and its spindle. An increasing acceleration threshold may indicate weakening of the capstan spring tangs as a result of wear or a decrease in friction between the capstan spring and its braking surface.

- Although changes in active hydraulic snubber parameters [i.e., locking velocity and bleed (release) rate] can indicate snubber degradation, these parameters are not considered practical trending parameters for monitoring progressive degradation.

- Reservoir fluid level is the most appropriate parameter for monitoring snubber fluid leakage.

\subsubsection{Testing}

The following functional test parameters are normally measured during inservice testing (IST):

- Activation Level: Locking velocity for poppet-valve hydraulic snubbers. Acceleration threshold for acceleration-limiting mechanical snubbers.

- Release Rate: Snubber velocity at a given load.

- Drag Force: Snubber resistance load at a given stroke velocity.

- Breakaway Force: Force required to initiate snubber motion.

These parameters are also useful in identifying potential degradation or in determining the cause of snubber failure.

\subsubsection{Evaluation of Inservice Test Results}

Since existing IST plans are statistically based on the number of failures, test results are often evaluated on only a pass/fail basis. Most test machines, however, provide a continuous trace of load and velocity for both activation tests and drag force tests. Such traces often contain information useful in identifying snubber degradation. For example, during mechanical snubber drag force testing, such characteristics as the number of load spikes, consistency of load spikes, duration of load spikes, noise, variations in drag force with stroke position, and directional sensitivity are all useful in identifying potential snubber degradation or impending snubber failure (see Figures 5.2 through 5.6). For hydraulic snubbers, traces can be used to identify air in the snubber or a clogged bleed orifice.

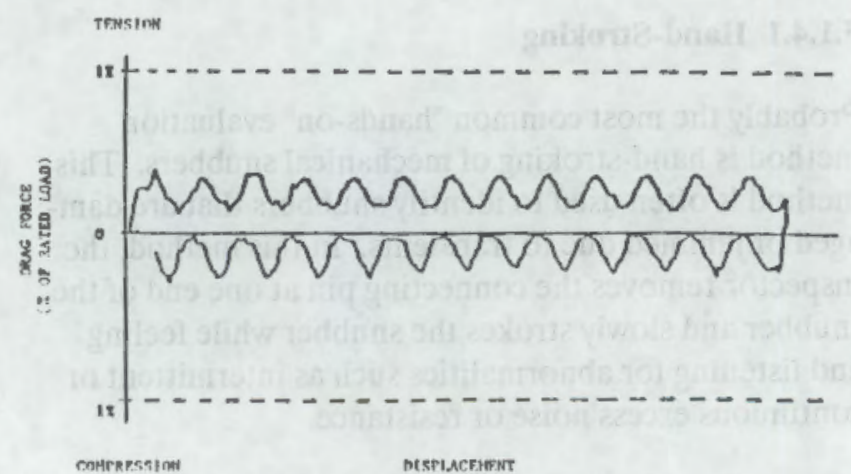

Figure 5.2 Mechanical snubber with normal drag force trace 


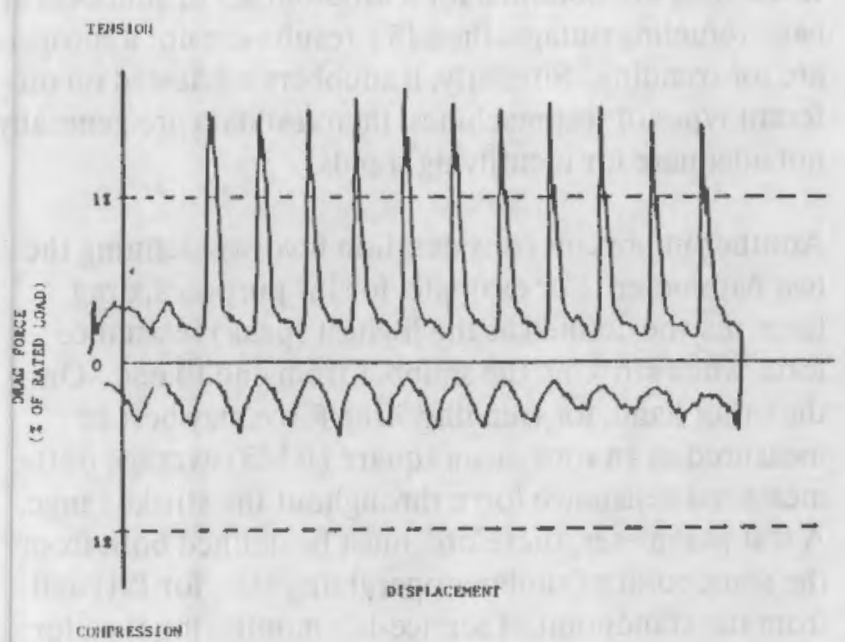

Figure 5.3 Mechanical snubber drag force with consistent spikes

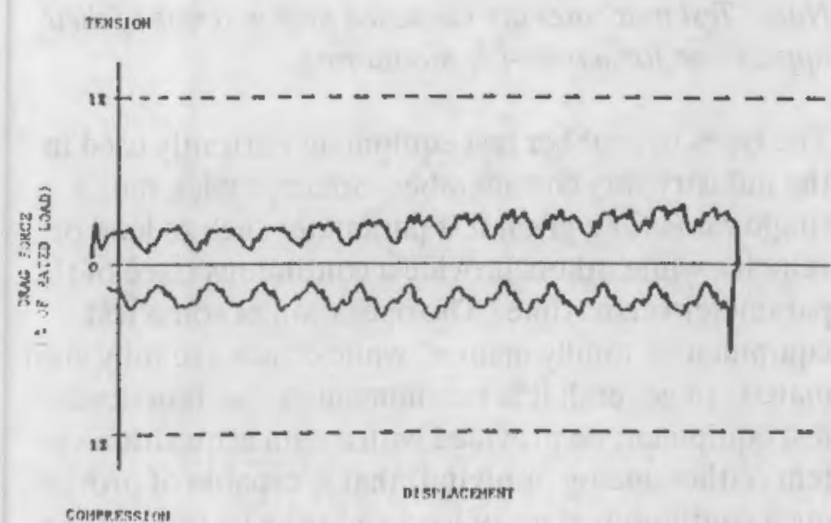

Figure 5.4 Mechanical snubber drag force with noise

\subsubsection{As-Found Testing}

As with IST results, a considerable amount of information can be obtained by conducting post-service functional tests on snubbers removed from service. In fact, as a general rule, such tests are recommended any time a snubber is removed from service, regardless of whether or not the snubber is to be reinstalled.

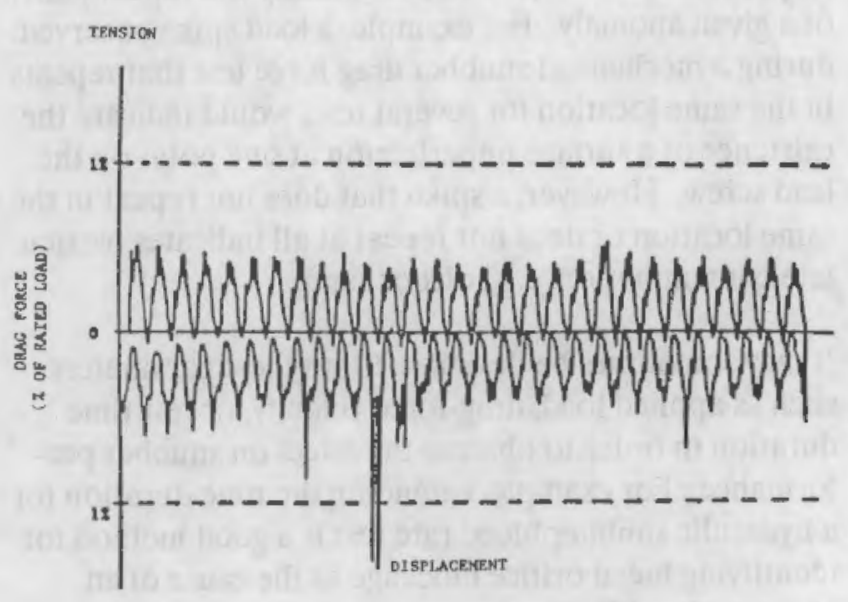

COMPRESSION

Figure 5.5 Mechanical snubber drag force with occasional spikes

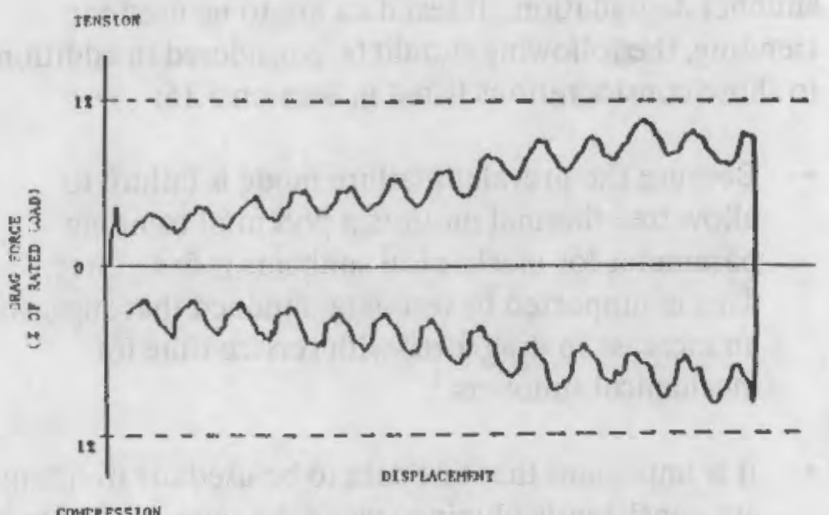

Figure 5.6 Mechanical snubber with high drag at one end

\subsubsection{Diagnostic Testing}

Diagnostic tests (see Section 7.0) are specifically designed to obtain useful information about the condition of a particular snubber, beyond what may be available from routine IST or as-found tests. For failures, diagnostic tests are often helpful in identifying the failure mechanism before disassembling the snubber. 
Repeat tests are helpful in determining the repeatability of a given anomaly. For example, a load spike observed during a mechanical snubber drag force test that repeats in the same location for several tests would indicate the existence of a surface imperfection at one point on the lead screw. However, a spike that does not repeat in the same location or does not repeat at all indicates particulate contamination, e.g., dirt or sand.

It may sometimes be desirable to vary test parameters such as applied load, drag-force velocity, or test time duration in order to observe the effect on snubber per-

formance. For example, extending the time duration for a hydraulic snubber bleed rate test is a good method for identifying bleed orifice blockage as the cause of an observed low bleed rate.

\subsubsection{Trending Test Results}

Trending is a useful tool for monitoring progressive snubber degradation. If test data are to be used for trending, the following should be considered in addition to those considerations listed in Section 5.15:

- Because the prevalent failure mode is failure to allow free thermal motion, a potential trending parameter for mechanical snubbers is drag force. This is supported by test data obtained that suggest an increase in drag force with service time for mechanical snubbers. ${ }^{1}$

- It is important that test data to be used for trending are consistently obtained using the same type of test machine, under the same test conditions. Ideally, the data from the same snubber should be used for comparison purposes.

- Administrative limits for functional test results are intended to ensure replacement or repair of a given snubber before failure. However, it is important to have a reasonable indication that the selected test parameter is progressing toward the failure limit. Overly restrictive administrative limits can have the negative effect of limiting the amount of data available for trending. They can also encourage replacement of reliable snubbers.
If test data are obtained for a different set of snubbers at each refueling outage, then IST results are not appropriate for trending. Similarly, if snubbers are tested on different types of test machines, then test data are generally not adequate for identifying trends.

Another important consideration involves defining the test parameter. For example, for ISI purposes, drag force may be defined as the highest (peak) resistance force when stroking the snubber from end to end. On the other hand, for trending, drag force may best be measured as an root mean square (RMS) average of the measured resistance force throughout the stroke range. A test parameter, therefore, must be defined both from the standpoint of snubber operability (i.e., for ISI) and from the standpoint of service-life monitoring (i.e., for trending).

\subsubsection{Test Equipment}

Note: Test machines are discussed here in terms of their application for service-life monitoring.

The types of snubber test equipment currently used in the industry vary considerably. Some provide only a single value for a given test parameter such as load or velocity, while others provide a continuous trace of the parameter versus time. The operation of some test equipment is totally manual, while others are fully automated. In general, it is recommended that functional test equipment be provided with a data acquisition system (either analog or digital) that is capable of providing a continuous trace of load and velocity versus time for the duration of the test. As discussed in Section 5.1.6.1, information from such traces is useful in detecting degradation and identifying failure mechanisms.

Some test equipment is of a "go/no-go" nature, in which the snubber is determined to be either operable or inoperable; however, this method neither accounts for variations in test results nor measures exact values for the given test parameter. Such equipment is not useful for test interpretation, diagnostic testing, or trending. Snubbers that fail functional tests using this equipment are often retested using a more accurate test machine.

Such a trend is yet to be fully substantiated. 
Many test machines are totally automatic. Automatic test machines may be advantageous for ISI because operator bias is minimized. Thus, data from automatic testers are generally acceptable for trending purposes. However, for diagnostic testing, the test operator should be able to vary the level of various test parameters for exploratory purposes.

It should be noted that whenever a snubber is tested in a different type of test machine than the one previously used, a number of new variables are introduced that may complicate the identification of trends. Such variables include test control methods and parameters, data acquisition systems, etc. For this reason, trending tests are most effectively conducted using the same test machine as well as the same test methods.

\subsubsection{External Seal Leakage Detection and Leakage Rate Determination}

Minor seal leakage is common for many snubber types and applications. A number of influences can cause seal leakage. A leaking snubber, however, does not necessarily imply inoperability nor does it necessarily require immediate snubber overhaul.

Measurement and trending of reservoir fluid level is probably the most practical approach to monitoring for external seal leakage. For this reason, reservoir fluid level should be recorded whenever fluid is added. An example of this method is discussed in Appendix A for Site A.

The location of seal leakage in many cases may be obvious by visual observation. However, in some cases the precise location of the seal leakage may require a time consuming follow-up evaluation.

It should be noted that in many cases, seal leakage can be the result of improper snubber assembly, defective parts, etc. A practical method for checking for seal leakage following snubber overhaul is to place the snubber on an absorbent (paper) pad where it can be observed for a period of time before installation.

\subsubsection{Visual Examination}

Snubbers are normally visually examined during each refueling outage in compliance with technical specification ISI requirements. However, the intent of these examinations is to identify characteristics that might indicate snubber inoperability. Several visual examination attributes included in ISI visual examinations are not related to service degradation. Service-life monitoring examinations may be conducted at the same time as those required for ISI or separately. However, qualification of personnel for such examinations is critical (see Appendix L).

Visual characteristics that would provide information in regard to service degradation are listed below. These snubber attributes may be used to define a visual examination checklist for service-life monitoring.

- deformed structural member or piston rod

- loose or missing threaded fasteners

- cold or hot position varies from specified value

- evidence of corrosion

- evidence of solid deposits (e.g., boric acid) from leaking components

- loss of hydraulic fluid since previous visual examination

- metal filings on or in the vicinity of the snubber

- observed fluid leakage

- evidence of significant dark (i.e., black or dark brown) material deposit on piston rod

- rod wiper adhered to piston rod

- abnormal color of hydraulic fluid

- wear or deformation of clevis pins 
Recommendations

- elongation of attachment holes

- evidence of wear on support cylinder

- cracked or deformed fluid reservoir

- evidence of foreign material (e.g., water, solid particles, etc.) in hydraulic fluid

- discoloration of metallic parts due to elevated temperature.

\subsection{Recommendations for the Working Group on Mechanical Equipment Restraints}

Based upon the results of the NPAR research, a number of suggestions are made in regard to the OM Code, Section IST, Subsection ISTD, Part 4 (ASME 1990). These suggestions are to be recommended to the Working Group on Mechanical Equipment Restraints for consideration in the next revision of Subsection ISTD.

In general, recommendations pertain to service-life monitoring, visual examination attributes, and failure grouping. A detailed discussion of these recommendations is included in Appendix $\mathrm{K}$. The recommendations are summarized in the following sections.

\subsubsection{Service-Life Monitoring Recommendations}

Service-life monitoring recommendations proposed for consideration in Subsection ISTD are generally based upon the recommendations discussed in Section 5.1. Specifically, they include:

- determination of snubber failure causes

- determination and documentation of the snubber operating environment

- evaluation of inservice test results

- diagnostic testing
- as-found testing

- trending

- augmented surveillance methods

- establishment of service-life categories.

\subsubsection{Visual Examination Attributes}

Typical visual examination attributes that may be used to update the Subsection ISTD, Appendix B, "Dynamic Restraint Examination Checklist Items," are suggested for consideration by the Working Group on Mechanical Equipment Restraints. Recommended attributes are listed separately in the following categories:

- preservice examination attributes only

- preservice and inservice examination attributes

- service-life monitoring examination attributes.

\subsubsection{Failure Grouping and Corrective Action}

Subsection ISTD currently requires that any snubber that fails to meet functional test acceptance criteria be classified into one of the following failure mode groups (FMGs):

- design/manufacturing

- application induced

- maintenance/repair/installation

- transient dynamic event

- isolated

- unexplained.

Depending upon the failure mode group, various corrective actions may apply. Recommendations are made in the following areas pertaining to failure grouping and associated corrective action. 


\subsubsection{Terminology}

It is recommended that the following terms (as defined in Section 7.0) pertaining to aging be incorporated into the proposed ISTD 8.0, Service-Life Monitoring:

- failure mode

- failure mechanism

- failure cause

- root cause.

\subsubsection{Isolated Failure Mode Group}

It is recommended that the isolated FMG be eliminated.

\subsubsection{Failure Categories}

Based upon the results of root cause evaluations, it is recommended that snubbers with a similar propensity for failure be grouped together to facilitate corrective action. How such root failure-cause groups are defined involves judgment on the part of the owner; a failure group should be defined after a failure has been identified. However, for purposes of determining follow-up action in Subsection ISTD, it is suggested that failures need only be identified as service related, nonservice related, or unexplained.

\subsubsection{Replacement or Modified Snubbers}

It is suggested that some flexibility be provided in ISTD 1.11.1 to allow for continued use of existing snubber models in cases where more compatible models are not available.

\subsection{Uniform Snubber Population Classifications by Environment}

Many utilities have elected to pre-group snubbers based on design differences for purposes of ISI. This approach presupposes that failure causes will be associated only with snubbers in the predefined group.

Another method of pre-grouping that is commonly used for ISI purposes is to catcgorize snubbers as either accessible or inaccessible and to examine them as separate populations. This approach is generally the result of practical considerations in order to minimize inspection activities during refueling outages, rather than having anything to do with susceptibility to degradation.

From the standpoint of service-life monitoring, a primary consideration for pre-grouping should be based on anticipated variations in service life. Snubbers in isolated severe environments, e.g., those with high temperatures and vibration operating conditions, should be separated from general population and managed on a case-by-case basis. For plants with general environmental extremes, such as temperature, it may be desirable to group the general snubber population into two or more subpopulations with separate service lives.

\subsection{Snubber Maintenance Recommendations}

A number of maintenance recommendations were identified during the NPAR in-plant research. Recommendations generally are associated with the service-life monitoring guidelines discussed in Section 5.1. A detailed discussion of maintenance recommendations is presented in Appendix L. Specific topics in this regard are listed below:

- General Maintenance Practices

- Identification of the Operating Environment

- Snubbers Prone to Rapid Degradation in Severe Environments

- Failure Evaluation

- Failure Grouping

- Modification of Operating Environment

- Snubber Elimination

- Augmented Inspections

- Snubber Maintenance Frequency

- Trending 
Recommendations

- Baseline Data

- Snubber Data Base

- Functional Test Equipment

- Spare Snubber Rotation
- Personnel Qualification

- As-Found Evaluation

- Coordination and Communication

- Replacement Parts and Materials 


\section{Recommendations for Additional Snubber Research}

Although compression set limits currently in use are supported by limited data available from this in-plant research, additional compression set studies should be undertaken to strengthen the credibility of the compression set limits and to establish optimal compression set limits. As plants accumulate service time, such data will probably become available.

This research has identified environmental conditions that are the most significant aging factors for snubbers. Development of service-life monitoring programs that ascertain realistic humidity, vibration, and temperature conditions are therefore encouraged within the industry. As plants implement service-life monitoring programs, a significant amount of additional service data will become available regarding these critical environmental influences and the associated age-related degradation of snubbers. Additional research would be required to evaluate this information.

Results of the work reported here should be transferred to industry in an active and assertive manner. A workshop/presentation developed from the in-plant research is suggested. The workshop would be presented to engineering, quality assurance (QA), and maintenance staff at the plant sites. The workshop should consist of two separate presentations, one for engineering and maintenance management staff and the other for the staff who perform the work; e.g., craft supervisors and craft workers. 


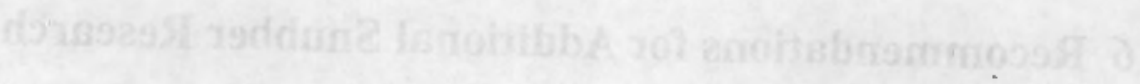

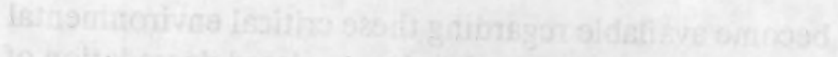

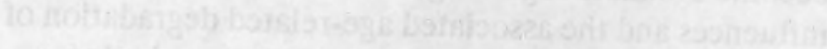

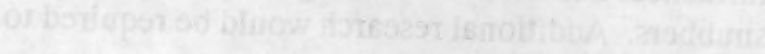

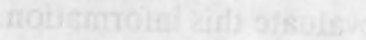

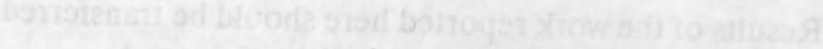

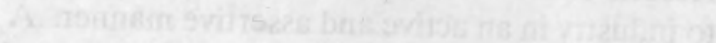

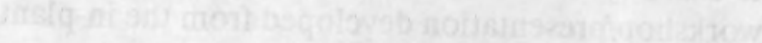

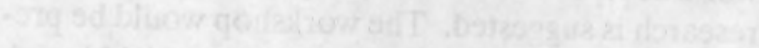

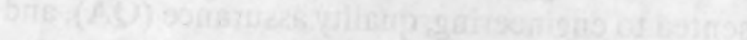

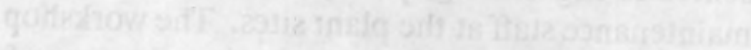

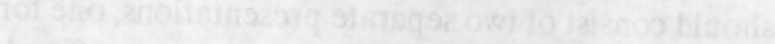

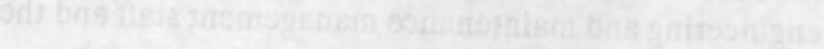

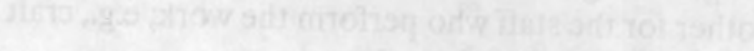

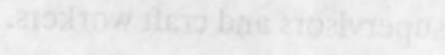

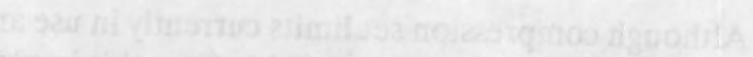

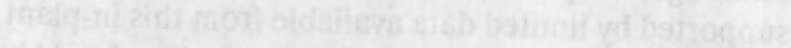

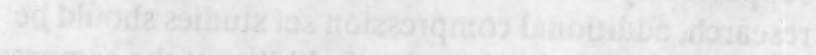

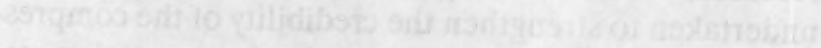

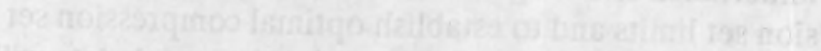

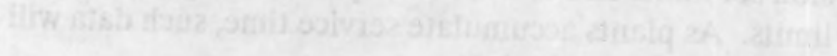

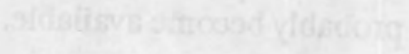

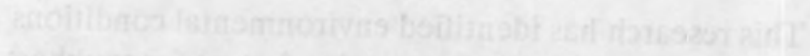

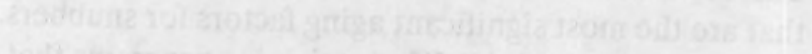

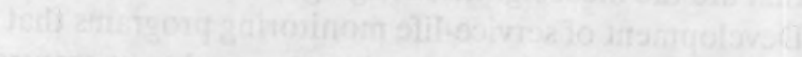

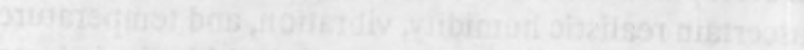

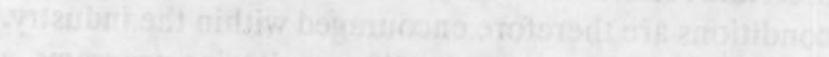

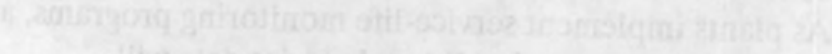

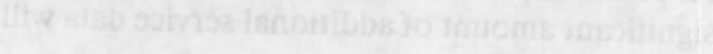




\section{References}

Barbarin, R. January 1977. "Selecting Elastomeric Seals for Nuclear Service." Power Engineering Magaxine. PennWell Corporation, Tulsa, Oklahoma.

Brown, D. P., G. R. Paimer, E. V. Werry, and D. E. Blahnik. 1990. Basis for Snubber Aging Research: Nuclear Plant Aging Research Program. NUREG/ CR-5386 (PNL-6911), prepared for the U.S. Nuclear Regulatory Commission by Pacific Northwest Laboratory, Richland, Washington.

Bush, S. H., P. G. Heasler, and R. E. Dodge. 1986. Aging and Service Wear of Hydraulic and Mechanical Snubbers Used on Safety-Related Piping and Components of Nuclear Power Plants. NUREG/CR-4279

(PNL-5479), prepared for the U.S. Nuclear Regulatory Commission by Pacific Northwest Laboratory, Richland, Washington.

Code for Operation and Maintenance, Rules for Inservice Testing of Light-Water Reactor Power Plants, Subsection ISTD Part 4, Inservice Testing of Dynamic Restraints (Snubbers) in Light-Water Reactor Power Plants. 1990. American Society of Mechanical Engineers (ASME), New York.
Gillen, K. T, et al. 1980. Predicting Life Expectancy and Simulating Age of Complex Equipment Using Accelerated Aging Techniques. NUREG/CR-1466 (SAND-79-1561), prepared for the U.S. Nuclear Regulatory Commission by Sandia National Laboratories, Albuquerque, New Mexico.

Mosca, F. July 1977. Radiation and Environmental Tests of Seal and Fluid Materials for Snubbers. ITT Grinnell Corporation, Providence, Rhode Island.

U.S. Nuclear Regulatory Commission. November 1984. Technical Specifications for Snubbers. Generic Letter 84-13, Washington, D.C.

U.S. Nuclear Regulatory Commission. 1987. Nuclear Plant Aging Research (NPAR) Program Plan, NUREG-1144, Rev. 1., Washington, D.C. 


\section{0naาisto}

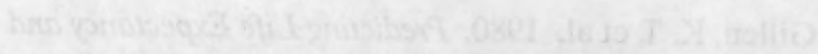

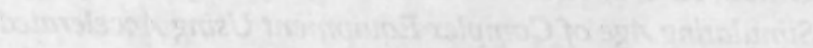

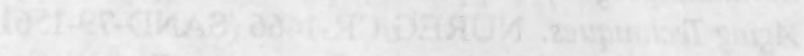

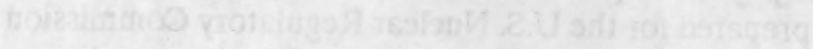

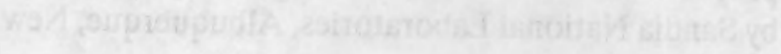

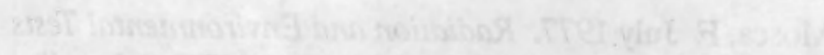

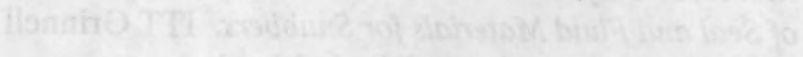

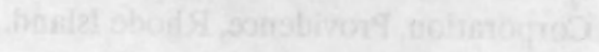

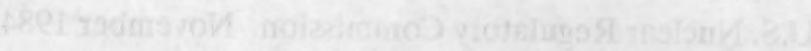

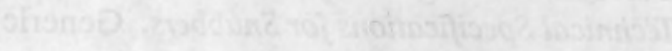

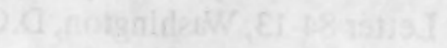

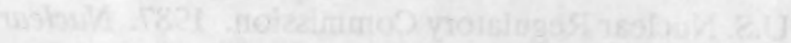

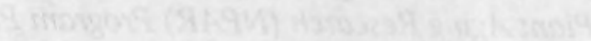

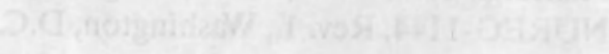

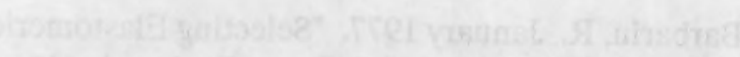

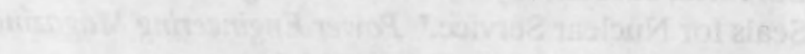

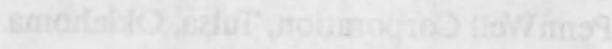

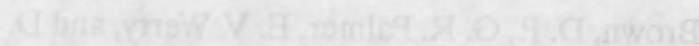

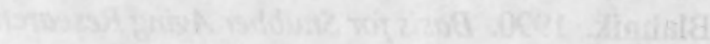

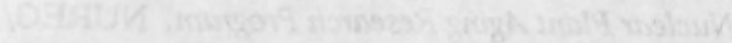

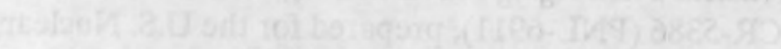

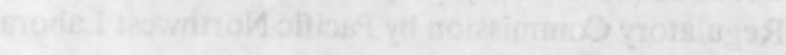

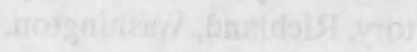

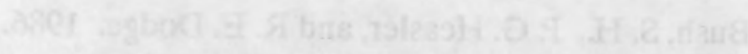

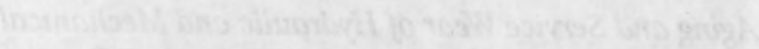

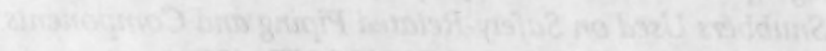

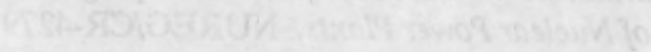

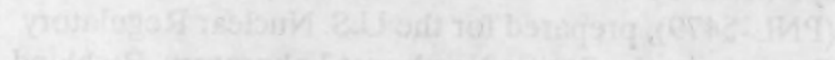

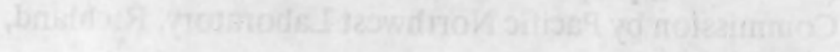
moth wintath

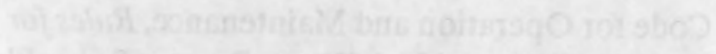

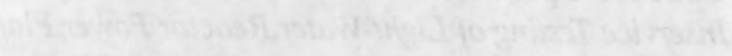

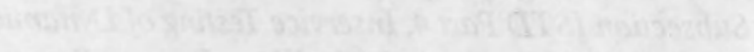

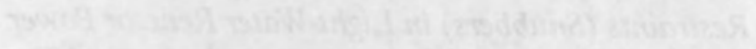

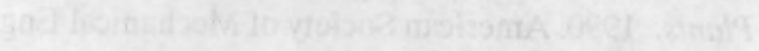

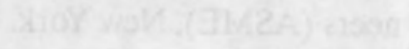


Appendix A

Plant Visit Summary Reports 


\section{Appendix A}

\section{Plant Visit Summary Reports}

This Appendix includes trip reports for eight key sites (one each from site A through $G$ ) visited as part of the NPAR snubber aging study. Plants are assigned letter codes from $A$ through $H$. Information pertaining to hydraulic snubbers was obtained from Plants A and B.
Information pertaining to mechanical snubbers was obtained from Plants C, D, E, F, and $\mathrm{H}$. Information pertaining to in situ monitoring of environmental stressors was obtained from Plant G. 
Appendix A

INTEROEEICE MEMO

Plane A

TO: D. P. Brown

DATE: August 17, 1990

FROM: S. Cole

REE:

The following are notes from my visit to the plant.

1. Notified resident NRC Inspector of upcomirg plant visit and meetings. Notification date: $7 / 31 / 90$.

2. Arrived on sice $8 / 8 / 90$ and was escorted by the snubber engineer. In depth discussion took place with the snubber engineer, and the snubber maintenance foreman.

3. General Planc Information

A. The plant consists of two mid-sized bolling water zeactors. The plant began commercial operation in the mid-1970's.

B. Each unit has over 600 Bergen-Paterson snubbers of which about 550 are saiety related (most of the stubbers are the M77 model). In addition to these, the plant bas approximately 350 hydraulic snubbers available as spares for both untts.

D. The plant utilizes a seal life with several separate populations besed upon accelerated aging teses and modified on a regular basis by temperature for chose suubbers in the drywell.

4. Plant has insticuted (start1ng in 1986) a comprehensive maintenance program which includes the following items:

- Filtering of snubber fluid lmmediately prior to use with a 5 micron filter. (Plant found 1t hard to keep pre-filtered fluid clean over long pertods of time.)

- Sand blasting (glass beads) to bare metal of all metalic parts.

- Complete deconning of all metalic parts using a freon blaster.

- Replacement (racher tian repair) of mose questionable parts.

- Automatic replacement of popper springs and piston rings.

- Use of the same trained personnel to rebuild snubber each cycle.

- All rebuilds take place in a "clean" room used only for snubbers. 
5. Plant is retro-ficting suubier poppets to a higher bleed rate poppet. This newer popper still allows the snubber to meet bleed rate limits as defined In the plant technical spectfications while moving the actual bleed rate more toward the middle of the allowable range (the plant suffered a significant number of functional fallures due to low bleed rates 1in the pasc.)

6. Due to a combination of the changing of the poppets, improved maintenance and changing of the functlonal test procedure to allow $1 / 2$ " bleed testing as opposed to full stroke bleed testing the number of functional failures has fallen dramatically.

\section{Fluid Leakage}

A. Fluid leakage (as indicated by low reservoir leve1) during visual examinations for the last three Unit 2 outages can be summarized as follows:

Refuel
Outage

\section{7}

8

9

OVERALC AVERAGE:
Number Inspected

581

553

553
Total Leaking

$50(8.9 \pi)$

$49(8.9 \%)$

$59(\underline{10.7 \%})$

\section{Significant Leaks}

$12(2.17)$

$5(0.9 \%)$

$6(\underline{1.1 \%})$

Note: The number of leaking snubbers is not the actual cotal number but rather those snubbers whose total indicared fluid has fallen below a given amount ( $53 / 4)$ since the last outage. Significant leaks are those who's total indicated fluid has fallen below $31 / 4$.

B. Those snubbers whth signtficant leakage were disassembled and inspected giving the following results.

\begin{tabular}{|c|c|c|c|}
\hline $\begin{array}{l}\text { Refuel } \\
\text { Outage }\end{array}$ & $\begin{array}{l}\text { Number } \\
\text { S1gnificant } \\
\text { Leaks }\end{array}$ & $\begin{array}{c}\text { Aging } \\
\text { Related }\end{array}$ & $\begin{array}{l}\text { Non-Aging } \\
\text { Relaced }\end{array}$ \\
\hline 7 & $\frac{12}{5}$ & $2(16.6 \pi)$ & $10(83.37)$ \\
\hline 8 & 5 & $2(40.07)$ & $3(60.0 \%)$ \\
\hline TOTAL & 17 & $4(23.5 \%)$ & $13(76.18)$ \\
\hline
\end{tabular}

Note: Fallure data was unavailable for those snubbers with significant leakage from refuel outage number 9 . 
Appendix A

C. A third category of leaking snubbers are those snubbers which show visual signs of leakage but still have an acceptable reservoir fluid level. These snubbers can be considered to elther have a-very slow leakage rate or only started to leak just prior to their inspection.

\begin{tabular}{lccc}
$\begin{array}{l}\text { Refuel } \\
\text { Outage }\end{array}$ & $\begin{array}{c}\text { Total } \\
\text { Leaks }\end{array}$ & $\begin{array}{c}\text { Visual } \\
\text { Leaks }\end{array}$ & $\begin{array}{c}\text { Indicated } \\
\text { Leaks }\end{array}$ \\
\cline { 2 - 3 } & 66 & $17(25.7 \%)$ & $49(74.27)$ \\
9 & 87 & $22(\underline{25.3 \%})$ & $65(74.7 \%)$ \\
OVERALI AVERAGE: & $25.4 \%$ &
\end{tabular}

Note: This data is not available from refuel outage no. 7 .

8. Critical Snubber Parts

Snubber parts must frequently be replaced during rebulld (excluding those parts automatically replaced) include: piston, cylinder tubes and piston Iods.

A. Pistons and Cylinder Tubes

These parts are most frequently replaced due to scoring of the piston and inner sylinder tube surface. This condition appears to be caused by vibracion, with side loading being a significant degradacion accelerator. This condition is considered to be aging related.

B. Piston Rods

Piston rod degradation most often consises of dings and scratches. These dings and scracches are most often caused by human error. (Metal to metal contact with the piston rod). This condition is not aging related.

9. Snubber Fluid Degradation

A. The plant has a significant number of snubbers, which when disassembled, yield darkened fluld with globules of a black grease-Iike substance. This effect is typical of snubbers that have been subjected to extensive high amplitude vibration.

It should be noted that darkened fluid and particulate contamination was found in a significant percentage of the low bleed snubhers that were disassembled and Inspected during RFO 7.

It should also be noted that due to changes in bleed rate testing criteria, many of these snubbers would no longer be considered functional fallures. 
Appendix A

\section{Chemical Analysis}

Fluld was chemically analyzed from 10 snubbers found to bave darkened fluid following the most recent outage. Chemical analysis revealed that the black globules were composed of silicon rather than grease. Prfor to being analyzed each sample was graded for visual clarity. Analysis revealed that those samples which were visually darker/had more black globules, and had a higher content of 1ron in the fluid. The fron is atcribuced to wear products resulting from wear of the cylinder tube and piston due to vibracion.

Note: No particle counts where made from the fluid sanples during analysis.

10. Snubber Trending

The plant recently set up a computer based trending system that allows sorting searching and seeking of any snubber atrribute by any other. The snubber engineer used this system to search snubbers with indicated leakage vs. snubber location (i.e. drywell and balance of plant).

\begin{tabular}{ccccc} 
Area & $\begin{array}{c}\text { Total } \\
\text { Snubbers }\end{array}$ & $\begin{array}{c}\text { \# of Indicated } \\
\text { Leaks }\end{array}$ & $\begin{array}{c}\text { \% of Indica } \\
\text { Leaiks }\end{array}$ \\
\cline { 2 - 4 } & 263 & 39 & $14.8 \%$ \\
nce of Plant & 287 & 27 & $9.4 \%$
\end{tabular}

Thus saubbers located in the dryweli showed a leakage rate $57.4 \%$ greater than those in the balance of the plant. It should be noted that cemperatures in the drywell are significancly bigher than anywhere else in the plant. Some correlation betreen plant operating temperature and seal degradation rate is, therefore, supported by this data.

11. Review of plant failure evaluations shows piston and cylinder tube scoring (possibly accelerated by side loading) to be the single largest failure cause. Scoring also leads to metalic particles in the fluid wich can shorten seal life and foul the bleed poppers.

One unexpected faflure cause that cropped up a signfficant number of times was fouling of the poppet by pieces of lint. The frequency of this failure cause has fallen off dramatically since the planc's adopeion of improved maintenance procedures. 
Appendix A

\section{CONCLUSIONS}

It is my oolnion that the plant has a very effective hydraulic snubber program. The utility appears to not only strive to meet the Intent of the Codes, Standards and Technical Specifications applicable to hydraulic snubbers but often to surpass them.

Areas where I believe the plant to be particularly effective in the handing of their snubber program include:

- The rebuilding of suubbers in a "clean room" atmosphere to prevent the inclusion of foreign material in the snubber.

- The use of a 5 micron filter to filter snubber fluid prior to use.

- The plant having a flexible snubber trending system up and running.

- The adjusting of smubber seal life up or down on a regular basis depending on ambient temperature.

- The use of the same personnel to perform snubber testing and rebuflding each cycle. This is facilitated by the smooth transition of personnel into and out of the snubber group coupled with a relatively low turnover rate.

Areas where I consider there may be room for improvement in the plant's snubber program include:

- The plant's rellance on area temperature monitors to track snubber environments rather than perforwing specific environmental surveys.

$\circ$

The need to go more in depth on root caue evaluations. This is particularly 1mportant since there erists a significant number of the same types of fallures whose root causes have been listed in the past as unknown.

SMC : aca: 1125A 
TO: D. P. Brown

FROM: S. M. Cole
DATE: July 26,1990

RE:

The following are notes from my visit to the plant:

1. Not1fied resident NRC Inspector of upcoming plant visit and meetings. Notification dace: $7 / 3 / 90$.

2. Arrived on site $7 / 9 / 90$ and was escorted by the snubber engineer. In depth discusslons took place with the current snubber englneer and the previous suubber engineer.

\section{General Plant Informat1on}

A. The Plant is a mid-sized boiling water reactor which began comercial operations in the mid-1970's.

B. Plant was originally supplied with approximately 350 hydraulic snubbers, all of which were Grinnell F1gure 200 's.

C. Due to agressive and on-going snubber reduction prograns, the plant now has 120 hydraulic snubbers (all Grinnell Figure 200). Of these, 64 are safety related. All hydraulic suubbers are accessible.

D. In 1990 , the plant began 18-month refuel cycles; prior to 1990 , the plant was on 12 -month cycles.

E. Sear life $1 \mathrm{~s}$ based upon an accelerated aging study that correlates service time with operating temperature.

4. Snubber fallures and rebuilds by outage:

$\begin{array}{llll}\text { Year } & \text { Fallures } & & \text { Rebuilds } \\ 1986 & 7(1) & & 84 \\ 1987 & 0 & 12 \\ 1988 & 2 & 27 \\ 1989 & 0 & 10 \\ 1990 & 0 & \text { app. } 40(2)\end{array}$

Note: (1) Curzent plant theory is that these fallures were caused by 1ncorrect test procedures (1.e. too high ramp rate, etc.) rather than actual snubber failures.

(2) The reason for the high number of rebuilds in 1990 was to prevent expiration of shelf life on seal kits in the warehouse. 
Appendix A

5. The plant has conducted specific area temperature surveys for all hydraulic snubbers with the exception of those located near the ceiling of the Heater Bay. This area may be the harshest environment in the plant consisting of temperatures exceeding $1500 F$ and a possibly significant amount of vibration.

A. The highest specific temperature surveyed was 1250 F.

B. Lookfng into resurveying snubber environments in more detail (possibly including vibration measurements) because of changing environments due to construction (outages).

6. A group of 15 snubbers in the Heater Bay regularly are found to have darkened fluid. The darkened fluid often has globules of a black grease-like substance dispersed throughout.

A. These snubbers are visually inspected on a more frequent basis than required by preventative maincenance procedures.

B. Upon evidence of fluid darkentng, snubbers are rebuilt as a matter of course.

C. No failure or root cause exams or fluid testing performed because these are all non-safery related snubbers. (Plans to fluid test these snubbers in fucure).

D. Per former snubber engineer, if these snubbers are left in place after the fluld turns dark, the fluid will thicken and congeal.

7: Plant has an extremely large percentage of spare snubbers to installed suubbers. Total number of spares is about 80 .

A. Spare snubbers are rotated to ensure those spares that bave the oldest rebuild dates are installed first.

B. Usually rebuilds number of snubbers required for replacement pius about $50 \%$ for emergencies.

C. Extra snubbers may be rebuilt when the warehouse has seal kits nearlng the end of their shelf life to avoid having to dispose of the kits.

8. Root cause evaluations indicate the plant has several suubbers that regularly fall due to being stepped on (broken reservoirs and connecting tubing). These are safety related snubbers, which per tech spec, require failure and roor cause evaluation. Even though being stepped on is a non-service relaced root cause, due to the frequency of this problem the plant is considering treating these snubbers as if they were in a severe environment. 
9. Failure evaluations are only performed if they have an operability related fallure of a tech spec (safaty related) saubber.

A. Root cause evaluations are done automatically as part of fallure evaluations.

B. Recent revisions to plant procedures require the taking of photos during failure evaluations to aid in the documentation of fallure causes and modes.

10. In the opinfons of both snubber engineers, the plant experiences few to ao age related snubber fallures unless the snubbers are located in harsh environments.

11. For the past three years ( 3 cycles), the plant has performed all hydraulte snubber testing in-house (both ISI and functional).

A. The planc also rebuilds hydraulic snubbers 1n-house.

B. In process of buylng Bergen-Pacerson MK IV test machine (have been leasing this model) with upgraded computer and printer.

c. It is the1r bellef that doing rebullds and testing in-house allows them tighter concrol of the snubber life cycle.

12. The plant currently uses two mainframe computer programs (ut1lity owned and specific) to track snubbers.

A. The programs are reasonably comprehensive and include tracking of the followlng flelds: sertal number, model, make, CIC (mark number), last test date, installed date, maintenance history, class and corments.

B. The single biggest problem with this system is that it takes approximately six months to updace following an outage.

C. Currently setting up a new system to allow better trending of saubber characteristics than current systems allow.

- New system will ailow search, sort and seek of any field by any other fields.

- New system should be operational in about six months.

13. The plant bas found the most critical (prone to failure) parts of Grinrell suubbers to be thread seals and tubing connections. I signtficant percentage of leaking snubbers has been traced to thread seals. In the past, tublng connections were a signiffcant source of leakage in the snubbers. The plant replaced these connections with Swagelock flttings to minfinize this source of leakage. 
Appendix A

14. Specific concerns of plant personnel:

A. Hot and cold setting of snubbers need to be revertfled on a semi-regular basis due to changlng plant conditions.

B. Drawings must always be kept updated.

C. Some plants were built to one spec and then changed to another farther fnto their life (1.e. Section III vs. B 31.7). This makes 1 t difficulc to rotate snubbers.

D. Side-loading resulting from the use of long extension pieces may accelerate snubber degradation caused by vibration. 
It is my opinion that the plant has an effective snubber program. There is evidence that the utillty is dedicated to not only meeting the intent of the Codes, Standards and Technical Specifications applicable to hydraulic snubbers, but to surpassing them when possible.

Areas where I believe the plant to be particularly effectlve in the handing of their snubber program include:

- The use of the same personnel to perform rebullds and visual inspections each outage. This is factlicated by the smooth transition of in-going and out-going snubber persoonel coupled with a relattvely low turaver rate.

- The performing of an environmencal survey to define snubber environments.

- Augmented 1nspection of snubbers in harsh environments.

- Photographtc documentation during failure evaluactons.

- Utility leasing/buylng theis own state of the art snubber test rrachine.

- Good snubber tracking system up and running.

- Currently secting up a system to allow the trendlag of snubbers.

Areas where I consider there way be room for improvement in the planc's snubber program include:

- Performing more frequent and more in depth failure evaluations.

- Finding and correcting the root cause of failing non-safety related snubbers.

- Performlng specific environmental surveys for all snubbers.

- Mrimizing the time aeeded to update the computerlzed saubber database following outages.

SHC : aca: $1110 \mathrm{~A}$ 
Appendix A

$\underline{\text { Plant C }}_{1}$

Notes from during the visit and subsequent which includes;

staff) and investigation and information reviewed (Tech staff),

(Tech Staff) and myself.

(Tech

1.

(NRC SI. Resident Inspector) was notified of the impending visit to the plant and subsequent meetings. Ext. 2490, called in on 7/3/90 at 10:30 AM.

2. Arrived at the plant on July 5, 1990, AM and was escorted by day. with whom I met with for the rest of the

General Plant Information:

a. There are 2 BWR Units of M. H. sizes - Unit 1 went into operation in and onit 2 went into operation in . Both units have been through refueling outages with $\frac{\|}{\pi} 2$ unit just completed this past spring.

b. The units were constructed with P.S.A snubbers ranging from PSA $1 / 4$ through PSA-100. The total population for the two units at start was 2384 which was divided as 1244 each for Unit 2 and 1140 each for Unit 1 . of this population a total of 2265 snubbers were tested by the end of the first refueling outage for both units, with the remaining snubbers being deleted and 3 being exempted fror ISI.

c. The testing of all snubbers was precipitated by the high percentage failure rate encountered during ist R.O. for Unit $\frac{\|}{\| I}$ which began and continued through - During this first outage 104 snubbers had failed in Unit 1 and 53 snubbers would fail in the first unit 2 refueling course which started on Jan. and continued through April . During the second R.O. for both units, a massive snubber reduction program had brought down the total population from 2384 to a total of 487 snubbers. This process was completed with full calculation review and necessary design changes.

a. During units 2 refueling outage all snubbers in service were again tested and a total of 8 snubbers for unit 1 and 18 for Unit 2 failed the functional test.

e. Failures are categorized by 1) Installation and Handling Deficiencies, - 2) Environmental Failure, - 3) Failure duto transient or vibration load, - 4) Manufacturing defects - snubbers failed in categories 2 \& 4 were relatively few in number, representing less than 18 of the total population by group sizing ( $1 / 4$ \& 1/2) small and (1 through 100) large. Failure attributed to Category $\frac{\Delta}{4} 3$, which indicated transient or vibration or both, were given greatest attention as 
Appendix A

2

these were the ones most likely to fail again. Aside from the systam operating low level vibration (amplitude and frequency), some systems had special problems requiring engineering review, such systems were:

1) High Pressure Core Spray (, ) venting relocation (Failure $\frac{\pi}{\overline{0} 5}$ )

2) Low Pressure Core Spray ( ) High point venting $(11,12,50,59)$

3) Residual Heat Removal () suction lines from vessel to RHR Pump (71.79).

4) Residual Heat Removal (RHR) discharge lines outside primary containment. (Failure 58,60,61, 66, 74, 82 for A Loop), (Failure 62, 63, 64, 72 for B Loop).

All the above systems required engineering evaluation and or plant modification in order to eliminate transient load and low level vibration causing snubber failure.

f. Other snubbers failed in various system where small drain and vent lines were connected to large lines and forces induced from the large piping, although not having detrimental effect on the larger snubbers directly connected to the main syster, they were effecting the smaller supports by induced vibration and transients. The system was modified to avoid future failure.

3) A 100\% testing of the 238 snubbers left in service in Jnit 1 second R.O. and a total of 8 snubbers failed to mest functional test limits. A tear-down and inspection was conducted to deternine the cause of failure which were categorized as follows:

a. 6 each due to installation and handling deficiencies, 2 each manufacturing defects.

It is evident that the snubber reduction program through elimination and modification was proved very effective considering the failure of the 8 units during the secord R.O. were attributed to causes other than fatigue related.

4) During the third R.O. the eight snubbers which had failed in the previous outage were retested, in addition a $10 \%$ test sample was implemented with the snubbers divided into two groups:

1) Sma11, consisting of PSA $1 / 4$ and PSA $1 / 2$ ( 3 tested), 2) Larger, consisting of PSA-1 through PSA-100 (22 tested) There were two failures in this surveillance, one was from the retest group and one PSA $1 / 4$ from the sample plan. 
Appendix A

Therefore, 3 additional snubbers were tested withou: failure. There was no failure in the large group.

It is evident that failure rates have decreased drastically by addressing system loads, transients, environment, location and other factors contributing to past failures as experienced during 1 R.O. -

The classification of primary causes of failure and consequent evaluation is an effective method of separating snubber units which would have a repeatable failure as it is caused by environment and/or load, - Other failures attributed to handing or installation deficiencies, manufacturing defects, are considered random failure and are addressed separately. Safety analysis and necessary corrective actions were performed for each individual failure and at a system level.

5) The same events were noted and addressed for Unit 2 with comparable results. The number of failures are somewhat different, however the investigation and corrective actions were conducted with the same diligence and thoroughness.

The failures occurred as follows:

1 R.o. - 53 total failures with 19 each in Category 1, 6 each in Category 2, 23 each in category 3 and 5 each in category 4.

2 R.O. - 18 total failures with 16 each in category 1 and 2 each in category 4 .

3 R.O. - No failure recorded

6) An overall view of failures for the Unit 1 \& 2 listed by failure cause and sizes (small \& large):

1 R.O. - 157 total failures of which 74 each were small $1 / 4$ \& $1 / 2,83$ each were large 1 through 100.

2 R.o. - 26 total failures of which 6 a were small, 20 ea were large.

3 R.0.- 2 total failures, of which both were small snubbers (PSA-1/4)

Further grouping by failure cause as defined by plant engineering:

Category 1: Installation and Handing Deficiencies Total failures 100 units (46 large bore, 54 small bore). These failures ranged from poor handling, storage or installation practices. 
Category 2: Environmental Failures

Total failures 17 units (1 large bore, 16 small bore)

These failures appeared divided into two groups, a) small snubbers failed due to grease drying out and causing excessive drag, b) units corroded internaliy due to being sprayed or dripped upon by water while in service.

Category 3: System Transient and/or vibration loads Total failures 49 units (40 large bores, 9 small bores) These failures are attributed primary to system transient loads during service, such as pump start-stop, valve opening - closing, causing snubber internals to degrade. The failed parts are listed as a) Thrust bearing races damaged or broken, b) Capstan spring damaged, c) ball screw bent or stripped.

Category 4: Manufacturing Defects

Total Failures 19 units ( 14 large bore, 5 smaIl bore) These failures are attributed to assembling or manufacturing problems existing as unit was reviewed from PSA - The most common being improper installation of capstan spring (to loose or to tight) and excessive grease. - Since most of these snubbers failed activation limits, these defects are not noted with hand stroke.

stated that since PSA performed a functional test on representative number for each size of snubber, it is very possible to install a defective unit as new snubbers are not functionally tested before installation.

There was also a very informative meeting between myself and and of the plant technical staff who have been involved with the snubber program for an extended period. - The following is a summary of their personal views and concerns based on passed experience.

It is commoniy agreed that continuous and/or periodic low level (amplitude and frequency) vibration has the most damaging effect on mechanical snubbers. This vibration may be induced by components change of state, like valves opening and closing, pumps starting and stopping, or it may be inherent to system design, as process llow. personnel have aggressively attacked the problems concerning support system in eliminating or minimizing failures by evaluating and resolving root cause. For example replacing snubbers with rigid supoort by verifying calculation, modifying systems in order to 
Appendix A

eliminate transients, revising systems ISI procedures, moving snubber supports to more effective and less damaging location. Also considering the replacement of some mechanical snubbers with lisega hydraulic as no other options were available. Heat shields are used in localized high temperature and additional chiller installed to lower ambient temperature in the upper part of the containment dome, changing procedure for venting system during test and the training of personnel in the handling of snubbers.

8) Standard Procedure is employed in snubber inspection which include visual, hand stroking, performance testing and failure evaluation. If a snubber fails, it is disassembled, inspected, identify failed part or parts and determine root cause. A report is written with the above findings which also includes system, location and conditions that may effect snubber performance. Where performance test results are marginal, good work practice is employed. Spikes of high amplitude, however of short duration may be considered acceptable. Grease has been the cause of high drag where the temperature is above $140^{\circ} \mathrm{F}$. It has been noted that where the temperature for a component reached $400^{\circ} \mathrm{F}$ and sustained for 36 hours, the adjacent snubber failed because of grease failure. A snubber also had a marginal performance test after being subjected to $300 \% \mathrm{~F}$ for 48 hours.

Where temperature and vibration are suspected for the failures thermocouples and accelerometers are utilized in evaluating working conditions and environment. 
conclusion:

It is of my opinion that the personnel at

have a very effective ongoing surveillance and testing snubber program. This is evident in the tremendous reduction in snubber failure since the first R.O.. This was accomplished through investigation of component, system, environment and failure analysis. Resolution utilizing analysis by the architect engineer support calculation by the A\&E and special testing by the system engineer were used to determine if system modification, snubber relocation or support redesign was warranted, which also led to a very extensive snubber reduction program. Personnel training and effective work practices were also implemented in order to eliminate or reduce failures due to handling.

Due to grease failure, I would think a qualification test may be warranted to determine lubricant requirements, classification of snubbers by system, size and environment may facilitate the possibility of necessary augmented inspection for specific apolication.

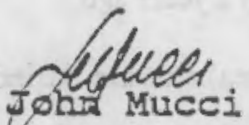

Wyle Laboratories

Huntsville, Alabama 35807

(205) $837-4411$ ext. 583 


\section{Appendix A}

$\underline{\text { Plant } D}$

\section{BATTELLE NPAR RESEARCH}

\section{MEETTNG NOTES - $5 / 1 / 90$}

Attachmeat 1

Joher Mued and David Browa met with

eristiog plant data on mechanieal soubbers (Objective 1B).

for evaluation of

Unit 1 went on line in 19 . Unit 2 weat on line in 19 . Breatdown of snubbers is as follows:

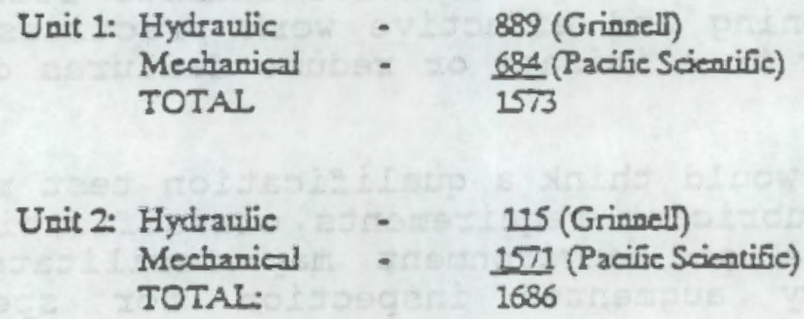

Plant has limited failure evaluation daca. Just initiated failure evaluation (root cause analysis) 2 years ago.

Plant has some snubbers located on the top of the steam generators (highest temperarure area) that are buried in insulacion and that bave consistently jammed (discovered by band stroking).

So far, for both units, there are approximately 11 mechanjeal szubbers that have failed functional tests. They have had numerous others that bave faijed hand stroking (conducted for all saubbers on high energy lines). Plant has bad no failed bydraulics.

Curreat drag acceptance limits are $2 \%$ (adminiserative) and $3 \%$ (failure limit). For accelesacion the limit is $0.025 \mathrm{~g}$

Plant has no PSA 1/4's (those that they did have, bave been replaced with PSA I/Zs).

to provide a breakdown of the snubber popuiation by size.

is the snubber gry at (E) He should be contacted in regard to a previous bigh failure rate that they encountered on PSA $1 / 2$ 's

Reviewed some of their failure analysis sheets. Plant has a tendency to attribute failures to snubber overload. This may be reasonably valid since failures were discovered by hand stroing on bigh energy lines (i.e. lines kown to have transients).

They have recendly implemented a pian whereby any snubbers that are removed as a part of their snubber reducion program are funcionally tested to obcain a test bench mark. They aiso hand stroke any remaining srubbers on that system. Any snubbers that are used to replace snubbers that failed the hand stroke, are aiso functionally tested to obtain a bench mark Replacement soubbers would aiso get tested again during the nerr ourage. This data is used for treading 


\section{BATTELLE NPAR RESEARCH}

\section{MEETING NOTES - $5 / 1 / 90$}

Attachment 1

Currencly, their service bife monitoring program just involves hand stroking, but will evearually involve bezch texting Service life monitoring is currendy limited only to those systems to which they previously tad probiems. They will phase in systems thas they ancicipate they may have problems on

During their last ortage, they band stroked all. snubbers on high energy lines (Le those lines known to bave tramsicuts).

Their Techmial Specifications allow them to exclude hand stroked failures from haviag to be considered as ISI fainures. However, theg haven't had any that have coincided with their functional test sample. Had they, they worid have considered them to be ISI failures evea though they are sot obligated to do this.

The following action iteons for the Bartelle evaiuation were establisted:

- For cratuation of drag foree treads:

- Evaluate data for sizes $1 / 2$ and 1

- Meastre drag foree for various amounts of service time (exciude data from test ploss indienting abnormal resuits such as unever load parters).

- Record serial no, size, unit no, tens, drag, comp. drag, service time (RFO no.), and beation? to provide environemental information).

- Ger fonctional test printouts for all functional test failures for which a failure evaluation was conducted (both units).

- Try to obcain functional test printouts (from previous tests) for snubbers that failed the hand stroke craluation.

- Get a copy of failure evaluation format. 
Appendix A

\section{TRIP REPORT}

$\underline{\text { Plant E }}$

John Mucci 8/23/90

Notes from subsequent discussion with support systems.
Investigation and Information reviewed during the visit and of the Engineering Staff assigned to

- General Plant Information:

a. There are two units of $1150 \mathrm{M}$.W. sizes - Unit \#1 went into operation in and has been through refueling outages. Unit $\# 2$ went into operation in , and is now going through its third refueling outage.

b. The units were constructed with mostly PSA ranging from $1 / 4 \mathrm{KIP}$ to 100 KIP. The total population for the two units are 1720 all mechanical with hydraulic ( 8 each) LESEGA used on the steam generator for Unit $\frac{*}{*} 1$, and a total of 1100 mechanical with (8 each) hydraulic LESEGA for Unit \#2. There has been a removal or replacement of 120 snubbers in Unit \#1 through a snubber reduction program. During the first $3 \mathrm{RO}$ a total of over 1000 snubbers had been tested through ISI for Unit \#1 with a total of 85 failures during performance test. There were also over 500 tested in Unit \#2 with a total of 69 failures during the first two refueling outages.

c. Failures are categorized by:
1) Environment
2) Overloading
3) Handling or mishandling
4) Manufacturing Defects
5) Vibration
6) Unknown

As for percentage of the total failures, Cat\#1 with $20 \%$, Cat $\frac{\pi}{2}$ with $17 \%$, Cat $\# 3$ with $28 \%$, Cat $\# 4$ with $22 \%$, Cat $\# 5$ with $8 \%$ and Cat \#6 with $5 \%$. This would account for $28 \%$ as aging related, $67 \%$ as non-aging related and $5 \%$ unknown.

d. As for systems having the most failures we can identify and classify them as follows:
1) Component Cooling System ( )
2) Reactor Cooling System ( )
3) Safety Injection System ( )
4) Steam Generator Blowdown Recycle ( )

The above systems exhibited the highest snubber failures with approximately $55 \%$ of the total with the remaining $45 \%$ being distributed among more than 20 other systems which experienced snubber failures.

1) The snubber reduction program is not in full swing as result of timing and priority. They have also purchased some Teledyne Load Pins with which to monitor continuous or transient loads in separate systems with overload failures. They have also replaced some PSA with corrosion problems, with $A / D$ because of unit construction. 
2) They have a formal failure analysis program addressing each failure with respect to failure mode, failure cause and corrective action. They had a photo of a snubber destroyed by overload, and also a metallurgical analysis of identifying material stress whici is included in the data collected.

3) Failures have occurred on all systems, however, the steam generator blowdown system has had a higher number of failures than any other system. Supports on primary system have less failures due to contamination or leaky components as in general leaks are less likely to develop and when they develop they are addressed with higher priority.

4) The plant has a tracking program in their computer system called ASIS, which addresses snubbers and support systems. They have divided the snubbers in three groups, Small, Medium, and Large and includes all relevant data associated with each unit. The system is not complete, as much of the necessary data has not been entered addressing past test data, failure causes, failure mechanism, ambient environment, which would be used eventually to establish service trend. It is the opinion of snubber personnel that because of basic design and lay out differences which exist between plants, a standard approach to service life monitoring would not be entireiy practical as each plant would have their own peculiarity associated with system design and operation, however, some basic surveillance and monitoring standards may be decided.

5) They identified the most critical snubber parts as the screw shaft, thrust bearing as the items which exhibit load related failures.

6) It is of the opinion of the snubber personnel that the test machine should have the automatic capability to test snubbers, however, it should allow the operator to vary input parameters without complicated procedure. This would allow the evaluation of snubber performance at levels different than the preset Tech. Spec. requirements. 
Appendix A

Plant F

\author{
TRIP REPORT - \\ John Mucci \\ Job 17131
}

A discussion was conducted between $J$. Mucci of Wyle and Snubber Engineering Central Support.

- The plant has been in operation since the early $80^{\prime} \mathrm{s}$ however, the testing program for snubbers was initiated during the forth refueling outage (2R4) which took place in April

- Since then all the snubbers have been tested twice and many have been tested more than twice.

- This effort was concentrated on Unit \#2 Mechanical Snubbers and in particular, PSA-1, which had an original population of 60 ea., however, several have been since replaced with $A D-501$ in cases where the inherent design was more suitable.

0

has also replaced all of their PSA-1/4 and PSA-1/2 with $A D-41, A D-43$ and $A D-71 R$ because of a high failure rate of the original PSA caused in most part by misshandling during inspection and testing.

- A total of 47 exam data was collected all from Unit $\frac{\| 2}{\pi}$ as onit $\ddot{\|} 1$ only had a total population of 3 in PSA-1 Model.

- All data was reviewed and 16 exams were selected for trending based on in-service-time. Data from these exams were grouped together, separated by tension run, compression run, which included average and peak values - graphs have been created in order to identify any possible trend or trends.

- The exams used in the evaluation are from snubbers installed at different locations in the plant, inside and outside containment, at elevations from $370^{\prime}$ to 420, with temperature ranging from $140^{\circ} \mathrm{F}$ to $90^{\circ} \mathrm{F}$. These temperatures are not considered accurate as we were unsuccessful locating operating temperature ranges for Unit \#2. A temperature study was conducted of Unit \#1 in 1987 for justification for continued operation, and it is generally assumed that temperatures for unit \#2 are approximately $20^{\circ} \mathrm{F}$ lower at respective locations. It is noted however, that varying temperatures do not reflect major changes in service performance. 
OFEICE ME MORANDUM

$\underline{\text { Plant } G}$

To: File

RE: Visit at

for

discussion of in-situ monitoring equipment

FROM: D. Brown

DATE: dugust 24, 1990

On $8 / 17 / 90$, I visited

and met with the following

personnel:

- ISI

- Nuclear Engineering

We discussed vibration problems they had experlenced on the mainsteam bypass piping. Vibration frequency was approximately $400 \mathrm{~Hz}$. and was actually the resulc of radial pulsaclons of the plpe wall. The vibration was causing locallzed cracking in the vicinity of interval attachment lugs used for the snubber plpe clamp. Vibration was monitored using straln gauges; data was retrived remotely. The vibration problem was, for the most part, resolved by increasing the pipe wall thlckness and by 1nstallacion of two aultiple orffice plates within the pipe. Vibration amplicude was reduced by a factor of 10 .

One remaining scrut that was locaced upstream of the orifice plates remalned subject to high amplitude vibration. The strut was instrumented with strain gauges for monitoring load; substantial loads were documented.

LVDT's (11near variable differentlal cransformers) generally are not accepcable for monicorlng vibracion. They are, however, useful for measuring thernal displacement and have been used in this respect at this plant.

Vibration can also be monitored using portable vibration monitoring inscrumentation. Two devices that were discussed in this regard are:

- Askania hand-held vibracion monitoring equipment.

This instrument has a circular chart that provides direct readings of vibracton amplitude. Frequency can be determined based on chart speed.

- B\& $\mathrm{K}$ hand-held accelerometer

This instrument has the capability of providing veloctty and displacement data vs. time integrating by acceleration.

Boch of the above described instruments are accepcable for nonttoring accessible systems, but must be hard-wired for use with remote data recrieval systems for inaccessible systems. 


\section{Appendix A}

The plant had also experienced translents in the HPSI system where they were experlencing back flow through the check valves. Other types of translents they have experienced are caused by turbine trip, SRV venting, pump start, etc.

Force measuring pins are probably the most practical way to measure arial loads on snubbers and struts due to system transients. Such equipment was particularly useful for axlal supports on the mainsteam plping system for straight runs of pipe.

In general, due to environmental considerations such as heat, wear, etc., monitoring instrumentation is nor readily practical for continuous use on various systems. Load pins had to be considered as temporary modifications of supports.

They had also experienced problems with high frequency vibration (approximately $800 \mathrm{~Hz}$. ) on mainsteam piping with a secondary vibration ac $10 \mathrm{~Hz}$. The high frequency vibration appeared to be due to pulsating radial plpe expansion and contraction similar to that experlenced on the mainsteam bypass system. The $10 \mathrm{~Hz}$. vibraclon appeared to involve gross movement of the piping system as opposed to the pulsating wall; in this case, they were able to use a spring loaded IVDT to measure vibrat1on. In their opinion, the low frequency vibracion was the result of small pressure pulses within the reactor which were also monitored at $10 \mathrm{~Hz}$.

In their opinion, accelerometers are not really a good cholce of instrumentation for measuring piping or support response to dynamic translents. However, their experlence has been positive in using these devices for measuring steady state vibration.

Snubbers installed on severely vibrating piping systems have, for the most: part, been removed as part of a snubber reduction program. However, two $50 \mathrm{KIP}$ snubbers remain and are continuously degraded. These snubbers are monitored and replaced frequently.

Plant personnel provided an extensive amount of back-up data including isometrics, instrumentation specifications, etc., that apply to the subject of chis memo. 
August 2, 1990

\section{Fattelle}

Pacific Northwest Laboratories

Battelle Buulevard

P.O. $80 \times 999$

Richiand. Woshing

Dave Brown

Lake Engineering Company

P.0. Box 296

10 Aust in Avenue

Greenvilie, RI 02828

Subject: Snubber Test Data from

Dear Dave,

Attached is the test data that we received from . Also included is a portion of the plant's Technical Specifications, snubber acceptance criteria and the validator acceptance criteria.

The test data does show a number of repeat tests for various sizes. The results shown are for a validator, not a test machine.

I have reviewed most of the data; however I haven't completed a summary for all sizes. For the repeat tests of 1,2 , and 3 year intervals, the sizes $\ldots 1 / 2,3$, and 10 (all PSAs), according to my analysis, show the following results:

- for the PSA size $1 / 2$... out of a total of 18 repeat tests,

5 indicate an increase in drag

8 indicate an improvement or less drag

2 indicate the same status

3 snubbers failed

- for the PSA size 3...out of a total of 6 repeat tests,

4 indicate an increase in drag

2 indicate an improvement or less drag

0 failures

- for the PSA size 10 ...out of a tctal of 25 repeat tests,

12 indicate an increase in drag

13 indicate an improvement or less drag

0 failures

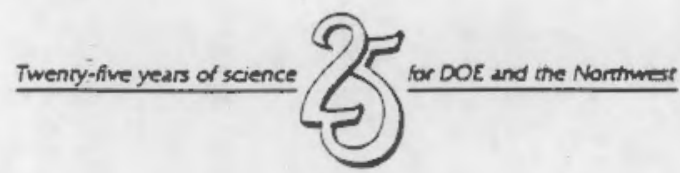




\section{Appendix A}

August 2, 1990

Dave Brown

Page 2

Also included in the data are $1 / 4,1$, and 35 size snubbers, I haven't summarized all of these at this time. For the $1 / 2 \mathrm{~s}, 3 \mathrm{~s}$, and $10 \mathrm{~s}$ the test data is not conclusive in showing increasing drag over time, i.e., the $10 \mathrm{~s}$ and $1 / 2 \mathrm{~s}$ show improvement over time. If you have any questions give me a call.

Sincerely,

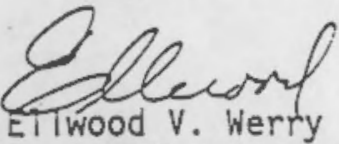

Senior Development Engineer

Energy Sciences Department

$\mathrm{EVW} / \mathrm{Cdr}$

Enclosures

cc: Mike Ximel

Scott Cole w/o enclosures

John Mucci w/o enclosures

Don Blahnik $\cdot w / 0$ enclosures 


\section{Appendix B}

\section{In Situ Monitoring Methods and Equipment for Snubbers}




\section{Appendix B}

\section{In Situ Monitoring Methods and Equipment for Snubbers}

This section includes a discussion and examples of in situ monitoring methods and equipment for snubbers.

Methods and equipment are available to monitor snubbers periodically or continuously for service stressors and degradation. Snubbers can be monitored either individually or collectively on a system basis. In situ monitoring is commonly used to confirm design loads and to help analyze problem snubbers located in severe environments. Stressors commonly monitored are load, vibration, and temperature. Snubber stroke position can also be monitored to verify thermal movements; displacement transducers are often used for this purpose.

\section{Load Monitoring}

Snubber loads can be monitored when the calculated design loads are to be verified or when piping and equipment adjustments need to be made. Loads can also be monitored on specific snubbers where overloading or excessive drag force is suspected. Snubbers placed in locations subject to water and steam hammer or flow stratification can be monitored for excessive loading.

Loads are commonly measured using shear pin transducers that replace the snubber clevis pins (Figure B.1) during the monitoring procedure. The shear pin transJucer uses a strain gage element that is sensitive to shear loads (Figure B.2). Bi-axial shear pin transducers are available where two components of the load need to be measured. The measurements can be read on a real time or recorded basis.

\section{Temperature Monitoring}

Snubbers subject to a potentially high temperature environment can be evaluated by monitoring the snubber's local temperature. The monitoring data can identify applications that require augmented surveillance or environmental modifications. The data can also help improve service-life predictions in such applications.

Temperatures can be accurately monitored, even in difficult access areas, using portable, non-contact infrared temperature measurement tools on a spot or continuous basis. Where practical, thermocouples and RTDs can be used to provide continuous data on the snubber at the heat source. Thermometers are used for measuring temperatures where access is possible. Temperaturesensing tape can be used to register peak temperatures on the snubber during operations. A shortcoming of the latter two alternatives, however, is that a continuous record is not provided.

\section{Vibration Monitoring}

Where vibration is suspected, snubbers can be monitored using state-of-the-art vibration monitoring equipment. Characterization of these conditions can help mitigate vibration effects through corrective action, such as system modification.

Various remote and local vibration monitoring equipment is available. Hand-held instruments are easier to use, but are limited to use only in those locations that are accessible during plant operation. Remote monitoring of vibration is another alternative; this approach generally involves instrumenting the pipe or snuhher with accelerometers. Typical acceleration monitoring instrumentation is shown in Figure B.3. Acceleration location isometrics are shown in Figure B.4. Frequency and amplitude are the most important parameters for characterizing vibration.

Note: Displacement transducers are generally not practical for use in monitoring snubber vibration due to their lack of adequate response. 


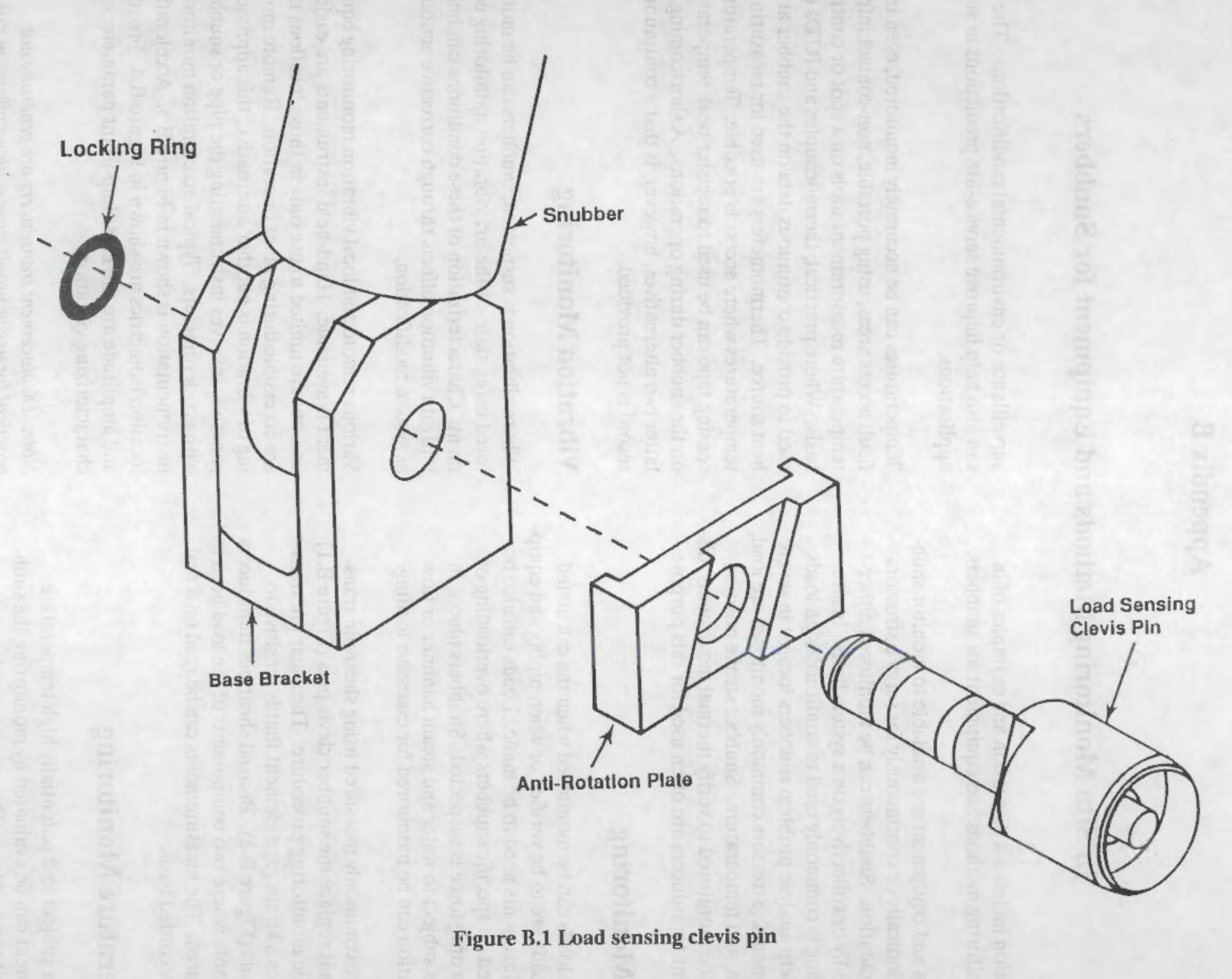




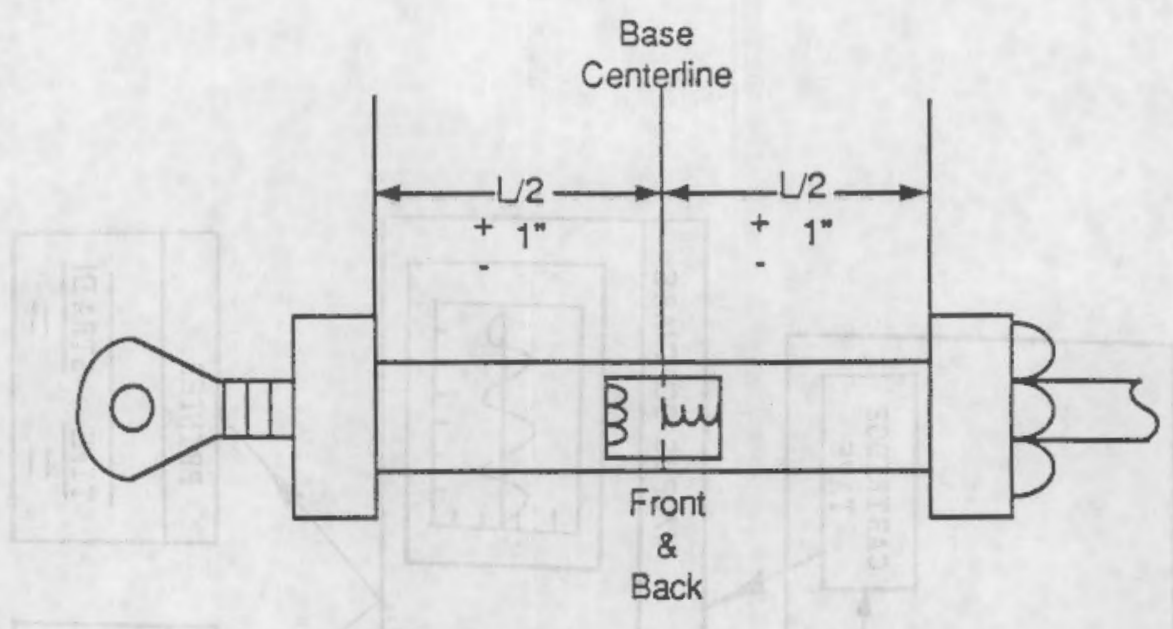

Place Two (2) - 2 Element $90^{\circ}$ Tee Rosettes at Mid Span of Strut $180^{\circ}$ Apart.

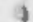

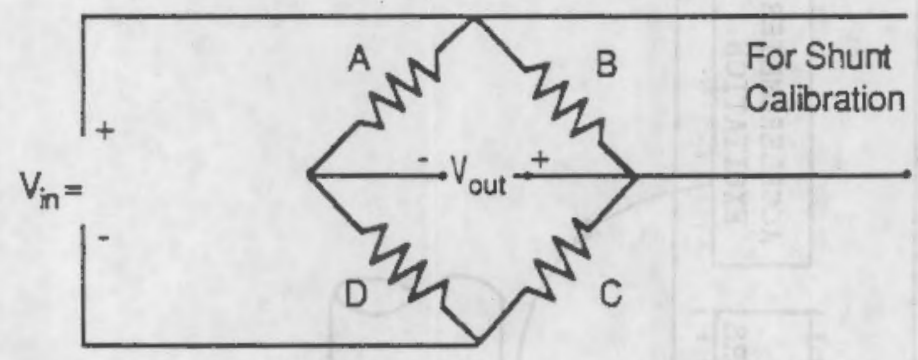
A - Front Axial
B - Front Poisson
C - Back Axial
D - Back Poisson

Strain Gage Bridge Connection

R9106142.1

Figure B.2 Stain gage element for load monitoring of snubbers 


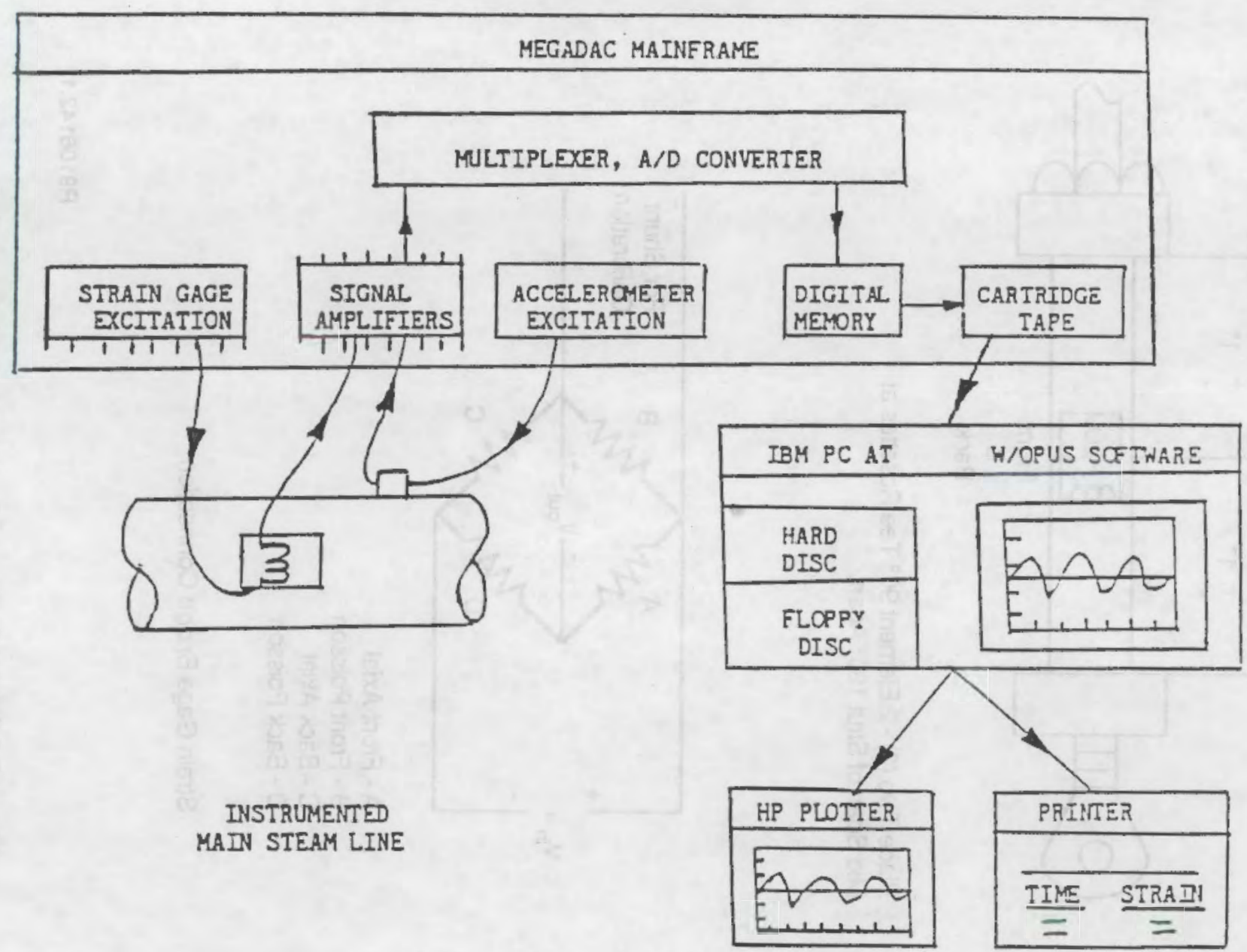

Figure B.3 Acceleration monitoring instrumentation scheme 


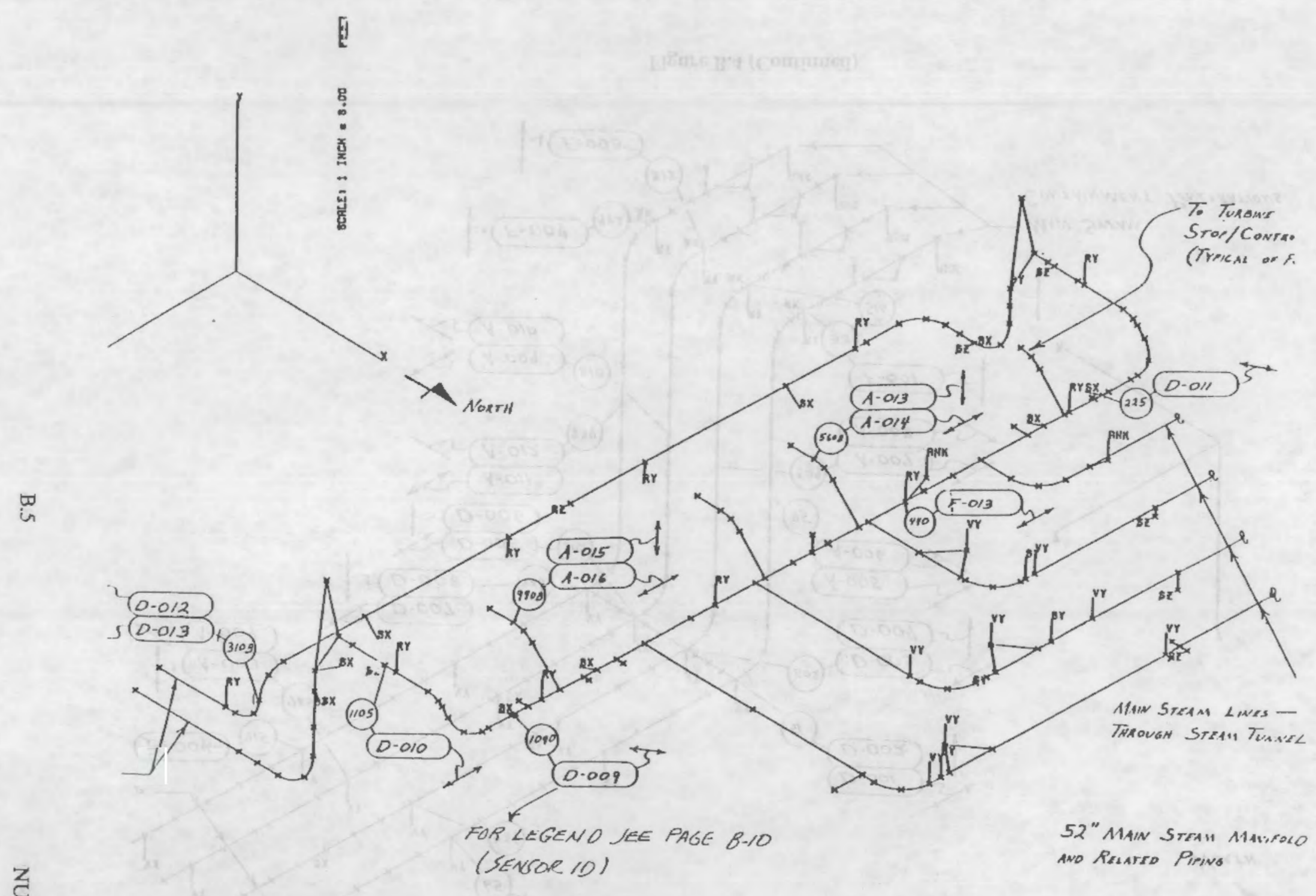

Figure B.4 Typical acceleration location isometric 


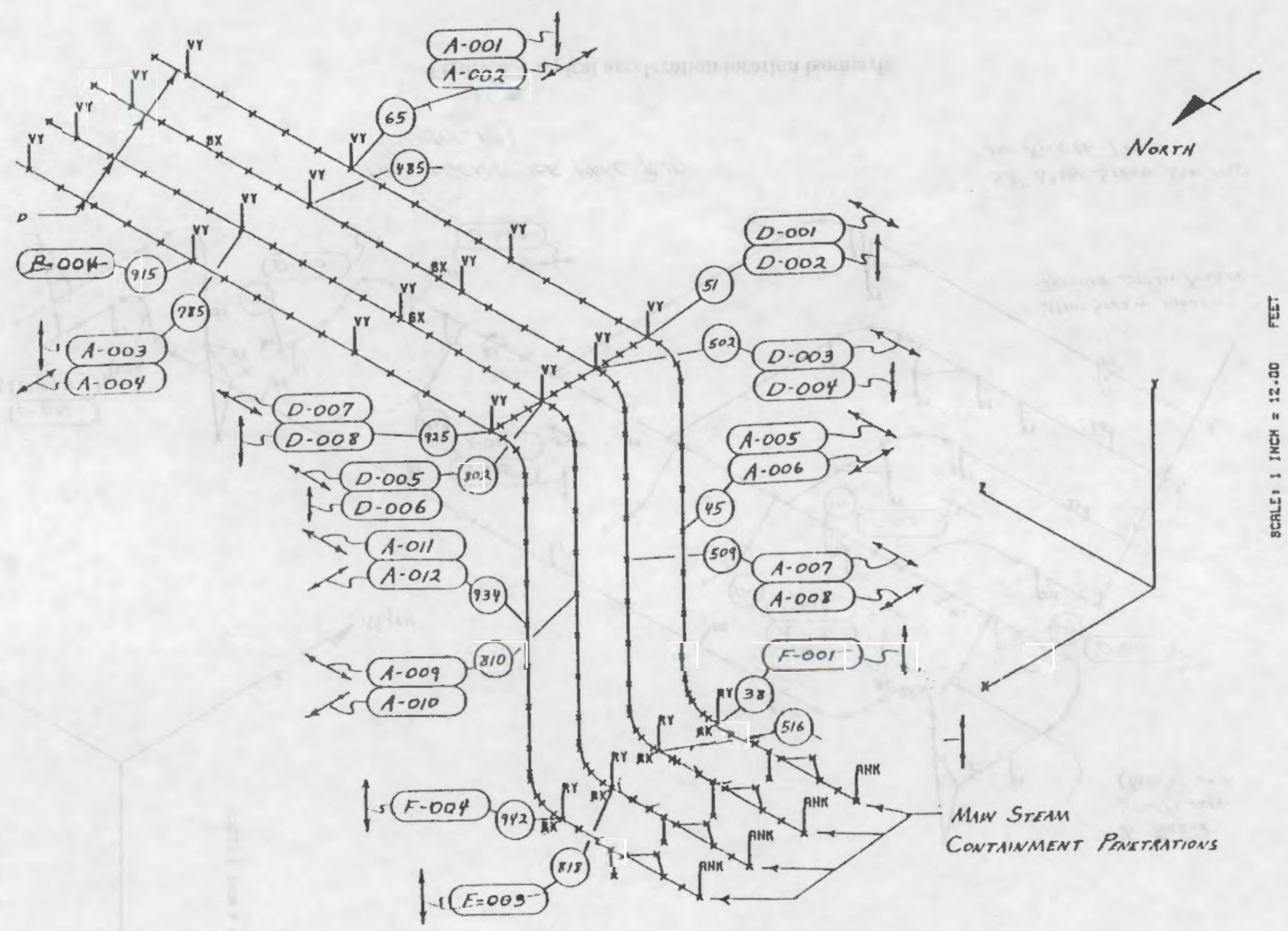

Figure B.4 (Continued) 


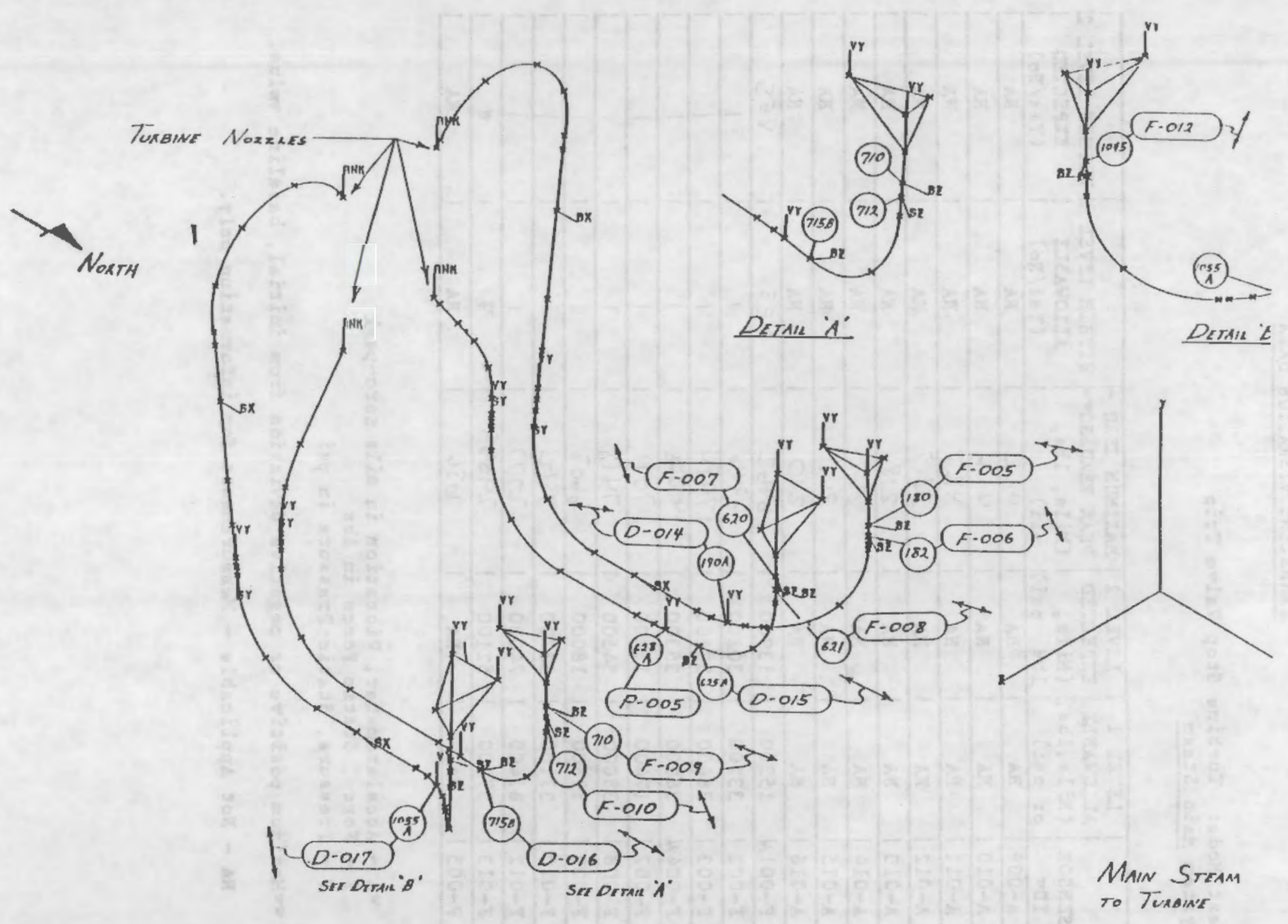

Figure B.4 (Continued) 
Appendix B

TRANSIEYT TIBRATION DATA

Tese Mode: Turbize Stop Valve Irip

Systes yin Stere

\begin{tabular}{|c|c|c|c|c|c|c|c|c|}
\hline \begin{tabular}{r|} 
ID \\
SEMSOR
\end{tabular} & $\begin{array}{l}\text { LEVEL 1 } \\
\text { AI:OWAII } \\
\text { (2ils, 1bs } \\
\text { or osi) }\end{array}$ & & $\begin{array}{l}\text { LEVEI } 2 \\
\text { EXEECD } \\
\text { (Yils, } \\
\text { lbs, osi }\end{array}$ & 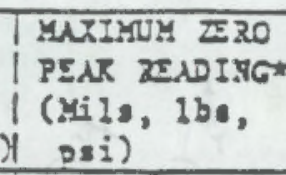 & 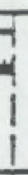 & 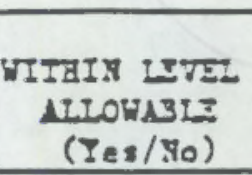 & 1 & 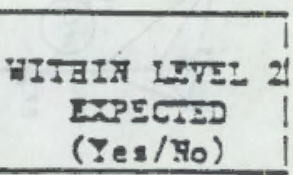 \\
\hline$A-0091$ & MA & 1 & $\mathrm{MA}$ & 14.2 & I & RA & I & RA \\
\hline$A-0101$ & ra & 1 & RA & 41.6 & 1 & $\mathrm{rA}$ & 1 & $\mathrm{rA}$ \\
\hline$A-0111$ & $\mathrm{MA}$ & 1 & $\mathrm{MA}$ & 47.7 & 1 & ga & 1 & $\mathrm{ra}$ \\
\hline$A-0121$ & FA & 1 & $\mathrm{MM}$ & 33.7 & 1 & $\mathrm{M}$ & 1 & $\mathrm{ma}$ \\
\hline $1-0131$ & $\mathrm{BA}$ & 1 & $\mathrm{MA}$ & 218 & 1 & $\mathrm{MA}$ & 1 & su \\
\hline $1-0141$ & SA & 1 & MA & 2,7 & 1 & $\mathrm{rA}$ & 1 & $\mathrm{BA}$ \\
\hline$A-0151$ & BA & 1 & ra & 261 & 1 & MA & 1 & re \\
\hline $1-0161$ & ra & 1 & ra & 210 & 1 & $\mathrm{ma}$ & 1 & $x A$ \\
\hline $\bar{F}-001 \mathrm{~N}$ & 15300 & 1 & 13900 & 6462 & 1 & YES & 1 & $x \in S$ \\
\hline $5-0021$ & 33200 & 1 & 30100 & 16946 & 1 & 1 & 1 & 1 \\
\hline $5-0031$ & 36400 & 1 & 33100 & 17424 & 1 & 1 & 1 & \\
\hline $5-004 \mathrm{~N}$ & 38900 & 1 & 35300 & 14228 & 1 & 1 & 1 & 1 \\
\hline $5-0071$ & 17400 & 1 & 15800 & 7011 & 1 & 1 & 1 & \\
\hline $7-0081$ & 38000 & 1 & 34500 & $741 \delta$ & 1 & 1 & 1 & 1 \\
\hline $7-0091$ & 19800 & 1 & 18000 & 6607 & 1 & 1 & 1 & 1 \\
\hline $8-0101$ & 37100 & 1 & 33700 & 7512 & 1 & 1 & 1 & 1 \\
\hline $7-0121$ & 81400 & 1 & 74000 & 2777 & 1 & 1 & 1 & 1 \\
\hline $7-0131$ & 57300 & 1 & 52100 & 24035 & 1 & 7 & 1 & 1 \\
\hline$p-0051$ & $\mathrm{ra}$ & 1 & AA & 686 & 1 & $\mathrm{MA}$ & & BA \\
\hline
\end{tabular}

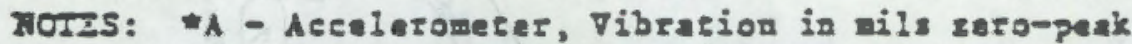

F - Force, Static Fores in lbs

P - Frensure, Seatic Freseurs is pai

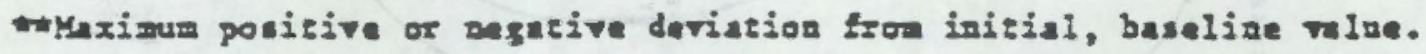

MA - Mot Appliesble - Kessurements for inforantion ooly. 


\section{TRAYSIEYT TIBRATION DAIA}

Tes: Mode: Turbize Stop Vulve Irip Syecem Main Stenm

\begin{tabular}{|c|c|c|c|c|c|c|c|c|c|}
\hline $\begin{array}{c}\text { sExSOR } \\
\text { IJ }\end{array}$ & $\begin{array}{l}\text { IEVEI 1 } \\
\text { AILOFA3LI } \\
\text { (Yils) }\end{array}$ & i & $\begin{array}{l}\text { LVVEL } 2 \\
\text { EPECIED } \\
\text { (Xils) }\end{array}$ & & 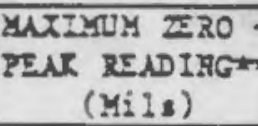 & & $\begin{array}{l}\text { WIIHIN IEYEI } \\
\text { AZLOWAJIL } \\
\text { (Yes/No) }\end{array}$ & & $\begin{array}{c}\text { WITIM LEYEL } \\
\text { EXPECTID } \\
\text { (Yes/Yo) }\end{array}$ \\
\hline$D-001$ & XA & T & $\mathrm{KA}$ & & 31 & $T$ & $\mathrm{MA}$ & T & IA \\
\hline$D-0021$ & $\mathbf{M}$ & 1 & ru & 1 & 24 & 1 & MA & 1 & $\mathbf{M}$ \\
\hline$D-0031$ & ru & 1 & ra & 1 & 66 & 1 & $\mathrm{ra}$ & 1 & $\mathrm{MA}$ \\
\hline$D-0041$ & $\mathrm{MA}$ & 1 & FA & 1 & $F A \| E D$ & 1 & $\mathrm{MA}$ & 1 & MA \\
\hline $\mathrm{D}-0051$ & $\mathrm{MA}$ & 1 & $\mathrm{ra}$ & 1 & 121 & 1 & MA & 1 & RA \\
\hline$D-0061$ & RA & 1 & $\mathrm{rA}$ & 1 & 24 & 1 & BA & 1 & KA \\
\hline$D-0071$ & $\mathbf{M A}$ & 1 & $\mathrm{~mA}$ & 1 & 43 & 1 & $\mathbf{R A}$ & 1 & $\mathrm{ra}$ \\
\hline$D-0081$ & SA & 1 & $\mathrm{ru}$ & 1 & 30 & 1 & su & 1 & $\mathrm{MA}$ \\
\hline$D-0091$ & $\mathrm{NA}$ & 1 & $\mathbf{M A}$ & 1 & 32 & 1 & $\mathrm{RA}$ & 1 & SA \\
\hline$D-0101$ & $\mathrm{MA}$ & 1 & MA & 1 & $5 \tilde{\delta}$ & 1 & $\mathrm{Ru}$ & 1 & ra \\
\hline$D-0111$ & MA & 1 & $\mathrm{~mA}$ & 1 & 70 & 1 & $\mathrm{MA}$ & 1 & $\mathrm{MA}$ \\
\hline$D-0121$ & $\mathrm{MA}$ & 1 & $\mathrm{MA}$ & 1 & $1 \varepsilon \varepsilon$ & 1 & $\mathrm{ma}$ & 1 & $\mathrm{MA}$ \\
\hline$D-0131$ & $\mathrm{RA}$ & 1 & $\mathrm{MA}$ & 1 & 166 & 1 & $\mathrm{MA}$ & 1 & $\mathrm{RA}$ \\
\hline $\mathrm{D}-0141$ & 402 & 1 & 366 & 1 & 162 & 1 & YES & 1 & YEड \\
\hline$D-0151$ & RA & 1 & $\mathrm{MA}$ & 1 & 113 & 1 & $\mathrm{ru}$ & 1 & $\mathbf{R A}$ \\
\hline$D-0161$ & $\mathrm{MA}$ & 1 & $\mathrm{ru}$ & 1 & 79 & 1 & M & 1 & $\mathrm{MA}$ \\
\hline$D-0171$ & 404 & 1 & 367 & 1 & 81 & 1 & YES & 1 & YES \\
\hline$A-0011$ & $\mathrm{XA}$ & 1 & $\mathrm{KA}$ & 1 & 6.4 & 1 & $\mathrm{MA}$ & 1 & $\mathbf{r A}$ \\
\hline$A-0021$ & $\mathrm{xu}$ & 1 & MA & | & 6.8 & 1 & $\mathrm{MA}$ & 1 & $\mathrm{ru}$ \\
\hline $1-0031$ & $\mathrm{MA}$ & 1 & $\mathbf{r u}$ & 1 & 12.8 & 1 & Ma & 1 & Ma \\
\hline $1-0041$ & $\mathrm{RA}$ & 1 & $\mathrm{kA}$ & 1 & 8.5 & 1 & $\mathrm{MA}$ & 1 & $\mathbf{M A}$ \\
\hline$A-0051$ & $\mathbf{s A}$ & 1 & MA & 1 & $35 \cdot 5$ & 1 & $\mathrm{MA}$ & 1 & $\mathrm{FA}$ \\
\hline$A=0061$ & $\mathbf{R A}$ & 1 & $\mathbf{R A}$ & 1 & 12.1 & 1 & $\mathbf{m A}$ & 1 & ru \\
\hline$A-0071$ & $\mathrm{~mA}$ & 1 & $\mathbf{R A}$ & $\perp$ & 25.7 & 1 & $\mathrm{FA}$ & 1 & $\mathbf{M}$ \\
\hline$A-0081$ & $\mathrm{rA}$ & 1 & $\mathbf{M A}$ & 1 & 46.3 & 1 & $\mathbf{M A}$ & 1 & $\mathbf{~ R A}$ \\
\hline
\end{tabular}

HCIS: A - Accelerometer, Vibration is nils zero-peak

D - Displecement, $\nabla$ ibration is nils zero-pesk

-Haximum poitive or sazative deviation from initial, baselize valoe. ru - Mot Applicable - Feasurements for informetion only. 


\section{Other Monitoring Methods and Equipment}

Other methods and equipment are available for evaluating specific snubber characteristics that may relate to service degradation.

- Fluid particle analysis equipment can be used to identify and to establish the density and size of solid particles in the hydraulic fluid. Such equipment is particularly useful for evaluating potential degradation in snubbers that are left in place for extended periods, e.g., snubbers that are not removed for refurbishment or functional testing. Particle contamination can result from internal corrosion products or from wear due to vibration.
- A boroscope is a useful device for internal visual examination of snubbers. This apparatus can be used to detect evidence of wear or other internal damage resulting from service.

- Spectrographic analysis equipment is often used to identify the source of contaminants in snubbers.

- Aerometers are used to determine the level of entrained and dissolved air in the hydraulic fluid.

- Various types of equipment are also available for determining the moisture content of hydraulic fluid.

- Acoustic emissions technology offers some potential for in situ inonitoring (e.g., vibration) of snubbers. This method should be evaluated further. 


\section{Appendix C}

\section{Typical Arrhenius Seal Life Extrapolation (Plant A)}




\section{Appendix C}

\section{Typical Arrhenius Seal Life Extrapolation (Plant A)}

This Appendix generically illustrates an empirically derived seal life curve reflecting an Arrhenius type relationship between seal life and temperature. A mathematical representation in this regard is also included. 


\title{
Appendix C
}

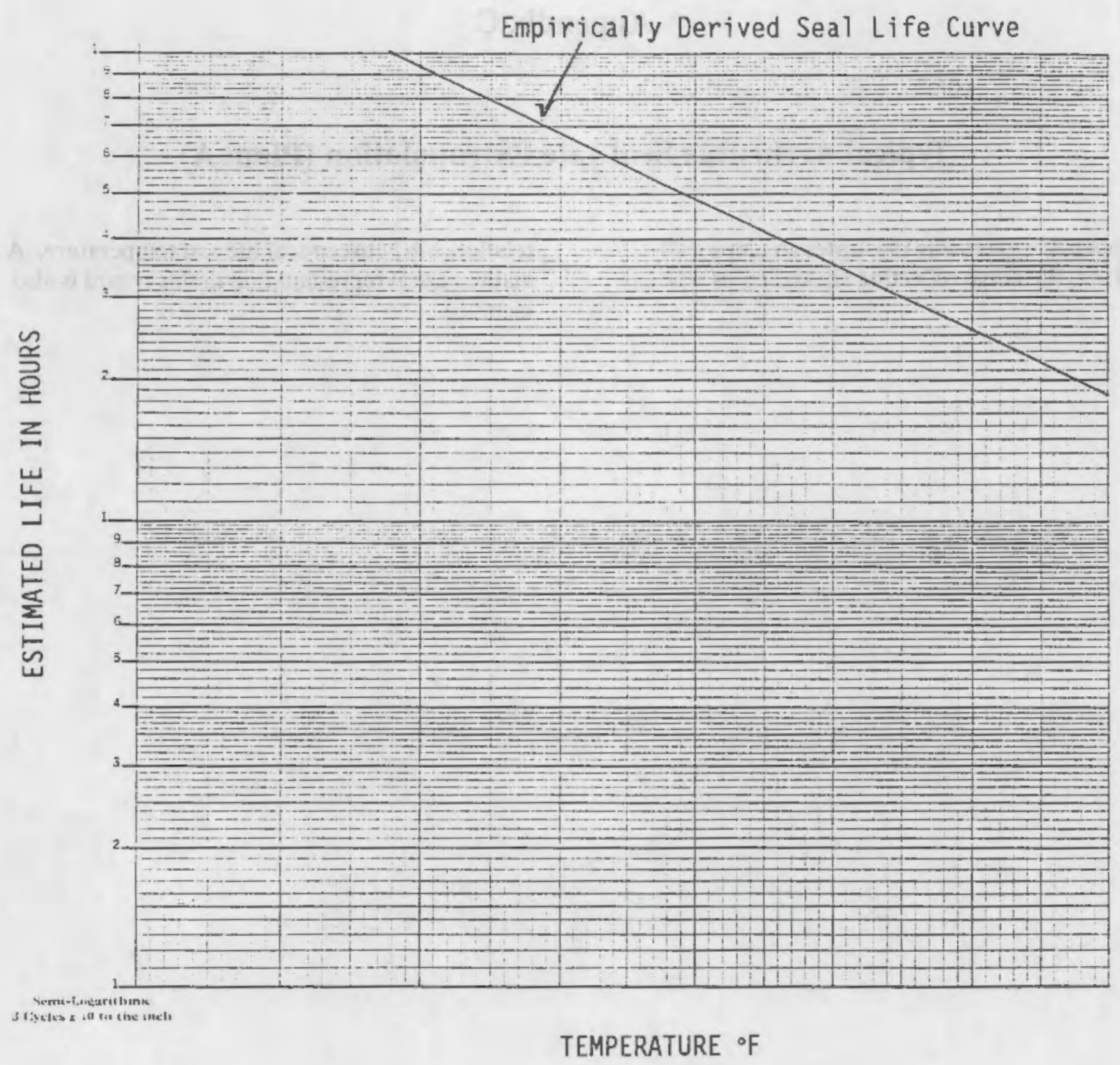

\author{
$I n(L)=m T^{n}+b$ \\ $I=1$ ife \\ $\mathrm{m}=$ constant \\ $T=$ Temperature \\ $n=$ constant \\ $b=$ constant
}




\section{Appendix D}

Effects of Compression Set on Low Pressure Seal Performance 


\section{Appendix D}

\section{Effects of Compression Set on Low Pressure Seal Performance}

This Appendix contains procedures and results for evaluation of seals removed from nonleaking snubbers that were anticipated to have high compression set. The goal of this evaluation was to obtain data that could be used to substantiate compression set limits, based upon low pressure performance, for various configurations of elastomeric seals. Inspection data sheets are included to show snubber conditions and as-found seal dimensions. Due to the limited amount of data in this regard, optimum compression set limits could not be totally confirmed. 
Appendix D

PREIIMINARY SEAL EVALUATION SUMMARY

COMPRESSION SET LIMITS STUDY

Preliminary evalustions were performed on six snubbers with no visfble signs of leakage. For the preliminary evaluation, easily accessible face seals were chosen. These are located between the valve body and reservoir on Bergen-Paterson suubbers and between valve body and cylinder cap on Grinnell model PH-74 snubbers.

To jusrify a secondary evaluation, a minimum compression set level of $45 \%$ was established. Only two of the six prelfminary evaluations ytelded a high enough level of compression set to justify secondary evaluations. The results of the preliminary evaluations were as follows:

\begin{tabular}{|c|c|c|c|}
\hline $\begin{array}{l}\text { Sample } \\
\text { Number } \\
\end{array}$ & $\begin{array}{l}\text { Snubber } \\
\text { Type } \\
\end{array}$ & $\begin{array}{l}\text { Plant } \\
\text { Type }\end{array}$ & Comments \\
\hline 1 & Bergen-Paterson & Fossil & $\begin{array}{l}\text { This snubber had been in service for a } \\
\text { relatively short time period, reportedly } \\
\text { in a severe environment. Evaluation did } \\
\text { not, however, result in compression set } \\
\text { levels high enough to justify continued } \\
\text { evaluation. }\end{array}$ \\
\hline 2 & Grinnell PH-74 & Fossil & $\begin{array}{l}\text { This snubber had been in service for } \\
\text { approximately } 15 \text { years. This snubber had } \\
\text { been shipped with no fluid and was removed } \\
\text { from further consideration. }\end{array}$ \\
\hline 3 & Grinnell $\mathrm{PH}-74$ & Fossil & $\begin{array}{l}\text { This snubber had been in service for } \\
\text { approximately } 15 \text { years under high } \\
\text { temperature (a) conditions. Visual } \\
\text { 1rspection revealed no signs of leakage. } \\
\text { Compression set evaluation resulred in } \\
\text { levels that were bigh enough to justify a } \\
\text { secondary evaluation. }\end{array}$ \\
\hline 4 & Bergeo-Paterson & Fossil & $\begin{array}{l}\text { This snubber had a long service life in a } \\
\text { relatively moderate environment. Visual } \\
\text { laspection revealed no signs of iakage. } \\
\text { ireliminary evaluation did not justify a } \\
\text { secondary evaluation. }\end{array}$ \\
\hline 5 & Bergen-Paterson & Nuclear & $\begin{array}{l}\text { Thts snubber had a short service life in a } \\
\text { high temperature (a) environment. Visual } \\
\text { inspection revealed no signs of leakage. } \\
\text { Prelimfnary evaluation did not justify a } \\
\text { secondary evaluation. }\end{array}$ \\
\hline 6 & Bergen-Paterson & Nuclear & $\begin{array}{l}\text { Moderate service life ( } 6 \text { yeers) in a high } \\
\text { temperature (a). No leakage. Secondary } \\
\text { evaluation cooducted. }\end{array}$ \\
\hline
\end{tabular}

(a) Greater than $150^{\circ} \mathrm{F}$. 


\subsection{BACKGROUND}

This procedure delineates the methods used to measure compression set in seals removed from snubbers selected for compression set evaluation for the NPAR Snubber Aging Study.

\subsection{EVALUATION PARAMETERS}

Note: Values for the below described parameters are Included in Table 3 for Grinnell snubbers and Table 4 for Bergen-Paterson snubbers. Where more than one measurement was obtalned for given seal or gland, average values are listed.

\subsection{Origlnal Seal Thickness}

Since orfiginal seal thicknesses $\left(W_{0}\right)$ were not measured, thickness values are based upon manufacturer's information (nominal values).

\subsection{Recovered Seal Thickness}

Recovered seal thickness $\left(W_{1}\right)$ is defined as the post-service thickness of the seal after removal from the gland.

\subsection{Compressed Thlckness (51mply Compressed Seals)}

Compressed thickness $\left(W_{s}\right)$ is the thickness of the seal when it is installed in the gland. The compressed thickness for each simply compressed seal was determined from snubber dimensional data obtained during the evaluation. Specific equations used in this regard are 11sted below for each seal.

Note: Dimensional variables are 1dentified in Figures 1 through 4 and Table 1 for Grinnell snubbers and in Figures 5 through 7 and Table 2 for Bergen-Paterson snubbers. 
Appendix D

\subsection{EVALUATION PARAMETERS}

2.3 Compressed Thickness (Simply Compressed Seals) (Cont'd)

2.3.1 Compressed Thickness (Bergen-Paterson Snubbers)

2.3.1.1 Item 3 - Reservo1r Piston Seal

$$
W_{S}=\frac{I-H}{2}
$$

2.3.1.2 Item 4 - Valve/Reservoir Mounting Seal

$$
w_{s}=J
$$

2.3.1.3 I I tem 13 - P1ston Rod Sea1

$$
W_{S}=\frac{S-R}{2}
$$

2.3.2 Compressed Thickness (Grinne11 Snubbers)

2.3.2.1 Item 1 - Piston Rod Seal

$$
\mathrm{W}_{\mathrm{s}}=\mathrm{H}
$$

\subsubsection{Item 2 - Piston Sea1}

$$
H_{s}=\frac{P-Q}{2}
$$

\subsubsection{Item 11 - Valve Mounting Seal}

$W_{S}=F$ 


\subsection{EVALUATION PARAMETERS}

\subsection{Conpression Set}

Compression set is defined as the mount of permanent deformation expressed as a percentage of the inttial seal compression.

Compression set (C) was calculated usting the following formula:

$$
c=\frac{w_{0}-w_{1}}{w_{0}-w_{8}} \times 100
$$

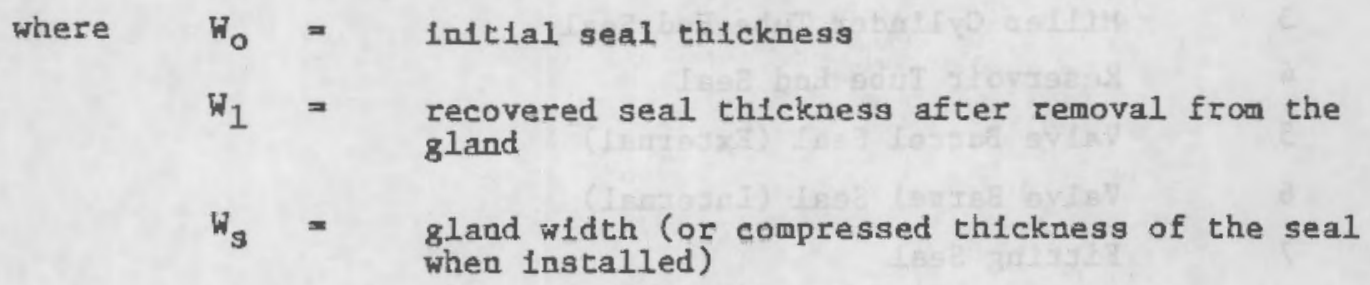

\subsection{Instrumentation and Test Equipment}

D1mensfonal data was obtalned using callbrated measuring devices* such as micrometers, depth gages, callpers, feeler gages, etc. 
Appendix D

TABLE 1

LIST OF SEALS AND SEAL RELATED PARTS

FOR GRINNELL MODEL PH-74 SNUBBER WITH MILLER CYLINDER

Pare

Number

1

2

3

4

5

6

7

8 $\underline{\text { Part }}$

Miller Piston Rod Seal

Miller Piston Seal Miller Cyllnder Tube End Sea1

Reservoir Tube End Seal

Valve Barrel Seal (External)

Valve Barrel Seal (Internal)

Fitting Seal

Reservolr Connecting Tube Boss Seal (PH-74 only)

Valve Body Plug Seal (PH-74 only)

Miller Eill Plug Seal ( $\mathrm{PH}-74$ only)

Valve Mounting Seal ( $\mathrm{PH}-74$ only)

Thread Seal - Valve Connecting Tube ( $\mathrm{PH}-74$ only)

Thread Seal - Locking Velocity Screw

Thread Seal - Bleed Rate Screw (PH-74 only)

Miller Rod Bushing

Miller Cylinder Tube

Reservoli Tube

Reservolr End Cap

Valve Barrel

Valve/Reservoir Conn. Tube (PH-74 only)

Miller Piston/Piston Rod Assembly

Valve Body

Valve Block ( $\mathrm{PH}-74$ only)

Miller Cylinder Head

Miller Cylinder Cap

PH-74 Tube Fitting
Quantity Per Snubber

1

2

2

2

2

2

4

2

1

2

2

2

2

2

1

1

1

2

2

1

1

1

1

1

1

2 
TABLE 2

LIST OF SEAL RELAIED PARTS

Part Number

2

3

3

4

5

6

7

8

9

10

11

12

13

(1) Manifold configuration only

(2) Quantity varies depending upon snubber size and configuration

Quantity Per Snubber

Reservolr Bleed-off Screw Seal

1

Reservolr Tube End Seal

Reservoir P1ston Seal

1

Valve/Reservair Mounting Seal

2

Connector Tube/Stop Plug Boss Seal

2

Port Plug Seal

(2)

Relief Valve Plug Internal Seal

1

Rellef Valve Plug Boss Seal

1 (1)

Back-up Rfng

1

Connector Tube Slidiog Seal

Cyllnder Tube End Seal

1

1

Allemite Fitting Seal

1

P1ston Rod Seal

1

Reservolr Bleed-off Screw

1

Reservoli Tube

Reservolr Cap

1

1

Reservolr Piston

1

Control Valve Body

1

Poppet Stop Plug

1

1

Port Plug

4

Rlief Valve Plug

1

1

Cyllnder head

1

P1ston Rod

1

Rod Bear1ng

1.

1

1

Cylinder Tube

1 


\section{Appendix D}

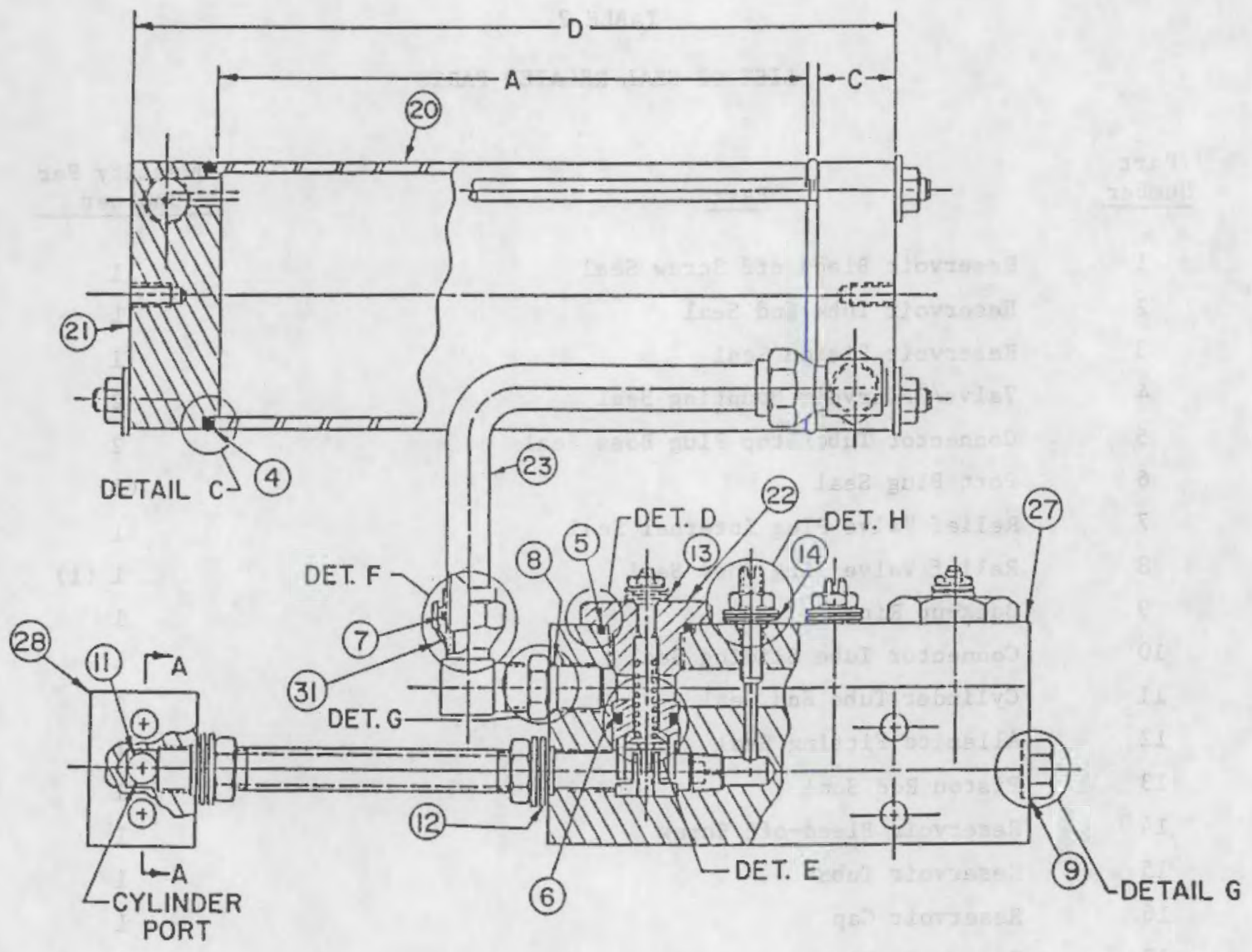

FIGURE

GRINNELL PIl-74 VALVE AND RESERVOIR ASSEMBLY 


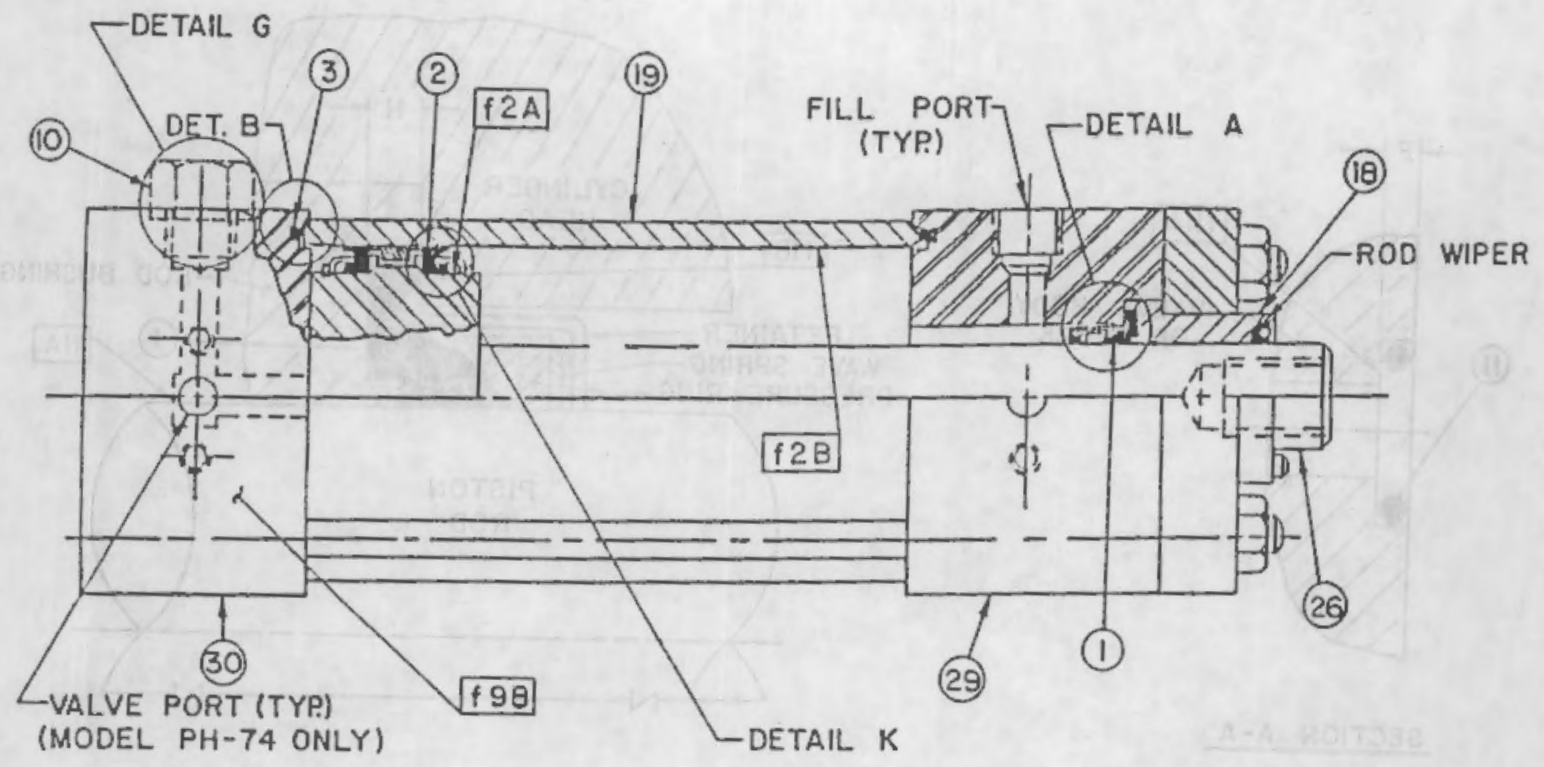

FIGURE 2

GRINNELL MILLER CYLINDER ASSEMBLY 


\section{Appendix D}

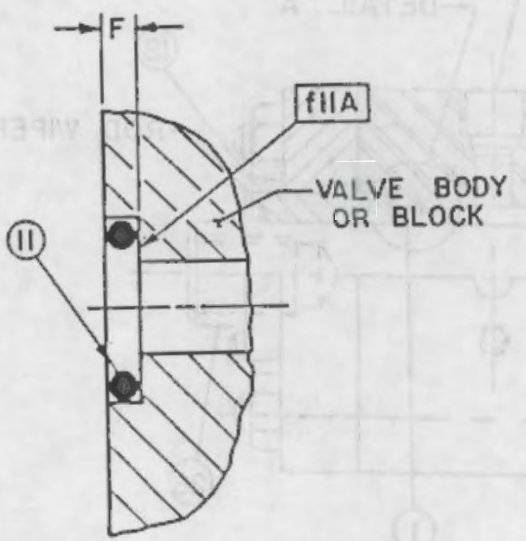

SECTION A-A

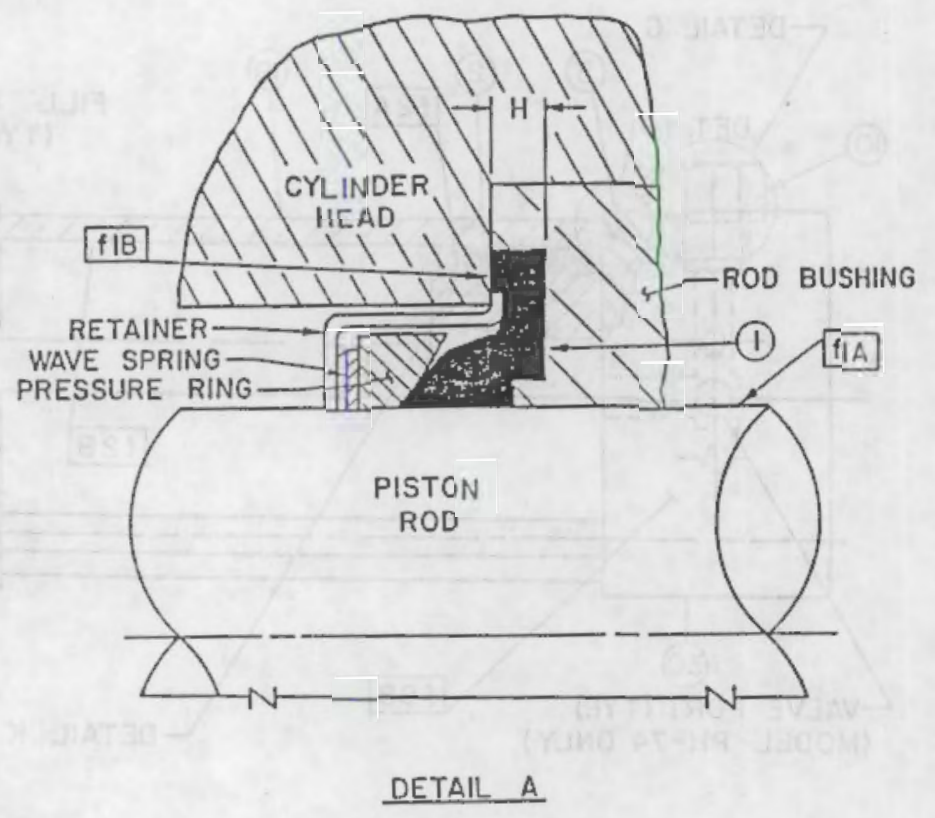

FIGURE 3

GRINNEIL, DETAILS - SHEET 1 
Appenau $\nu$

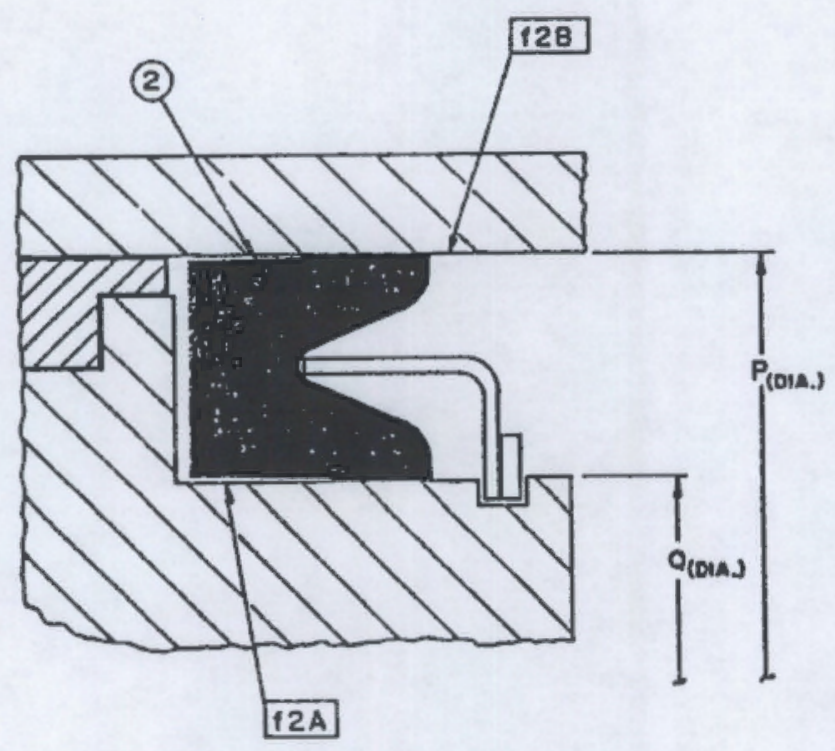

DETAIL $K$

FIGURE 4

GRINNEIL DETAILS - SHEET 2 


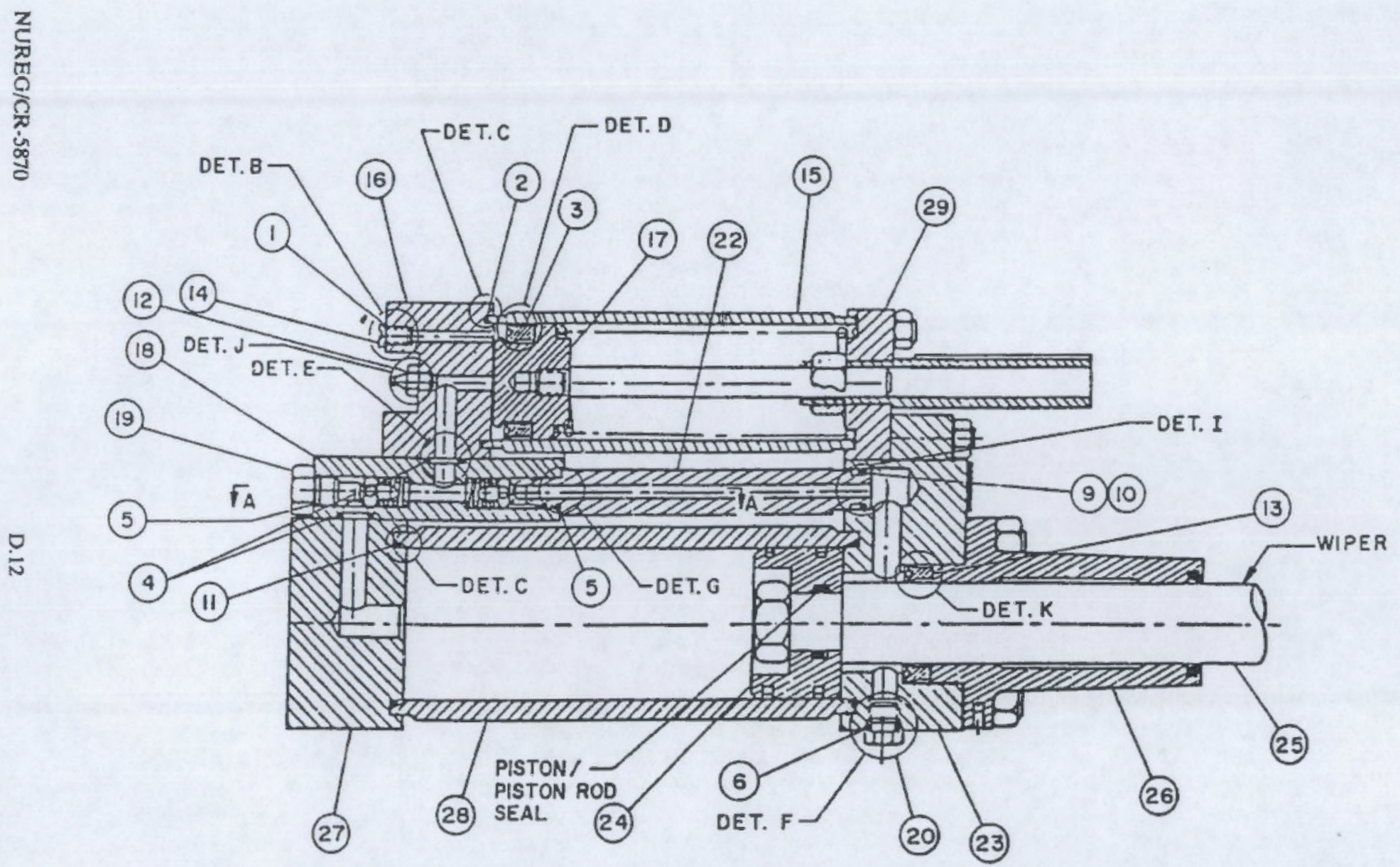

FIGURE 5

BERGRN-PATERSON GENERAL ASSEMBLY 


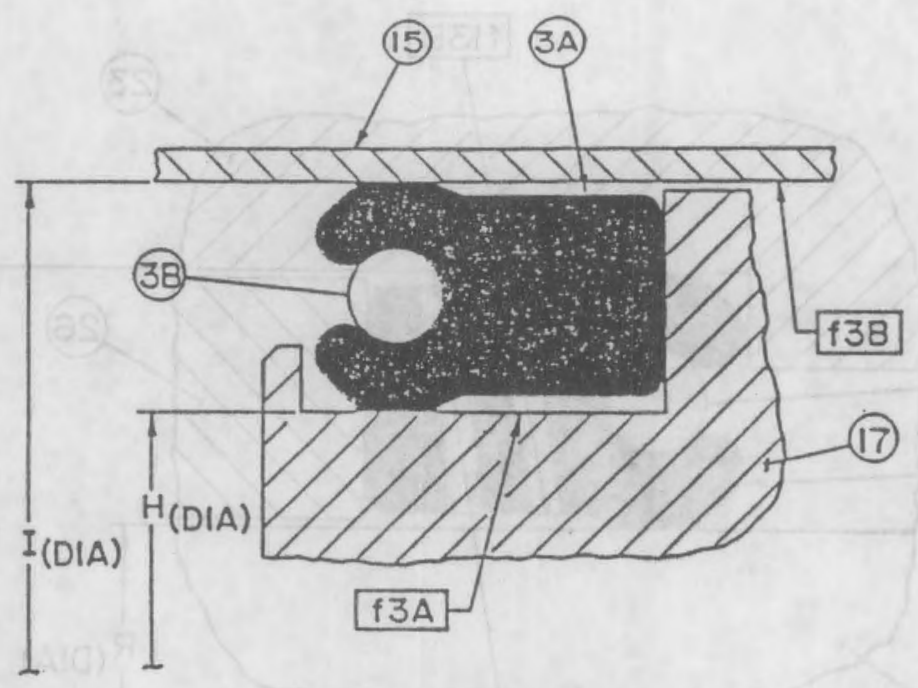

DETAIL D

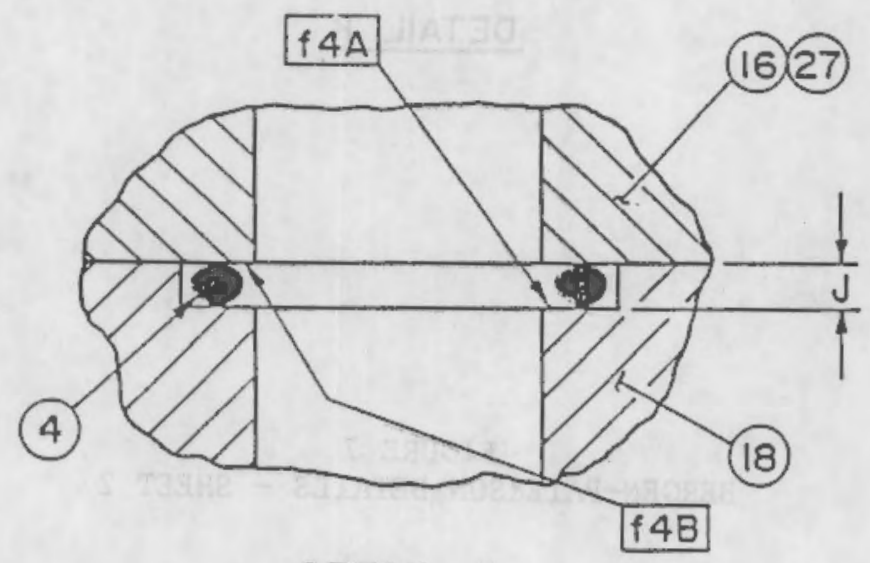

DETAIL E

FIGURE 6

BERGEN-PATERSON DETAILS - SHEET 1 


\section{Appendix D}

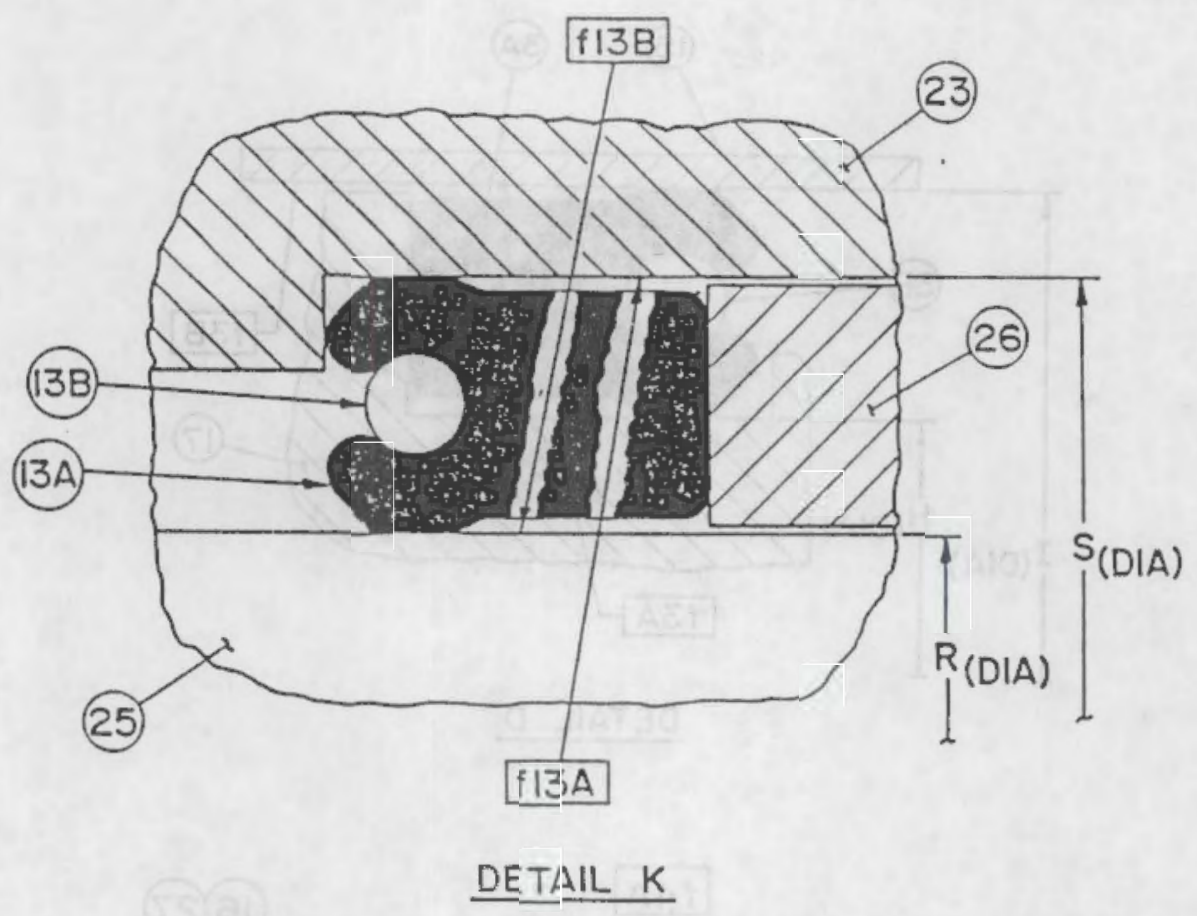

FIGURE 7

BERGEN-PATERSON DETAILS - SHEET 2 
TABLE 3

GRINNELL EVALUATION PARAMETERS

\begin{tabular}{|c|c|c|c|c|}
\hline Seal No. & $\begin{array}{c}\text { Wo } \\
\text { (1nches) }\end{array}$ & $\begin{array}{c}\text { W1 } \\
\text { (1nches) }\end{array}$ & $\begin{array}{c}\text { Ws } \\
\text { (inches) } \\
\end{array}$ & $\begin{array}{c}\text { Compression } \\
(\bar{x})\end{array}$ \\
\hline 1 & .128 & .103 & .101 & $93 \%$ \\
\hline 2 & .330 & .276 & .250 & $69 \%$ \\
\hline 11 & .070 & .061 & .050 & $52 \%$ \\
\hline
\end{tabular}

TABLE 4

BERGEN-PATERSON EVALUATION PARAMETERS

\begin{tabular}{cccccc} 
Seal No. & $\begin{array}{c}\text { Wo } \\
\text { (1nches) }\end{array}$ & 年ches) & & $\begin{array}{c}\text { Ws } \\
\text { (1nches) }\end{array}$ & $\begin{array}{c}\text { Compression Set } \\
(\boldsymbol{z})\end{array}$ \\
\hline 3 & .312 & .276 & .250 & $50 \%$ \\
4 & .103 & .098 & .078 & $20 \%$ \\
13 & .312 & .273 & .250 & $63 \%$
\end{tabular}


Appendix D

DATA SHEET 1

Page 1 of 1

GRINNEII

Snubber Sample Number: 3

Size (Bore X Stroke): $\mathrm{PH}-74$

Configuration: Millec

GENERAL COMMENTS:

- Snubber in gaod physieal condition.

- Reservair level $21 / 2$ full.

- No visible signs of lenkage

- Wiper crumbled when removed

- Wiper hard and brittle (high temperature exposured

- No sigas of high amplitude vibrotion degreelation.

Insp. by: Sattmale

Date: $7 / 3 / 90$ 
GRINNEI.L

$\begin{gathered}\text { Snubber Sample Number: } \\ \text { Model: }\end{gathered}$
Cyl1nder Type: $\frac{3}{\text { Miller }}$

\section{POST-SERVICE SEAL DIMENSIONAL DATA}

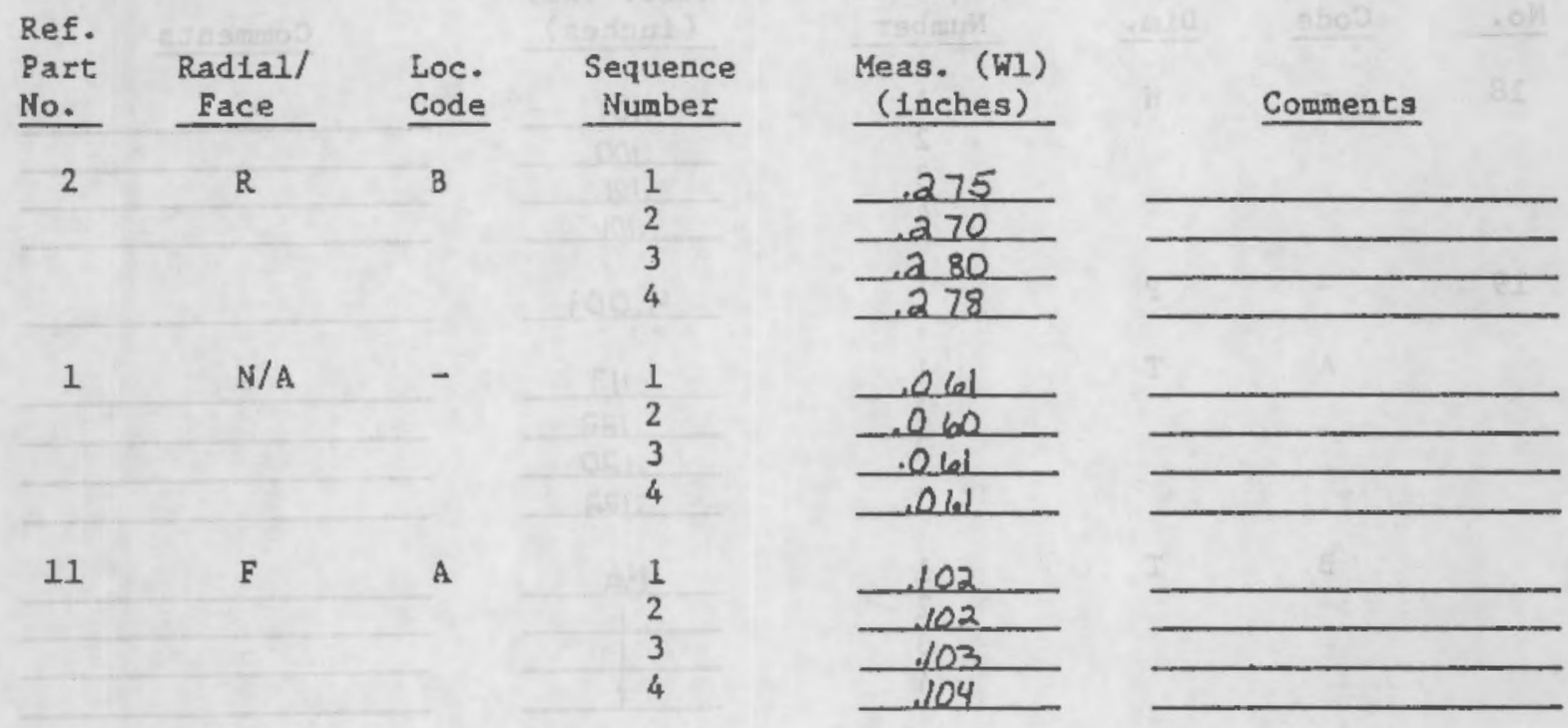

COMRENTS:

Insp. by: $\quad \mathrm{ad} M$ Date: $7 / 3 / 90$ 


\section{Appendix D}

DATA SHEET 3

Page 1 of 1

GRINNELL

Saubber Sample Number:

Cyllader Type:

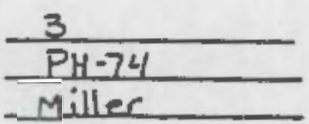

POST-DISASSEMBLY PART DIMENSIONAL DATA

\begin{tabular}{|c|c|c|c|c|c|c|}
\hline $\begin{array}{l}\text { Part } \\
\text { No. } \\
\end{array}$ & $\begin{array}{l}\text { Loc. } \\
\text { Code }\end{array}$ & Dim. & $\begin{array}{c}\text { Sequence } \\
\text { Number } \\
\end{array}$ & $\begin{array}{c}\text { Meas. (W1) } \\
\text { (inches) }\end{array}$ & Comments & 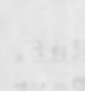 \\
\hline \multirow[t]{4}{*}{18} & - & $H$ & 1 & .101 & 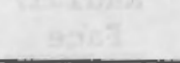 & +2 \\
\hline & & & 2 & .100 & & \\
\hline & & & 3 & Jel & - & 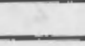 \\
\hline & & & 4 & .101 & & \\
\hline \multirow[t]{9}{*}{19} & - & $\mathbf{P}$ & - & 4.001 & & \\
\hline & A & $T$ & 1 & 119 & 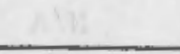 & - \\
\hline & & & 2 & .122 & & \\
\hline & & & 3 & .120 & & \\
\hline & & - & 4 & -.122 & & \\
\hline & B & $\mathrm{T}$ & 1 & $N / A$ & 2 & \\
\hline & & & 2 & $i$ & & \\
\hline & & & 3 & 1 & & \\
\hline & & & 4 & 1 & & \\
\hline 26 & B & $Q$ & - & 3.502 & & \\
\hline \multirow[t]{4}{*}{27} & - & $F$ & 1 & .050 & & \\
\hline & & & 2 & .051 & & \\
\hline & & & 3 & .049 & & \\
\hline & & & 4 & .050 & & \\
\hline
\end{tabular}

COMENTS:

Insp. by: Sattmlale

Date: $7 / 3 / 90$ 


$\frac{6}{30}$

- Snubber in good Thysical condition.

- Reservair level - $7 / 8$ marlss, Piston rodextension 7/8".

- No visible signt of lenknger.

- Fluid very dack with black globules.

- Heny sacing on exlinder tube and piston.

- Reservair piston seal (item 3) has severe surface cracking alang out side diameter. And top of seal.

- piston seal energizer also shows signs of cracking.

- out side diometer of seal hes shiny/glazed eppeacence

* It should be noted that only fluid in cylureles tube was dorkened. Flurd in reservair was relitively clean.

Insp. by: Sadfylans Date: $7 / 18 / 90$ 


\section{Appendix D}

DATA SHEET 5

Page 1 of 1

\section{BERGEN-PATERSON}

Snubber Sample Number: Size (Bore X Stroke): Configuration:

$\frac{\frac{6}{30}}{\text { Manifold }}$

\section{POST-SERVICE SEAL DIMENSIONAL DATA}

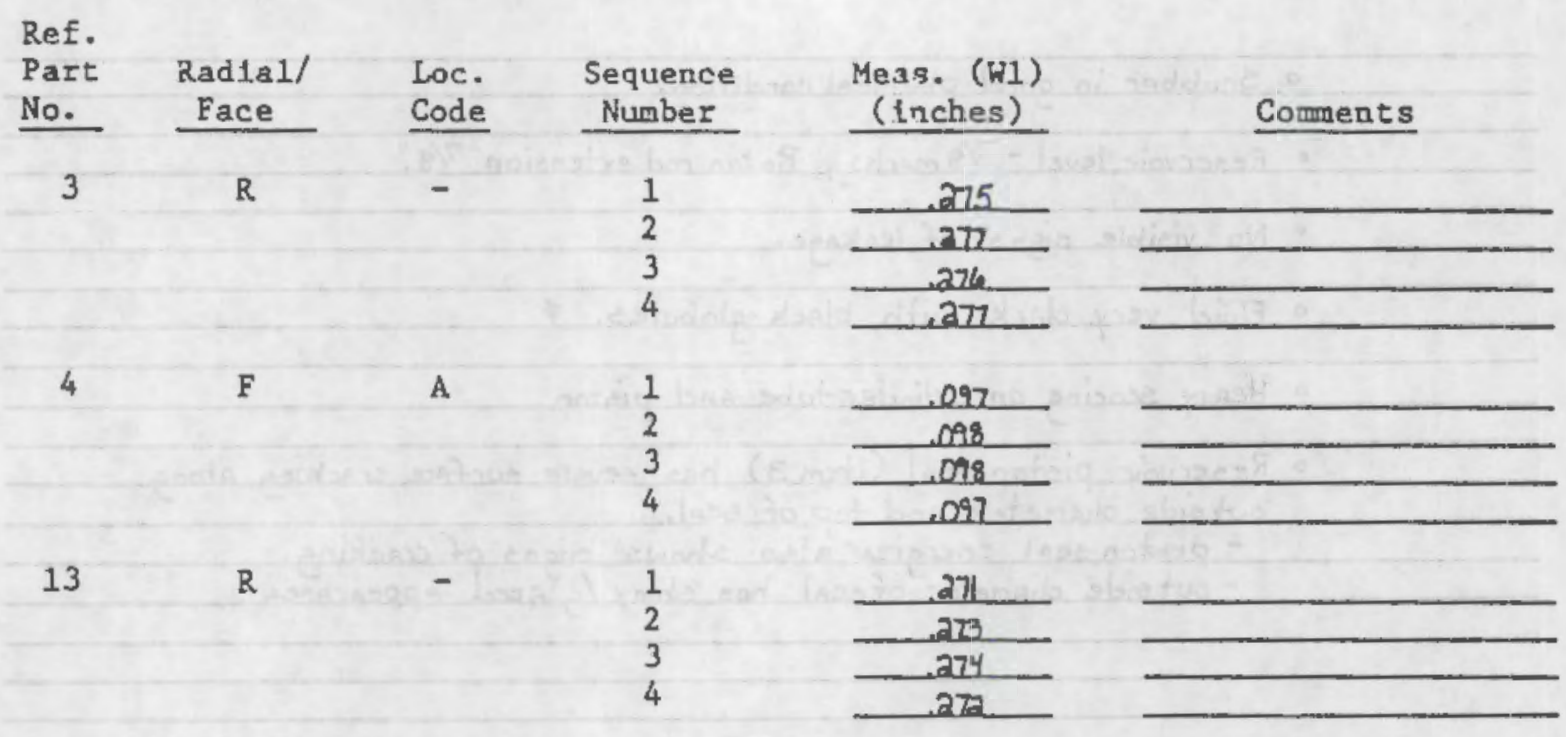




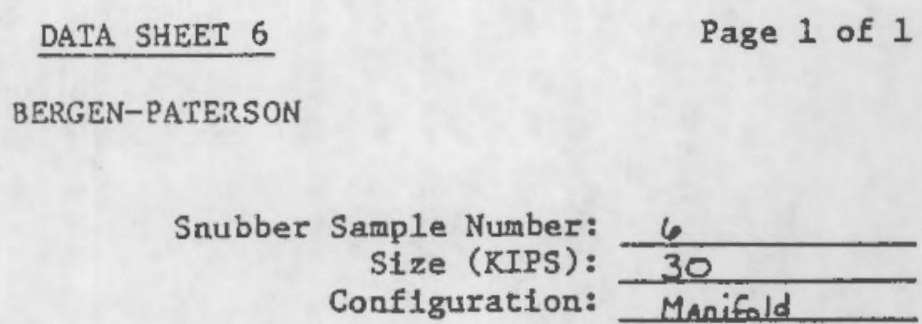

POST-DISASSEMBLY PART DIMENSIONAL DATA

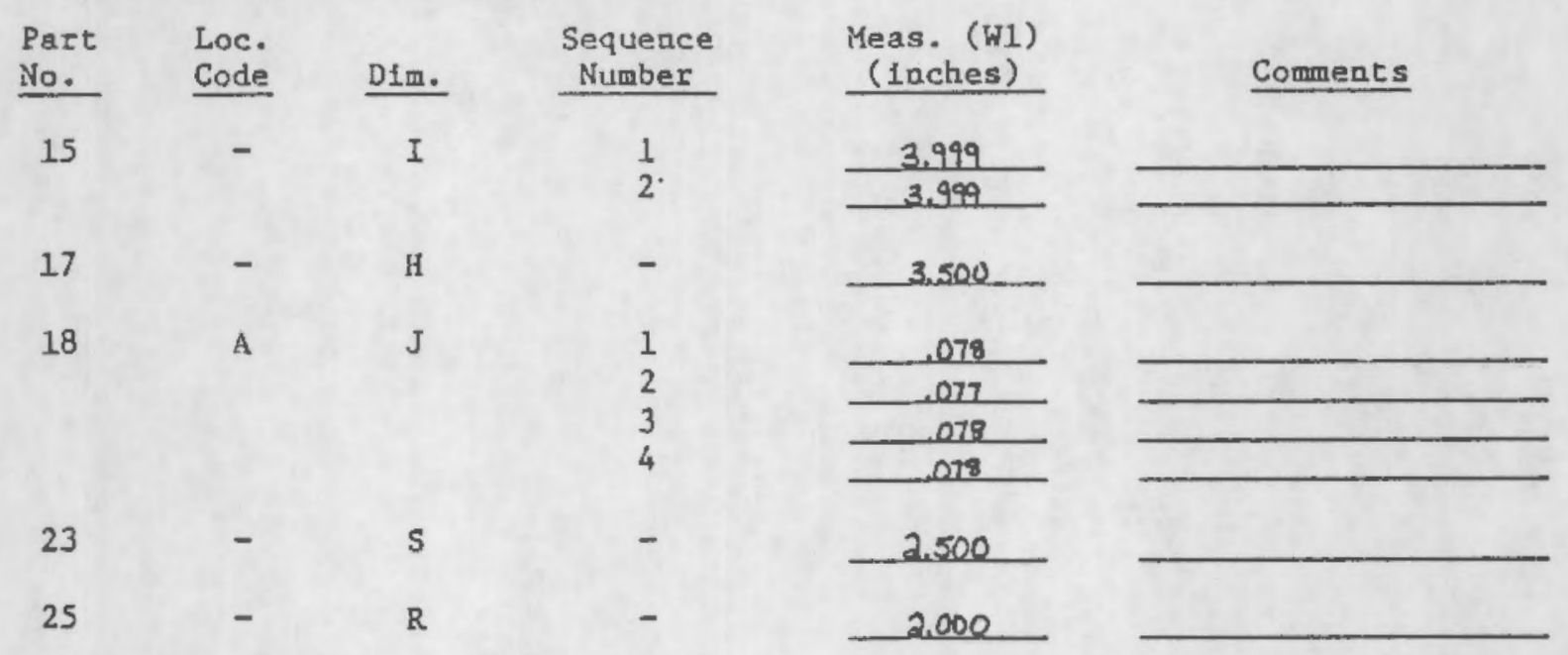


Appendix E

Evaluation of Drag Force Versus Time (Plant D) 


\section{Appendix E}

\section{Evaluation of Drag Force Versus Time (Plant D)}

This Appendix includes drag force data obtained from Plant D for two sizes of mechanical snubbers. The data were used in an attempt to correlate drag force with time. All snubbers were tested on the same test machine. No snubbers were tested on more than one occasion. Average drag force (i.e., average of the drag force values for several snubbers) is plotted versus service time. No trends are evident. 
Appendix E

Table E.1 Historical drag force data for snubbers at Plant D, Unit 1 (PWR)

\begin{tabular}{|c|c|c|c|c|}
\hline & Average $\mathrm{T}$ & Average C & Peak T & Peak C \\
\hline - $\operatorname{sin|}$ & 4.33 & 4.33 & 8.0 & 7.0 \\
\hline \multirow[t]{4}{*}{1} & 3.24 & 2.48 & 5.0 & 3.2 \\
\hline & 2.16 & 2.7 & 3.24 & 3.6 \\
\hline & 1.62 & 1.62 & 2.37 & 2.4 \\
\hline & 2.2 & 2.2 & 3.3 & 3.3 \\
\hline 1984 & 1.7 & 1.1 & 2.5 & 2.0 \\
\hline \multirow[t]{4}{*}{ PSA-1/2 } & 1.1 & 2.0 & 2.2 & 3.0 \\
\hline & 1.9 & 1.65 & 2.7 & 2.7 \\
\hline & 2.0 & 2.2 & 3.2 & 3.8 \\
\hline & 2.2 & 2.7 & 3.25 & 4.3 \\
\hline 1 & 2.24 & 2.30 & 3.57 & 3.53 \\
\hline & 3.75 & 6.3 & 7.5 & 12.5 \\
\hline $\bar{t}$ & 5.0 & 5.0 & 10.0 & 11.5 \\
\hline 1984 & 5.0 & 3.75 & 10.0 & 8.0 \\
\hline PSA-1 & 3.1 & 5.0 & 7.5 & 10.0 \\
\hline \multirow[t]{2}{*}{$\underline{!}$} & 4.21 & 5.01 & 8.75 & 10.5 \\
\hline & 2.0 & 1.7 & 2.66 & 2.2 \\
\hline \multirow[t]{2}{*}{$\bar{t}$} & 2.2 & 2.2 & 3.3 & 3.3 \\
\hline & 4.5 & 6.5 & 9.0 & 13.0 \\
\hline 1985 & 1.3 & 1.4 & 2.8 & 2.65 \\
\hline \multirow[t]{5}{*}{ PSA-1/2 } & 3.75 & 4.65 & 4.7 & 6.0 \\
\hline & 4.85 & 2.65 & 10.8 & 4.8 \\
\hline & 3.0 & 2.55 & 4.9 & 6.5 \\
\hline & 3.08 & 3.09 & 5.45 & 5.50 \\
\hline & 2.75 & 5.0 & 9.2 & 10.0 \\
\hline PSA-1 & 2.70 & 2.5 & 6.25 & 6.0 \\
\hline$\perp$ & 2.72 & 3.75 & 7.72 & 8.0 \\
\hline
\end{tabular}

Note: numbers in bold indicate averages.

$\mathrm{T}=$ tension drag force (lb).

$\mathrm{C}=$ compression drag force (lb). 
Table E.1 (Continued)

\begin{tabular}{|c|c|c|c|c|}
\hline 15 & Average $\mathrm{T}$ & Average C & Peak T & Peak C \\
\hline & 2.0 & 2.5 & 4.4 & 4.5 \\
\hline \multirow{5}{*}{$\overline{\mathbf{t}}$} & 1.65 & 1.75 & 3.25 & 3.20 \\
\hline & 2.0 & 2.2 & 3.50 & 3.75 \\
\hline & 7.7 & 10.25 & 12.0 & 15.5 \\
\hline & 3.1 & 3.0 & 4.8 & 4.3 \\
\hline & 1.60 & 2.05 & 3.85 & 3.90 \\
\hline 1986 & 3.10 & 2.10 & 5.50 & 3.50 \\
\hline \multirow[t]{2}{*}{ PSA-1/2 } & 1.60 & 1.90 & 3.20 & 3.3 \\
\hline & 2.10 & 3.3 & 3.3 & 5.1 \\
\hline 70, 2 & 1.70 & 1.8 & 3.0 & 3.0 \\
\hline & 1.60 & 2.0 & 2.2 & 3.0 \\
\hline $20 x-5$ & 1.75 & 1.0 & 3.25 & 2.0 \\
\hline 20.8 & 0.9 & 0.9 & 1.80 & 1.5 \\
\hline$\underline{1}$ & 2.37 & 2.67 & 4.20 & 4.35 \\
\hline \multirow[b]{3}{*}{22.10} & 3.75 & 2.2 & 6.5 & 6.2 \\
\hline & 3.3 & 2.5 & 6.25 & 7.0 \\
\hline & 2.0 & 5.0 & 6.25 & 7.0 \\
\hline \multirow[t]{3}{*}{ PSA-1 } & 5.0 & 4.0 & 11.5 & 8.0 \\
\hline & 2.5 & 3.0 & 5.0 & 8.75 \\
\hline & 3.75 & 3.75 & 8.75 & 8.75 \\
\hline \multirow[t]{3}{*}{$\underline{1}$} & 3.38 & 3.40 & 7.37 & 8.53 \\
\hline & 60 & a & 258 & yege \\
\hline & 1.3 & 1.6 & 2.0 & 2.75 \\
\hline \multirow[t]{3}{*}{$\overline{1}$} & 1.25 & 1.6 & 2.25 & 2.2 \\
\hline & 1.2 & 1.7 & 1.95 & 2.7 \\
\hline & 1.1 & 1.1 & 2.0 & 2.15 \\
\hline 1987 & 1.7 & 1.85 & 3.0 & 1.0 \\
\hline \multirow[t]{3}{*}{ PSA-1/2 } & 1.25 & .9 & 2.16 & 1.0 \\
\hline & 2.3 & 1.6 & 3.85 & 3.40 \\
\hline & 6.5 & 7.8 & 8.2 & 9.75 \\
\hline \multirow[t]{2}{*}{82.35} & 1.5 & 1.1 & 2.1 & 1.6 \\
\hline & 1.6 & 2.6 & 2.6 & 3.2 \\
\hline 1 & 1.97 & 2.18 & 3.01 & 3.26 \\
\hline PSA-1 & 3.3 & 3.0 & 6.3 & 7.0 \\
\hline
\end{tabular}


Appendix E

Table E.1 (Continued)

\begin{tabular}{|c|c|c|c|c|}
\hline $2 x+109$ & Average T & Average C & Peak T & Peak C \\
\hline \multirow{4}{*}{-} & 2.89 & 2.11 & 5.55 & 4.12 \\
\hline & 4.60 & 2.35 & 6.95 & 4.80 \\
\hline & 3.37 & 3.10 & 6.5 & 6.15 \\
\hline & 2.45 & 2.75 & 6.0 & 5.62 \\
\hline 1988 & 2.95 & 2.75 & 6.10 & 4.45 \\
\hline \multirow{5}{*}{ PSA-1/2 } & 2.37 & 2.75 & 4.40 & 4.35 \\
\hline & 1.78 & 2.45 & 4.20 & 4.65 \\
\hline & 3.30 & 1.92 & 6.25 & 3.92 \\
\hline & 2.76 & 5.20 & 5.10 & 7.05 \\
\hline & 2.95 & 2.82 & 5.67 & 5.01 \\
\hline \multirow[t]{3}{*}{$\bar{t}$} & 5.56 & 4.55 & 10.95 & 11.67 \\
\hline & 5.79 & 5.71 & 13.27 & 12.96 \\
\hline & 6.75 & 4.15 & 11.02 & 8.66 \\
\hline \multirow[t]{5}{*}{ PSA-1 } & 5.17 & 6.53 & 11.17 & 15.99 \\
\hline & 6.24 & 9.42 & 13.52 & 22.98 \\
\hline & 7.63 & 5.64 & 13.30 & 13.30 \\
\hline & 5.63 & 5.36 & 12.12 & 11.55 \\
\hline & 7.25 & 5.91 & 13.42 & 12.75 \\
\hline$\perp$ & 6.25 & 5.90 & 12.35 & 13.73 \\
\hline \multicolumn{5}{|l|}{$\bar{t}$} \\
\hline- & 7.40 & 5.20 & 13.0 & 11.0 \\
\hline$t$ & 5.20 & 4.50 & 8.30 & 7.80 \\
\hline 1989 & 3.75 & 2.75 & 6.0 & 3.75 \\
\hline \multirow[t]{4}{*}{ PSA-1/2 } & 5.25 & 3.25 & 7.0 & 5.40 \\
\hline & 1.60 & 1.10 & 3.10 & 1.90 \\
\hline & 0.85 & 1.25 & 1.75 & 2.10 \\
\hline & 2.0 & 2.25 & 3.50 & 4.25 \\
\hline \multirow[t]{2}{*}{$\perp$} & 3.72 & 2.90 & 6.09 & 5.17 \\
\hline & 2.5 & 2.75 & 5.0 & 7.50 \\
\hline \multirow[t]{3}{*}{ PSA-1 } & 9.0 & 2.50 & 17.5 & 6.25 \\
\hline & 5.0 & 6.25 & 10.0 & 12.0 \\
\hline & 5.5 & 3.83 & 10.8 & 8.58 \\
\hline
\end{tabular}




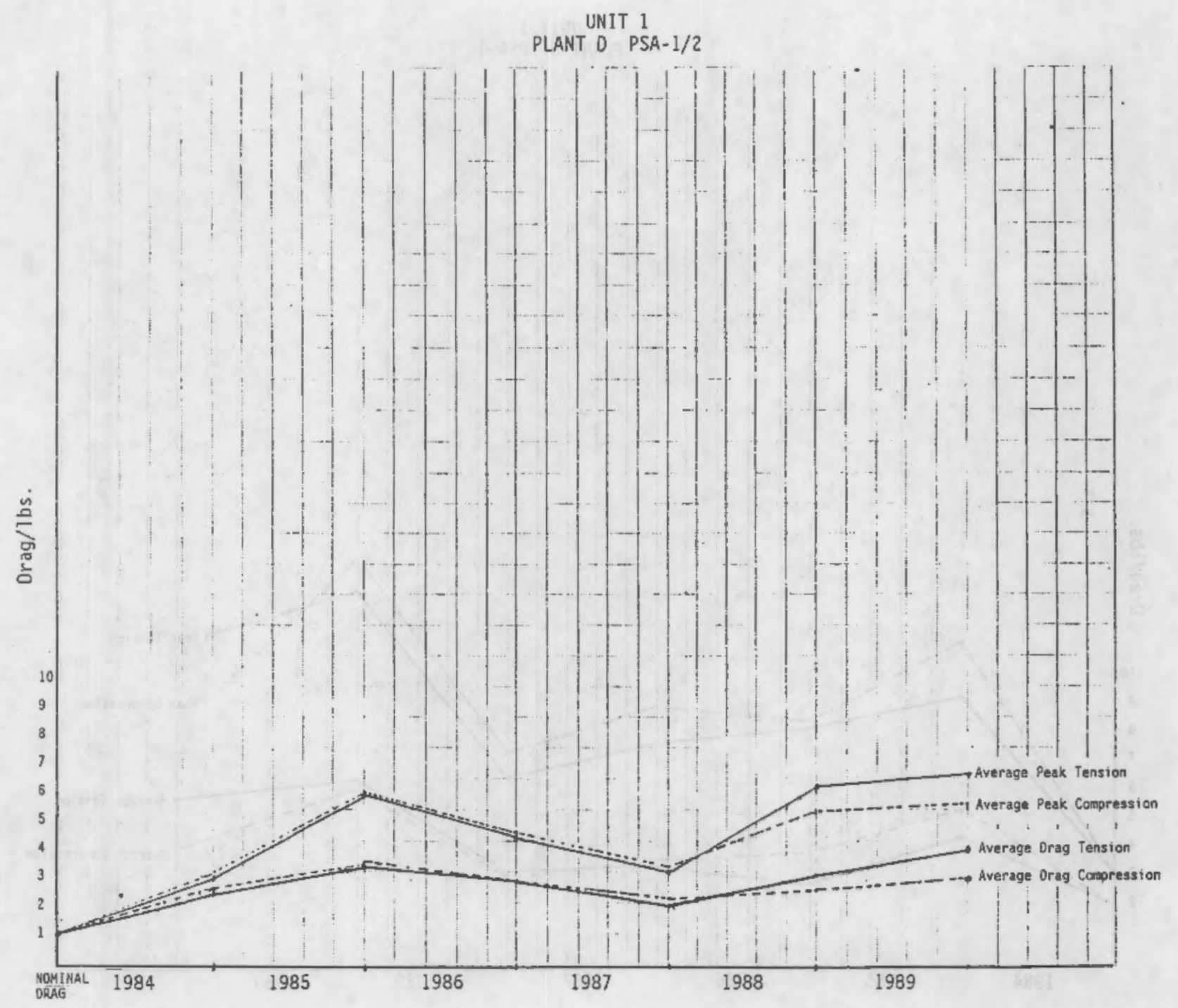

Figure E.1 PSA-1/2 drag force versus service time Unit 1, Plant D 


\section{Appendix E}

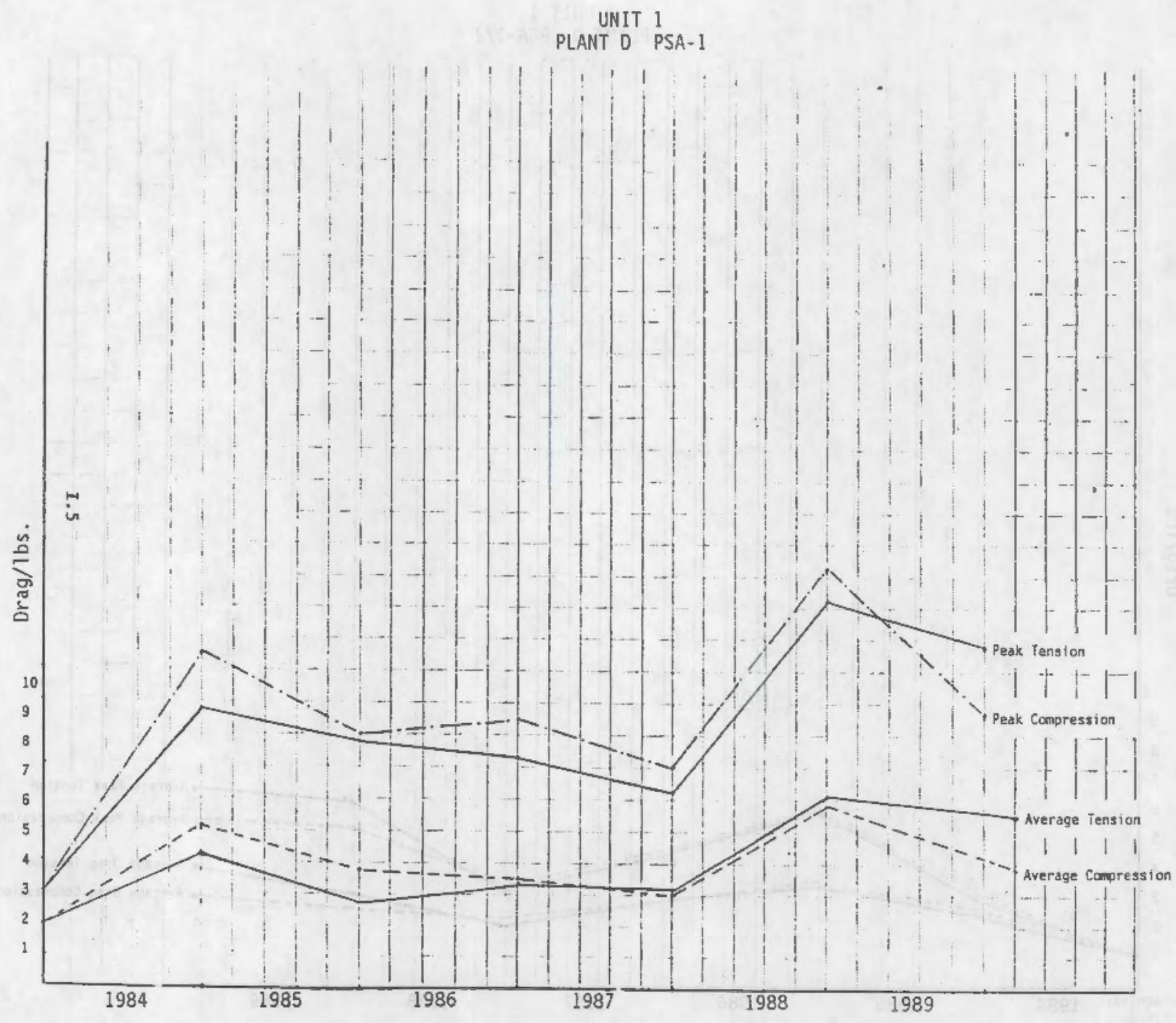

Figure E.2 PSA-1 drag force versus service time 
Table E.2 Historical drag force data for snubbers at Plant D, Unit 2 (PWR)

\begin{tabular}{|c|c|c|c|c|}
\hline & Average T & Average C & Peak T & Peak C \\
\hline \multirow[t]{9}{*}{1985} & 2.00 & 1.60 & 3.20 & 3.25 \\
\hline & 1.56 & 1.00 & 2.20 & 2.10 \\
\hline & 1.25 & 1.75 & 3.20 & 3.75 \\
\hline & 1.60 & 1.40 & 3.25 & 2.35 \\
\hline & & 2.70 & 5.40 & 5.30 \\
\hline & 1.50 & 3.00 & 3.25 & 6.50 \\
\hline & 2.25 & 2.45 & 3.25 & 3.25 \\
\hline & 1.90 & 1.80 & 3.10 & 3.00 \\
\hline & 1.80 & 1.45 & 3.25 & 2.50 \\
\hline \multirow{3}{*}{$\begin{array}{l}\text { PSA-1/2 } \\
(26)\end{array}$} & 2.70 & 1.60 & 3.75 & 2.60 \\
\hline & 2.20 & 1.75 & 3.75 & 3.25 \\
\hline & 4.85 & 1.60 & 9.30 & 2.90 \\
\hline \multirow{2}{*}{2089} & 1.68 & 1.75 & 3.20 & 3.25 \\
\hline & 1.95 & 2.85 & 3.00 & 4.20 \\
\hline \multirow{2}{*}{ sex } & 2.20 & 1.45 & 3.50 & 2.65 \\
\hline & 2.60 & 2.75 & 5.90 & 4.60 \\
\hline \multirow{3}{*}{ (66) } & 1.70 & 1.45 & 2.70 & 2.25 \\
\hline & 3.40 & 3.24 & 5.40 & 5.20 \\
\hline & 2.00 & 2.10 & 2.70 & 3.10 \\
\hline 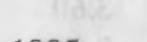 & 2.00 & 3.70 & 4.30 & 7.58 \\
\hline \multirow{6}{*}{1985} & 3.10 & 3.00 & 3.85 & 4.35 \\
\hline & 2.10 & 1.70 & 3.25 & 2.40 \\
\hline & 3.40 & 3.60 & 5.65 & 7.10 \\
\hline & 1.00 & 1.10 & 2.15 & 2.16 \\
\hline & 1.80 & 1.70 & 2.90 & 2.70 \\
\hline & 1.15 & 1.40 & 2.25 & 2.20 \\
\hline \multirow{7}{*}{-} & 2.05 & 2.07 & 3.75 & 3.6 \\
\hline & 8.20 & 9.50 & 15.00 & 26.00 \\
\hline & 7.50 & 3.00 & 17.50 & 12.50 \\
\hline & 6.00 & 4.00 & 12.50 & 10.00 \\
\hline & 3.50 & 3.75 & 10.00 & 8.75 \\
\hline & 5.00 & 5.20 & 11.00 & 11.50 \\
\hline & 5.50 & 4.50 & 11.50 & 11.25 \\
\hline PSA-1 & 3.00 & 3.75 & 7.50 & 11.00 \\
\hline \multirow[t]{8}{*}{ (15) } & 3.75 & 3.95 & 10.00 & 12.00 \\
\hline & 6.00 & 2.50 & 13.00 & 11.00 \\
\hline & 4.00 & 4.50 & 17.50 & 12.50 \\
\hline & 11.00 & 8.50 & 18.50 & 17.50 \\
\hline & 4.85 & 11.00 & 10.50 & 24.00 \\
\hline & 6.00 & 3.50 & 12.00 & 15.00 \\
\hline & 3.50 & 4.50 & 8.50 & 11.50 \\
\hline & 5.43 & 6.01 & 12.50 & 13.90 \\
\hline \multicolumn{5}{|c|}{$\begin{array}{l}\mathrm{T}=\text { tension drag force }(\mathrm{lb}) \\
\mathrm{C}=\text { compression drag force }(\mathrm{lb})\end{array}$} \\
\hline
\end{tabular}




\section{Appendix E}

Table E.2 (Continued)

\begin{tabular}{|c|c|c|c|c|}
\hline 47 & Average $\mathrm{T}$ & Average C & Peak T & Peak C \\
\hline & 1.30 & 1.30 & 2.40 & 3.00 \\
\hline \multirow[t]{7}{*}{1986} & 1.10 & 1.50 & 2.00 & 3.20 \\
\hline & 1.05 & 2.00 & 2.20 & 3.25 \\
\hline & 1.20 & 1.85 & 2.00 & 2.65 \\
\hline & 1.70 & 2.40 & 3.25 & 3.75 \\
\hline & 1.85 & 1.10 & 3.85 & 2.40 \\
\hline & 1.10 & 1.60 & 1.60 & 2.50 \\
\hline & 1.55 & 4.80 & 4.00 & 13.00 \\
\hline PSA-1/2 & 2.20 & 2.70 & 3.50 & 5.40 \\
\hline \multirow[t]{2}{*}{ (19) } & 1.00 & 1.60 & 1.75 & 3.00 \\
\hline & 1.20 & 1.65 & 2.45 & 2.75 \\
\hline & 1.10 & .90 & 2.05 & 1.55 \\
\hline 2 & 1.35 & 1.95 & 2.55 & 2.35 \\
\hline 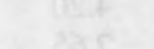 & 3.40 & 2.75 & 4.75 & 3.85 \\
\hline & 1.20 & 1.20 & 2.20 & 1.95 \\
\hline & 0.95 & 1.45 & 1.65 & 2.20 \\
\hline & 2.35 & 1.65 & 3.70 & 2.60 \\
\hline & 2.25 & 1.00 & 3.20 & 3.25 \\
\hline & 1.62 & 1.95 & 2.87 & 3.60 \\
\hline & 3.45 & 3.25 & 6.90 & 7.00 \\
\hline & 4.25 & 6.30 & 11.00 & 14.00 \\
\hline PSA-1 & 3.75 & 2.50 & 6.25 & 6.75 \\
\hline \multirow[t]{3}{*}{ (6) } & 3.40 & 4.45 & 8.25 & 9.00 \\
\hline & 3.50 & 3.60 & 7.50 & 11.25 \\
\hline & 5.10 & 3.75 & 16.0 & 15.0 \\
\hline \multirow{6}{*}{-} & 3.90 & 3.97 & 9.31 & 10.5 \\
\hline & 1.70 & 1.60 & 3.00 & 4.80 \\
\hline & 2.00 & 2.85 & 3.50 & 4.30 \\
\hline & 2.40 & 3.50 & 6.50 & 4.50 \\
\hline & 3.30 & 1.40 & 2.40 & 8.50 \\
\hline & 1.60 & 5.40 & 7.00 & 4.32 \\
\hline 1987 & 2.50 & 3.15 & 7.40 & 3.00 \\
\hline PSA-1/2 & 1.00 & 2.25 & 4.80 & 2.65 \\
\hline \multirow[t]{7}{*}{ (14) } & 1.90 & 3.25 & 2.70 & 2.4 \\
\hline & 2.40 & 3.00 & 3.00 & 4.3 \\
\hline & 3.25 & 2.20 & 4.30 & 6.4 \\
\hline & 1.60 & 4.80 & 5.40 & 2.2 \\
\hline & 4.40 & 2.15 & 3.20 & 10.0 \\
\hline & 3.00 & 2.00 & 3.60 & 4.7 \\
\hline & 3.20 & 1.55 & 2.20 & 4.2 \\
\hline \multirow{3}{*}{-} & 2.44 & 2.80 & 4.21 & 4.5 \\
\hline & 5.00 & 4.00 & 10.00 & 8.75 \\
\hline & 3.75 & 2.75 & 7.00 & 6.50 \\
\hline
\end{tabular}


Table E.2 (Continued)

\begin{tabular}{|c|c|c|c|c|}
\hline & Average T & Average $\mathrm{C}$ & Peak T & Peak C \\
\hline PSA-1 & 5.00 & 3.00 & 11.00 & 7.50 \\
\hline \multirow[t]{11}{*}{ (6) } & 2.50 & 3.00 & 6.00 & 7.50 \\
\hline & 2.50 & 3.75 & 5.10 & 8.75 \\
\hline & 3.00 & 3.70 & 8.20 & 20.0 \\
\hline & 3.62 & 3.36 & 7.88 & 9.8 \\
\hline & 2.62 & 6.07 & 6.10 & 8.69 \\
\hline & 3.07 & 4.08 & 5.58 & 7.44 \\
\hline & 1.65 & 1.66 & 2.85 & 5.70 \\
\hline & 2.92 & 2.63 & 5.44 & 6.73 \\
\hline & 5.03 & 4.26 & 7.33 & 6.94 \\
\hline & 1.73 & 3.33 & 3.08 & 6.40 \\
\hline & 3.55 & 2.05 & 5.38 & 3.63 \\
\hline 1988 & 1.43 & 3.05 & 2.96 & 5.11 \\
\hline \multirow[t]{3}{*}{ (21) } & 3.65 & 2.48 & 6.06 & 5.50 \\
\hline & 4.26 & 2.64 & 5.64 & 6.37 \\
\hline & 8.62 & 4.74 & 16.30 & 8.63 \\
\hline \multirow[t]{10}{*}{ PSA-1/2 } & 2.53 & 1.85 & 3.75 & 3.08 \\
\hline & 4.39 & 4.72 & 11.20 & 12.70 \\
\hline & 3.69 & 2.47 & 6.25 & 4.95 \\
\hline & 1.38 & 2.90 & 2.92 & 4.41 \\
\hline & 4.49 & 3.85 & 7.55 & 9.43 \\
\hline & 3.72 & 1.91 & 6.01 & 4.54 \\
\hline & 3.74 & 1.81 & 6.20 & 3.76 \\
\hline & 3.99 & 2.30 & 6.14 & 5.52 \\
\hline & 1.66 & 3.14 & 3.95 & 6.74 \\
\hline & 2.54 & 2.27 & 5.29 & 4.30 \\
\hline \multirow{6}{*}{ - } & 3.36 & 3.05 & 6.0 & 6.21 \\
\hline & 6.19 & 5.67 & 11.00 & 11.96 \\
\hline & 4.69 & 5.99 & 10.24 & 10.34 \\
\hline & 5.61 & 5.01 & 11.92 & 10.15 \\
\hline & 6.42 & 5.63 & 13.93 & 12.64 \\
\hline & 6.43 & 4.51 & 14.63 & 11.99 \\
\hline PSA-1 & 3.68 & 6.08 & 6.95 & 12.87 \\
\hline \multirow[t]{5}{*}{ (11) } & 16.68 & 9.12 & 37.13 & 21.52 \\
\hline & 11.64 & 7.90 & 22.74 & 15.68 \\
\hline & 9.76 & 10.18 & 18.59 & 18.30 \\
\hline & 6.85 & 6.18 & 15.71 & 12.00 \\
\hline & 6.49 & 8.45 & 21.29 & 23.97 \\
\hline \multirow[t]{7}{*}{ - } & 7.67 & 6.79 & 16.74 & 14.66 \\
\hline & 4.20 & 2.70 & 8.66 & 4.32 \\
\hline & 1.90 & 1.20 & 3.70 & 3.25 \\
\hline & 4.32 & 3.25 & 6.80 & 7.00 \\
\hline & 0.85 & 3.25 & 2.00 & 4.85 \\
\hline & 3.25 & 3.25 & 5.10 & 5.40 \\
\hline & 4.60 & 5.40 & 7.60 & 7.60 \\
\hline
\end{tabular}




\section{Appendix E}

Table E.2 (Continued)

\begin{tabular}{lcccc}
\hline & Average T & Average C & Peak T & Peak C \\
\hline PSA-1/2 & 1.10 & 1.10 & 2.00 & 1.60 \\
1989 & 1.70 & 1.20 & 2.20 & 1.80 \\
$(16)$ & 2.30 & 2.00 & 4.32 & 3.30 \\
& 1.20 & 1.60 & 2.25 & 3.00 \\
& 2.00 & 1.00 & 3.25 & 2.00 \\
& 2.25 & 3.10 & 4.05 & 6.10 \\
& 1.35 & 1.40 & 2.70 & 2.50 \\
& 3.10 & 3.20 & 5.40 & 4.30 \\
& 1.70 & 1.95 & 3.25 & 3.25 \\
& 1.15 & 1.65 & 2.20 & 2.30 \\
& 2.31 & 2.32 & 4.21 & 3. \\
& 2.00 & 2.25 & 7.00 & 5.10 \\
& 2.00 & 2.00 & 5.00 & 4.90 \\
PSA-1 & 5.00 & 4.50 & 11.00 & 12.00 \\
$(11)$ & 3.75 & 3.10 & 8.50 & 7.00 \\
& 5.30 & 3.90 & 18.00 & 11.00 \\
& 3.00 & 5.00 & 7.50 & 10.50 \\
& 4.45 & 3.20 & 7.00 & 7.00 \\
& 3.75 & 3.00 & 8.50 & 7.00 \\
& 3.75 & 2.50 & 8.55 & 6.20 \\
& 2.50 & 3.20 & 7.50 & 7.00 \\
& 3.75 & 5.00 & 10.50 & 9.25 \\
& 3.56 & 3.42 & 8.91 & 7.96 \\
\hline
\end{tabular}




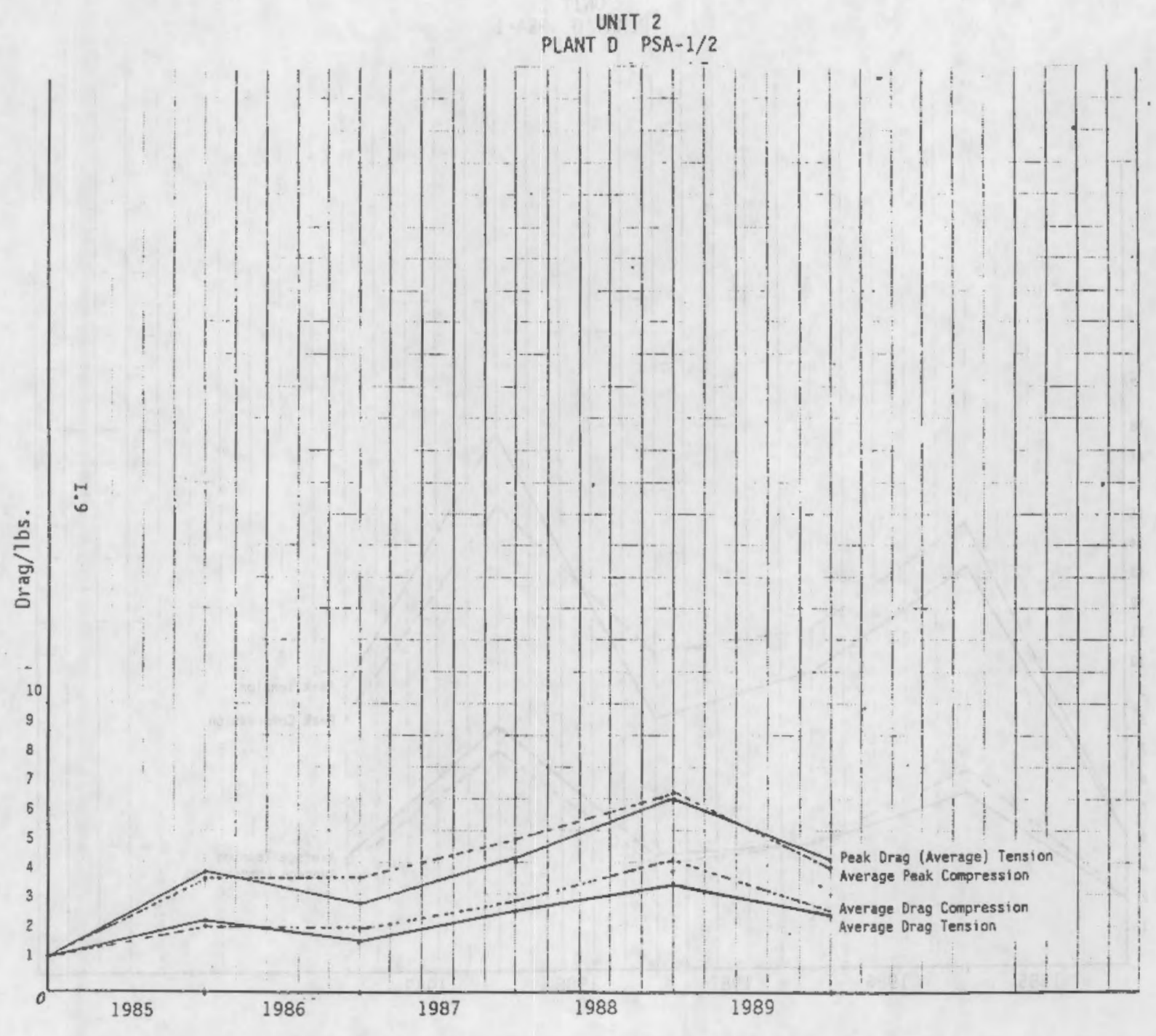

Figure E.3 PSA-1/2 drag force versus service time Unit 2, Plant D 


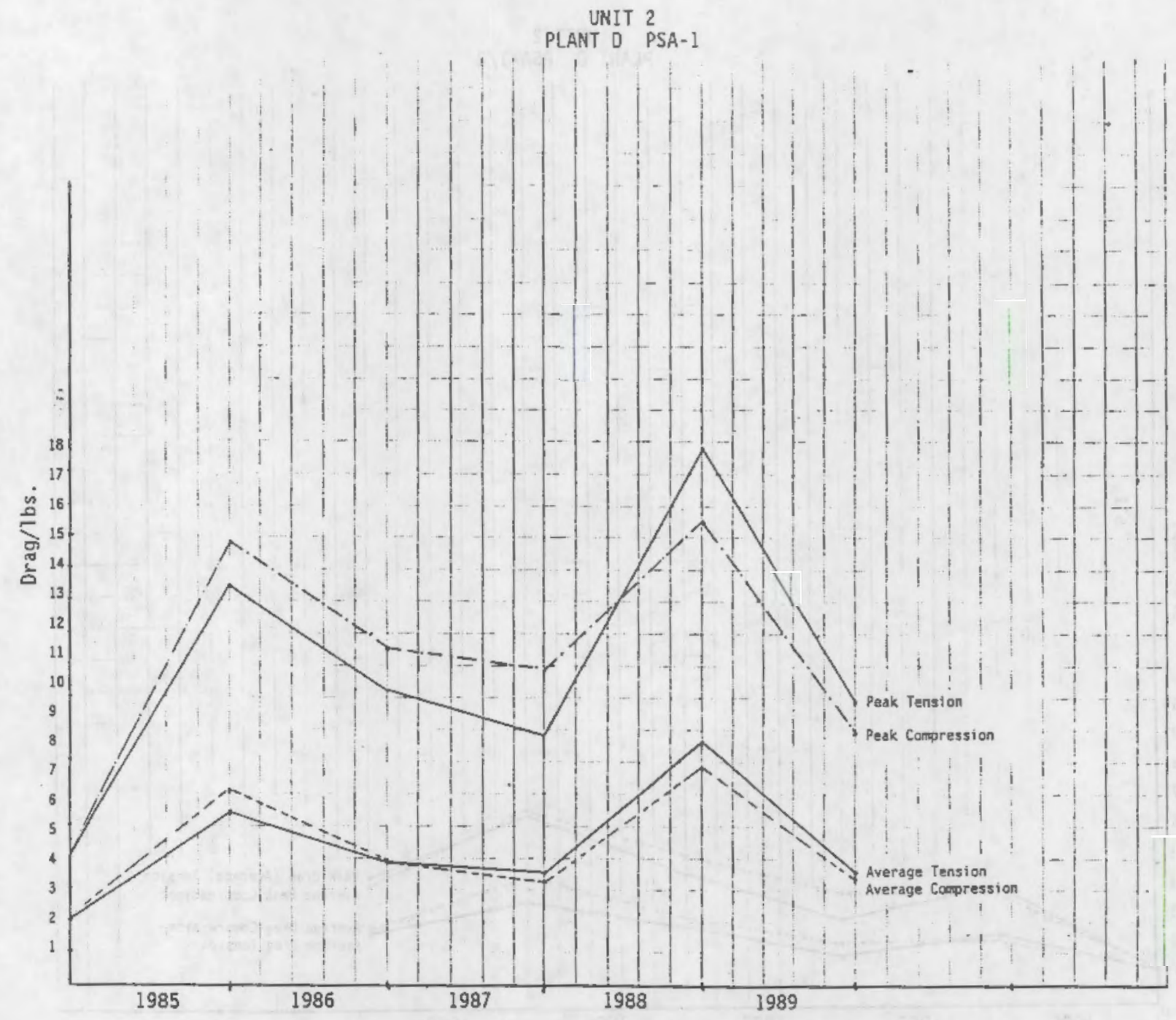

Figure E.4 PSA-1 drag force versus service time Unit 2, Plant D 
Appendix F

Evaluation of Drag Force Versus Time (Plant F) 


\section{Appendix F}

\section{Evaluation of Drag Force Versus Time (Plant F)}

This Appendix contains drag force data from site $\mathrm{F}$ for one size of mechanical snubber. The data were used in an attempt to correlate drag force with service time. All snubbers were tested using the same type of test machine. All snubbers were tested on a minimum of two separate occasions (refueling outages). Average drag force (average for all snubbers at each refueling outage) is plotted versus service time. Individual snubber drag force is also plotted versus service time for five typical snubbers, samples A through E. Some trend toward increasing drag force with service time is observed. 
Appendix $\mathrm{F}$

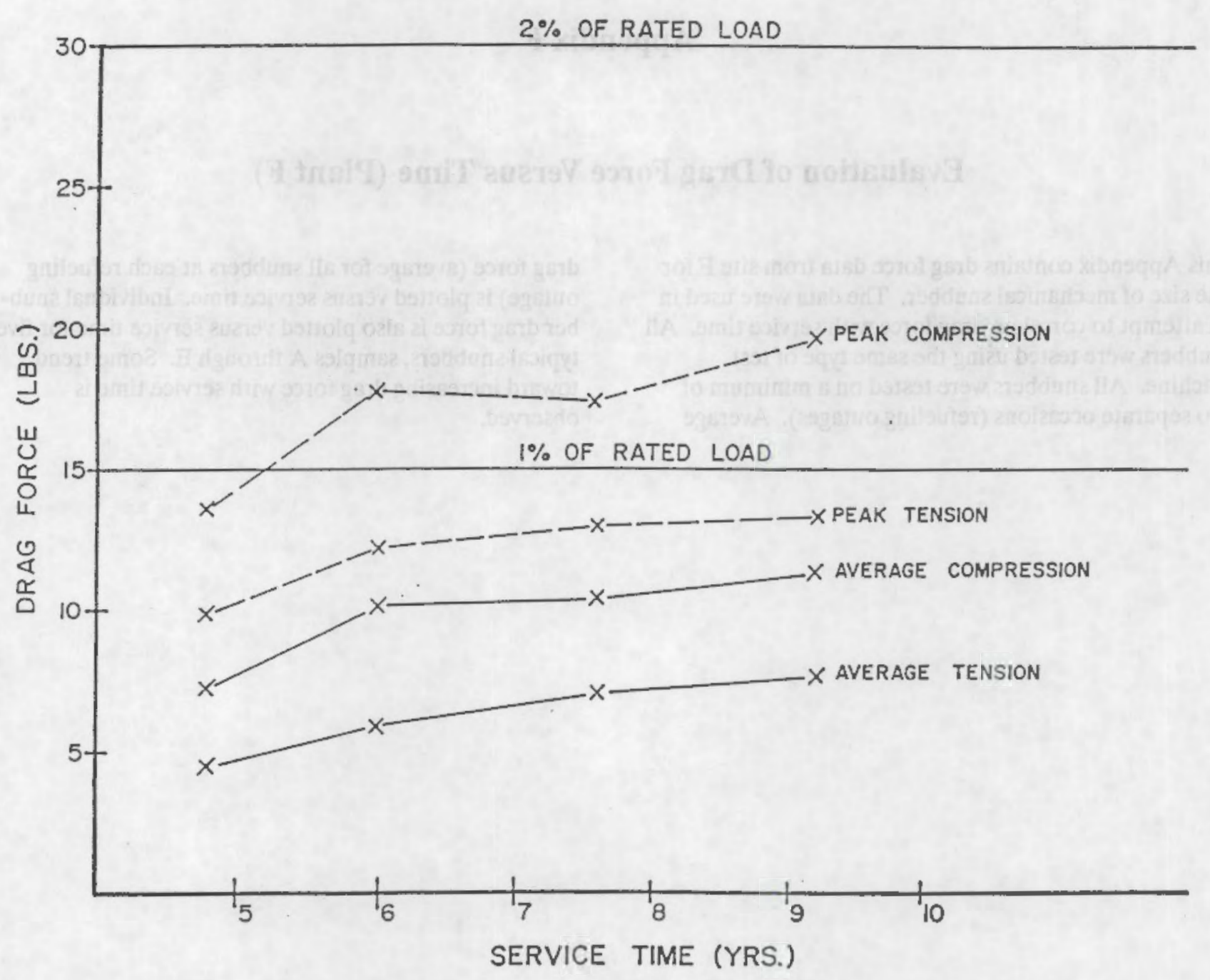

Figure F.1 Drag force vs. service time, Plant F average of all samples 
Appendix F

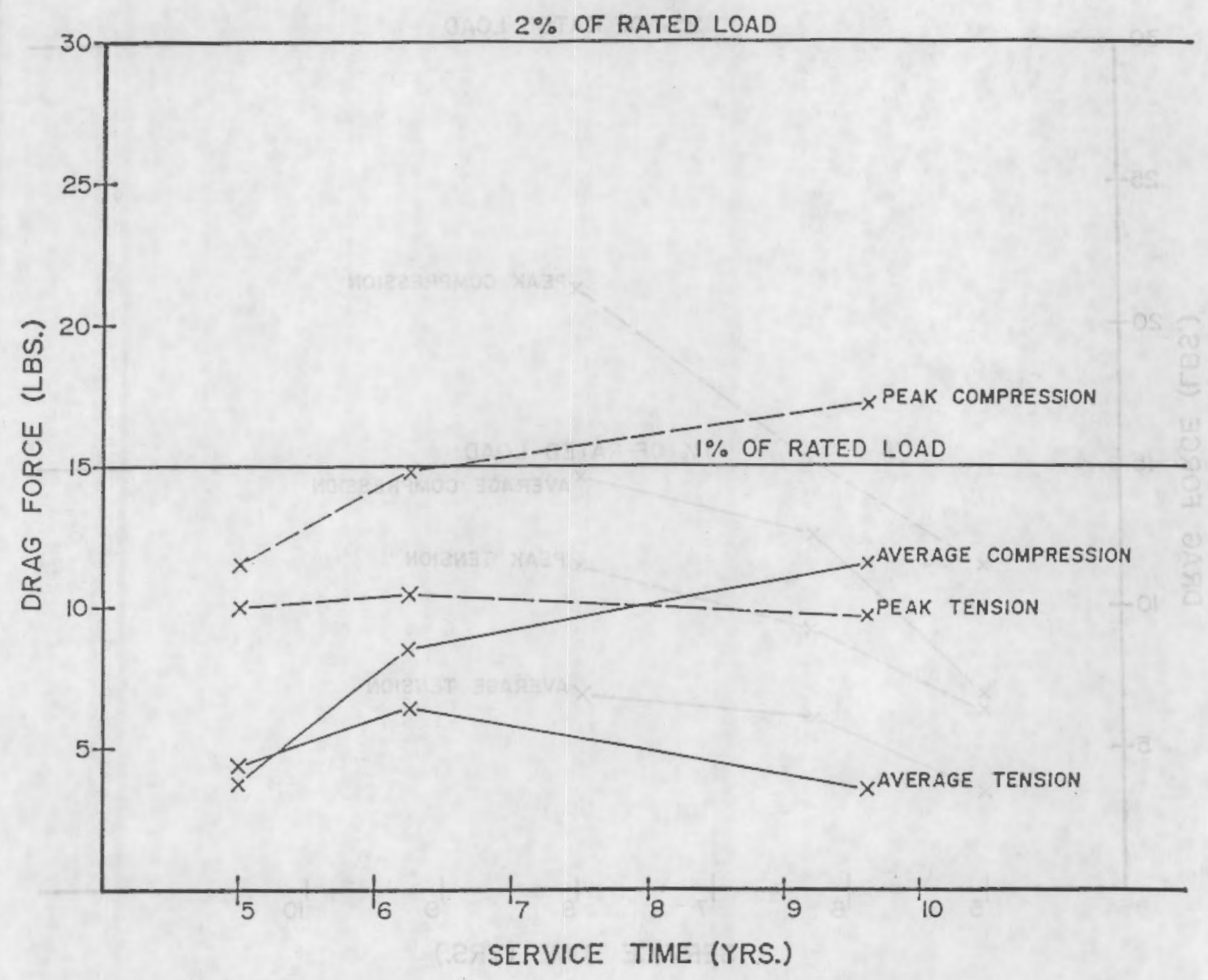

Figure F.2 Drag force vs. service time, Plant F sample A (\# 188) 


\section{Appendix F}

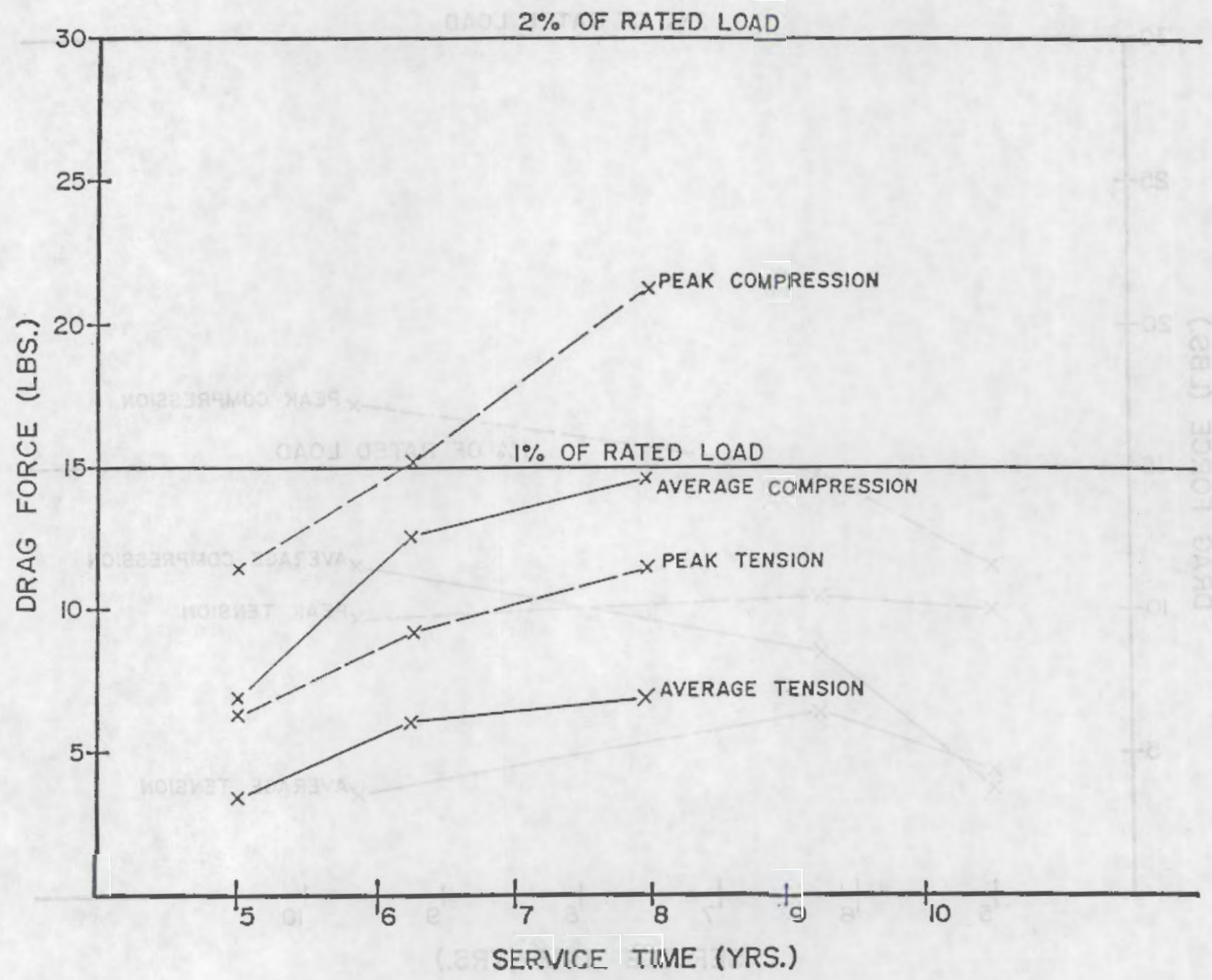

Figure F.3 Drag force vs. service time, Plant F sample B (\# 96) 


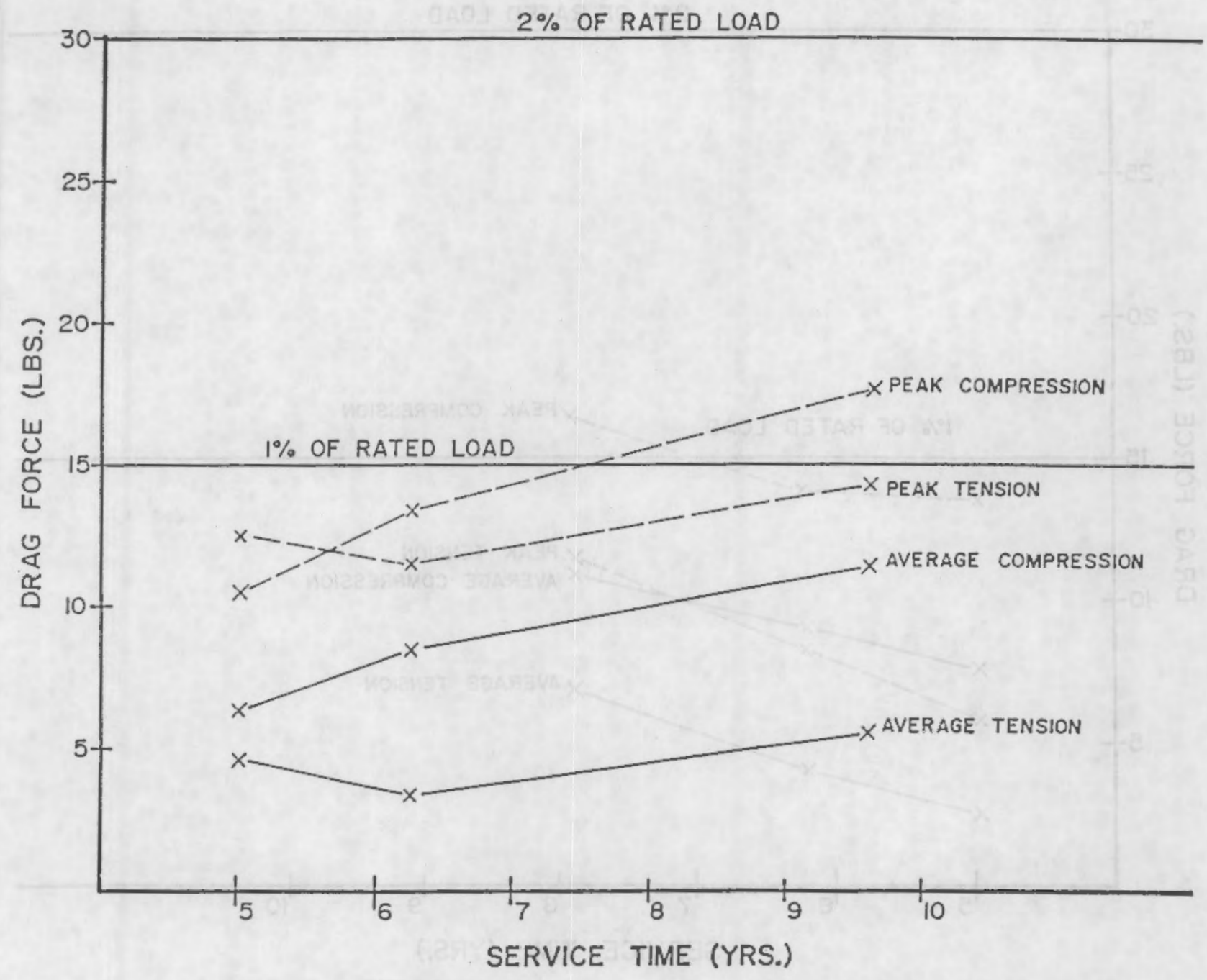

Figure F.4 Drag force vs. service time, Plent F sample C (\# 62) 
Appendix F

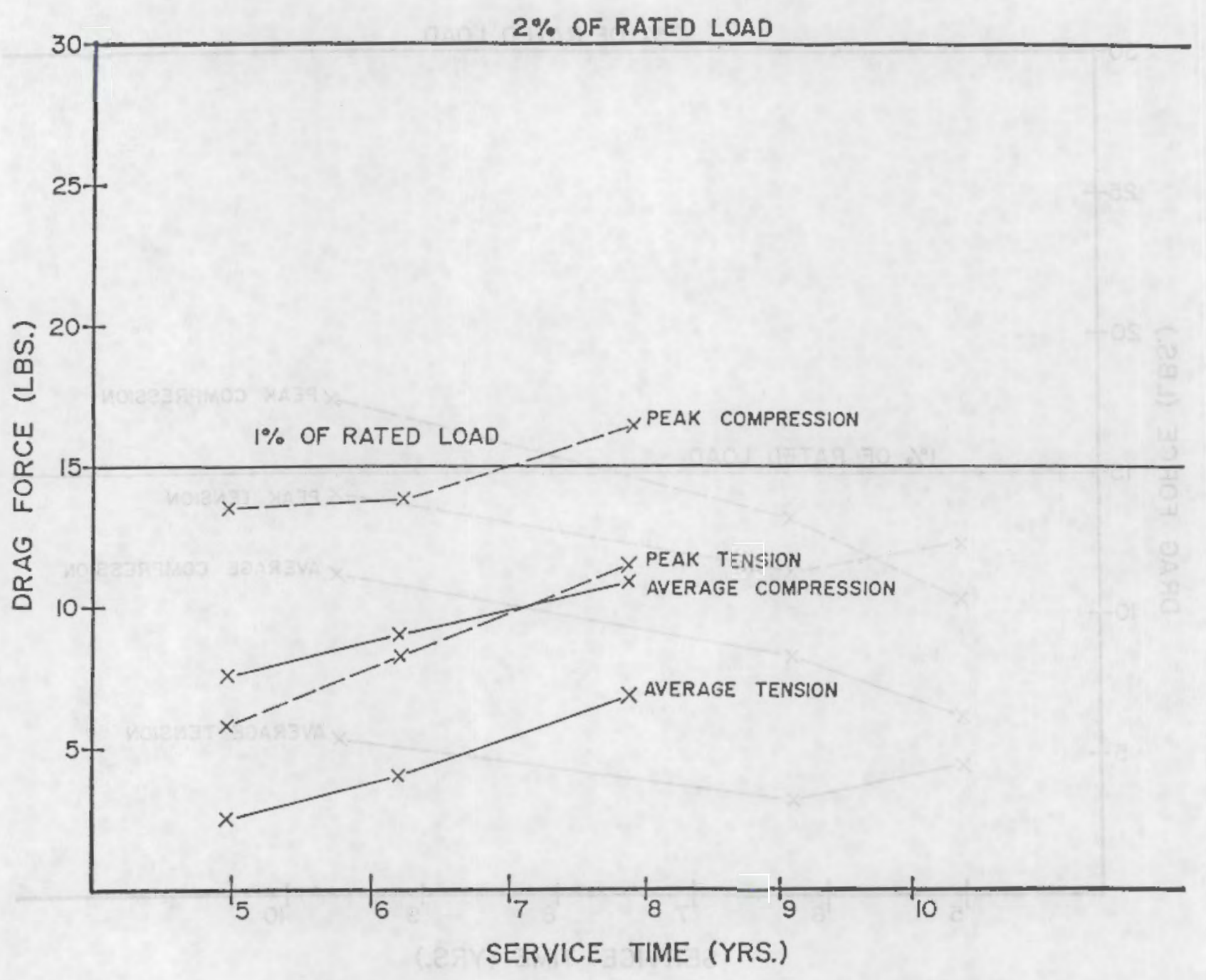

Figure F.5 Drag force vs. service time, Plant F sample D (\# 13) 


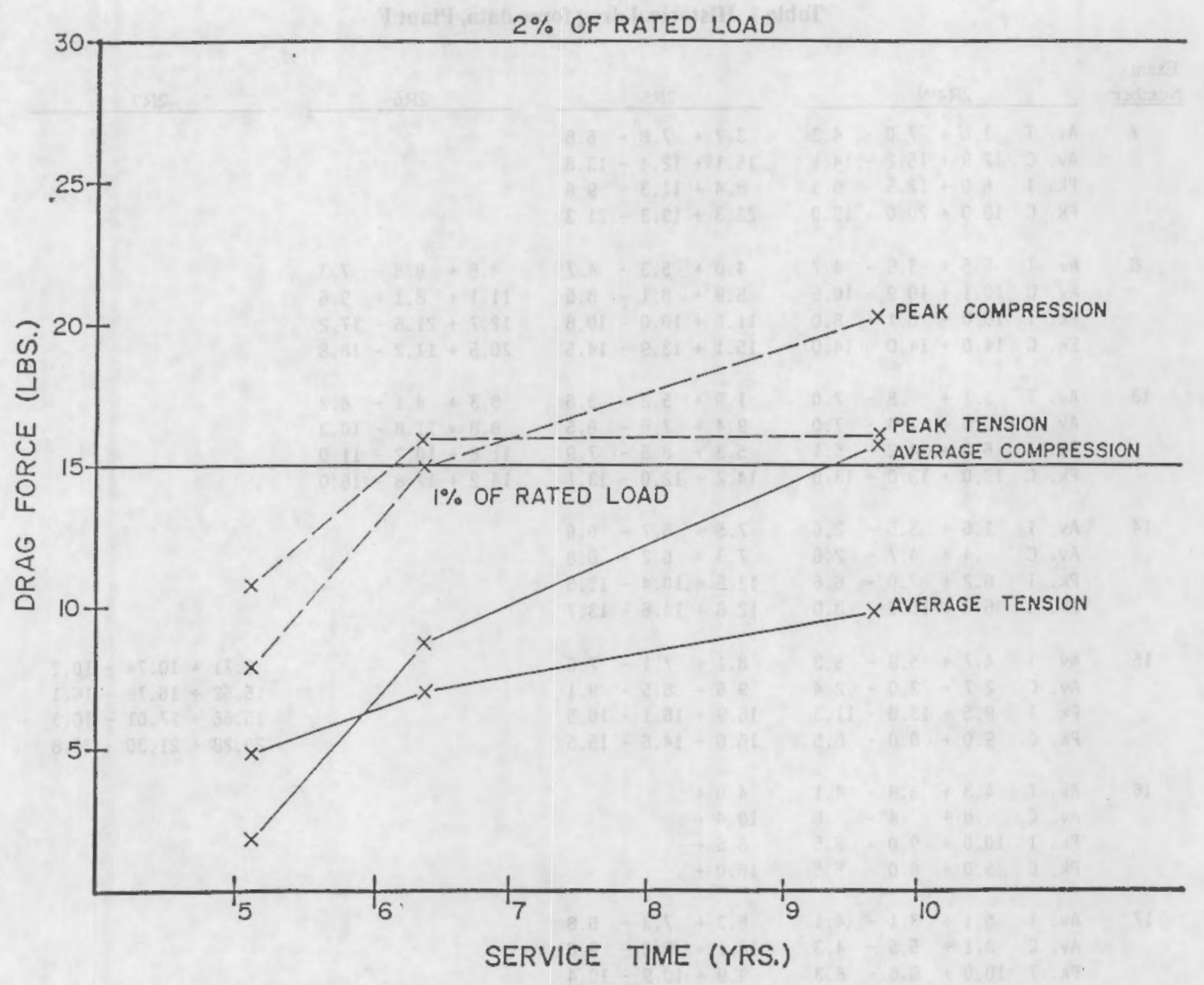

Figure F.6 Drag force vs. service time, Plant F sample E (\# 15) 
Appendix F

Table 1 Historical drag force data, Plant $F$

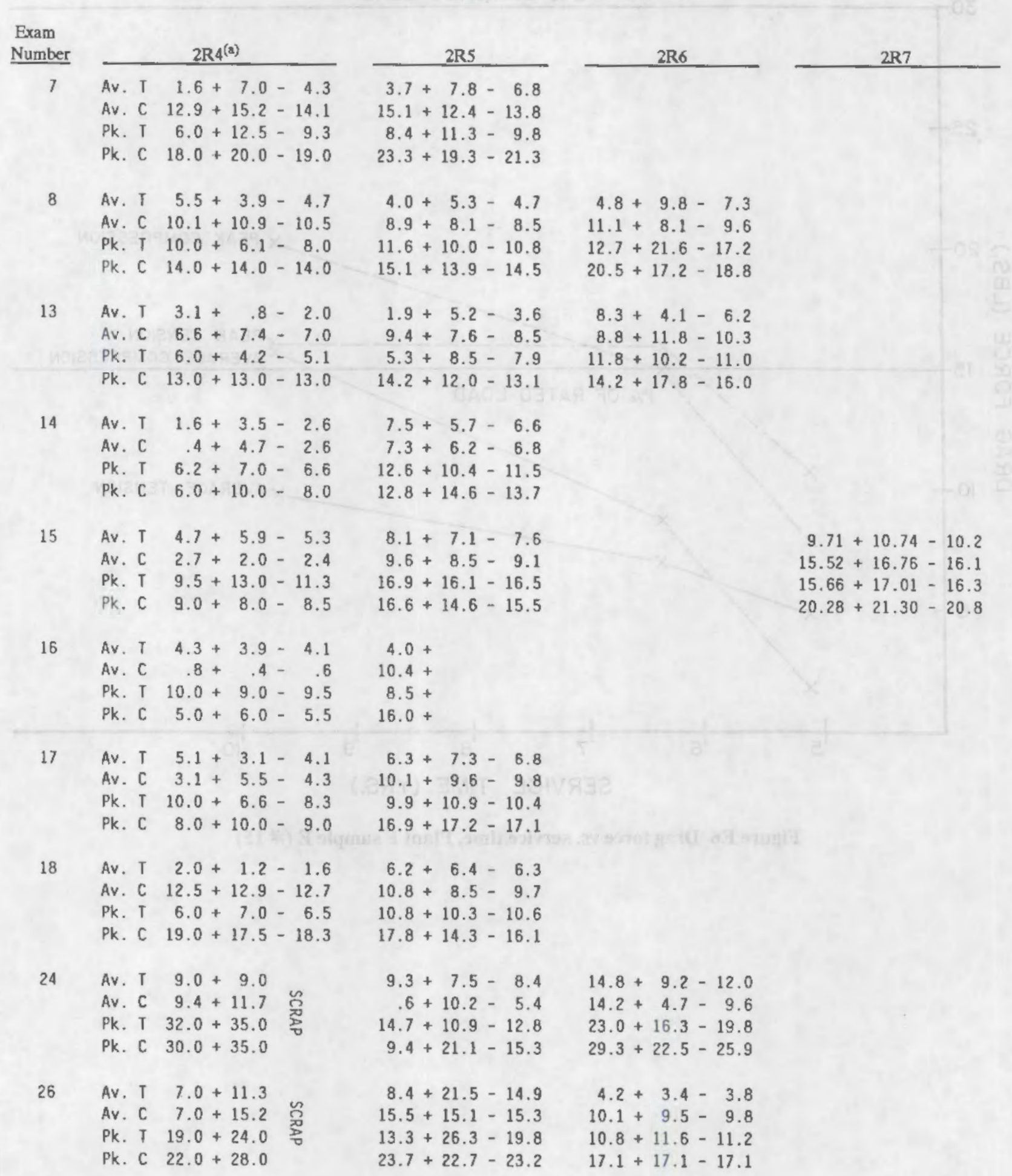

(a) 2 = unit 2 (PWR), $\mathrm{R}=$ refueling outage number, $\mathrm{T}=$ tension drag force (lbs.), $\mathrm{C}=$ compression drag force (Ibs.) 
Table 1 (Continued)

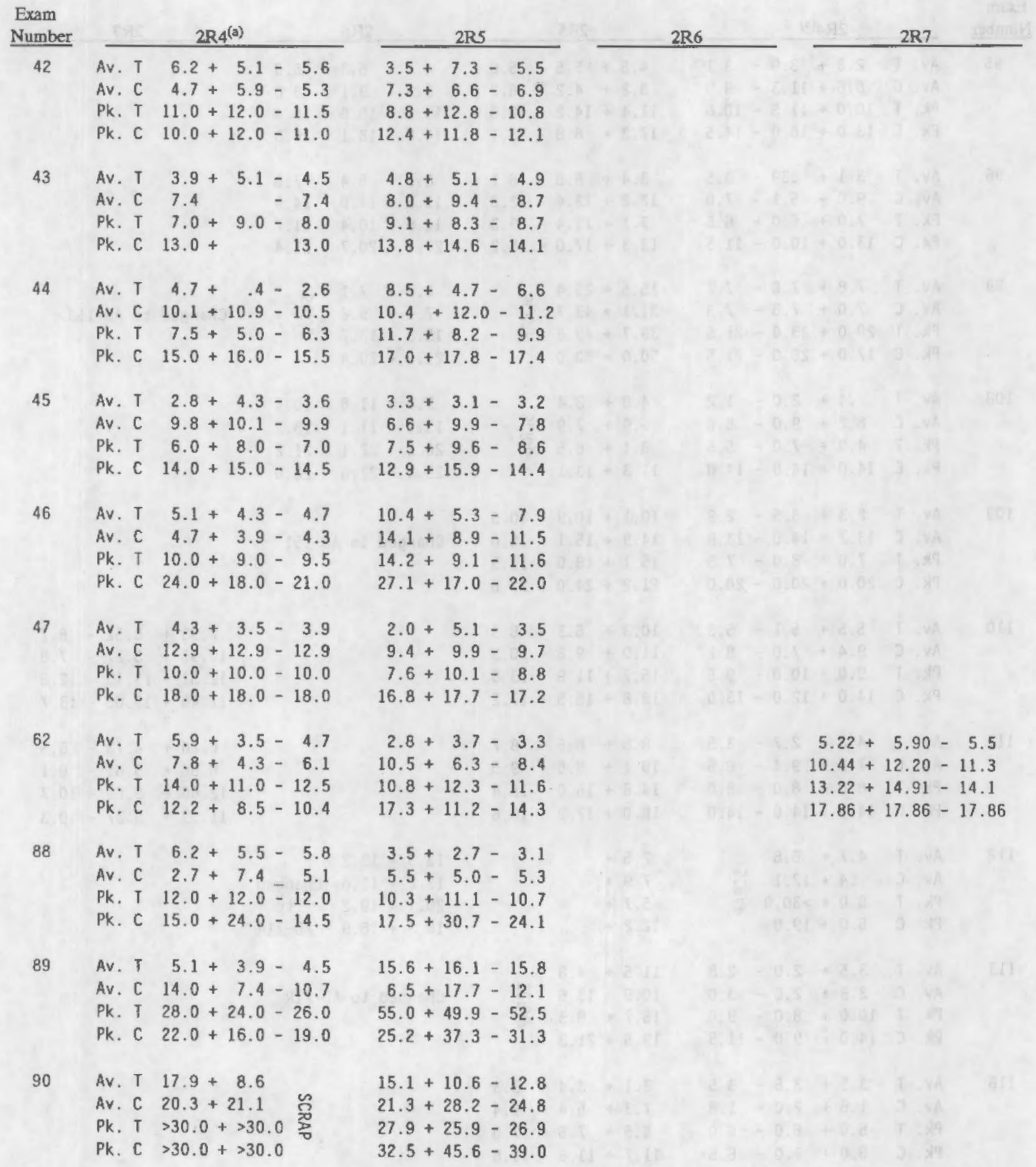

(a) 2 = unit 2 (PWR), $R=$ refueling outage number, $\mathrm{T}=$ tension drag force (lbs.), $\mathrm{C}=$ compression drag force (lbs.) 
Table 1 (Continued)

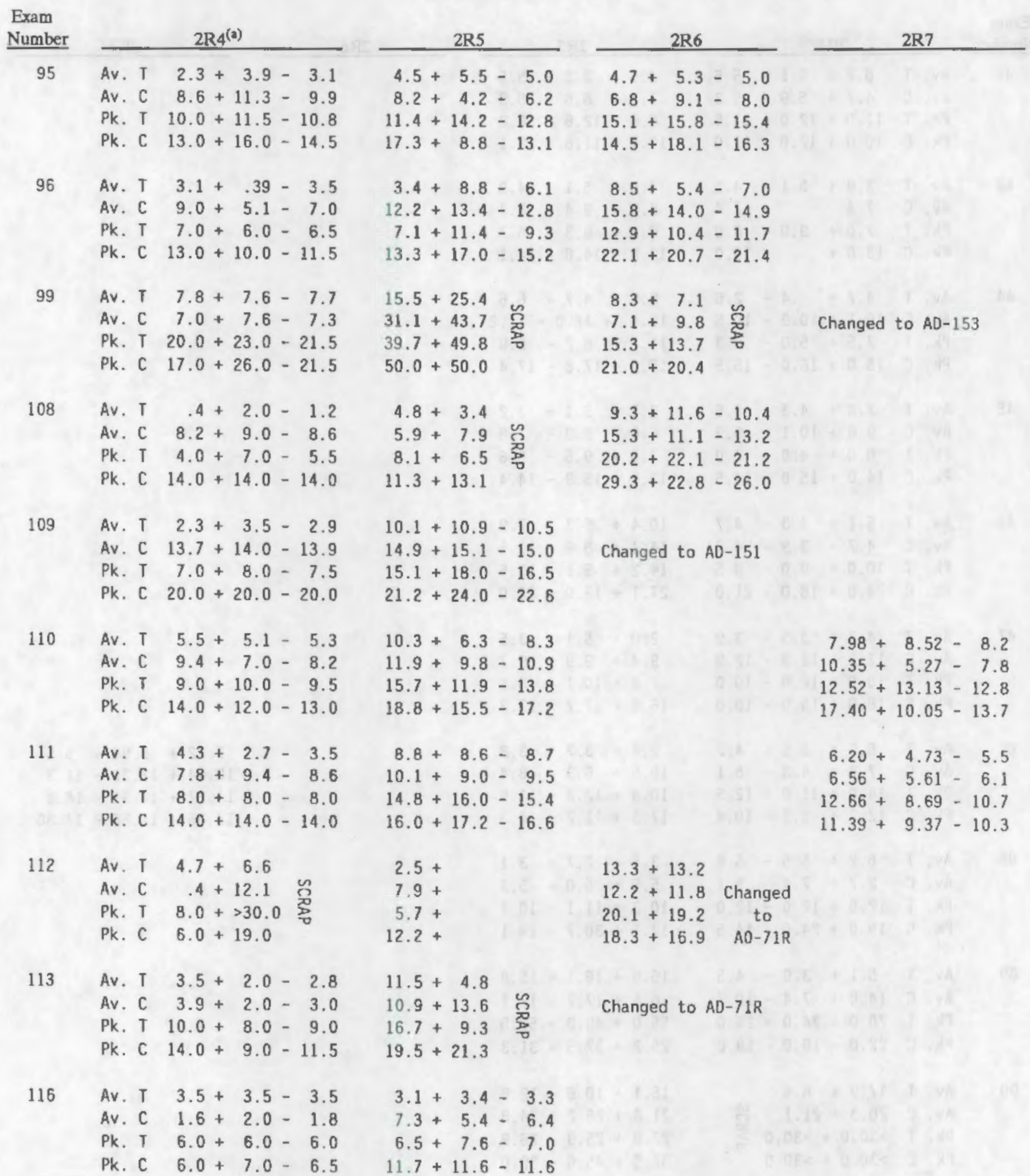

(a) 2 = unit 2 (PWR), $\mathrm{R}=$ refueling outage number, $\mathrm{T}=$ tension drag force (lbs.), $\mathrm{C}=$ compression drag force (lbs.) 


\section{Table 1 (Continued)}

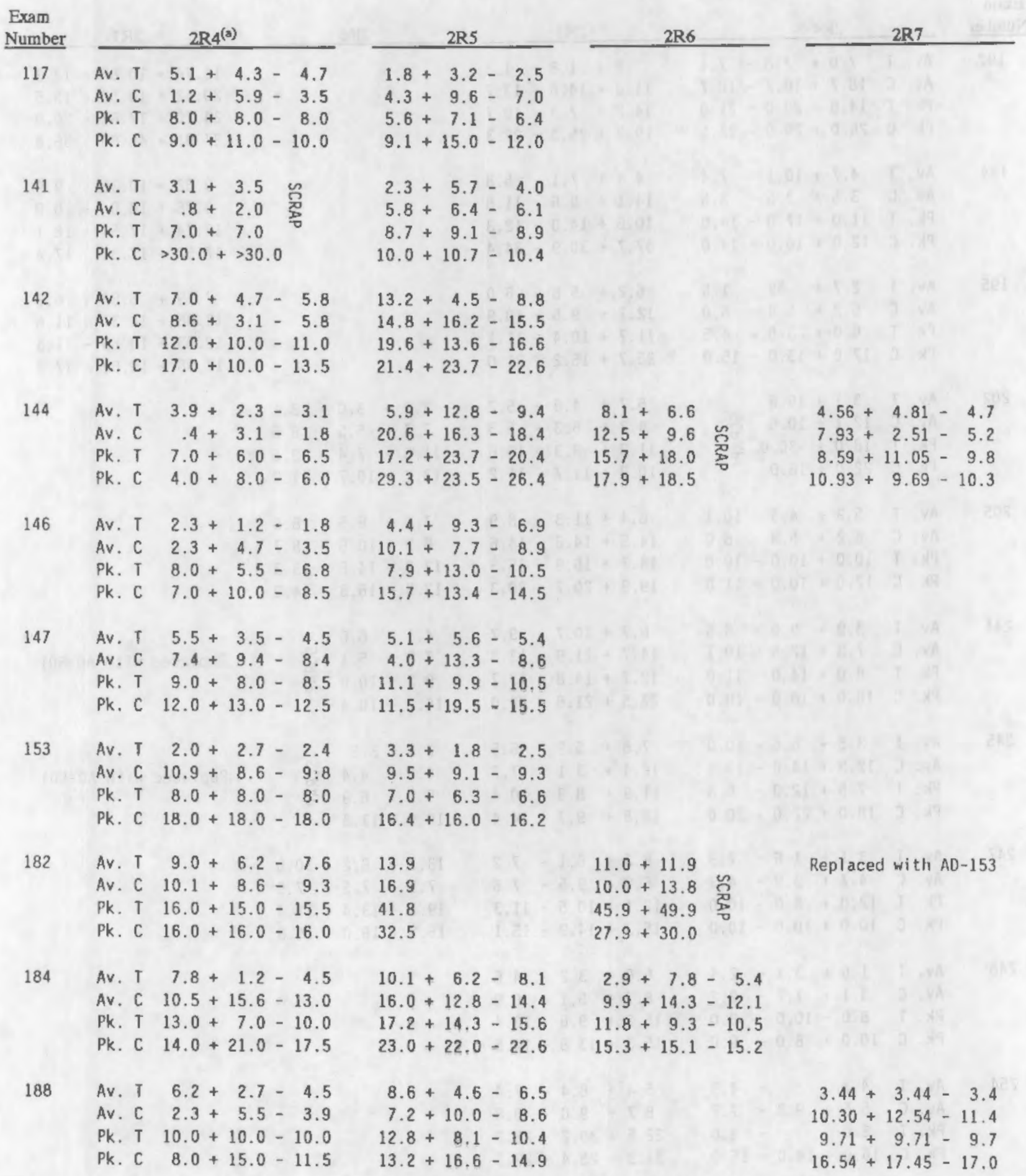

(a) $2=$ unit 2 (PWR), $\mathrm{R}=$ refueling outage number, $\mathrm{T}=$ tension drag force (lbs.), $\mathrm{C}=$ compression drag force (lbs.) 
Table 1 (Continued)

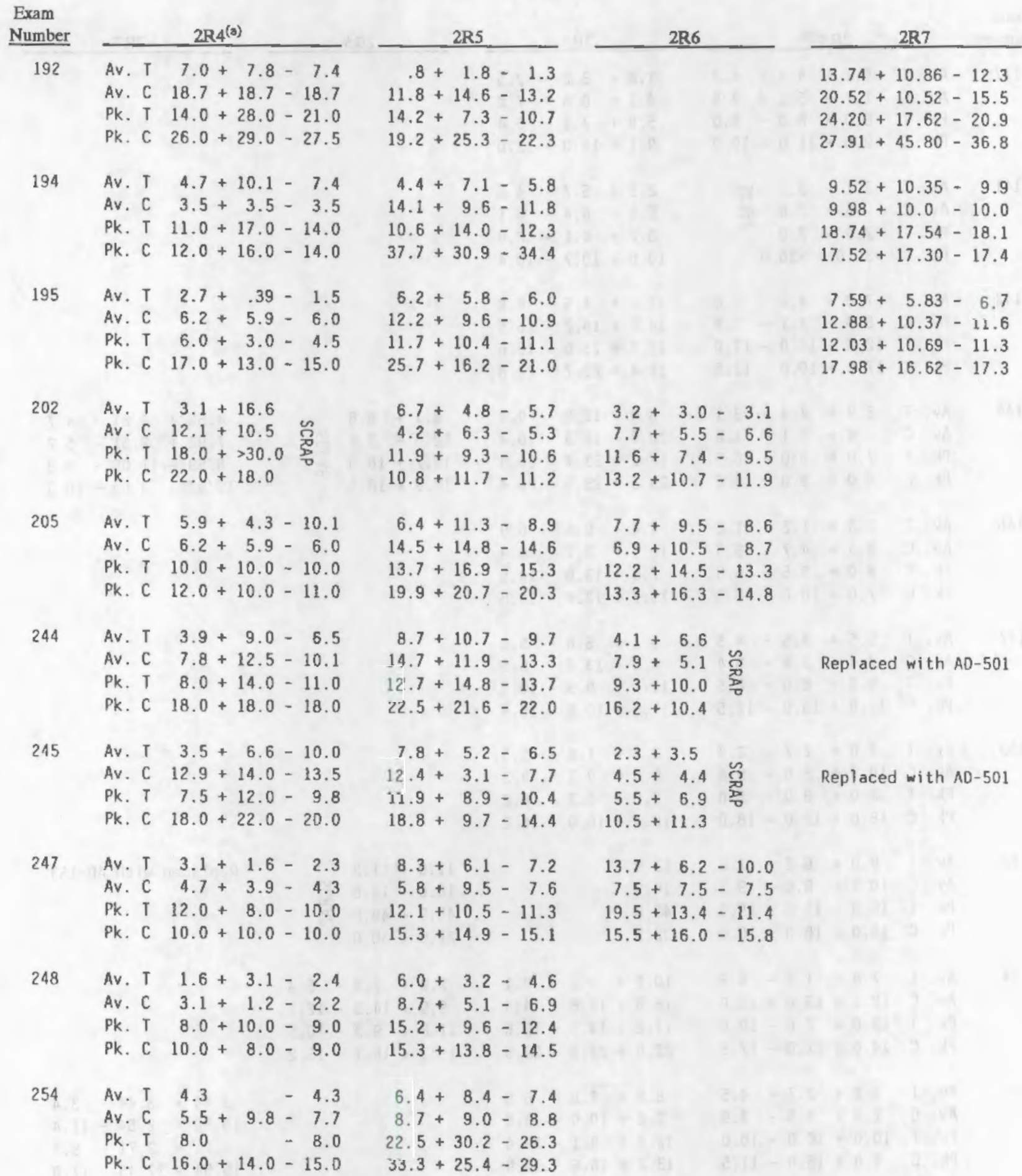

(a) 2 = unit 2 (PWR), $\mathrm{R}=$ refueling outage number, $\mathrm{T}=$ tension drag force (lbs.), $\mathrm{C}=$ compression drag force (lbs.) 


\section{Table 1 (Continued)}

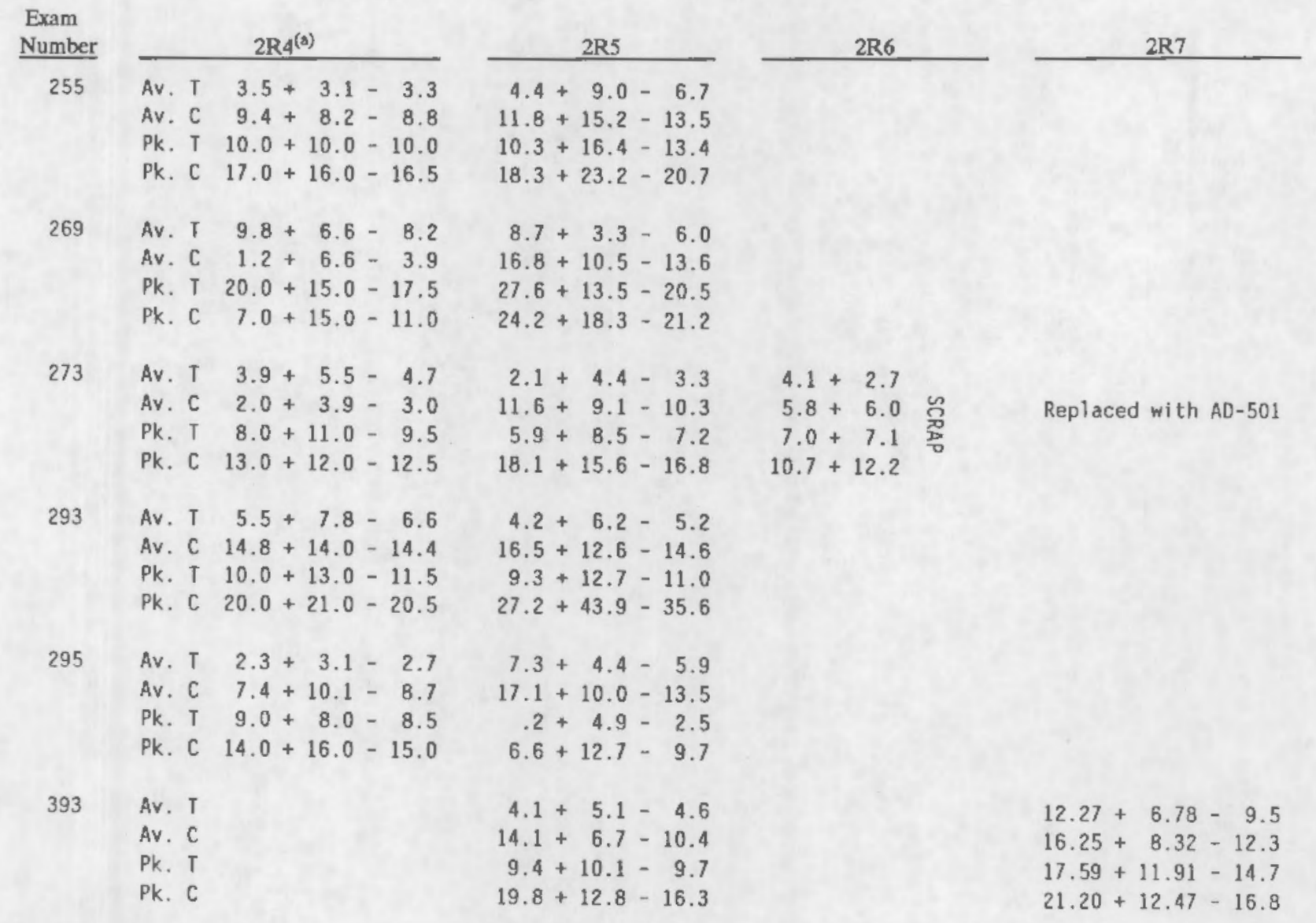

(a) $2=$ unit 2 (PWR), $\mathrm{R}=$ refueling outage number, $\mathrm{T}=$ tension drag force (lbs.), $\mathrm{C}=$ compression drag force (lbs.) 


\section{Appendix G}

Typical Mechanical Snubber Failure Causes (Plant C) 


\section{Appendix G}

\section{Typical Mechanical Snubber Failure Causes (Plant C)}

This Appendix contains a list of mechanical snubber failure causes documented by plant personnel at Plant C. Failure causes are categorized in accordance with the following functional test failure categories:
- high drag force

- exceeded maximum acceleration limit

- below minimum acceleration limit. 


\section{Appendix G}

TYPICAL MECHANICAL SNUBBER FAILURE CAUSES

Page 1

\section{PLANT C}

\section{HIGH DRAG FORCE}

- Lubricant dried out internally. Unft exposed to radiant heat from reactor recirculacling pump.

- Significant corrosion of torque drum and Capstan Spring. Torque carrler screw shaft bend caused when Unit tried to stroke under thermal expansion.

- Held slag spattered on Indlcating tube caused blading during stroke.

- Guide rods and bearing assembly bent. Unit 1mproperly twisted with wrench to align pad eyes during installation.

- Capstan Spring ears outside of cluteh window. Unit 1mproperly pulled apart while dust cover snap ring was loosened to align Unit pad eye during installation.

- Internally corroded. Installed In noranlly dry area of primary containment. May have been Improperly stored during Initial plant construction.

- Repetitive vibratory loads on Unit caused balls in thrust bearing to cut groove in its races.

- Capstan Spring wound too tight by manufacturer. Rubbed on Unit cylinder during normal stroke instead of spinning freely caused breaking action of Unit.

- Unft mounted vertically and housing became fllled with water. Internals severely corroded. Poor protection during maintenance activities in the area.

- Telescoping members binding due to high side load of unit.

- Rough spots on planetary gears and shaft of unit due to poor handing of large snubber.

Bearing retainer nut became loose which occured due to handilng or was loose at fabrication.

- Fouling of snubber internals with dirt and metal fillng causing binding. Screw shaft sheared in two places. Unit overloaded due to system translent.

- Poor machining of inner and outer telescoplng members at factory. Pleces not concentric, causing a rub on one side. 


\title{
PIANT C
}

\author{
HIGH DRAG FORCE (Cont'd)
}

- Slight bend in screw shaft near inertia areas. Inertia mass rubbing inside of dust cover.

- Dirt and dust on screw shaft thereby restricting movement.

- Adhesive on Indlcating tube causing binding of telescoping member. (Adhesive was left from tape used to cover unft whth plastic during plant construction).

- Damaged inner race of thrust bearlng (cracked in several places) due to transient overload forces.

\section{EXCEEDED MAXIMUM ACCELERATION LIMIT}

- Spring not wound tightly eaough at factory. Would not tighten against cylinder at required acceleration.

- Capstan Spring not properly installed. Spring ears outside eluteh window, unit could not activate.

- Smal1 retaining parts of snubber internals were loose, Capstan Spring worn when untt was rattled durlng service checks.

- Improper assembly of Internals did not allow Capstan Spring to tighten fully to activate Unit.

- Manufacturer's defect. Keeper rlag not installed properly.

- Snubber ws damaged during handling. Stroked too hard causing it to lock.

- Dirt between Inertla mass and lead screw caused mass to sllp during activation.

- Capstan Spring not properly placed in unit at factory. Spring ears outside clutch whdow so unit could not activate. high acceleration. 


\section{Appendix $\mathrm{G}$}

TYRICAL MECHANICAL SNUBBER FAILURE CAUSES

Page 3

PLANT C

\section{BELOW MINIMUM ACCELERATION LIMIT}

- Capstan Spring Installed crooked at factory. Bound up on dust cover during cyc11ng.

- Dirt and grit was caked on seat area of Capstan Spring, causing it to activate too 10 .

- Saubber Inner thrust bearlng race chipped, torque drum retalner bent. Subjected to frequent transients within design $11 \mathrm{mits.}$

- Excessive grease placed in inertia mass area at factory causing slippage of 1nterdal parts during activation test.

- Severe corrosion of Capstan and clutch spring area. Onft was leaked upon by damaged pump seal. 


\section{Appendix H}

\section{Typical Mecbanical Snubber Examination Record}




\section{Appendix H}

\section{Typical Mechanical Snubber Examination Record}

This Appendix Contains a typical mechanical snubber examination record. This record was not obtained from one of the key study plants. 


\section{Appendix $\mathrm{H}$}

Snubber Examination Record

\begin{tabular}{|c|c|c|}
\hline Eson Kunder....: 89 & Orientation to Pide : 90 & [SO Nuaber $\ldots .:$ : $1-P-A B-27]$ \\
\hline Hanger Huaber . . . : & High Vibration?.. : N & Systes ...... : 18 \\
\hline Coroanent: Nusber. . : . & Service Teaperatur: : 135 & LOOD........ \\
\hline Serial Nusber . . : 36291 & Hunidity. . . . : ORY & Line Number. . : : I-AB-1CCA-1038 \\
\hline \$ize. . . . . . : p\$ 1/6 & Raciation Condition : 5 & N-5 Nunber . . . : B88111 \\
\hline Rated Lood. . . : 350 & Actessibility code. : 9 & Scoffold Reauired? . : N \\
\hline Desisn Troe....: MSHL & Building/Roon . . : 1220 & Safety Class ... : : $A-0$ \\
\hline Punctional Tyoe . . : ni & Elevation ...: 113 & Nuclear Class. . . : \\
\hline Dote Sesls Reoloced: 11 & Oryuell Zone.... : 10 & Hot Piston Set...: $29 / 16$ \\
\hline Date New Sesis Due. : $1 /$ & Grio Row. . . . : 1'N 18 & Cold Piston Set. . : $17 / 16$ \\
\hline Date Installed. . : $02 / 26 / 88$ & Grid Column ....: 5 ' $\mathrm{R}$ & Noverent. .... : $+11 / 8$ \\
\hline Vertical Orientation: 90 & Orauing Nusber. . . : & Last fi Dote... : 09/22/89 \\
\hline location Deseriotion: & & Last FT Result . . . : P \\
\hline
\end{tabular}

Perforn Visual Esan? Y Date Perforaed: 09/20/99 Result: S Exainer:

Work order/non I: Date Initiated: I I Date Resolved: I I failure Code: Describtion: Resolution:

Acceotance Cade: Date Re-Examined: 10/11/89 Result: S Exaniner:

runctional Test Code: $f$ Date Perforned: 09/22/89 Result: P Erainer: Date As-Left Test Perforaed: / / Result: Exaniner:

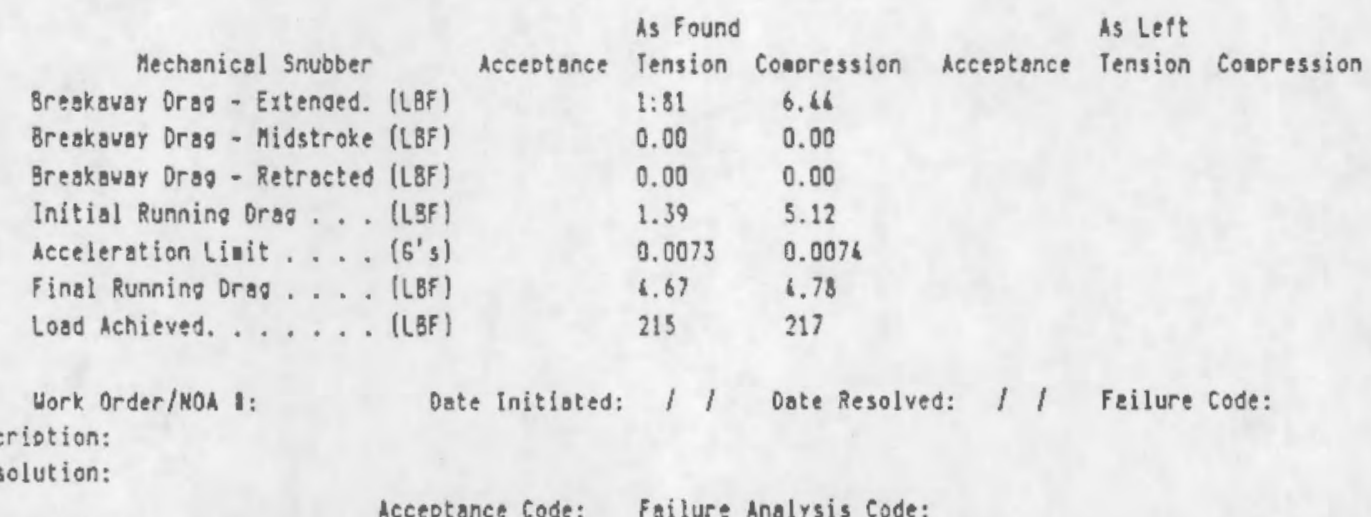

Snubber Replacenent Code: inconino Snubber fron Soares? N

Reolocesent Exas Hunber: 0 Cosoonent Nunber: Seria

Date Installed: $/ /$ Disposition of Resoved Snubber:

Size:

Work Package Revieved and Acceoted: $Y$ Reviever: 
Appendix I

Sample Mechanical Snubber Failure Evaluation Report 


\section{Appendix I}

\section{Sample Mechanical Snubber Failure Evaluation Report}

This Appendix contains a failure evaluation report that reflects comprehensive evaluation of a mechanical snubber that was found to be frozen in service. The report reflects the methods used to identify and verify the problem and to determine the cause of failure.
This Appendix also includes a failure evaluation report associated with failure of two mechanical snubbers due to overload in the compression direction. 
Appendix I

STNOPSIS OF EVENTS

The following is a brief recount of the events surrounding the failure of high temperature snubber serial No.

Der the requirements of Technical specification a VT-3 examination was performed on support no. on $10 / 18 / 86$. The exam, sited

two conditions: the insulation for the reactor vessel head appeared to be binding the snubber extension tube, and paint on the lower ball bushing was hindering free rotation in the cone of action. Condition Report (CR) was written to evaluate these findings.

While reviewing the CR. Design Engineering found the field setting to be over $11 / 2$ " off the design setting. MR. was generated to address this additional concern. At this time the operability of the snubber was not believed to have been compromised, and on 10/28/86 Maintenance Work Order (MWO) was written to correct the conditions noted in the field.

On 11/04/86, MR. was work released to changs the snubber setting in the field. $C R$ was written on $1 i / 05 / 86$ as a means of documenting the events prior to the discovery of the incorrect field setting.

On 11/06/86. Design Engineering was informed that the line to which the suject snubber was attached shifted over $11 / 2$ when the clamo was removed. This was the first indication that the snubber was damaged. FCN 1 to MR was then ger: later cancelled as not reauired), and FCN 2 was generated to reolace the failed snubber with one already installed just a few feet away.

was brought to the site on $11 / 09 / 86$ to perform the snubber failure analysis. The cause of failure was determined to be from foreign matter iodged in the screw sho-t, assembly. 
ILIUSTRATIONS

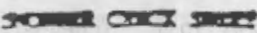

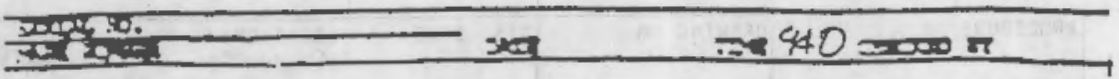

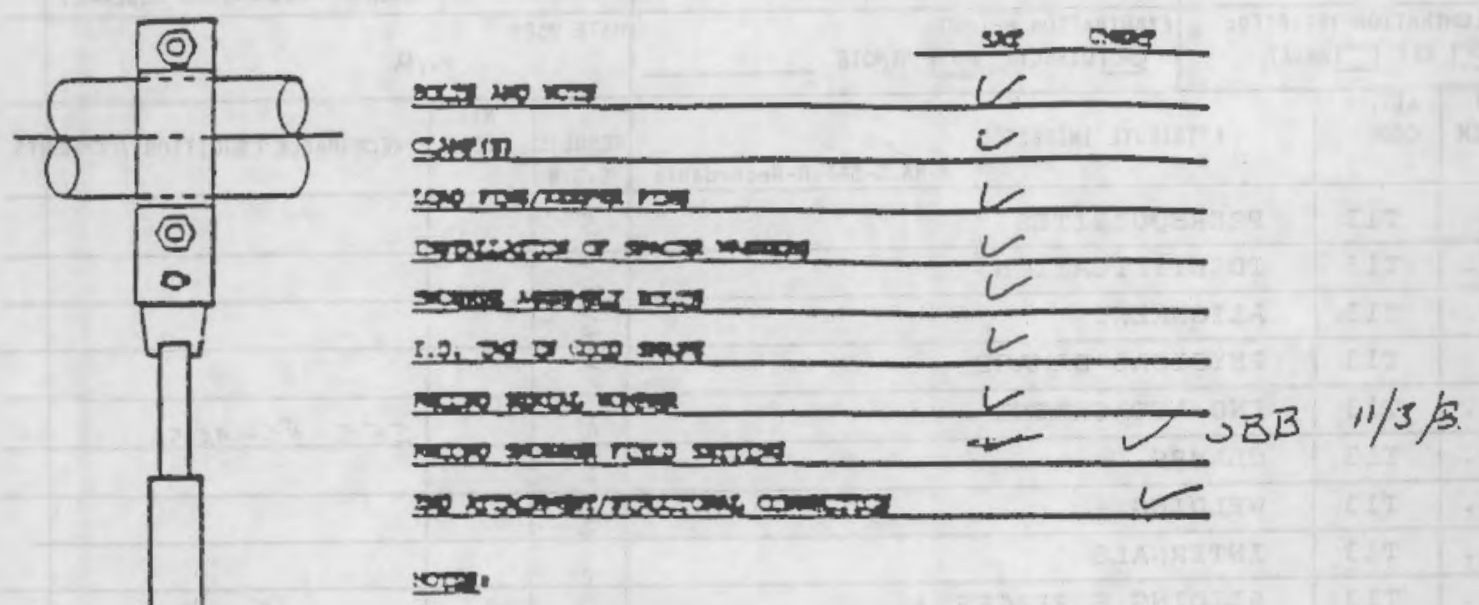

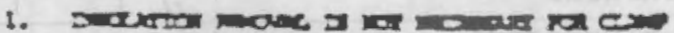

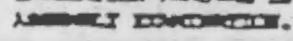

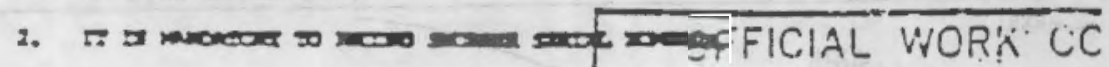
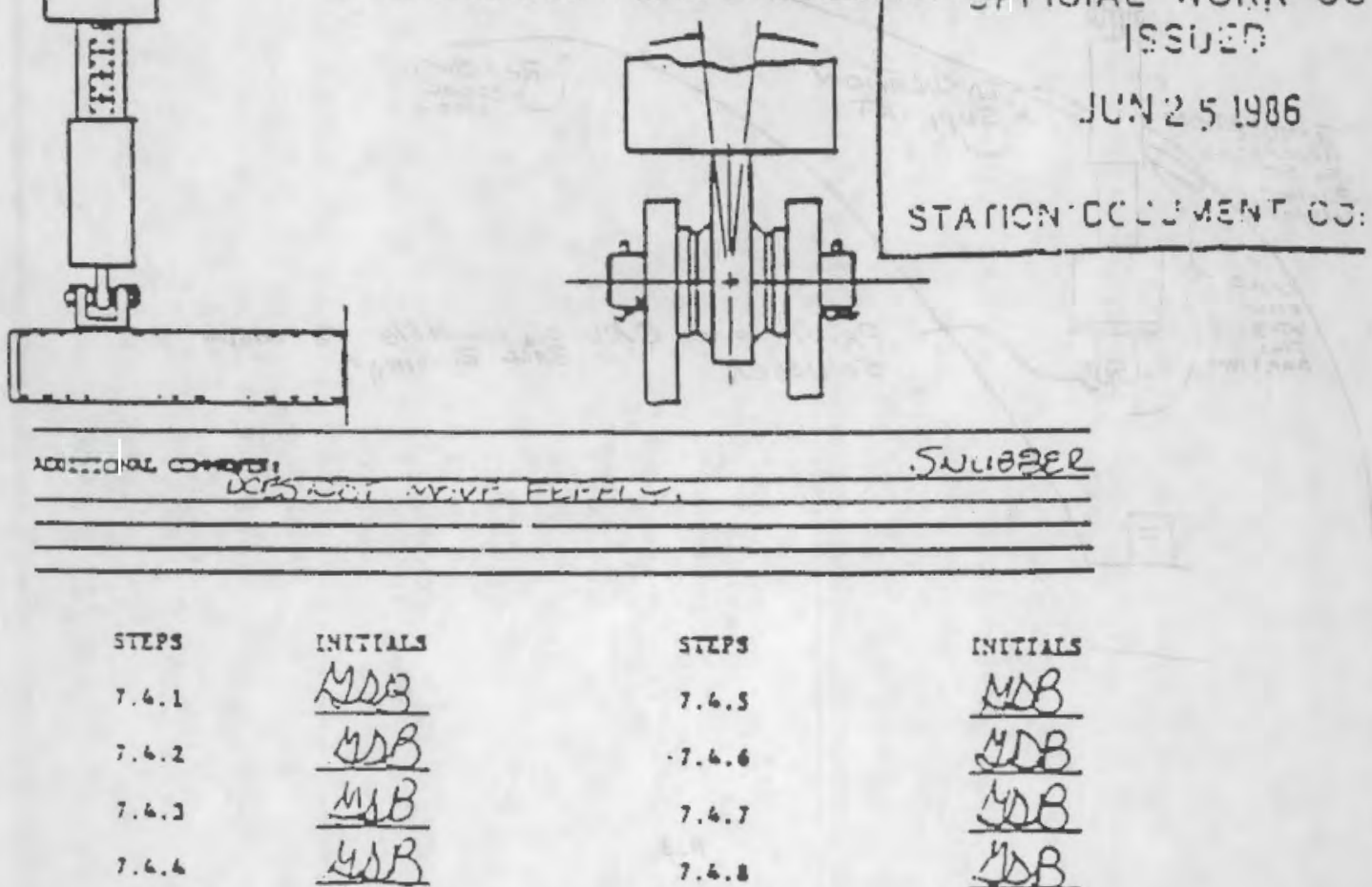

SNuazer

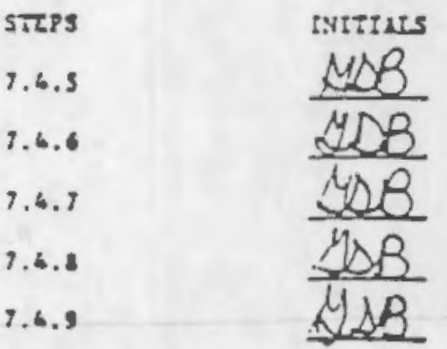


VISUAL INSPECTION VT-3 INSPECTION REPORT

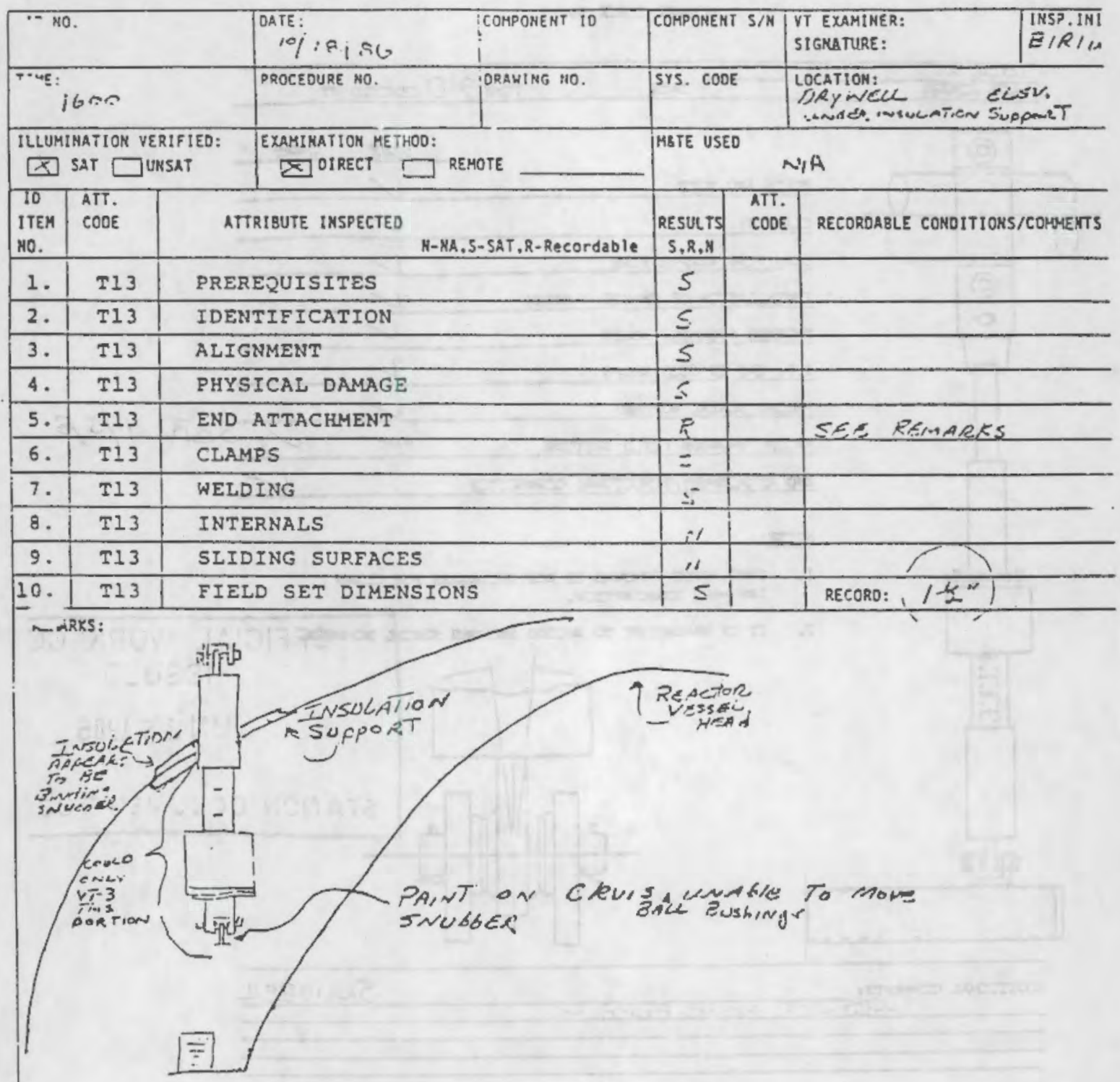

N. 3 
DATE : $11 / 09 / 6 G$

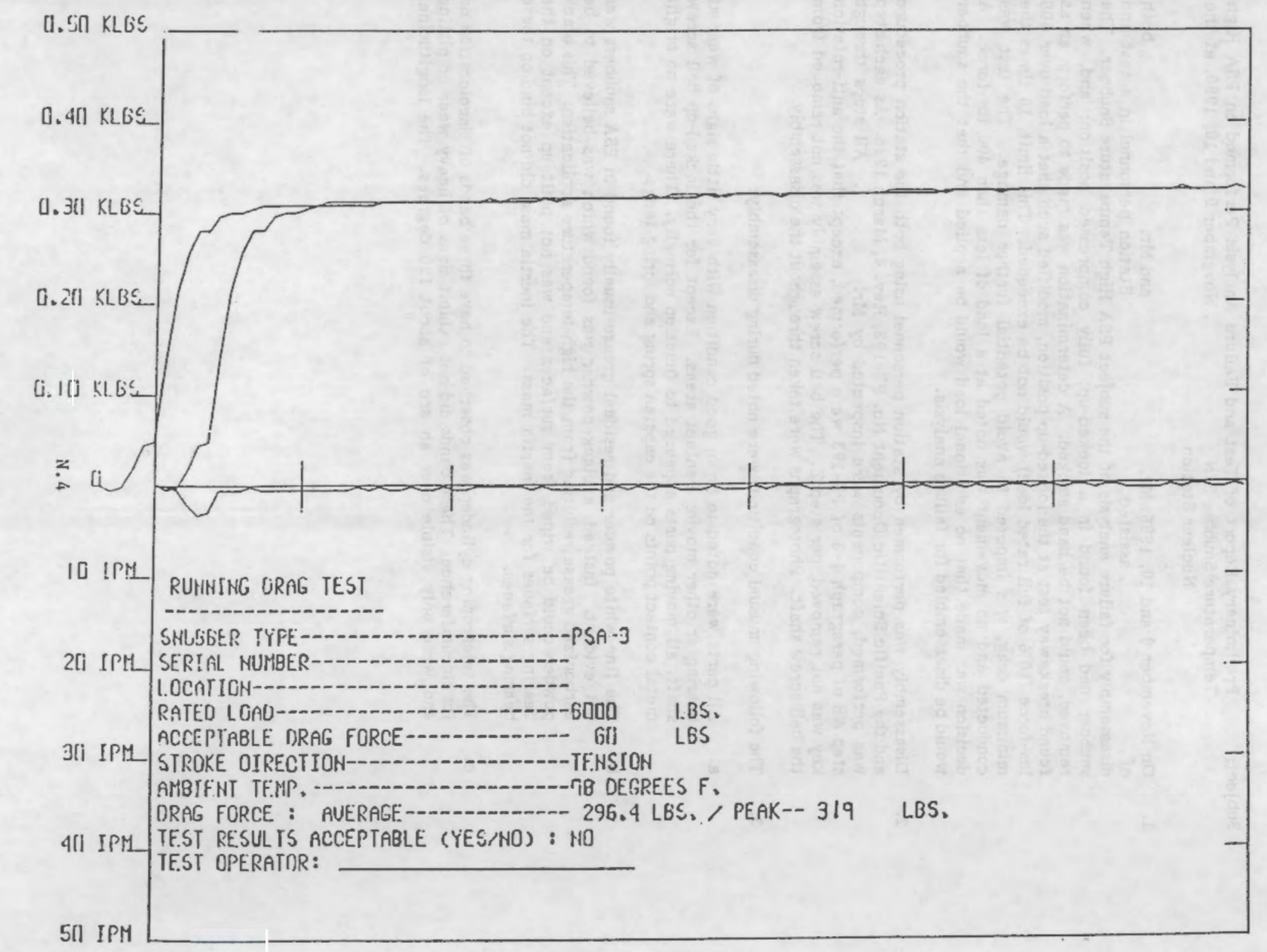


Subject: Preliminary Report of Test and Failure Analysis Performed on PSA High Temperature Snubber S/N , November 9 and 10, 1986, at the Nuclear Station

1. On November 9 and 10, 1986. Mr. and Mr. both of assisted Station personnel in a test and disassembly for failure analysis of the subject PSA High Temperature Snubber. The snubber had been found in a locked-up, fully compressed position; and, when removed, could not be hand stroked. A determination was made to perform an as found breakaway test at the locked-up position, modified such that a load over 600 lbs-force (10\% of full rated load) would not be exceeded. This limit, 10 times the minimum drag, was imposed to avoid potential further damage. The test was condueted and no movernent. was noted at a load of less than 400 lbs-force. A decision was made that no additional load would be applied and that the snubber would be disassembled for failure aralysis.

2. Disassembly was performed by station personnel using both the station procedure and the Pacific Scientific Document No. PS-193, Rev. 4, March 1986. As each step was performed, components were inspected by Mr. All steps through step AB of paragraph 4-3 of PS-193 were performed, except that the anti-rotation key was not removed, per step $Z$. The ball screw assembly was not removed from the ball screw shaft. Photographs were taken throughout the disassembly.

3. The following unusual conditions were noted during disassembly:

a. All parts were noted to be in good condition with very little signs of wear at bearing or other moving contact areas. Except for the locked-up ball screw shaft, all moving parts appeared to function normally. There were no bright metal contact points on the capstan spring and spring tangs.

b. The fine white powder and residual grease usually found in PSA snubbers was not evident. Instead, a black powder was found which was believed to be carbonized grease resulting from the high temperature application. This biack powder could be wiped from surfaces and was not built up except on the bearing surfaces for the inertia mass. The inertia mass did not bind on these bearing surfaces.

c. The telescoping cylinder was observed to have three bands of discoloration on its circumference. These bands did not exhibit signs of heavy wear or pitting and were only visible over an are of about 120 degrees. The longitudinal 
spacing of these bands was measured. It was found that relative to the location of the lip on the support cylinder tube, the three bands corresponded to the snubber at cold, hot, and as found settings. The bands appeared to be the result of a steady side-load on the snubber.

d. The snubber did not show evidence of unlocking until the bell screw assembly was removed from the telescoping tube. When the end plug was removed, care was taken to empty the tube on a clean cloth. This was also accomplished while unstaking the telescoping cylinder from the ball screw assembly. Several particles of grit were noted on the cloth. Two bright metal particles appeared to come from the unstaking process. The other particles and were not easily identified as to source. Upon inspection a similar particle was noted inside the telescoping tube. That particle did not jar loose and was left in place. In service the snubber was mounted in a vertical position with the end plug up. In this position the snubber would be susceptible to lock-up in tension if a particle in the tube had fallen into the ball screw.

e. When free of all other assemblies, the ball screw would move hesitatingly up and down the ball screw shaft under its own weight. A slight touch would reinitiate motion. The shaft appeared satisfactory, but lacked signs of movement and wear. The ball screw appeared satisfactory, but would not sustain motion for more than two or three revolutions up or down the shaft under its own weight. As the ball screw was worked from end to end, this condition improved, but not to the extent of free motion from end to end.

f. Prior to testing and disassembly, plent personnel had indicated that the henging position of the snubber was in an axially displaced position to one side, such that spherical bearing movernent would be required. They further indicated that the spherical bearing on the housing end wes frozen by paint, and that this bearing motion had been freed only after deconning had removed the paint. Evidence of this paint in and around the bearing was noted.

Conclusions reached from the above and other conditions found are as follows:

a. The snubber had been subjected to very little motion and spparently no vibration. All parts appeared in good condition.

b. Lack of lubrieant did not appear to restrict motion of the inertia mass, thrust bearing, or other moving parts, except for the ball serew and shaft assembly.

c. The bands on the telescoping tube are clear evidence of side loading at the three positions of extension noted by measurement. This evidence of side loading is supported by the frozen spherical besring.

d. Evidence of some grit in the telescoping tube was found after some shock to the assemblies during removai of the end eap, and unstaking the ball screw assembly. Other evidence of grit was found on the tubes inside wall. The ball screw was locked until these disassembly steps were performed. As the snubber was hung vertically, any grit in the tube could have fallen into the ball screw. 
e. The screws securing the indicating tube to the end plug were found finger tight. Likewise, the set screws below were found finger tight. The end plug was misaligned approximately 10 degrees from the rear housing, indicating possible readjustment or removal during installation for alignment purposes.

f. The ball screw assembly appeared reasonably free in full length action only after removal from the telescoping tube. The noted hesitation in the travel of the ball screw on the screw shaft may have caused lock-up; however, only a light touch was required to initiate continued motion.

\section{OVERALL CONCLUSTON}

Most probable cause of lock-up was from grit wedged in the ball screw assembly. This cause is not considered generic to the high temperature type snubber.

\section{RECOMMENDATIONS}

1. Hand stroking other similarly installed snubbers would indieate no lock-up condition exists and probably less than minimum running drag of 60 lbs-force. Based upon the excellent condition noted in the disassembled snubber, a high probability exists these snubbers are fully functional.

2. Although evidence of side loading was found, this did not appear to be the cause of lock-up. However, spherical bearings should be kept free from paint, etc., to allow complete freedom of motion.

3. The loose screws in the end plug showed no evidence of "lock tite," and were in fact barely finger tight. This, plus the visible realignment of the end plug indicates a possible removal at one time, and a source of particle contamination. PSA installation instructions should be followed.

4. The ball screw and shaft assembly should be replaced and the snubber rebuilt per PS-193 (with special instructions regarding parts and grease required for the high temperature snubber obtained from Pacific Scientific Co.). The removed ball screw and shaft should be returned to Pacific Scientific Co. for further analysis. 
The cause of failure of ball-screw shafts from two

system snubbers is attributed to sudden loading of the snubber resulting in buckling of the shafts. The fracture mode of the precipitation hardened stainless steel shafts is combined ductile and brittle fracture. Seams and.cracking at the crowns of the threads are attributed to thread rolling during the manufacturing process and are not related to the snubber failures. Confirming chemical analysis shows the ball-screw shaft material to be $17-4$ PH stainless steel.

\section{INTROOUCTION}

The failed snubbers are Pacific Scientific size 1 snubbers with a load rating of 1500 pounds. The service location of the snubbers was the auxiliary steam line for the Unit 1 auxiliary feedwater turbine. Failure of the snubbers was detected during routine surveillance required by technical specifications.

\section{MACRO-EXAMINATION}

The damaged ball screw shafts and capstan springs are shown in figures 1 and 2. The shaft from sample 405-1 fractured at two locations while 405-1I iractured at a single location. The ball screw shafts plastically deformed adjacent to the fracture locations by bending prior to fracture. A tensile shear $l i p$ and compressive shear lip on both shafts indicated the shafts buckled under compressive loading. The specific location and size of the shear lips varied from fracture to fracture. The major portion of the fracture face possessed a shiny, brittle appearance (Figure 3 ). The key between the ball screw shaft and capstan spring housing was twisted out of the key slot in both snubbers indicating the shaft experienced a sudden torsional load. Seams formed during the thread rolling process are visible at the crowns of the threads. 
Appendix I

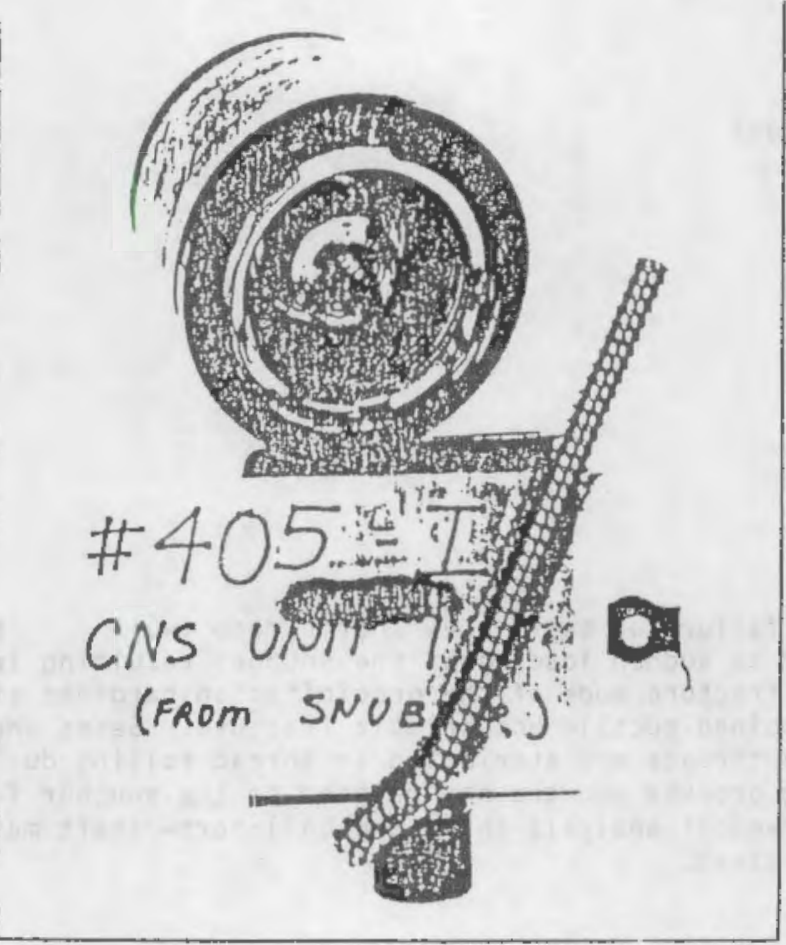

FIGURE 1 As received view of snubber ball-serew shaft and torque transfer drum. Shaft failed in buckling as the result of a sudden compressive load. Fracture occurred at two locations. Ma-661.

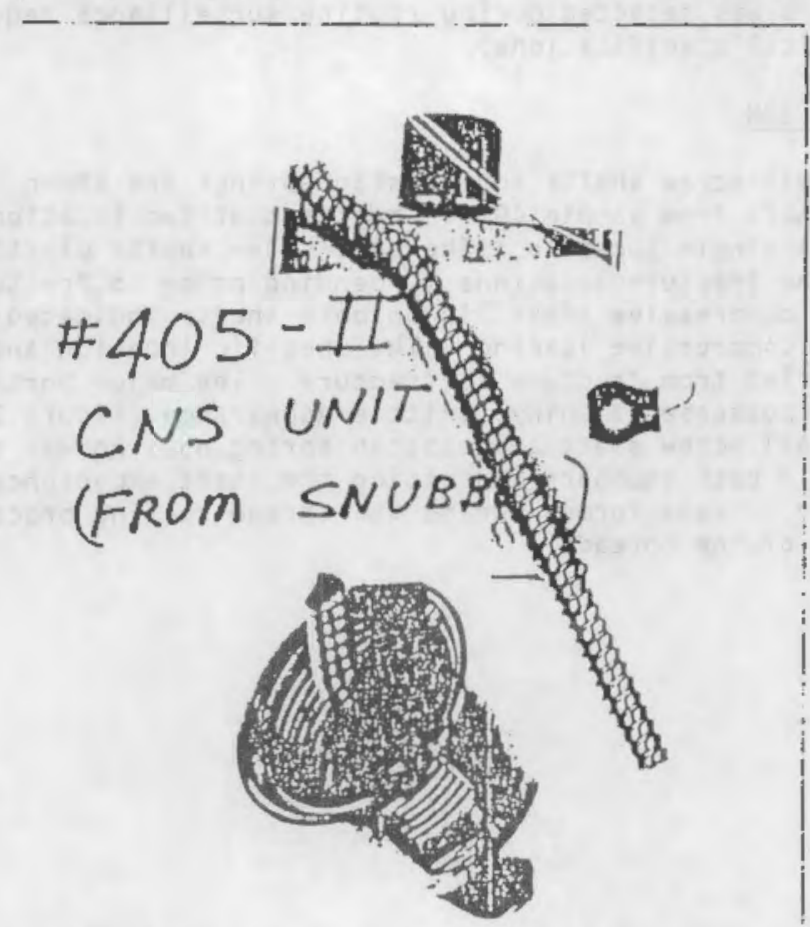

FIGURE 2 Second snubber ball-screw shaft which falled by buekling.

Close inspection of capstan spring housing shows the key to the ball-screw shaft twisted out of the key slot. Ma-662. 
The ehemical analysis of the shaft material is consistent with that of $17-4$ precipitation hardened stainless steel.

\section{CONCLUSIONS}

The ball-screw shafts of the Pacific Scientific size 1 snubber failed in buckling as a result of a sudden compressive overload force applied externally to the snubber. The keys between the ball-screw shaft and capstan spring housing were twisted out of the key slot by a sudden application of torque. The fracture faces are characterized by a combination of tensile and compressive fracture indicative of buckling. The material is in the hardened condition and the chemistry appears to be correct. The load required to buckle the bal1-screw shaft has not been determined.

If the Metallurgy Lab can be of further assistance, please call. 
Appendix I

\section{ILIUSTRATIONS}

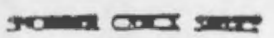

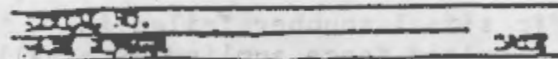
$=940=000$
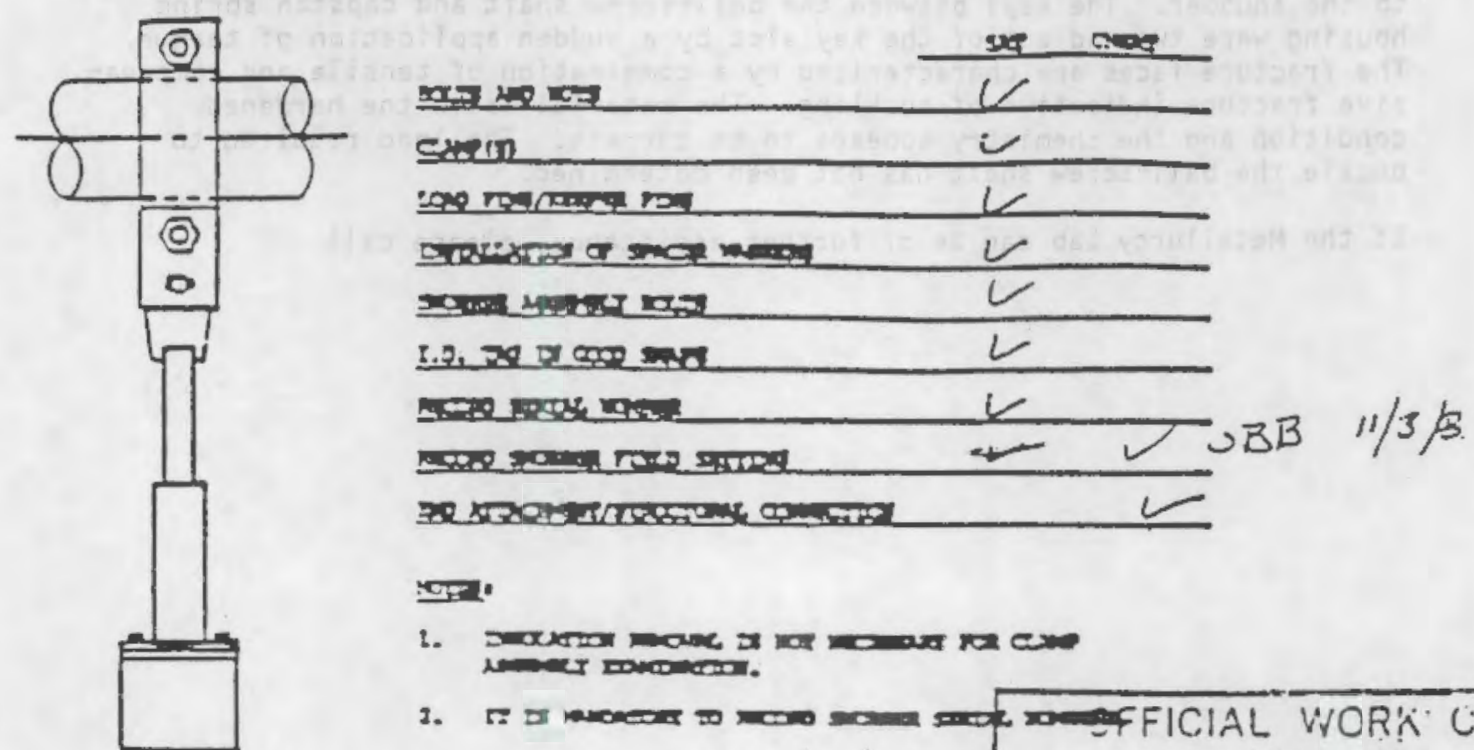

뚜다.

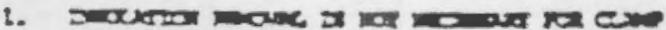

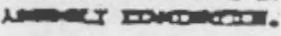

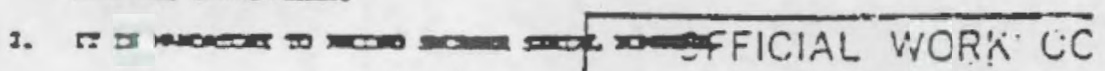<smiles>C1=CC2CCCCC12</smiles><smiles>C=CC1CC2CC1C2</smiles>
IS Sij:? JU'N $25 ! 986$
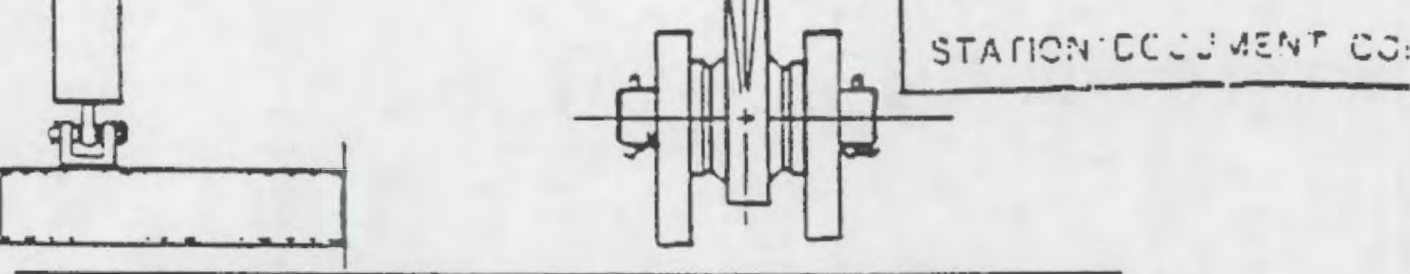

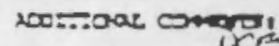

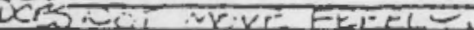

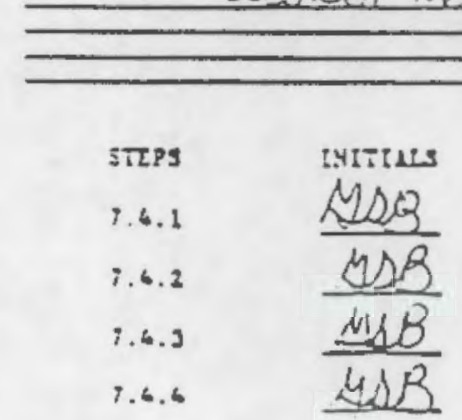

SNüBzer 
Appendix J

Typical Visual Indicators of Snubber Degradation 


\section{Appendix J}

\section{Typical Visual Indicators of Snubber Degradation}

This Appendix contains photographs of snubbers and snubber parts associated with various types of degradation. 


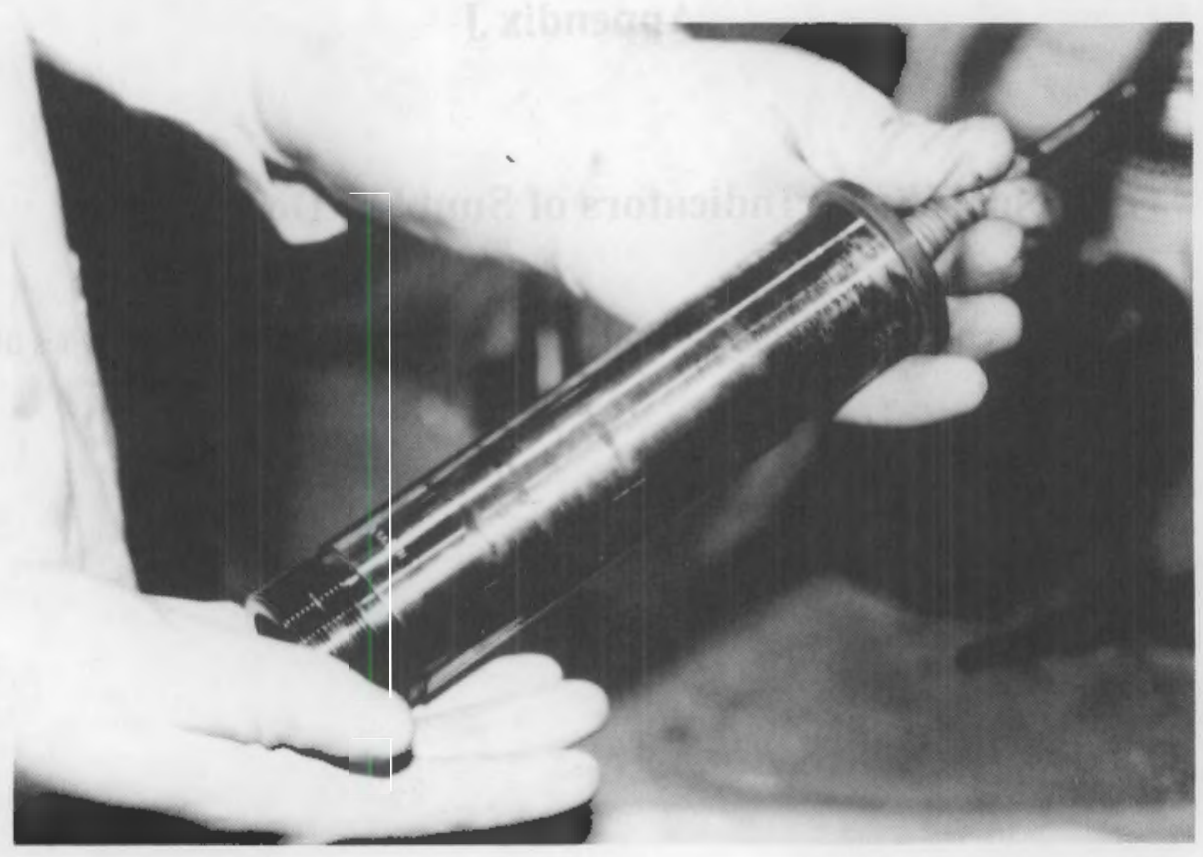

Figure J.1 Mechanical snubber telescoping cylinder (with side loading marks from support cylinder in bot, cold, and as-found position)

Figure J.2 Gelated, blackened bydraulic fuid (snubber subjected to high amplitude vibration) 


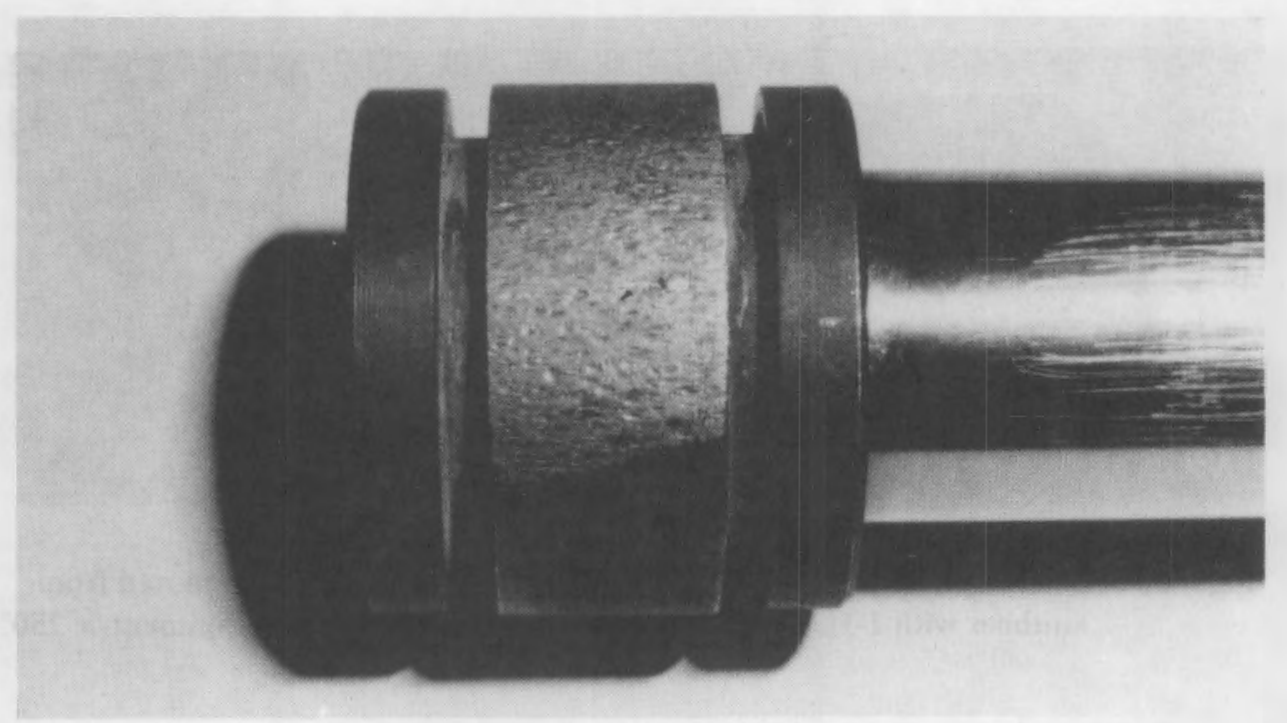

Figure J.3 Extensive piston wear (snubber subjected to high amplitude vibration)

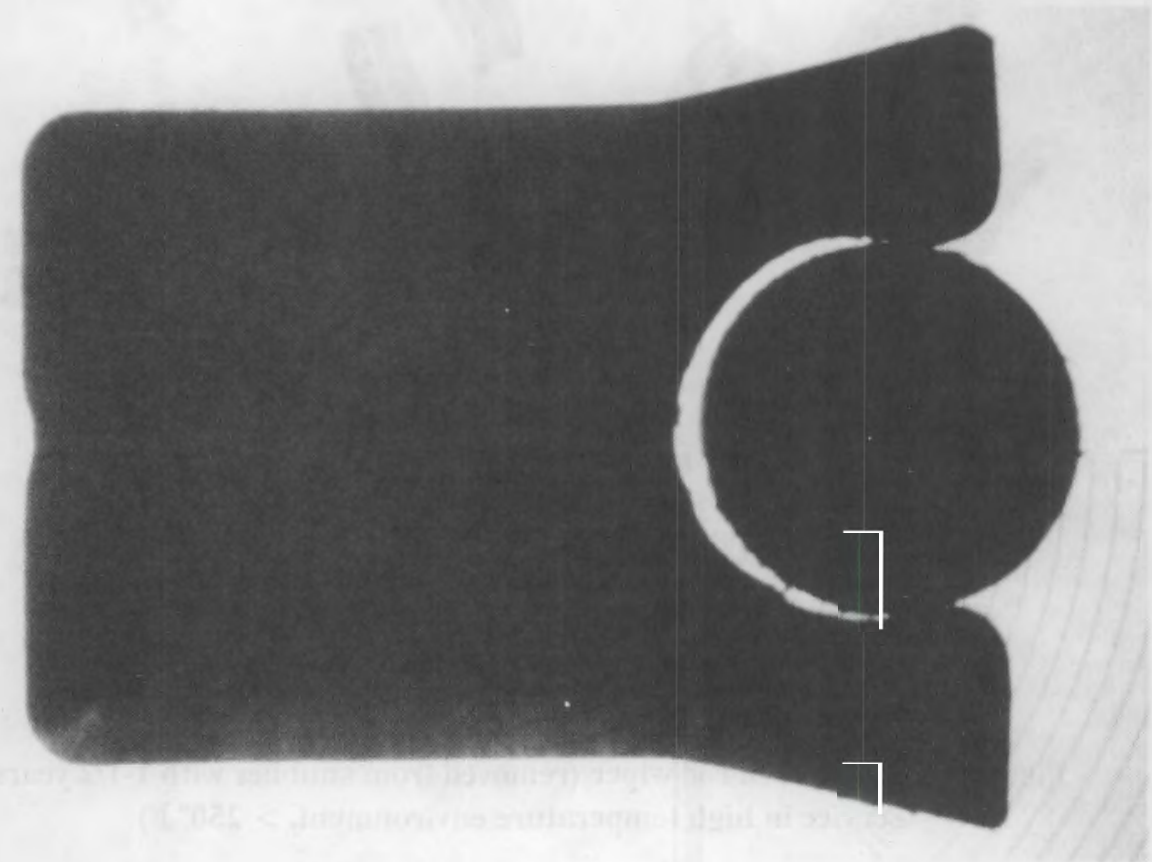

Figure J.4 Typical used o-ring lip seal (removed from snubber with 7 years service in moderate operating environment) 
Appendix J

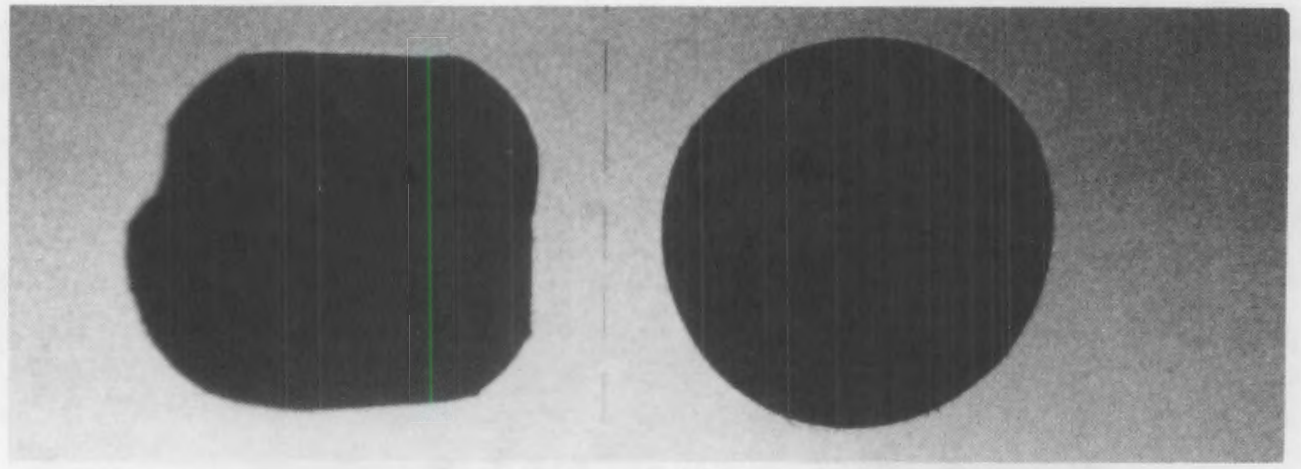

Figure J.5 Section photograph - 0-ring with extensive set (left side) (removed from snubber with 1-1/2 years service in high temperature environment $>250^{\circ} \mathrm{F}$ )

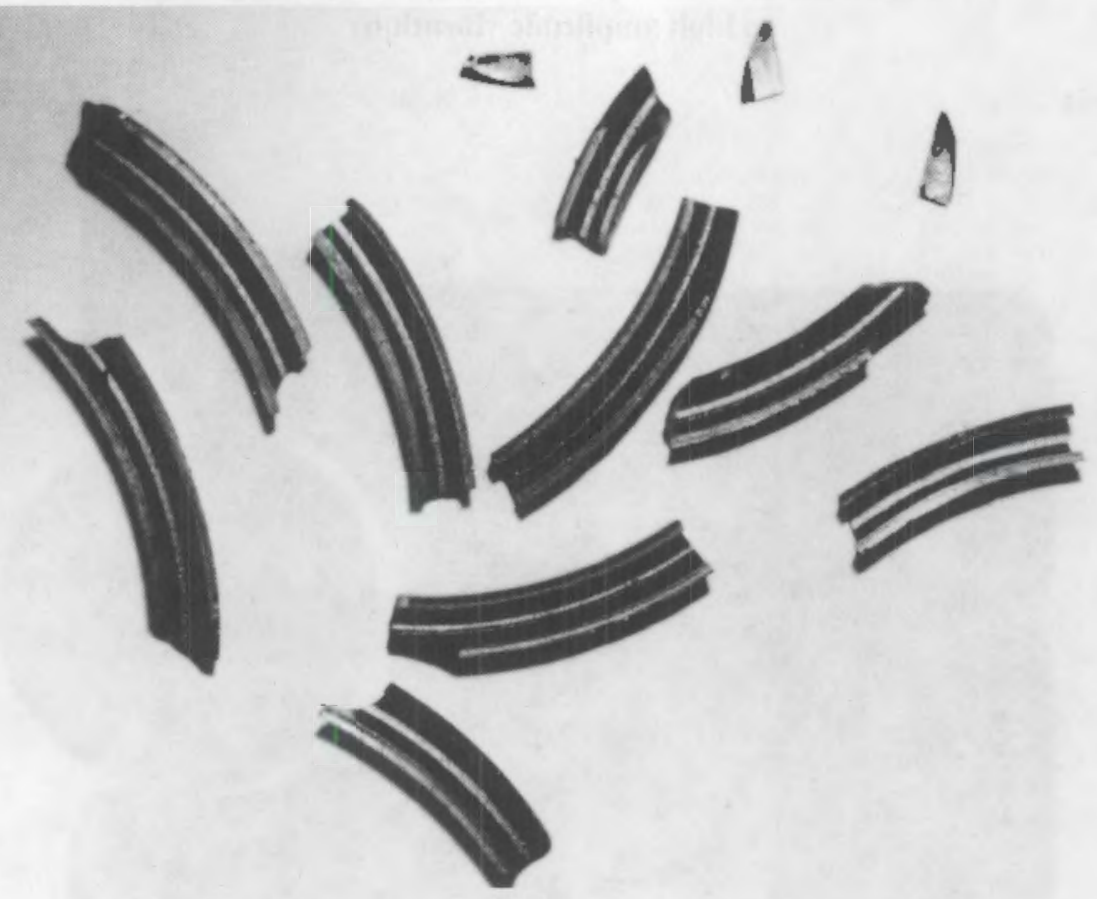

Figure J.6 Embrittled rod wiper (removed from snubber with 1-1/2 years service in high temperature environment, $>250^{\circ} \mathrm{F}$ ) 


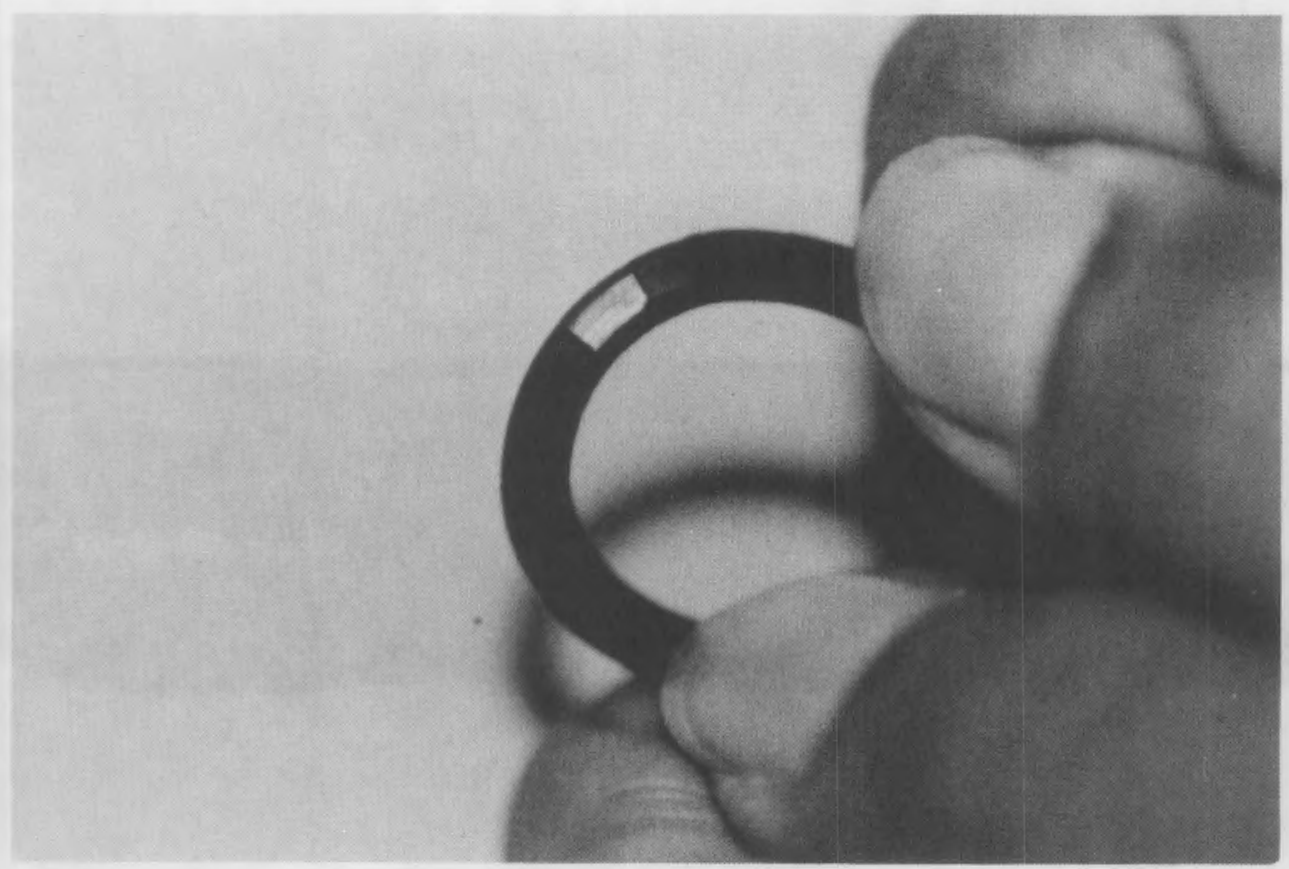

Figure J.7 Embrittled o-ring with surface cracks (removed from snubber with $1-1 / 2$ years of service in high temperature environment $>250^{\circ} \mathrm{F}$ )

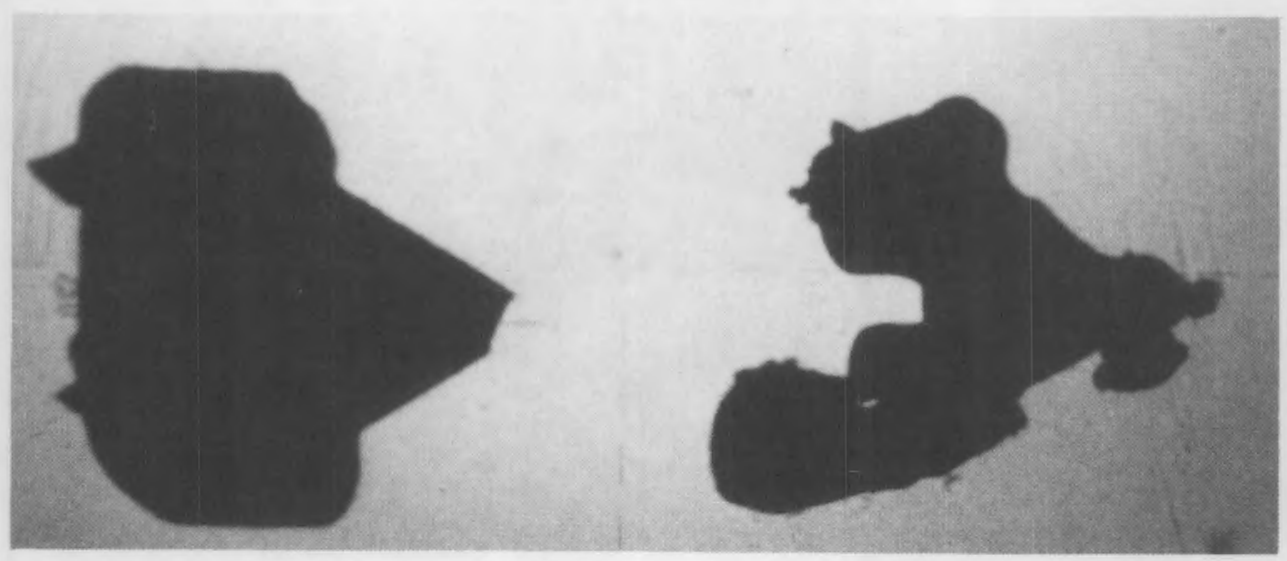

Figure J.8 Section photograph - damaged thread seal (right side) (seal damaged due to failure to utilize flat washer with nut) 
Appendix J

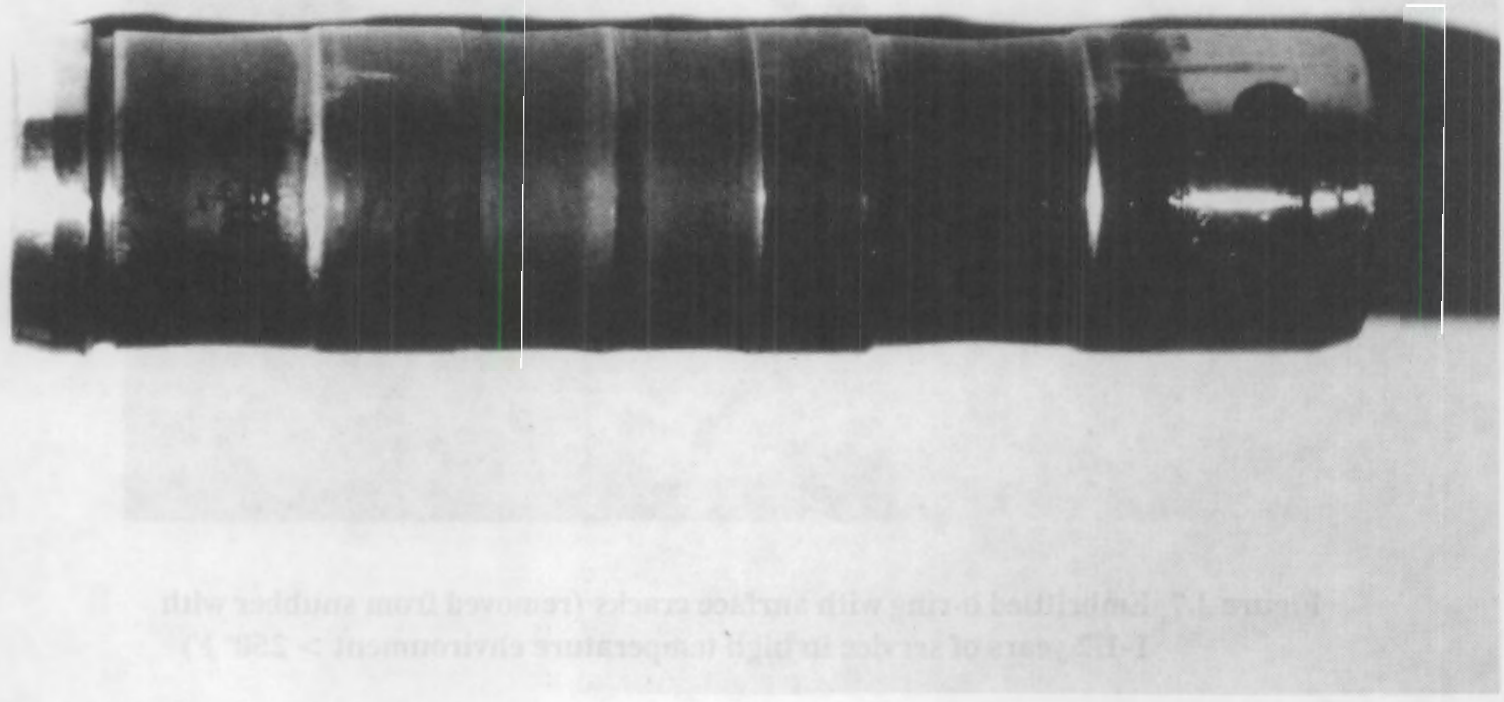

Figure J.9 Uniformly worn clevis pin (snubber subjected to continuous, low amplitude vibration) 


\section{Appendix K}

Recommendations for Subsection ISTD 


\section{Appendix K}

\section{Recommendations for Subsection ISTD}

This appendix includes recommendations identified from the NPAR In-plant Research for the Operations and Maintenance (OM) Part 4 Code, Section IST,
Subsection ISTD, Examination and Performance Testing of Nuclear Power Plant Dynamic Restraints (Snubbers). 


\section{Contents}

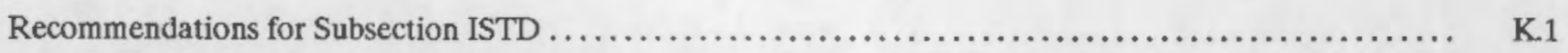

1 NPAR Snubber Aging Research Recommendations for ISTD $\ldots \ldots \ldots \ldots \ldots \ldots \ldots \ldots \ldots \ldots \ldots \ldots \ldots \ldots \ldots \ldots \ldots$

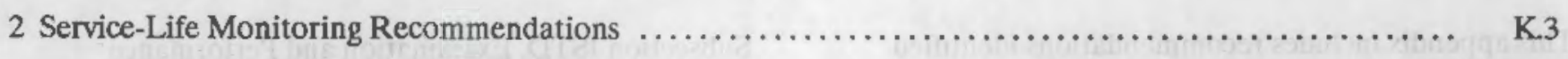

2.1 Determination of Snubber Failure or Degradation Causes $\ldots \ldots \ldots \ldots \ldots \ldots \ldots \ldots \ldots \ldots \ldots \ldots \ldots \ldots \ldots \ldots$

2.2 Determination and Documentation of the Operating Environment $\ldots \ldots \ldots \ldots \ldots \ldots \ldots \ldots \ldots \ldots \ldots \ldots \ldots \ldots \ldots$

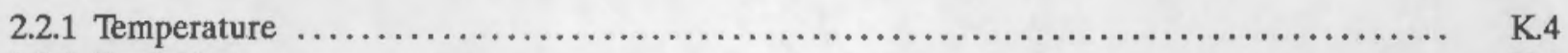

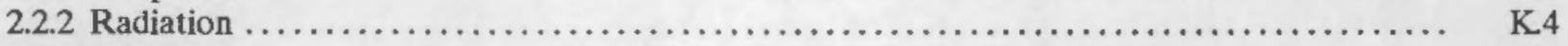

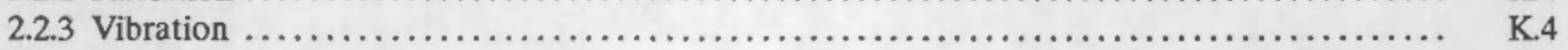

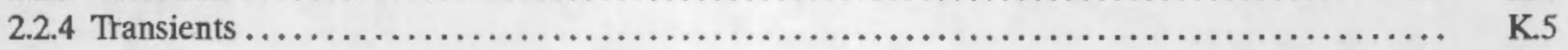

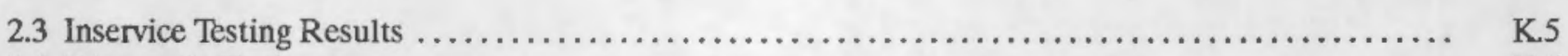

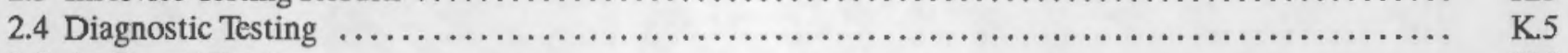

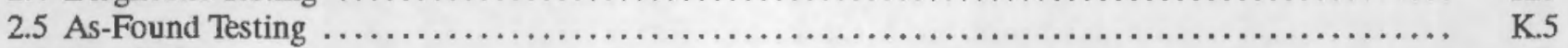

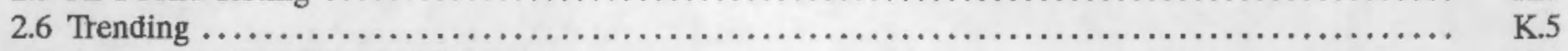

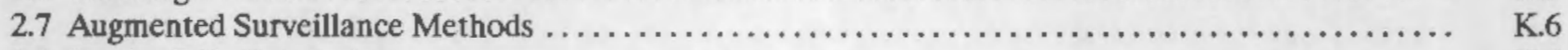

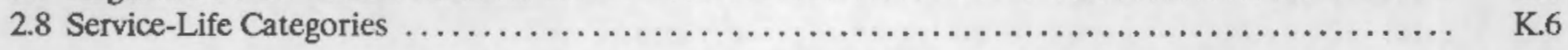

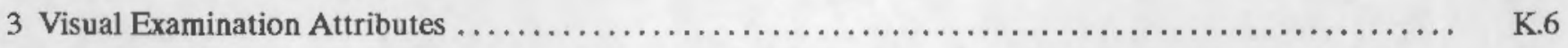

3.1 Recommended Examination Checklist Attributes (Pre-Service Examination Only) ............ K.6

3.2 Recommended Examination Checklist Attributes (Pre-Service and Inservice Examination) ........ K.6

3.3 Recommended Examination Checklist Attributes (Service-Life Monitoring) $\ldots \ldots \ldots \ldots \ldots \ldots \ldots \ldots$ K.7

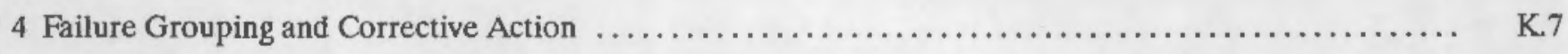

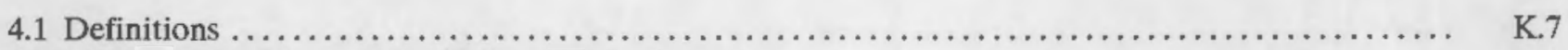

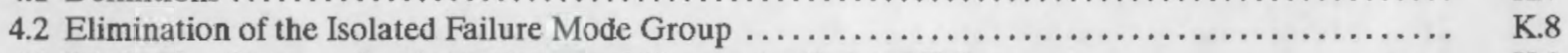

4.3 Distinction Between Service-Related and Nonservice-Related Failures . . . . . . . . . . . . . . .

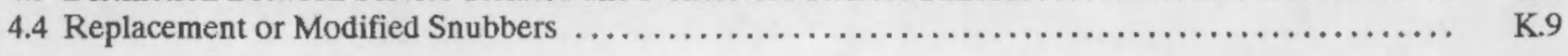




\section{NPAR Snubber Aging Research Recommendations for ISTD}

As a result of information obtained during the NPAR Snubber Task research, recommendations are made in the three following areas for the next revision of the ASME OM Code, Subsection ISTD:
- Service-Life Monitoring

- Visual Examination Attributes

- Failure Grouping and Corrective Action.

\section{Service-Life Monitoring Recommendations}

Service-life monitoring recummendations were developed from the results of the NPAR research. Major recommendations are highlighted below for consideration in the next revision of ISTD (Section 8.0 and Appendix F).

It should be noted that suggestions pertaining to service-life monitoring include a number of recommendations for testing in addition to that specified in ISTD, Section 7.0. Such testing includes trending tests, diagnostic tests, and post-service as-found tests. If such tests are included in ISTD, a statement should be included to specify that the results of such tests will not require testing of additional snubber samples in accordance with ISTD Section 7.9 or 7.12 .

\subsection{Determination of Snubber Failure or Degradation Causes}

A service-life monitoring program will be most effective if it distinguishes between service-related and nonservice-related failures. It is important that the root cause of snubber failure or degradation (e.g., dynamic transient, vibration, excessive temperature, etc.) be identified along with the failure mode (e.g., high drag force, low activation, etc.) and the failure mechanism (e.g., deformation of screen shaft, solidification of grease, etc.).

It is suggested that failure evaluation data sheets provide key information, including failure mode, failure mechanism, failure cause, environment, service time, abnormal conditions, visual observations, test data, test observations, etc.
For effective determination of failure cause and root cause, it is important that personnel involved in failure evaluation have adequate expcrience. Failure evaluation data sheets should not be formatted in a manner that might lead the examiner to a potentially incorrect failure cause.

Table 1 lists typical irregularities that may be observed during visual examination or during snubber disassembly. These items characterize features of snubber degradation and may be useful to pinpoint the potential cause.

\subsection{Determination and Documentation of the Operating Environment}

Service-life monitoring techniques take into consideration the capability of the various snubber models to endure the full range of plant environments (benign to severe). Previously unidentified severe environments may often be identified by root cause evaluation of failed or degraded snubbers. Information regarding the snubber endurance capability is often obtained from operating experience (i.e., from failure data or by monitoring degradation).

Determination of specific environmental information often involves specialized instrumentation and equipment that would be impractical for use at every snubber location. The use of such equipment, therefore, would be most practical for those applications where moderate to severe environments are anticipated or as a diagnostic aid in determining the cause of snubber degradation. 
Table K.1 Typical indicators of snubber degradation

\begin{tabular}{ll}
\hline \multicolumn{1}{c}{ Indicator } & \multicolumn{1}{c}{ Possible Cause } \\
\hline Dark hydraulic fluid & High amplitude vibration \\
Black material deposit on rod & High amplitude vibration \\
Excessive piston and cylinder wear & High amplitude vibration \\
Worn capstan spring tangs & High amplitude vibration \\
Localized ball screw fretting & High amplitude vibration \\
Unsymmetrical wear of clevis pins & High amplitude vibration \\
Elongation of attachment holes & High and/or low amplitude vibration \\
Loose fasteners & High and/or low amplitude vibration \\
Symmetrical wear on clevis pins & Low amplitude vibration \\
Discoloration of metallic parts & Excessive temperature \\
Hardened piston rod wiper & Excessive temperature \\
Rod wiper adhered to piston rod & Excessive temperature \\
High compression set & Excessive temperature \\
Cracked seal & Excessive temperature \\
Lack of fluid pigmentation & High radiation level \\
Corrosion of metallic parts & High humidity/leaking components \\
Bent piston rod or attachments & Overloading \\
Changes in cold/hot position setting & Increased drag or jamming \\
\hline
\end{tabular}

Various methods and equipment used for measurement of specific environmental parameters are described below.

\subsubsection{Temperature}

Temperature-sensitive tape is useful for identifying hot spots. Ideally, however, to monitor environmental temperatures, a time/temperature profile is most useful. Chart recorders or digital data acquisition systems (e.g., bit loggers, computers, etc.) may be used for this purpose.

\subsubsection{Radiation}

Normal radiation levels in operating plants do not usually contribute significantly to snubber degradation. Pertinent data pertaining to plant radiation levels can generally be obtained from health physics area surveys. Measurement of radiation levels specifically for servicelife monitoring does not seem justified, except in cases of snubber degradation where other potential causes have been ruled out.

\subsubsection{Vibration}

A number of methods and equipment for detecting and measuring vibration are available. They vary from simple visual observation, detection by "hands on" 
Appendix $\mathrm{K}$

inspection, portable vibration measuring instrumentation, and remote vibration measuring equipment.

Vibration can often be identified during routine snubber visual examination or during failure evaluation. Characteristics such as metal filings, darkened hydraulic fluid, deformed connecting pins, elongated attachment holes, and fretting of mating parts are indicators of vibration.

\subsubsection{Transients}

As with vibration, dynamic load transients that exceed the snubber load capacity may often be identified during routine inspections (e.g., observation of deformed structural members), augmented inspections (e.g., during hand-stroking of the snubber), and failure evaluation (e.g., deformed internal parts). In situ devices, such as load measuring clevis pins, are also available to monitor snubber load in applications where such transients are suspected.

\subsection{Inservice Testing Results}

Evaluation of time traces (e.g., load and velocity) obtained during routine functional testing is useful in identifying degradation that could lead to functional failure if not corrected. For example, an unusual number of load spikes may indicate the presence of dirt or other solid particles in the snubber; a single load spike may indicate local fretting of the ball screw. Follow-up diagnostic tests (see below) are useful for further evaluating such anomalies.

\subsection{Diagnostic Testing}

Diagnostic tests may be used to obtain information beyond that available from rontine functional test data. Results from diagnostic testing can be helpful in identifying the failure or degradation mechanism. For example, a progressive decrease in the "bleed" velocity of a hydraulic snubber during a sustained load can be indicative of particulate contamination of the hydraulic fluid. Test equipment used for diagnostic tests should be configured to allow the application of various levels of controlled test parameters such as load and velocity.

\subsection{As-Found Testing}

Considerable information can be obtained by conducting post-service tests on snubbers removed from service.

\subsection{Trending}

Trending is a useful tool to monitor progressive snubber degradation. Trending has a number of important considerations:

- The establishment of baseline data is essential for trending.

- Trenđing data should be sufficiently accurate so that trends may be identified.

- Trending parameters should relate directly to the anticipated aging failure mode. Such parameters include, but are not limited to, drag force for mechanical snubbers and seal compression set for hydraulic snubbers.

Note: An important example of inappropriate monitoring parameters is the use of functional test data for monitoring or trending seal degradation. Although seal degradation can affect functional test results to some extent, loss of low pressure sealing integrity--the primary aging failure mode for snubber seals--would not be reflected in functional test data.

- If test đata are to be used for trending, it is recommended that the data be obtained consistently by the same type of test machine, under the same test conditions. Ideally, the same snubber should be used. Snubbers selected for trending should be representative of the service environment related to the snubber population to be monitored.

- Reservoir fluid level is the most appropriate trending parameter for monitoring snubber leakage.

Trends in average drag force are generally more detectable than for peak drag force.

- A number of plants have established administrative limits for functional test parameters in order to prompt the replacement or repair of a given snubber 
Appendix $\mathbf{K}$

before failure. This approach assumes that the parameter in question (e.g., drag force) is progressing toward the failure limit, which may or may not be the case. It is therefore recommended that administrative limits be established at a level that is outside the range of normal variations for the given parameter. Premature replacement or maintenance can increase the probability of snubber failure by introducing potential maintenance or manufacturing defects and reduce the potential benefits of the trending analysis.

\subsection{Augmented Surveillance Methods}

Various "hands-on" methods may be used to identify snubber degradation and to detect severe environmental conditions. These include hand stroking for verification of free movement, rotation of the snubber about its spherical bearings as a check for jamming, hand detection of vibration, and hand detection of high temperature.

\subsection{Service-Life Categories}

Depending on the significance of environmental extremes from one area in the plant to another, separate and distinct service-life populations may be practical. For example, it may be practical to establish a separate service-life population for snubbers in the upper level of the drywell for some BWR plants, due to relatively high temperatures in that area that may result in more rapid seal degradation. On the other hand, isolated applications involving very severe environments (e.g., steam tunnel, pressurizer cubical, etc.), should be managed separately on a case-by-case basis.

\section{Visual Examination Attributes}

Many attributes that should be included in snubber preservice examinations need not be checked again during inservice examination. Snubber characteristics that are potential indicators for inoperability, e.g., empty reservoir, missing clevis pin, etc., are normally evaluated during inservice inspection (ISI). For service-life monitoring, characteristics that relate more to degradation prior to failure are emphasized. It is, therefore, recommended that Appendix B (Recommended Examination Checklist Items) be divided into three basic checklists: one for pre-service examination only, another for inservice and pre-service examination, and another for service-life monitoring.

\subsection{Recommended Examination Checklist Attributes (Pre-Service Examination Only)}

It is recommended that snubbers be visually examined for the following unacceptable attributes during preservice examination only:

- snubber installed with preset locking screws (used for shipment only)
- snubber installed in wrong location

- protective coverings or shipping plugs not removed

- snubber freedom of movement impaired by interference with adjacent equipment

- other one-time pre-service checks recommended by the manufacturer.

\subsection{Recommended Examination Checklist Attributes (Pre-Service and Inservice Examination)}

Visual examination attributes that may indicate snubber inoperability during pre-service inservice examinations are listed below:

- non-pressurized reservoir oriented such that hydraulic fluid cannot gravitate to snubber

- severe corrosion or solid deposits that could impair snubber performance 
- inadequate swing clearance

- paint on piston rod (could cause a frozen condition)

- permanent deformation (e.g. bending) of the snubber or its structural attachments

- inadequate reservoir fluid level

- clevis pin not installed

- weld arc strikes, weld slag, adhesive, or other deposits on piston rod or support cylinder (could cause a frozen condition)

- loose or missing fasteners

- cold or hot position setting varies from specified value

- spherical bearing not fully engaged in attachment lug

\subsection{Recommended Examination Checklist Attributes (Service-Life Monitoring)}

Typical attributes that should be noted for service-life monitoring purposes are as follows:
- evidence of corrosion

- evidence of solid deposits (e.g., boric acid) from leaking components

- loss of hydraulic fluid since previous visual examination

- metal filings on or in the vicinity of the snubber

- observed fluid leakage

- evidence of significant dark (i.e., black or dark brown) material deposit on piston rod

- rod wiper adhered to piston rod

- abnormal color of hydraulic fluid

- wear or deformation of clevis pins

- elongation of attachment holes

- evidence of wear on support cylinder

- cracked or deformed fluid reservoir

- evidence of foreign material (e.g., water, solid particles, etc.) in hydraulic fluid

- discoloration of metallic parts due to heat.

\section{Failure Grouping and Corrective Action}

Subsection ISTD currently requires that any snubber that fails to meet functional test acceptance criteria be classified into one of six Failure Mode Groups (FMGs) (see Figure K.1). Depending on the FMG, various corrective action alternatives may apply.

The following recommendations pertain to the classification of failures and follow-up corrective action.

\subsection{Definitions}

It is recommended that the following definitions be included in Subsection ISTD. These definitions are consistent with those proposed by the Technical Committee on Common Aging Terminology (CAT):

- Failure Mode: The manner in which the snubber failed (e.g., high drag force, high acceleration, high bleed rate, low locking velocity, etc.). 


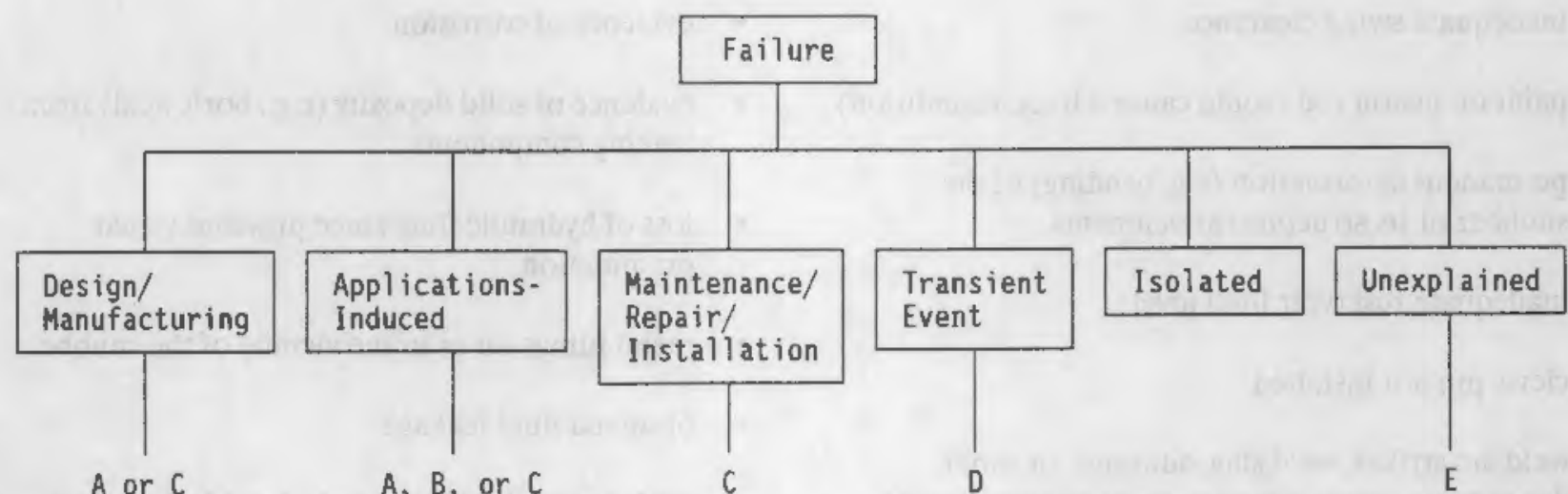

A: Replace all FMG snubbers with compatible snubbers; no additional testing.

$B$ : Change the environment; no additional testing.

C: Additional testing in FMG.

D: Test or stroke all FMG snubbers; no additional testing.

E: Continue testing in sampling plan.

Figure K.1 Current failure categorization and additional testing requirements

- Failure Mechanism: The physical process that resulted in failure (e.g., deformation of screw shaft, thermally induced compression set, etc.).

- Failure Cause: The circumstances during design, manufacture, or use which led to failure (e.g., excessive temperature, defective plating process, vibration, side loading, etc.).

- Root Cause: The fundamental reason(s) for failure which, when corrected, prevents its recurrence.

\subsection{Elimination of the Isolated Failure Mode Group}

Isolated failures should be identified by root cause evaluation. However, due to their singular nature, such failures cannot represent a group. It is therefore recommended that the isolated failure mode group be eliminated.

\subsection{Distinction Between Service- Related and Nonservice-Related Failures}

A snubber failure that is associated with a manufacturing or design deficiency could nonetheless be service related. For example, the root cause for a seal failure resulting from the inadvertent use of a seal material that is less resistant to heat than the material specified by the manufacturer may be identified as inadequate material control (a manufacturing-related failure cause).

Although the seal may not have endured for as long as one manufactured from the specified material, it is likely that it did provide some amount of service prior to failure. The option should be allowed, therefore, for continued use of additional snubbers that may utilize this material, provided that the environment is adjusted to be compatible with the seal material. 
Appendix K

Snubbers with a potential for failure from the same root cause should be assigned to the same root cause group (RCG) in order to take steps that would reduce potential failure during future operation. However, in order to establish additional testing requirements (ISTD), it need only be determined whether or not the failure is service-related, nonservice-related, or unexplained (see Figure K.2). Therefore, it is probably not necessary to pre-establish failure cause groups in Subsection ISTD.

Categorization using the snubber-grouping plan in Figure 2 would distinguish between service-related and nonservice-related failures. This is important for two reasons:

1. To monitor the rate of occurrence of service-related failures.

2. To provide the option to modify the environment for all snubbers subject to service-related failures without having to test additional snubbers. (This option is currently allowed for "applicationsinduced" failures only.)

Resulting data would facilitate the compilation of useful failure statistics, both plant-specific and for the industry in general, and would allow flexibility in establishing various RCGs in an industry data base without concern over conflict with ISTD. ${ }^{1}$

By comparing Figures K.1 and K.2, it can be seen that additional testing requirements associated with the proposed classification system are consistent with those currently in the ISTD standard. One change, however, is that the option to replace, modify, or repair all snubbers in the RCG (failed and unfailed) without requiring additional testing would be allowed for all failures. This option was previously allowed only for design, manufacturing, and application-induced failures.

\subsection{Replacement or Modified Snubbers}

Snubbers are occasionally subject to operating environments for which they have not been qualified. Such environments include dynamic load transients, high amplitude vibration, high temperature, etc. Paragraph ISTD 1.11.1 of the standard requires that replacement or modified snubbers have a proven suitability for the

\footnotetext{
${ }^{1}$ The Snubber Utility Group (SNUG) has encountered difficulties in establishing failure categories for the SNUG data base due to potential inconsistencies with FMGs currently included in ISTD.
}

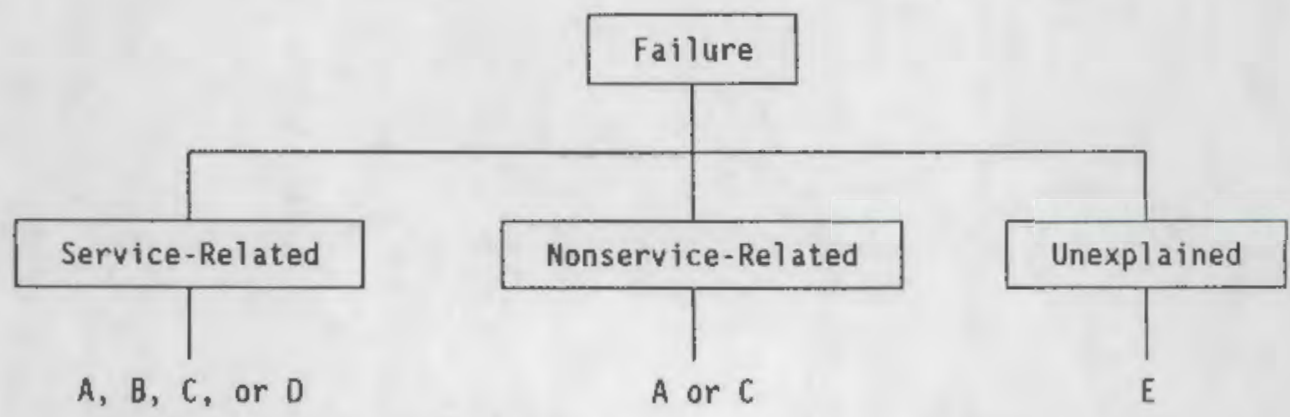

A: Replace all RCG snubbers with compatible snubbers; no additional testing.

B: Change the environment; no additional testing.

C: Additional testing in RCG.

D: Test or stroke all transient event snubbers; no additional testing.

$\mathrm{E}$ : Continue testing in sampling plan.

Figure K.2 Proposed failure categorization and corrective action 


\section{Appendix K}

application or environment. Because environmentally compatible snubbers are not available for all such applications, utilities often have no alternative but to continue to use the same snubber model or another unqualified model.
It is suggested, therefore, that some flexibility be provided in ISTD 1.11.1 that would allow for continued use of existing snubber models in such cases. For example, requirements for augmented inspections for these applications would ensure that snubbers would be replaced or maintained before failure. 
Appendix L

Snubber Maintenance Recommendations 


\section{Appendix L}

\section{Snubber Maintenance Recommendations}

This appendix includes a number of recommendations pertaining to snubber maintenance that were developed during the NPAR research. 


\section{Contents}

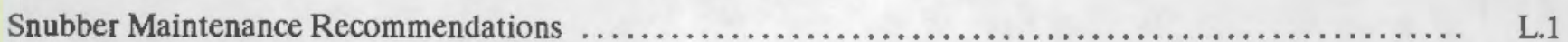

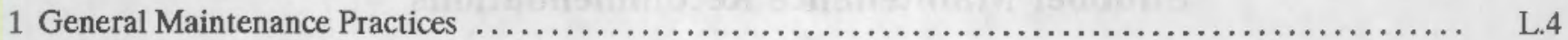

2 Identification of the Operating Environment $\ldots \ldots \ldots \ldots \ldots \ldots \ldots \ldots \ldots \ldots \ldots \ldots \ldots \ldots \ldots \ldots \ldots \ldots, \quad$ L.4

3 Snubbers Prone to Rapid Degradation in Severe Environments $\ldots \ldots \ldots \ldots \ldots \ldots \ldots \ldots \ldots \ldots \ldots \ldots \ldots \ldots \ldots \ldots \ldots$

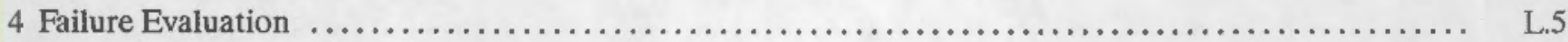

5 Failure Grouping $\ldots \ldots \ldots \ldots \ldots \ldots \ldots \ldots \ldots \ldots \ldots \ldots \ldots \ldots \ldots \ldots \ldots \ldots \ldots \ldots \ldots \ldots \ldots \ldots \ldots \ldots \ldots \ldots \ldots \ldots, \quad$ L.5

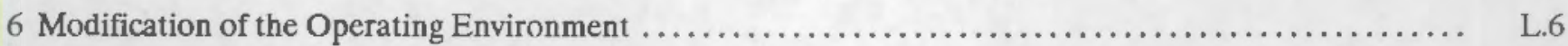

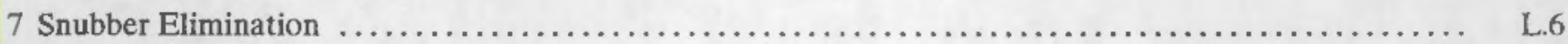

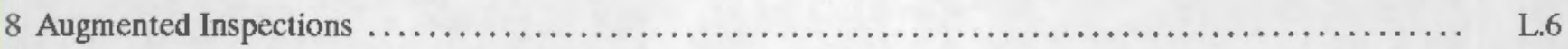

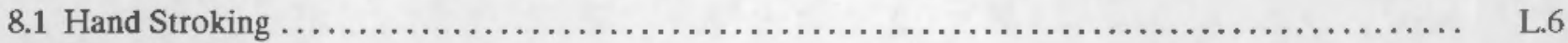

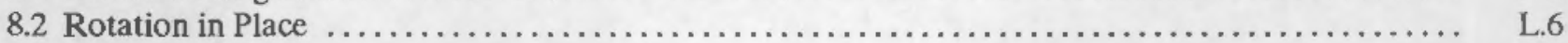

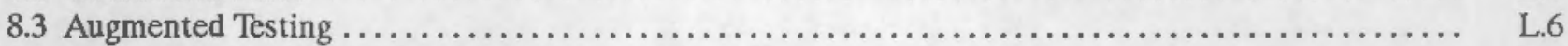

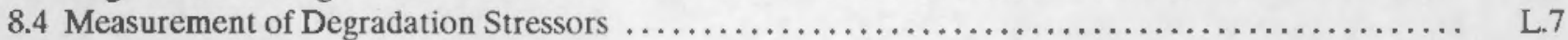

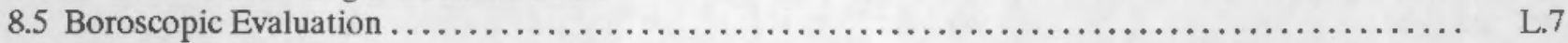

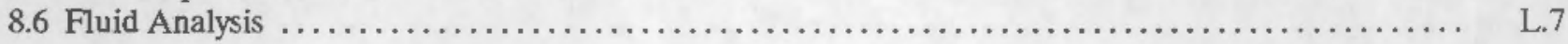

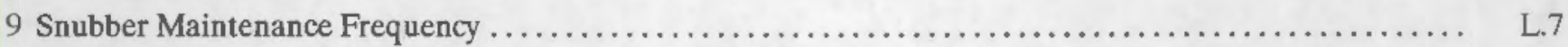

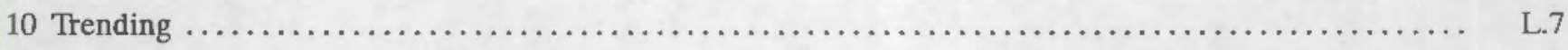

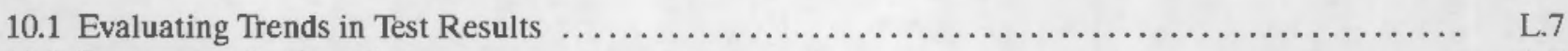

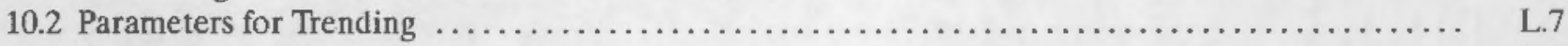

10.3 Reservoir Fluid Level $\ldots \ldots \ldots \ldots \ldots \ldots \ldots \ldots \ldots \ldots \ldots \ldots \ldots \ldots \ldots \ldots \ldots \ldots \ldots \ldots \ldots \ldots \ldots \ldots \ldots, \quad$ L.7

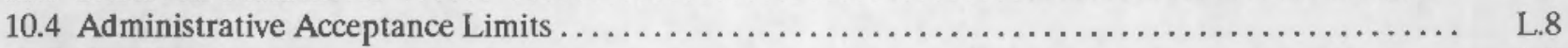

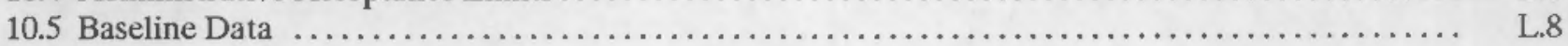

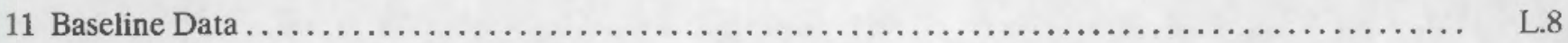

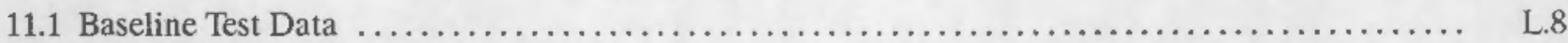

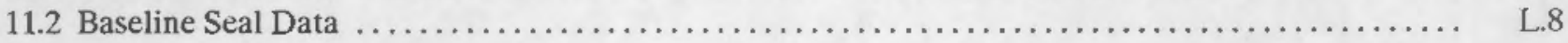

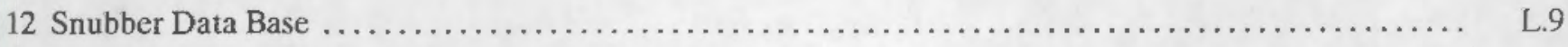

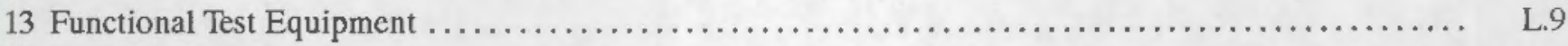

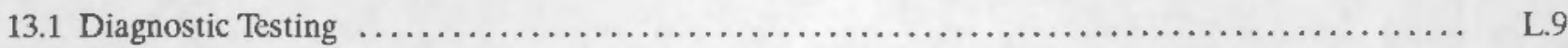


13.2 Trending

13.3 Verification of Degradation

14 Spare Snubber Rotation

15 Personnel Qualification

16 As-Found Evaluation

17 Coordination and Communication

18 Replacement Parts and Materials 


\section{General Maintenance Practices}

In general, the effects of aging on snubber performance may be mitigated through the implementation of sound maintenance practices, including an effective service-life monitoring program. The goal of snubber aging management should be to ensure that snubbers are removed from service or maintained prior to failure. In this regard, if a snubber is suspected of being in a failed condition, it should not be repaired, modified, or altered before determining its operability, in compliance with current inservice inspection (ISI) requirements. However, this does not include snubbers not suspected of being in a failed condition that are subjected to preventive maintenance (e.g., the addition of hydraulic fluid to a low fluid reservoir).

\section{Identification of the Operating Environment}

Stressors of primary concern for snubbers are heat, vibration, transient loads, and moisture. Measurement of temperature and humidity levels in various plant areas is recommended; such information is useful in predicting snubber service life and for identifying possible service-life populations. However, some judgement must be used in deciding the number and location of areas to be monitored.

Measurement of environmental parameters for specific snubber locations should be limited to applications for which severe operating conditions are suspected or used as a diagnostic aid to verify the cause of degradation or failure. Characteristics noted during visual examination or testing of degraded snubbers are often helpful in identifying the existence of severe operating environments. A number of instruments and techniques are available to measure environmental parameters, including temperature-sensitive tape, thermocouples, portable area temperature and humidity monitors, hand-held and remote vibration measuring equipment, load measuring clevis pins, strain gauges, etc. Various data acquisition systems are available for use in obtaining a time profile for environmental parameters.

\section{Snubbers Prone to Rapid Degradation in Severe Environments}

Snubbers in isolated applications that are prone to rapid degradation, i.e, within two to three operating cycles, should be identified and managed on a case-by-case basis. Such applications frequently involve small capacity snubbers installed on piping that is attached to large capacity, high energy systems. Snubbers with particularly long extension pieces appear to be vulnerable to such degradation. Environmental stressors that can cause rapid degradation include high amplitude vibration, dynamic transients, and high temperature, e.g., above $250^{\circ} \mathrm{F}$. Such applications may require augmented inspections (Section 8.0) or maintenance or frequent replacement with new or refurbished snubbers. Other alternatives include replacement with snubber models or materials that are more compatible with the environment, e.g., Viton seals for high temperature applications, modification of the environment (Section 6.0), or elimination of the requirement for a snubber at that location (Section 7.0). 
Appendix L

\section{Failure Evaluation}

Determination of the cause of snubber failures or degradation is essential for adequate management of snubber aging. Separation of service-related and nonservicerelated degradation and failures is necessary to ensure that nonservice-related degradation is not included in the data base used to monitor snubber aging. Also important is identification of the root cause in order that conditions resulting in the degradation or failure may be rectified.

Various techniques and considerations are recommended for evaluating and documenting failure or degradation causes. These include:

- pre-identification of logical steps to be used in the evaluation
- visual examination

- personnel training

- diagnostic testing (Section 13.1)

- photographic documentation of observations

- metallographic analysis

- hydraulic fluid analysis (Section 8.6)

- chemical analysis

- physical property analysis.

\section{Failure Grouping}

Failure grouping is a useful method for ensuring that all snubbers subject to a particular root cause of failure are identified and managed accordingly. Implementation of this method involves using insight and judgement to optimize its effectiveness.

Failure groups should be based upon the root cause of failure, not necessarily the simple cause. It may be determined, for example, that the failure cause for a given snubber was high temperature, and that the root cause was a local steam leak associated with a valve having a particular manufacturing defect. The failure group should include only those snubbers that are subject to degradation from that root cause, i.e., degradation due to leakage from that valve or other valves having potential for the same manufacturing defect. Elimination of the root cause, e.g., repair of defective valves, and evaluation of all snubbers in the group would justify elimination of the failure group as well as any augmented inspection requirements. However, this would not justify the elimination of special requirements for other snubbers that may be subject to high temperature degradation resulting from another root cause.

For the above reasons, failure groups should not be established prior to the identification of a failure and its subsequent root cause analysis. 


\section{Modification of the Operating Environment}

One method for minimizing snubber degradation in a severe operating environment is to modify that environment. Examples of this approach involve the following:

- use of heat shields for high temperature applications

- repair of leaking components in order to reduce the humidity or corrosives
- improved plant ventilation or cooling

- system modification to reduce vibration or dynamic transients

- use of protective boots to minimize corrosion.

\section{Snubber Elimination}

Snubber applications involving severe operating environments and snubber models that are particularly susceptible to service degradation should be priority targets in a snubber elimination program. This supports the need for close coordination between maintenance and engineering personnel (Section 17.0).

\section{Augmented Inspections}

Augmented inspections, i.e., inspections in addition to that required during routine ISI, are recommended for snubbers in severe operating environments (Section 3.0) and for snubbers susceptible to rapid degradation. A number of techniques and hardware that are useful for conducting such inspections are described in the following subsections.

\subsection{Hand Stroking}

Removal of one clevis pin and hand stroking a mechanical snubber while listening and feeling for abnormalities is a useful method for identifying degradation that could lead to eventual snubber failure. This method requires some judgement on the part of the inspector, supporting the need for experienced personnel and adequate training (Section 15.0). This method is also particularly useful for identifying degradation due to dynamic transients.

\subsection{Rotation in Place}

A useful method for evaluating snubbers that are suspected of being locked-up (or jammed) is to attempt to rotate the snubber about its longitudinal axis within the physical limits allowed by the clevis attachments. If the snubber can be rotated freely, the probability is low that the snubber is locked, since lockup during thermal motion of the piping or equipment would have resulted in a significant axial load, prohibiting free rotation of spherical end bearings. This method is most effective for snubbers with a load capacity of $3,000 \mathrm{lb}$ or less.

\subsection{Augmented Testing}

Snubber degradation may often be detected by evaluating functional test traces. Diagnostic testing (Section 13.1) in which controlled test parameters are varied is also uscful in this regard. 


\subsection{Measurement of Degradation Stressors}

Various degradation stressors such as operating environment, dynamic transients, etc., may be monitored using various types of instrumentation or devices (Section 2.0). Such methods are particularly useful for monitoring snubbers subject to severe operating conditions.

\subsection{Boroscopic Evaluation}

A boroscope is sometimes useful for internal inspection of hydraulic snubbers. Such inspections may reveal, for example, significant wear of internal parts or the existence of solid particles caused by wear or internal corrosion.

\subsection{Fluid Analysis}

Microscopic evaluation of hydraulic fluid samples can identify the existence of solid contaminants and can often be used to identify the source of such particles, e.g., particles generated during machining, corrosion products, wear products, etc. Moisture evaluation of the fluid is also useful for evaluating fluid from snubbers with vented reservoirs in high humidity environments.

\section{Snubber Maintenance Frequency}

Scheduled maintenance should be based on realistic considerations in regard to progressive degradation. It should be noted that frequent, unnecessary maintenance, e.g., seal replacements, can actually increase the probability of snubber failure due to damage or errors.

Maintenance frequency should be based on an assessment of the degradation rate for the general snubber population in the plant, i.e., those snubbers in the normal plant operating environment, excluding isolated snubbers in severe environments (Section 2.0). If degradation data from snubbers in service are to be used to establish the scheduled maintenance frequency, then such data should be obtained from snubbers exposed to operating environments that represent the environmental extremes for the general population of snubbers, e.g., snubbers from the upper level of the drywell etc. In some cases, depending upon environmental variations in the plant, it may be practical to establish more than one service-life population.

\section{Trending}

\subsection{Evaluating Trends in Test Results}

In general, evaluations to identify trends in snubber degradation should not rely on functional test data obtained during ISI. Such data is often not useful for identifying trends because more than one data point for the same snubber is often not available (i.e. the same snubbers are not tested during each outage. For this reason, if test data, e.g., snubber drag force, are to be used for trending, representative snubbers should be selected and tested periodically, using the same test machine. For any trending evaluation, the establishment of baseline data (Section 11.0) is extremely important. Such tests should be conducted separately from routine ISI tests.

\subsection{Parameters for Trending}

Parameters to be used for trending should relate to the anticipated degradation mechanism, e.g. compression set in seals or drag force for mechanical snubbers.

\subsection{Reservoir Fluid Level}

Reservoir fluid level for snubbers with a pressurized reservoir can be easily determined by observing the fluid 
level indicator. However, for vented reservoirs used on many hydraulic snubbers the fluid level may not be easily quantified. Verification of progressive fluid loss is therefore difficult. A method to verify fluid loss from one inspection to the next is to mark the fluid level on the reservoir and to compare the level with this mark during subsequent inspections.

\subsection{Administrative Acceptance Limits}

If administrative functional test acceptance limits are used to identify snubbers to be replaced or overhauled, they should not be too restrictive such that snubbers that are not progressively degrading are unnecessarily replaced or refurbished.

\subsection{Baseline Data}

If degradation parameters, e.g. snubber drag force, are to be monitored for trends, the establishment of baseline data is essential (Section 11.0).

\section{Baseline Data}

For trends to be identified, more than one data point for a given parameter is required with respect to time (or number of cycles). Therefore, attempts to identify trends based on a single inservice data point, e.g. drag force, without the existence of baseline (initial) values, require unnecessarily conservative assumptions. Two examples in this regard are the assumption that a measured drag force value of $2 \%$ indicates that drag forces is increasing, and 2) the assumption, in calculating compression set, that the initial seal thickness was the maximum value allowed by the manufacturer.

\subsection{Baseline Test Data}

It is recommended that baseline test data for snubber activation parameters (locking velocity, release rate, acceleration threshold, etc.) and drag force (for mechanical snubbers) be obtained for plant snubbers, whenever possible. Ideally, this data should be consistently obtained under the same test conditions, using the same test machine (Section 13.2). Baseline data would be available for comparison with inservice data for identifying degradation trends.

\subsection{Baseline Seal Data}

Premeasurement of the section thickness of replacement seals before their installation in the snubber will provide baseline data that may be used for a more accurate (i.e., less conservative) evaluation of seal life at a future date. Similarly, baseline data for seal hardness would also be useful.

Data from plant seal life evaluations have indicated variations in seal degradation for various plants and for different seals in the same snubber in the same plant. Unless the seal compound is documented, it is impossible to determine whether or not such variations are the result of differences in seal materials.

Documentation of seal compounds for replacement seals will provide a basis for evaluating the performance characteristics of various seal compounds. 


\section{Snubber Data Base}

An automated snubber data base is strongly recommended for managing snubber service data, documenting snubber installation locations, and documenting maintenance activities. It is important that such data bases be updated regularly.

\section{Functional Test Equipment}

It is recommended that a snubber test machine be maintained at the plant, in addition to any test equipment that might be temporarily located at the plant during ISI. The plant test machine should be available for diagnostic testing, trending, and verification of degradation.

\subsection{Diagnostic Testing}

Diagnostic tests are extremely useful for verifying test results obtained during ISI and for determining the mechanisms associated with any failures or degradation. For diagnostic testing, the test machine should be capable of producing a time-related trace of test parameters, e.g., velocity and load. Manual operation of the tester is also important as well as the ability to vary the level of controlled test parameters.

\subsection{Trending}

ISI data is generally not usable for identifying degradation trends, such as increasing drag force in mechanical snubbers. Separate trending tests should be conducted using the same test machine that was used to establish baseline data (Section 11.0) for the selected snubbers. The test machine should have some automated capability to minimize operator influence during trending tests. Since average drag force is generally more meaningful in identifying trends, a data management system capable of calculating average drag force would be useful.

\subsection{Verification of Degradation}

The operability of snubbers for which degradation or failure is suspected, e.g., unacceptable snubbers identified during visual examinations, may be evaluated by functional testing. The availability of an in-house test machine will allow for expeditious evaluation, in lieu of shipping the snubbers off-site or postponement of testing until ISI tests are conducted.

\section{Spare Snubber Rotation}

Replacement (rotation) of snubbers removed from service with spare snubbers is useful in reducing the need for snubber refurbishment during refueling outages. The following suggestions pertain to spare snubber rotation:
- Judgement should be used for snubbers with a significant amount of remaining service life that are removed for reasons other than maintenance, e.g., for functional testing. Arbitrary replacement of such snubbers will reduce the amount of service data 
Appendix L

that will be available for use in the service life data base, and possibly increase the probability of snubber failure due to the introduction of maintenance or manufacturing deficiencies that may exist in the replacement snubbers.

- Seal life begins when the seals are installed. Therefore, in order to optimize service life, seal replacements for spare hydraulic snubbers should be scheduled so that the period of time between seal replacement and anticipated snubber installation is
- A data base for tracking the various installed locations for each snubber should be maintained (Section 12.0).

- If snubbers with remaining service life are removed and then reinstalled without refurbishment, every effort should be made to install the snubbers in the same locations from which they were removed. The cause of failure or degradation of snubbers that were installed in various plant locations would otherwise be extremely difficult to determine.

\section{Personnel Qualification}

A key maintenance consideration in managing snubber aging is the qualification of maintenance personnel. Adequate training is obviously important, but since good maintenance practice involves considerable judgement, experience is of equal importance. Steps should therefore be taken to minimize turnover of experienced maintenance personnel.

As a minimum, training in the following areas is recommended:

- snubber testing, diagnostic testing, testing for trends, and recognition of test anomalies
- snubber visual examination and recognition of meaningful visual anomalies

- snubber rebuilding and recognition of meaningful anomalies during overhaul

- determination of failure or degradation causes (Section 4.0)

- snubber handling, installation, and storage procedures.

\section{As-Found Evaluation}

As-found evaluations may provide information that is useful in identifying and managing degradation that might otherwise have gone undetected. It is recommended that snubbers removed from service be visually examined and functionally tested before reinstallation in the plant and before performing any maintenance. Hand stroking of mechanical snubbers is also recommended.

\section{Coordination and Communication}

Continuous coordination between ISI, maintenance, engineering, quality assurance, and engineering staff is important. For example:
- Coordination with ISI staff can optimize service data for both ISI and service-life monitoring use. 
Appendix L

- Coordination with engineering staff can ensure elimination of problem applications in a snubber reduction program.
- Communication with operations staff will aid in the identification of dynamic transients.

\section{Replacement Parts and Materials}

The use of replacement parts that are most resistant to degradation due to the service environment are recommended. Examples here include:

- use of temperature-resistant lubricants
- use of temperature-resistant seal materials, e.g., Viton

- use of corrosion-resistant materials for snubbers in high humidity environments. 


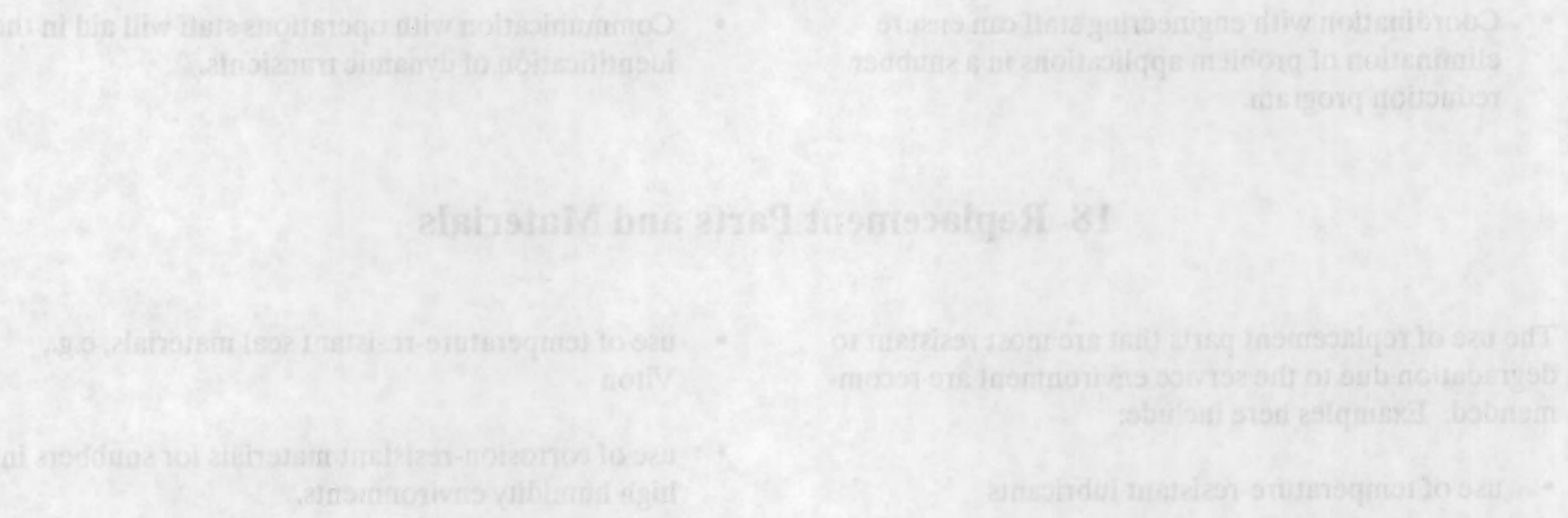




\section{DISTRIBUTION}

No. of

Copies

\section{OFFSITE}

M. Vagins

U.S. Nuclear Regulatory Commission

MS: NS217B

Washington, DC 20555

J. P. Vora

U.S. Nuclear Regulatory Commission

MS: NS217B

Washington, DC 20555

20

J. J. Burns

U.S. Nuclear Regulatory Commission

MS: NS217B

Washington, DC 20555

H. K. Shaw

U.S. Nuclear Regulatory Commission

MS: $9 \mathrm{H}-3$

Washington, DC 20555

J. D. Page

U.S. Nuclear Regulatory

Commission

MS: NS217A

Washington, DC 20555

D. P. Brown

Lake Engineering Company

POB 296

10 Austin Avenue

Greenville, RI 02828

5 C. Cauthen, Chairman

Snubber Utility Group

Duke Power Company

Catawba Nuclear Station

POB 256

Clover, SC 29710
No. of

Copies

J. Corey

Electric Power Research Inst.

POB 10412

Palo Alto, CA 94304

D. M. Eissenberg

Oak Ridge National Laboratory

P.O. Box 2009

Oak Ridge, TN 37831

J. F. Gleason

Wyle Laboratories

Scientific Services \& Systems

Group

POB 1008

Huntsville, AL 35807

D. C. Hafley, Chairmen ASME ISTD Working Group

Tennessee Valley Authority

BR $5578 \mathrm{~A}$

1101 Market Street

Chattanooga, TN 37402-2801

M. H. Kimel

Wyle Laboratories

POB 1008

Huntsville, AL 35807

L. Magelby

EG\&G Idaho, Inc.

P.O. Box 1625

Idaho Falls, ID 83415

J. Mucci

Wyle Laboratories

POB 1008

Huntsville, AL 35807

G. R. Palmer

Siemens Nuclear Power Service, Inc. 5959 Shallowford Road

Suite 531

Chattanooga, TN 37421 
No. of

Copies

R. Rana, Secretary

ASME ISTD Working Group

Washington Public Power Supply

System

3000 George Washington Way

POB 968 (PE 18)

Richland, WA 99352

J. E. Rhoads

Washington Public Power Supply System

3000 George Washington Way

P.O. Box 968

Richland, WA 99352

J. H. Taylor

Brookhaven National Laboratory

Building 130

Upton, NY 11973

A. G. Ware

EG\&G Idaho, Inc.

POB 1625

Idaho Falls, ID 83415-3503

E. V. Werry

701 S. Hartford St.

Kennewick, WA 99336
No. of

Copies

\section{ONSITE}

43 Pacific Northwest Laboratory

R. P. Allen, P8-55 (10)

D. E. Blahnik, P8-10 (20)

S. H. Bush, K2-05

M. E. Cunningham, P8-10

M. D. Freshley, K6-77

A. B. Johnson, Jr., P8-10

L. D. Kannberg, K5-20

R. L. Moffitt, K6-46

R. C. Pedersen, P8-10

Publishing Coordination

Technical Information (5) 


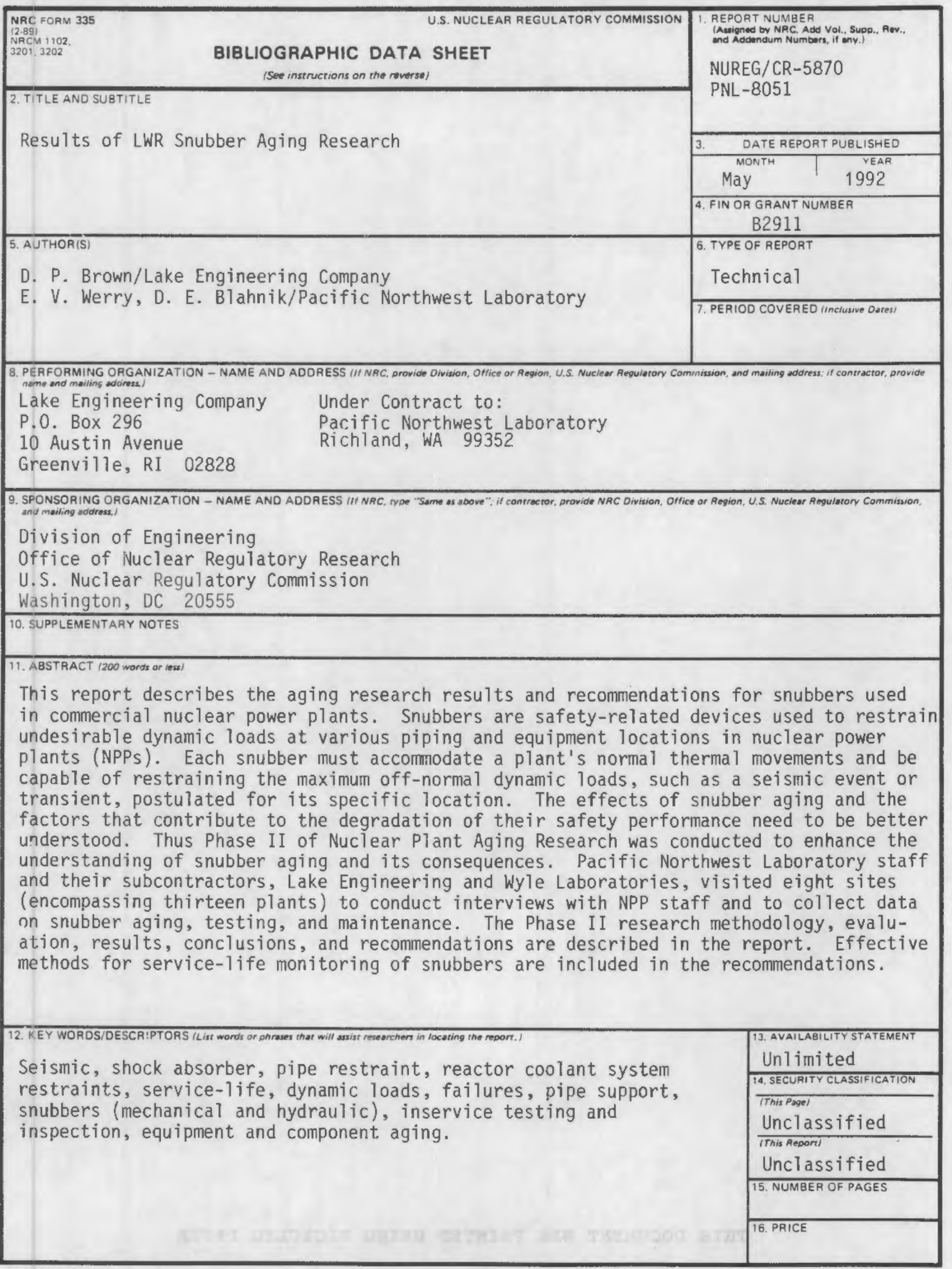




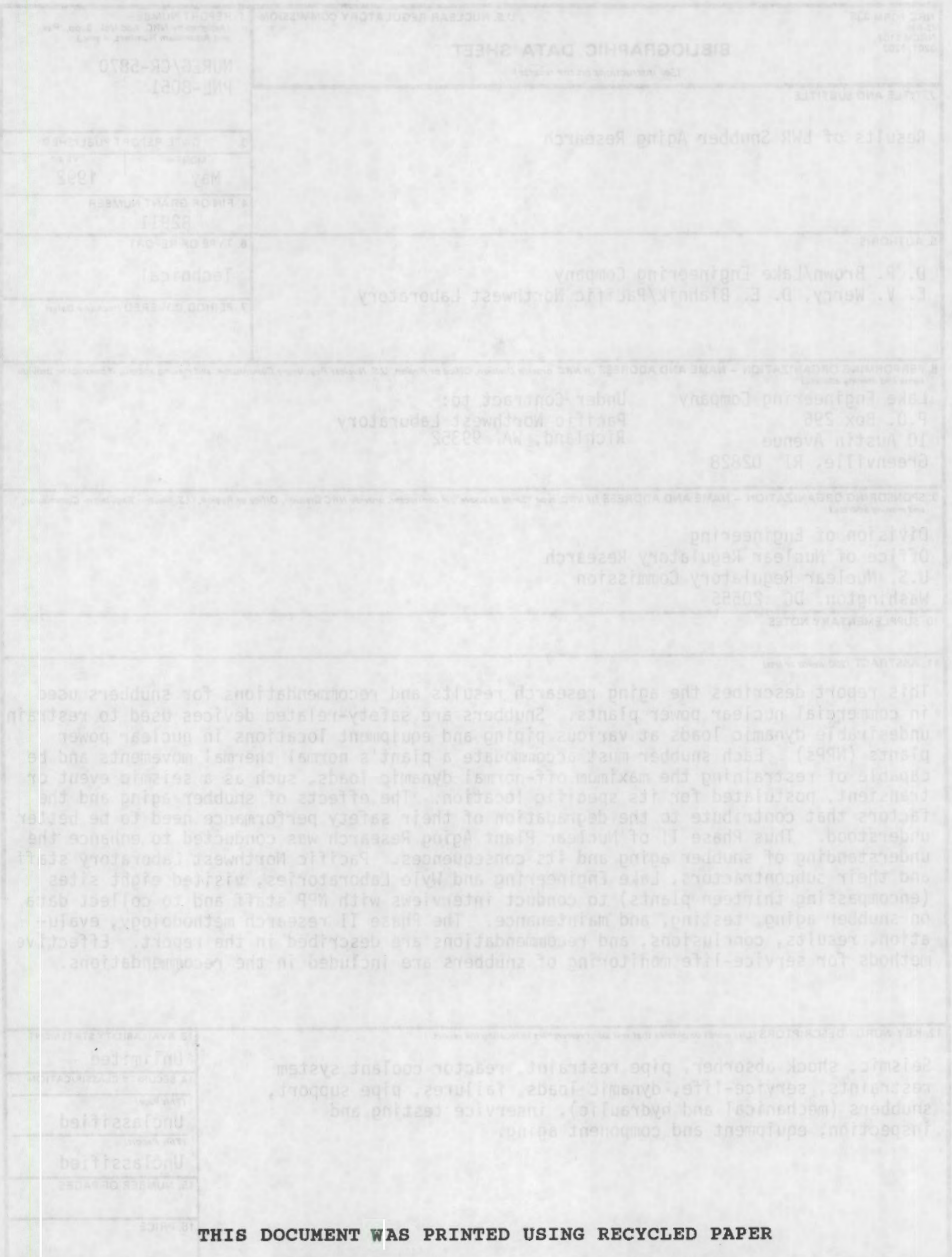

